\title{
Metabolic modulators as a treatment of atrial fibrillation
}

Citation for published version (APA):

Opacic, D. (2019). Metabolic modulators as a treatment of atrial fibrillation. [Doctoral Thesis, Maastricht University]. ProefschriftMaken Maastricht. https://doi.org/10.26481/dis.20190704do

Document status and date:

Published: 01/01/2019

DOI:

10.26481/dis.20190704do

Document Version:

Publisher's PDF, also known as Version of record

\section{Please check the document version of this publication:}

- A submitted manuscript is the version of the article upon submission and before peer-review. There can be important differences between the submitted version and the official published version of record.

People interested in the research are advised to contact the author for the final version of the publication, or visit the DOI to the publisher's website.

- The final author version and the galley proof are versions of the publication after peer review.

- The final published version features the final layout of the paper including the volume, issue and page numbers.

Link to publication

\footnotetext{
General rights rights.

- You may freely distribute the URL identifying the publication in the public portal. please follow below link for the End User Agreement:

www.umlib.nl/taverne-license

Take down policy

If you believe that this document breaches copyright please contact us at:

repository@maastrichtuniversity.nl

providing details and we will investigate your claim.
}

Copyright and moral rights for the publications made accessible in the public portal are retained by the authors and/or other copyright owners and it is a condition of accessing publications that users recognise and abide by the legal requirements associated with these

- Users may download and print one copy of any publication from the public portal for the purpose of private study or research.

- You may not further distribute the material or use it for any profit-making activity or commercial gain

If the publication is distributed under the terms of Article $25 \mathrm{fa}$ of the Dutch Copyright Act, indicated by the "Taverne" license above, 


\section{Metabolic modulators as a treatment of atrial fibrillation}

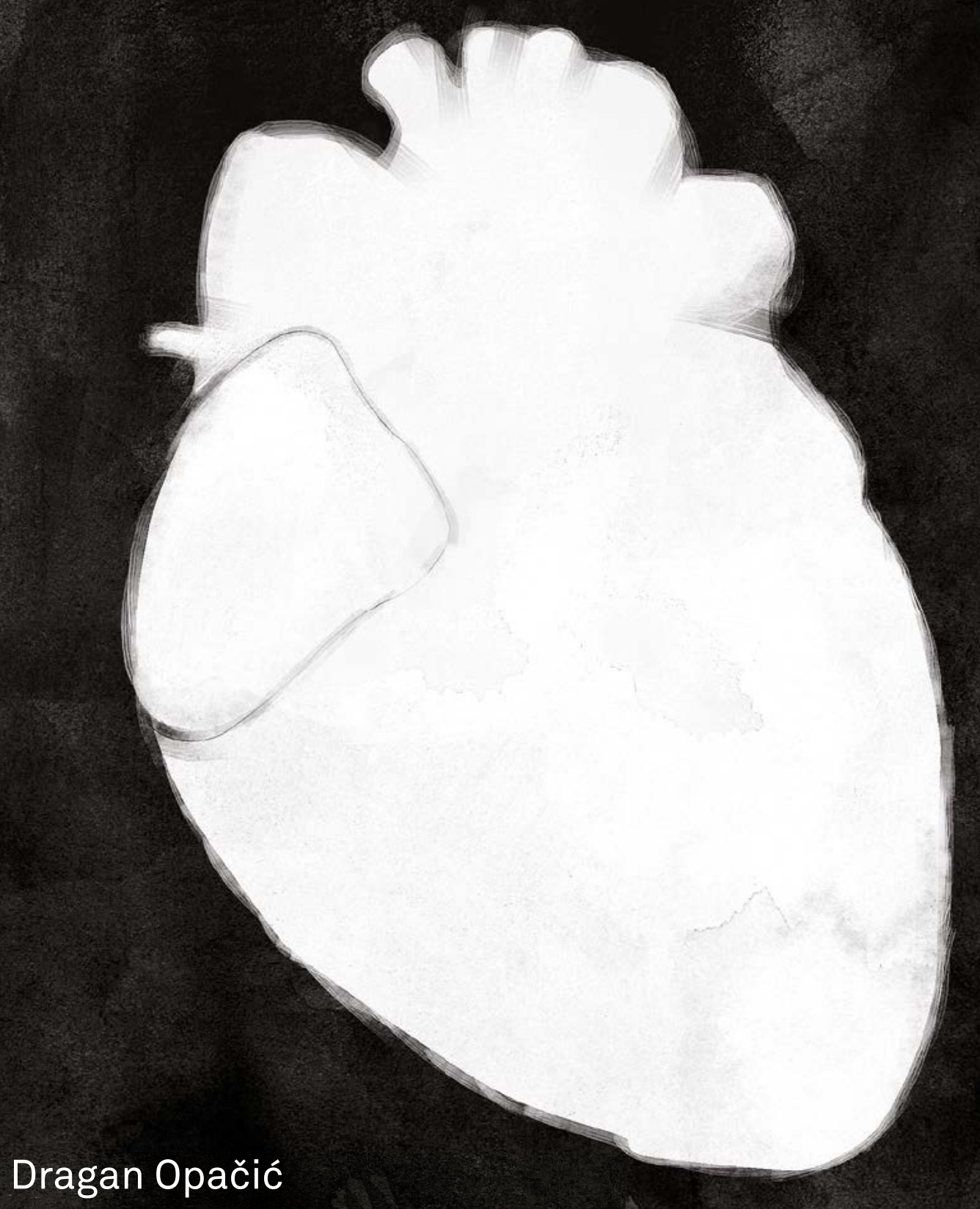




\section{Colofon}

Cover and design:

Nemanja Manjenčić

Printing:

ISBN:

Proefschriftmaken || Proefschriftmaken.nl

978-94-6380-399-1

All rights reserved. No part of this publication may be reproduced, stored in a retrieval system or transmitted, in any form or by any means, electronic, mechanical, photocopying, recording or otherwise, without prior permission of the author or the copyright-owning journals for previous published chapters. 


\title{
Metabolic modulators as a treatment of atrial fibrillation
}

\author{
PROEFSCHRIFT
}

Ter verkrijging de graad van doctor aan de Universiteit Maastricht, op gezag van de Rector Magnificus, Prof. dr. Rianne M. Letschert, volgens het besluit van het College der Decanen

in het openbaar te verdedigen op: donderdag 4 Juli 2019 om 10.00 uur

door

\section{Dragan Opačić}

Born on the 25th of October 1987 in Šabac, Serbia 


\section{Supervisor:}

Prof. dr. U. Schotten

\section{Co-supervisors:}

Dr. S. Verheule

Dr. S. Zeemering

\section{Assessment Committee:}

Prof. dr. F.W. Prinzen (chair)

Prof. dr. H.J.G.M. Crijns

Prof. dr. A.J. van Zonneveld, Leids Universitair Medisch Centrum

Prof. dr. B.J.J.M. Brundel, VU Medisch Centrum Amsterdam

This research is supported by European Initial Training Network grant "RADical reduction of OXidative stress in cardiovascular diseases (RADOX)" by the Dutch Heart Foundation; RACE V: Reappraisal of Atrial Fibrillation: Interaction between hyper-Coagulability, Electrical remodeling, and Vascular Destabilisation in the Progression of AF (CVON201409) and by a scholarship from the Serbian Ministry of Youth and Sports; Fund for Young Talents - Dositeja (DO). 


\section{Table of contents}

Chapter I General introduction 6

Chapter II Atrial metabolism and tissue perfusion as determinants of electrical and structural remodeling in atrial fibrillation 18

Chapter III Effect of ranolazine in a goat model of lone atrial fibrillation 54

Chapter IV The inward rectifier current inhibitor PA-6 terminates atrial fibrillation and does not cause ventricular arrhythmias in dedicated goat and dog models

Chapter V The effect of chronic atrial fibrillation on responsiveness of isolated left atrial and ventricular resistance arteries in goats

Chapter VI The metabolic modulator trimetazidine inhibits AF-induced atrial structural remodeling

Chapter VII General discussion

Сажетак

Valorization

The novelty of our research

References

Acknowledgements

Curriculum vitae

List of publications 


\section{Chapter \\ General introduction}




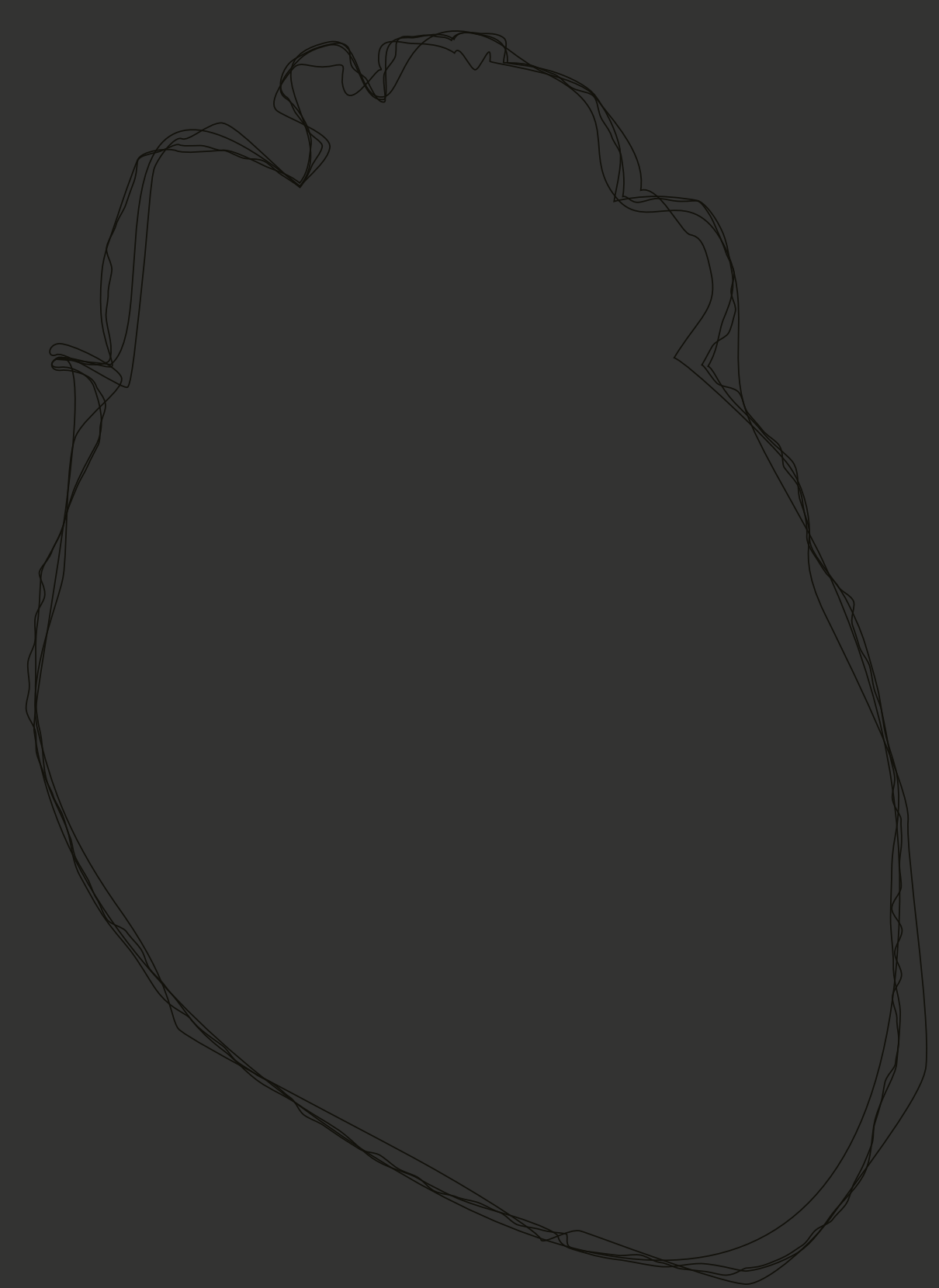




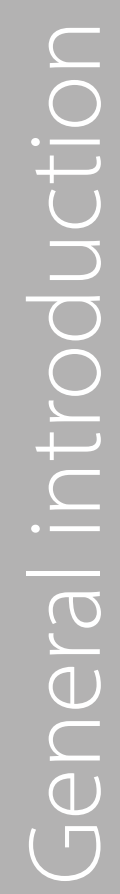


Atrial fibrillation (AF), one of the most common sustained arrhythmias in humans, is characterized by a fast and irregular activation of atria, and associated with palpitations and numerous cardiac and extra-cardiac complications ${ }^{1}$. The estimated prevalence of AF in 2010 was approximately $1.6 \%$ of the total Dutch population and $1.8 \%$ of the total European Union population ${ }^{2}$. With the aging population of European Union countries, it is estimated that AF prevalence will have doubled double by the year 2060, which will lead to a dramatic increase in AF-associated morbidity, mortality and health care costs ${ }^{2}$.

Even after extensive research of this common arrhythmia, treatment of AF is still unsatisfactory. Many of the current treatment modalities are directed towards the prevention of AF complications e.g. stroke, rather than treatment of AF itself ${ }^{3}$. Therefore, a better understanding of AF pathophysiology and the development of novel treatment strategies that may widen the treatment spectrum for AF patients are crucial to addressing the upcoming AF epidemic.

\section{Natural course of AF and role of metabolic remodeling}

AF is a progressive disease in which the efficacy of restoring sinus rhythm declines drastically with increasing duration of the arrhythmia ${ }^{4}$. The natural course of AF is usually characterized by the gradual progression from initially short, self-terminating AF episodes (paroxysms) until AF becomes persistent (not self-terminating) ${ }^{5}$. Once initiated, AF maintains itself by causing electrical and structural remodeling of atrial myocardium ${ }^{6,7}$ (Figure 1.). Electrical remodeling is a rapid process that starts immediately after AF initiation and reaches its maximal effect within 2-3 days ${ }^{6}$. It includes a decrease in the current densities of $\mathrm{I}_{\mathrm{CaL}}$ and $\mathrm{I}_{\mathrm{to}}$ and an increase in $\mathrm{I}_{\mathrm{K} 1}$ that results in shortening of the action potential duration (APD) and atrial effective refractory period (AERP) ${ }^{7,8}$. These changes shorten the time needed for the atrial tissue to recover after an activation, making the atria more vulnerable for reentrant arrhythmias ${ }^{7,8}$. Electrical remodeling is completely reversible within a couple of days after restoration of $\mathrm{SR}^{9,10}$. 


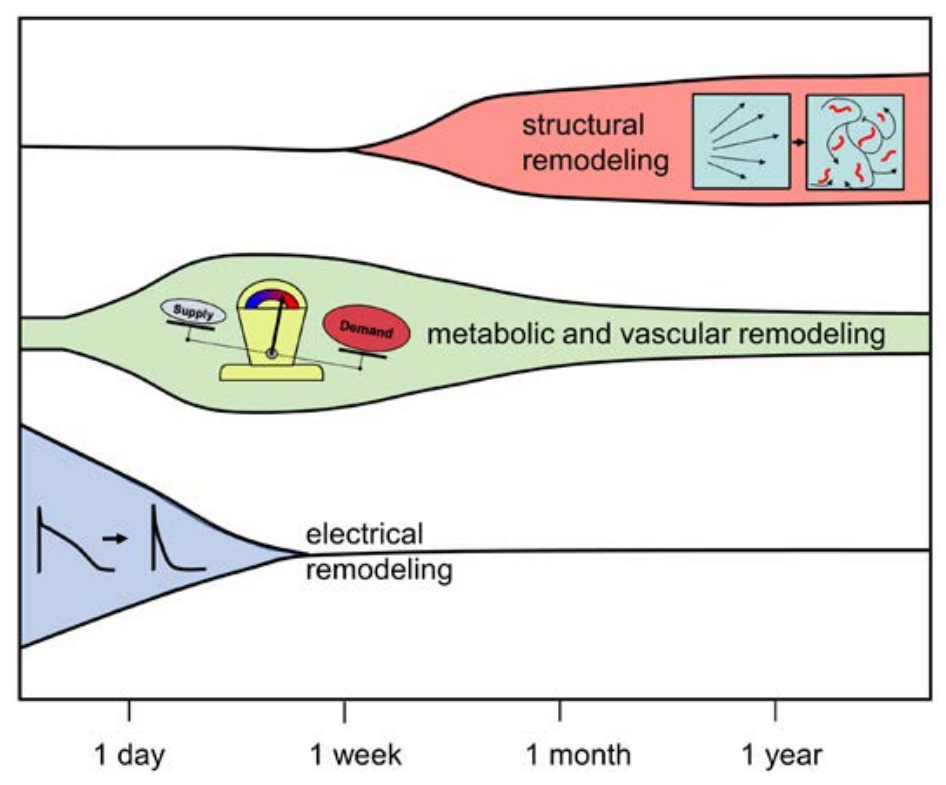

Time in AF

Figure 1.Chronology of AF induced atrial remodeling. Electrical remodeling is the first and the shortest aspect of AF induced atrial remodeling that is taking place during the first days of AF. It is characterized by the changes in the expression and the function of several ion channels that causes the reduction of the action potential duration. Metabolic remodeling also starts during the first moments after AF induction, reaches its peak during the first couple of weeks of AF, but remains present also during long-lasting AF. Metabolic remodeling is defined and perpetuated by the mismatch in the energy supply-demand of the fibrillating atrial muscle that causes different alterations in mitochondrial function and increases reactive oxygen species production. Structural remodeling is the slowest remodeling process that causes changes in the atrial wall structure alternating conduction properties of the tissue. These alterations cause numerous functional and structural block in the conduction of the numerous fibrillatory waves that further increases the complexity of the fibrillatory pattern. The high complexity of the AF fibrillatory pattern is determinant of the AF stability.

Structural remodeling, on the other hand, develops much more slowly, over a time course of months to years and is only partially reversible ${ }^{6,7}$. Structural changes that are recognized to occur due to AF are atrial dilatation ${ }^{11}$, increased endomysial fibrosis ${ }^{12}$, myocyte hypertrophy, loss of sarcomeres, accumulation of glycogen, and mitochondrial abnormalities ${ }^{13,14}$. Some aspects of this broad category of 'structural remodeling', such as fibrosis, hypertrophy and adipocyte infiltration are likely to directly impact electrical propagation. These would increase the complexity of fibrillatory conduction, with a larger number of simultaneously propagating wavefronts ${ }^{15}$. Importantly, high AF complexity and conduction abnormalities are recognized as major determinants of AF stability ${ }^{16,17}$. 
Although electrical and structural remodeling are well documented and described both in humans and animal models, the exact mechanism that initiates and propels these changes is still not fully elucidated. During AF, the fast activation rates of the atrial myocardium increase energy expenditure for both ion transport (electrical activity) and contraction. Supply (delivery of $\mathrm{O}_{2}$ and metabolic substrates) should be increased to meet the demand of fibrillating atria. If not, supply-demand ischemia would ensue (Figure 1).

There is some direct and more extensive indirect evidence for a supply-demand mismatch during $A F^{18-21}$. Recently, our group has shown that acute episodes of $A F$ in pigs are associated with increased lactate production, indicating that acute AF leads to supplydemand ischemia ${ }^{18}$. The levels of high energy phosphates and related compounds are significantly reduced during the first weeks of AF in goats, but reversed to baseline values after 16 weeks of $\mathrm{AF}^{20}$. Metabolic perturbations including a decrease in high energy phosphates, potential changes in substrate preference and alterations of mitochondrial function and structure were observed in a pig model of short term $\mathrm{AF}^{22}$. Furthermore, increased expression of HIF1a in atrial tissue both in AF patients and in the AF goats as well as isolated atrial microvascular dysfunction in patients with chronic AF indicate that tissue hypoxia and insufficient tissue perfusion may also be a chronic phenomenon ${ }^{19,23,24}$.

Although mainly described during acute or short-term models of AF, these metabolic disturbances may have prolonged effects and may trigger atrial structural remodeling. Chronic structural and ultrastructural changes of the atrial tissue that occur in chronic AF have been described as hibernating myocardium, resembling the changes observed in the ventricles in low flow ischemia ${ }^{13,20,25}$. This circumstantial evidence further supports the role of tissue perfusion and energy depletion in AF pathogenesis.

Importantly, many of the recognized clinical risk factors for AF can already precipitate initial alterations in cellular metabolism and energy production that can trigger the vicious circle which begets AF associated atrial remodeling ${ }^{26}$. Effects of different concomitant risk factors could be recognized as a tissue perfusion reduction associated with structural changes in heart failure, valvular disease or in coronary artery disease. Similarly, inadequate pulmonary function in chronic obstructive pulmonary disease and sleep apnea can further worsen oxygen supply, while different hormone and metabolic disbalances such as hyperthyroidism and diabetes mellitus or metabolic syndrome could alter mitochondrial function and structure, and induce oxidative stress. 


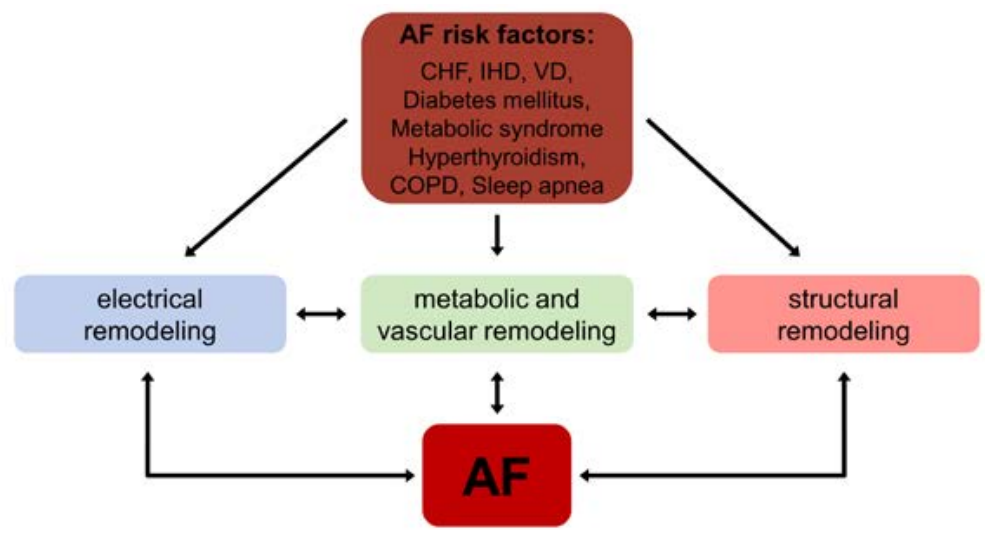

Figure 2. The role of common risk factors in precipitating and triggering AF induced atrial remodeling. The diseases such as chronic heart failure (CHF), ischemic heart disease (IHD) and valvular disease (VD) can lead to structural remodeling and capillary rarefaction which would impair tissue perfusion, while lung diseases including chronic obstructive pulmonary disease (COPD) and sleep apnea would further reduce oxygen availability. Additionally, different metabolic and hormonal diseases interfere with tissue metabolism and mitochondrial structure and function.

The exact role of metabolic remodeling during AF is not well understood, leaving the question unanswered whether these metabolic alterations are protective or harmful. Investigating whether prevention or attenuation of the metabolic disturbances and conservation of energetic status of the atrial tissue during AF would modify AF-associated remodeling processes and/or inhibit AF progression would definitely clarify the role of metabolic changes in AF pathogenesis.

\section{Outline of this thesis}

The general aim of this thesis was to make a synopsis of the metabolic changes in atrial tissue that are identified to occur as a result of AF and to investigate the effect of currently available metabolic modulators to treat both short term and long-term AF in a goat model of AF.

In chapter 2, we provide a detailed literature review about the role of atrial tissue perfusion and metabolism in atrial remodeling and AF stabilization. Possible treatment options for improving atrial metabolism are agents that shift cellular metabolism from fatty acids to glucose utilization.

Glycolysis is $10-15 \%$ more $\mathrm{O}_{2}$ efficient compared to fatty acids oxidation ${ }^{27}$ and shifting metabolism towards glucose utilization could therefore be beneficial in the settings of limited oxygen supply. Indeed, the substrate preference in ischemic myocardium is shifted from fatty acids oxidation towards glycolysis, but it is still not clear whether this shift is beneficial or detrimental for a cardiac energetic status and pathological remodeling processes ${ }^{28}$. 
Among the currently available agents that alter substrate preference are etomoxir, perhexiline, trimetazidine and ranolazine. All of these drugs cause a metabolic shift towards glucose utilization, mainly by inhibiting different steps of $\beta$-fatty acids oxidation. Etomoxir ${ }^{29}$ and perhexiline ${ }^{30}$ inhibit carnitine palmitoyltransferase-1 (CPT1), trimetazidine ${ }^{31}$ inhibits long-chain 3-ketoacyl-coenzyme A thiolase (3-KAT), while ranolazine ${ }^{32}$ inhibits $\beta$-oxidation and increases $\mathrm{PDH}$ activity and therefore consequently favors glucose oxidation.

At the moment, ranolazine and trimetazidine are registered in several European countries and often prescribed as the additional therapy for patients with angina pectoris and structural heart disease. However, both trimetazidine and ranolazine have significant effects beyond the shift in substrate preference. Trimetazidine has potent antioxidant properties both in patients ${ }^{33,34}$ and in animal models of diseases with increased ROS production $^{35}$. Next to its antioxidant effects and metabolic effects, trimetazidine has also protective effects on mitochondria structure and function ${ }^{36,37}$.

Increased reactive oxygen species (ROS) production and ROS induced damage have been implicated in both electrical and structural remodeling during $A F^{38}$. Sources of increased $\mathrm{ROS}$, recognized to contribute to the AF pathogenesis, vary with the duration of AF and include NADPH oxidases in the first weeks of AF and mitochondria and uncoupled NOS in the long-lasting $\mathrm{AF}^{39}$. Mitochondria are considered to be the largest source of ROS in most cell types, including cardiomyocytes. Therefore, increased mitochondrial ROS production and eventual consequent mitochondrial dysfunction would further aggravate the metabolism and energetic status of the cell contributing to atrial remodeling and AF stabilization.

Ranolazine, on the other hand, besides affecting substrate preference, is a late $I_{\mathrm{Na}}$ and $\mathrm{I}_{\mathrm{Ks}}$ inhibitor with a marked atrial selectivity for peak $\mathrm{I}_{\mathrm{Na}}$ blockade, that has already been proposed as an antiarrhythmic drug for $\mathrm{AF}^{3}$. However, due to ambiguous results from several clinical trials, there is still not enough evidence for ranolazine to be considered as an antiarrhythmic drug to treat $\mathrm{AF}^{3}$. Therefore, we hypothesize that that ranolazine can be used as a therapy for AF with a short-term benefit of sinus rhythm maintenance, and a benefit on the longer term of preventing metabolic and structural remodeling. As a first step, in chapter 3, we have evaluated the short-term antiarrhythmic effects of ranolazine the goat at different stages of AF-induced electrical remodeling.

As previously discussed, AF-induced atrial electrical remodeling includes alterations of several other ion currents ${ }^{6}$. One of the most relevant currents for APD and AERP shortening is the $\mathrm{K}^{+}$inward rectifier current $\left(\mathrm{I}_{\mathrm{K} 1}\right)$ which is upregulated in $\mathrm{AF}^{40}$. Even in the normal heart, atrial cardiomyocytes have six to ten folds lower $\mathrm{I}_{\mathrm{K} 1}$ density compared to ventricular cardiomyocytes $^{41,42}$. Therefore, selective inhibition of $I_{\mathrm{K} 1}$ could affect the atrium, without pronounced proarrhythmic effects on the ventricles. The pentamidine analog 6 (PA-6) is a selective inhibitor of $\mathrm{I}_{\mathrm{K} 1}{ }^{43}$. In chapter 4 we have investigated the effectiveness of PA- 6 in a restoration of SR in a goat model of short-term AF as well as safety profile of the drug in inducing ventricular arrhythmia in anaesthetized chronic AV block dogs. 
In Chapter $\mathbf{5}$ of this thesis we have characterized the responsiveness of atrial and ventricular resistance sized arteries during long term AF. Resistance arteries are small muscular arteries that are responsible for the peripheral vascular resistance, and therefore the tissue perfusion pressures. Recently we have observed that short term rapid atrial pacing (RAP) in pigs alters the responsiveness of atrial and ventricular small muscular arteries $^{22}$. Both atrial and ventricular arteries of RAP pigs produced higher contractile force compared to controls without changes of the arterial structure. However, atrial arteries of RAP pigs had also increased endothelium dependent vasodilation compared to controls. Endothelium dependent vasodilation is conducted through the release of the smooth muscle cell-relaxing substances from the endothelial cells. The involved pathways include NO synthesis by the endothelial NOS (eNOS), a release of different prostaglandins, as well as activation other mechanisms usually described as Endothelium-Derived Hyperpolarizing Factors (EDHF). Increased endothelium vasodilatation in first weeks could be attributed to the increased eNOS activity that would result in increased NO production. However, long-lasting AF is associated with the increased ROS production originating from the mitochondria and uncoupled eNOS ${ }^{39}$. The uncoupled eNOS is one of the major causes of endothelial dysfunction that can further jeopardize tissue perfusion and oxygen supply ${ }^{44}$. Therefore, as the next step we have investigated whether the changes observed in a short-term model of AF remain in chronic AF further clarifying underling mechanisms.

Finally, as a first attempt to investigate whether a metabolic intervention can affect AF progression, we studied the long-term effects of trimetazidine (TMZ) in a goat model of AF. The pleiotropic effects of TMZ should improve $\mathrm{O}_{2}$ efficiency, decrease ROS production and preserve atrial mitochondria. We hypothesized that TMZ can thereby inhibit atrial structural remodeling and delay AF stabilization ${ }^{31}$. We have evaluated the effect of trimetazidine treatment on early AF stabilization as well as on AF complexity after 16 weeks of AF. Furthermore, we have characterized the effect of TMZ treatment on a number of cardiac metabolic parameters, including ROS production, and on AF-induced structural and ultrastructural remodeling of atrial tissue. 


\section{References}

1. Benjamin EJ, Wolf PA, D'Agostino RB, Silbershatz H, Kannel WB and Levy D. Impact of atrial fibrillation on the risk of death: the Framingham Heart Study. Circulation. 1998;98:946-52.

2. Krijthe BP, Kunst A, Benjamin EJ, Lip GY, Franco OH, Hofman A, Witteman JC, Stricker BH and Heeringa J. Projections on the number of individuals with atrial fibrillation in the European Union, from 2000 to 2060. Eur Heart J. 2013;34:2746-51.

3. Kirchhof P, Benussi S, Kotecha D, Ahlsson A, Atar D, Casadei B, Castella M, Diener HC, Heidbuchel $\mathrm{H}$, Hendriks J, Hindricks G, Manolis AS, Oldgren J, Popescu BA, Schotten U, Van Putte B, Vardas P, Authors/Task Force M and Document R. 2016 ESC Guidelines for the management of atrial fibrillation developed in collaboration with EACTS: The Task Force for the management of atrial fibrillation of the European Society of Cardiology (ESC)Developed with the special contribution of the European Heart Rhythm Association (EHRA) of the ESCEndorsed by the European Stroke Organisation (ESO). Eur Heart J. 2016.

4. Frick M, Frykman V, Jensen-Urstad M, Ostergren J and Rosenqvist M. Factors predicting success rate and recurrence of atrial fibrillation after first electrical cardioversion in patients with persistent atrial fibrillation. Clin Cardiol. 2001;24:238-44.

5. Kopecky SL, Gersh BJ, McGoon MD, Whisnant JP, Holmes DR, Jr., Ilstrup DM and Frye RL. The natural history of lone atrial fibrillation. A population-based study over three decades. The New England journal of medicine. 1987;317:669-74.

6. Allessie M, Ausma J and Schotten U. Electrical, contractile and structural remodeling during atrial fibrillation. Cardiovascular research. 2002;54:230-46.

7. Schotten U, Verheule S, Kirchhof P and Goette A. Pathophysiological mechanisms of atrial fibrillation: a translational appraisal. Physiol Rev. 2011;91:265-325.

8. Bosch RF, Zeng X, Grammer JB, Popovic K, Mewis C and Kuhlkamp V. Ionic mechanisms of electrical remodeling in human atrial fibrillation. Cardiovascular research. 1999;44:121-31.

9. Yu WC, Lee SH, Tai CT, Tsai CF, Hsieh MH, Chen CC, Ding YA, Chang MS and Chen SA. Reversal of atrial electrical remodeling following cardioversion of long-standing atrial fibrillation in man. Cardiovasc Res. 1999;42:470-6.

10. Schotten U, Duytschaever M, Ausma J, Eijsbouts S, Neuberger HR and Allessie M. Electrical and contractile remodeling during the first days of atrial fibrillation go hand in hand. Circulation. 2003;107:1433-9.

11. Shi Y, Ducharme A, Li D, Gaspo R, Nattel S and Tardif JC. Remodeling of atrial dimensions and emptying function in canine models of atrial fibrillation. Cardiovasc Res. 2001;52:217-25.

12. Verheule S, Tuyls E, Gharaviri A, Hulsmans S, van Hunnik A, Kuiper M, Serroyen J, Zeemering $\mathrm{S}$, Kuijpers $\mathrm{NH}$ and Schotten U. Loss of continuity in the thin epicardial layer because of endomysial fibrosis increases the complexity of atrial fibrillatory conduction. Circulation Arrhythmia and electrophysiology. 2013;6:202-11.

13. Ausma J, Wijffels $M$, Thone F, Wouters $L$, Allessie $M$ and Borgers M. Structural changes of atrial myocardium due to sustained atrial fibrillation in the goat. Circulation. 1997;96:3157-63.

14. Morillo CA, Klein GJ, Jones DL and Guiraudon CM. Chronic rapid atrial pacing. Structural, functional, and electrophysiological characteristics of a new model of sustained atrial fibrillation. Circulation. 1995;91:1588-95. 
15. Eckstein J, Maesen B, Linz D, Zeemering S, van Hunnik A, Verheule S, Allessie M and Schotten $\mathrm{U}$. Time course and mechanisms of endo-epicardial electrical dissociation during atrial fibrillation in the goat. Cardiovascular research. 2011;89:816-24.

16. Allessie MA, de Groot NM, Houben RP, Schotten U, Boersma E, Smeets JL and Crijns HJ. Electropathological substrate of long-standing persistent atrial fibrillation in patients with structural heart disease: longitudinal dissociation. Circ Arrhythm Electrophysiol. 2010;3:606-15.

17. de Groot NM, Houben RP, Smeets JL, Boersma E, Schotten U, Schalij MJ, Crijns H and Allessie MA. Electropathological substrate of longstanding persistent atrial fibrillation in patients with structural heart disease: epicardial breakthrough. Circulation. 2010;122:1674-82.

18. van Bragt KA, Nasrallah HM, Kuiper M, Luiken JJ, Schotten $U$ and Verheule S. Atrial supplydemand balance in healthy adult pigs: coronary blood flow, oxygen extraction, and lactate production during acute atrial fibrillation. Cardiovasc Res. 2014;101:9-19.

19. Gramley F, Lorenzen J, Jedamzik B, Gatter K, Koellensperger E, Munzel T and Pezzella F. Atrial fibrillation is associated with cardiac hypoxia. Cardiovasc Pathol. 2010;19:102-11.

20. Ausma J, Coumans WA, Duimel H, Van der Vusse GJ, Allessie MA and Borgers M. Atrial high energy phosphate content and mitochondrial enzyme activity during chronic atrial fibrillation. Cardiovasc Res. 2000;47:788-96.

21. Thijssen VL, van der Velden HM, van Ankeren EP, Ausma J, Allessie MA, Borgers M, van Eys GJ and Jongsma $\mathrm{HJ}$. Analysis of altered gene expression during sustained atrial fibrillation in the goat. Cardiovasc Res. 2002;54:427-37.

22. Nasrallah H. Left atrial vascular and metabolic remodeling in pig models of atrial fibrillation; 2015.

23. Thijssen VL, Ausma J, Liu GS, Allessie MA, van Eys GJ and Borgers M. Structural changes of atrial myocardium during chronic atrial fibrillation. Cardiovascular pathology : the official journal of the Society for Cardiovascular Pathology. 2000;9:17-28.

24. Skalidis El, Hamilos MI, Karalis IK, Chlouverakis G, Kochiadakis GE and Vardas PE. Isolated atrial microvascular dysfunction in patients with lone recurrent atrial fibrillation. J Am Coll Cardiol. 2008;51:2053-7.

25. Vanoverschelde JL, Wijns W, Borgers M, Heyndrickx G, Depre C, Flameng W and Melin JA. Chronic myocardial hibernation in humans. From bedside to bench. Circulation. 1997;95:196171.

26. Brandes A, Smit MD, Nguyen BO, Rienstra M and Van Gelder IC. Risk Factor Management in Atrial Fibrillation. Arrhythm Electrophysiol Rev. 2018;7:118-127.

27. Horowitz JD, Chirkov YY, Kennedy JA and Sverdlov AL. Modulation of myocardial metabolism: an emerging therapeutic principle. Curr Opin Cardiol. 2010;25:329-34.

28. Nickel A, Loffler J and Maack C. Myocardial energetics in heart failure. Basic Res Cardiol. 2013;108:358.

29. Kruszynska YT and Sherratt HS. Glucose kinetics during acute and chronic treatment of rats with 2[6(4-chloro-phenoxy)hexyl]oxirane-2-carboxylate, etomoxir. Biochem Pharmacol. 1987;36:3917-21.

30. Inglis S and Stewart S. Metabolic therapeutics in angina pectoris: history revisited with perhexiline. European journal of cardiovascular nursing : journal of the Working Group on Cardiovascular Nursing of the European Society of Cardiology. 2006;5:175-184.

31. McCarthy CP, Mullins KV and Kerins DM. The role of trimetazidine in cardiovascular disease: beyond an anti-anginal agent. Eur Heart J Cardiovasc Pharmacother. 2016;2:266-72. 
32. McCormack JG, Stanley WC and Wolff AA. Ranolazine: a novel metabolic modulator for the treatment of angina. Gen Pharmacol. 1998;30:639-645.

33. Fabiani JN, Ponzio O, Emerit I, Massonet-Castel S, Paris M, Chevalier P, Jebara V and Carpentier A. Cardioprotective effect of trimetazidine during coronary artery graft surgery. J Cardiovasc Surg (Torino). 1992;33:486-91.

34. Belardinelli $R$, Solenghi $M$, Volpe $L$ and Purcaro A. Trimetazidine improves endothelial dysfunction in chronic heart failure: an antioxidant effect. Eur Heart J. 2007;28:1102-8.

35. Liu X, Gai Y, Liu F, Gao W, Zhang Y, Xu M and Li Z. Trimetazidine inhibits pressure overloadinduced cardiac fibrosis through NADPH oxidase-ROS-CTGF pathway. Cardiovasc Res. 2010;88:150-8.

36. Argaud L, Gomez L, Gateau-Roesch O, Couture-Lepetit E, Loufouat J, Robert D and Ovize M. Trimetazidine inhibits mitochondrial permeability transition pore opening and prevents lethal ischemia-reperfusion injury. J Mol Cell Cardiol. 2005;39:893-9.

37. Shi W, Shangguan W, Zhang Y, Li C and Li G. Effects of trimetazidine on mitochondrial respiratory function, biosynthesis, and fission/fusion in rats with acute myocardial ischemia. Anatol J Cardiol. 2017;18:175-181.

38. Simon JN, Ziberna K and Casadei B. Compromised redox homeostasis, altered nitroso-redox balance, and therapeutic possibilities in atrial fibrillation. Cardiovasc Res. 2016;109:510-8.

39. Reilly SN, Jayaram R, Nahar K, Antoniades C, Verheule S, Channon KM, Alp NJ, Schotten U and Casadei $B$. Atrial sources of reactive oxygen species vary with the duration and substrate of atrial fibrillation: implications for the antiarrhythmic effect of statins. Circulation. 2011;124:1107-17.

40. Zhang H, Garratt CJ, Zhu J and Holden AV. Role of up-regulation of IK1 in action potential shortening associated with atrial fibrillation in humans. Cardiovasc Res. 2005;66:493-502.

41. Cordeiro JM, Zeina T, Goodrow R, Kaplan AD, Thomas LM, Nesterenko VV, Treat JA, Hawel L, 3rd, Byus C, Bett GC, Rasmusson RL and Panama BK. Regional variation of the inwardly rectifying potassium current in the canine heart and the contributions to differences in action potential repolarization. J Mol Cell Cardiol. 2015;84:52-60.

42. Wang $Z$, Yue $L$, White $M$, Pelletier $G$ and Nattel $S$. Differential distribution of inward rectifier potassium channel transcripts in human atrium versus ventricle. Circulation. 1998;98:2422-8.

43. Takanari $H$, Nalos L, Stary-Weinzinger A, de Git KC, Varkevisser R, Linder T, Houtman MJ, Peschar $M$, de Boer TP, Tidwell RR, Rook MB, Vos MA and van der Heyden MA. Efficient and specific cardiac IK(1) inhibition by a new pentamidine analogue. Cardiovasc Res. 2013;99:203-14.

44. Vallet B. Endothelial cell dysfunction and abnormal tissue perfusion. Crit Care Med. 2002;30:S229-34. 


\section{Chapter II}

\section{Atrial metabolism and tissue perfusion as determinants of electrical and structural remodeling in atrial fibrillation}

Dragan Opačić, Kelly A. van Bragt, Hussein M. Nasrallah, Ulrich Schotten and Sander Verheule 


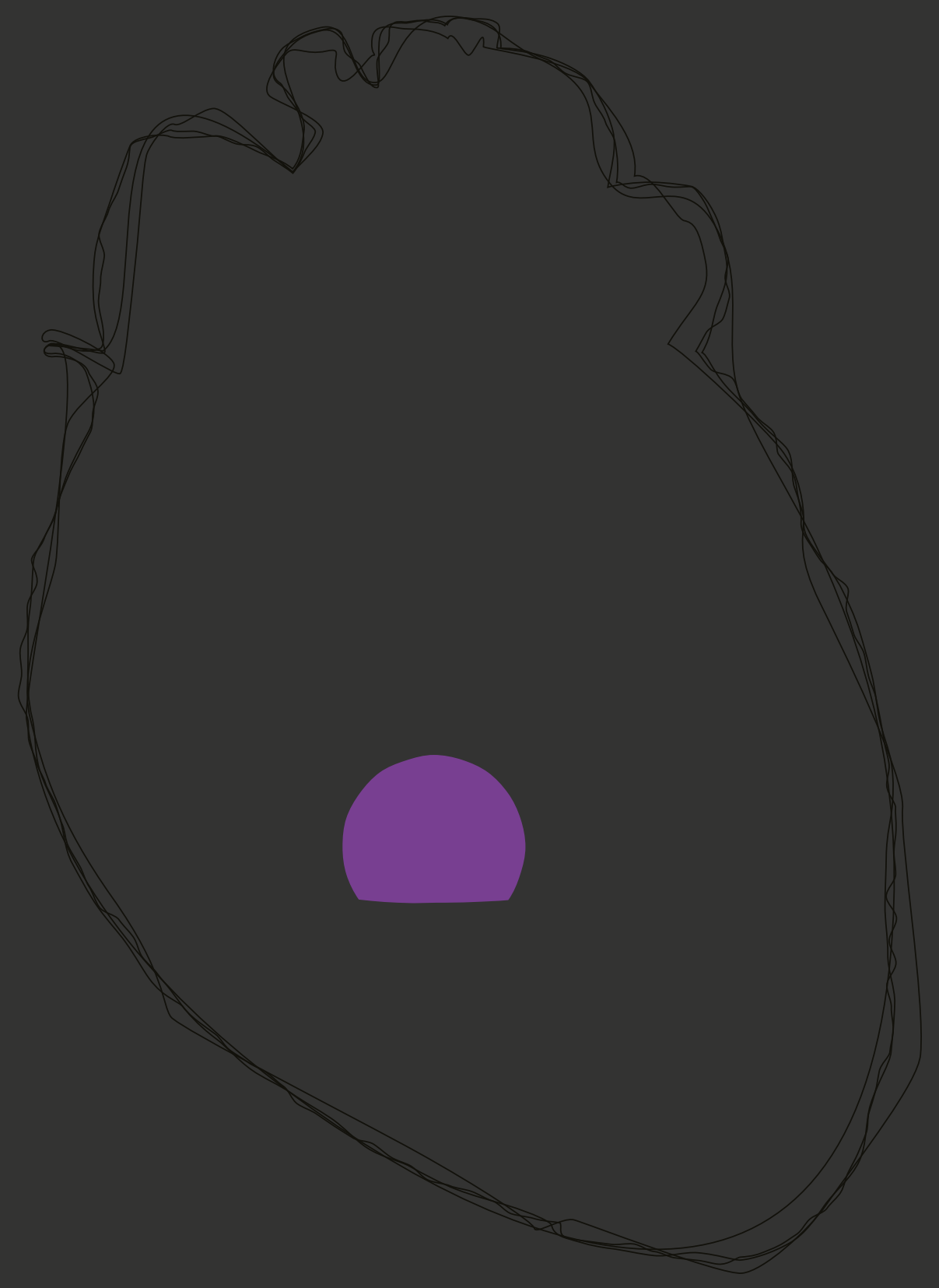




\section{Atrial fibrillation (AF) is the most common tachyarrhythmia in clinical practice}

Over decades of research, a vast amount of knowledge has been gathered about the causes and consequences of AFrelated to cellularelectrophysiology and features of the tissue structure that influence the propagation of fibrillation waves. Far less is known about the role of myocyte metabolism and tissue perfusion in the pathogenesis of AF. However, the rapid rates of electrical activity and contraction during AF must present an enormous challenge to the energy balance of atrial myocytes. This challenge can be met by scaling back energy demand and by increasing energy supply, and there are several indications that both phenomena occur as a result of AF. Still, there is ample evidence that these adaptations fall short of redressing this disbalance, that may represent a driving force for atrial electrical as well as structural remodeling. In addition, several 'metabolic diseases' such as diabetes, obesity and abnormal thyroid function precipitate some well-known 'culprits' of the AF substrate such as myocyte hypertrophy and fibrosis, while some other AF risk factors, such as heart failure, affect atrial metabolism. This review provides an overview of metabolic and vascular alterations in AF and their involvement in its pathogenesis. 


\section{Scope of this review}

Because of their obvious relevance in diseases such as ischemic heart disease and heart failure, (left) ventricular metabolism and blood supply have been investigated in great detail for decades. By comparison, we know very little about atrial metabolism and tissue perfusion, how they are affected by risk factors for AF, and the way in which they contribute to the pathogenesis of AF. An estimated $2 \%$ of the cellular adenosine tri-phosphate (ATP) pool is utilized during each heart beat during normal sinus rhythm (SR) ${ }^{1}$. The rapid rates of electrical and contractile activity during AF will increase ATP consumption. This increased demand needs to be matched by increased ATP production, and the required oxygen and nutrients have to be supplied by the atrial vasculature (Figure $1 \mathrm{~A}$ ).

AF changes the behavior of e.g. fibroblasts ${ }^{2}$, adipocytes ${ }^{3}$ and paracrine interactions with these and other cell types may in turn affect the energy balance of atrial myocytes (Figure 1A). The role of some aspects of atrial metabolism in the pathogenesis of AF have already been investigated extensively. Most notable among these are changes in ROS signaling (reviewed $\mathrm{in}^{4,5}$ ) and calcium homeostasis (reviewed $\mathrm{in}^{6,7}$ ), which will therefore be discussed in less detail here. In this review, we provide an overview of AF from a broader metabolic perspective. We assess the alterations in atrial metabolism and atrial coronary perfusion resulting from $A F$ itself and $A F$ risk factors and discuss the potential contribution of these changes in the pathogenesis of AF (Figure 1B).

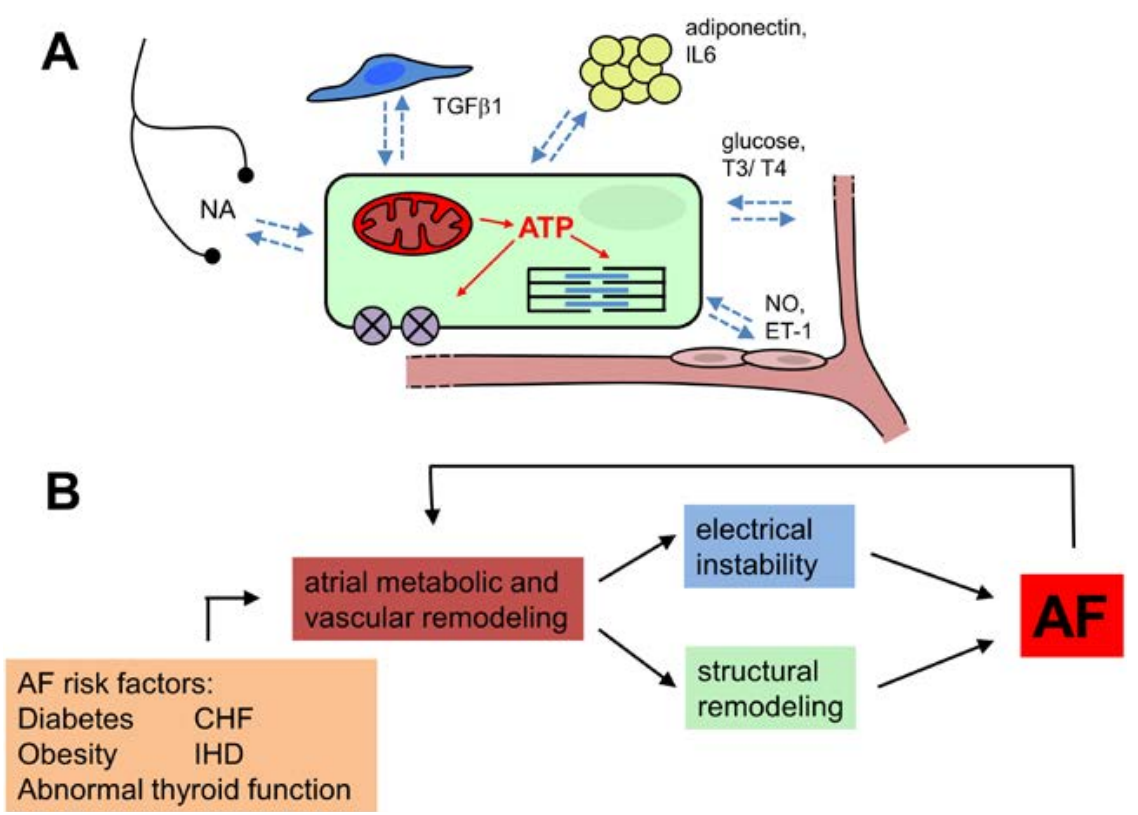

Figure 1. Atrial metabolism and metabolic remodeling. A) Atrial metabolism determines the balance between energy consumption and production in myocytes. Paracrine interactions with other cell types in the atrial myocardium that affect this balance may be altered in AF. B) Both AF itself and risk factors for AF lead to remodeling of atrial metabolism and vasculature. Through resulting effects on calcium handling and tissue structure, these remodeling processes may contribute to the progression of AF. 


\section{Determinants of atrial coronary supply}

\subsection{Atrial coronary anatomy and flow regulation}

As in any other tissue, blood supply by the atrial coronaries is regulated to match the energy/ oxygen demand ${ }^{8}$. In the heart, it is particularly important that even under increased demand, metabolism remains aerobic, to avoid acidification and muscle fatigue that would be detrimental to cardiac pump function. Therefore, the balance between oxygen supply and demand has to be carefully guarded. Among the major determinants of myocardial oxygen demand are heart rate ${ }^{9}$, myocardial wall tension ${ }^{10,11}$, and contractility ${ }^{12}$ (Figure 2A). During acute AF, the rate of electrical and contractile activity increases 4-6 fold $^{13-15}$, which is likely to increase atrial energy and oxygen expenditure considerably. If this increase in demand cannot be met by an increase in supply, a state of supply/demand ischemia ensues (Figure 2B).

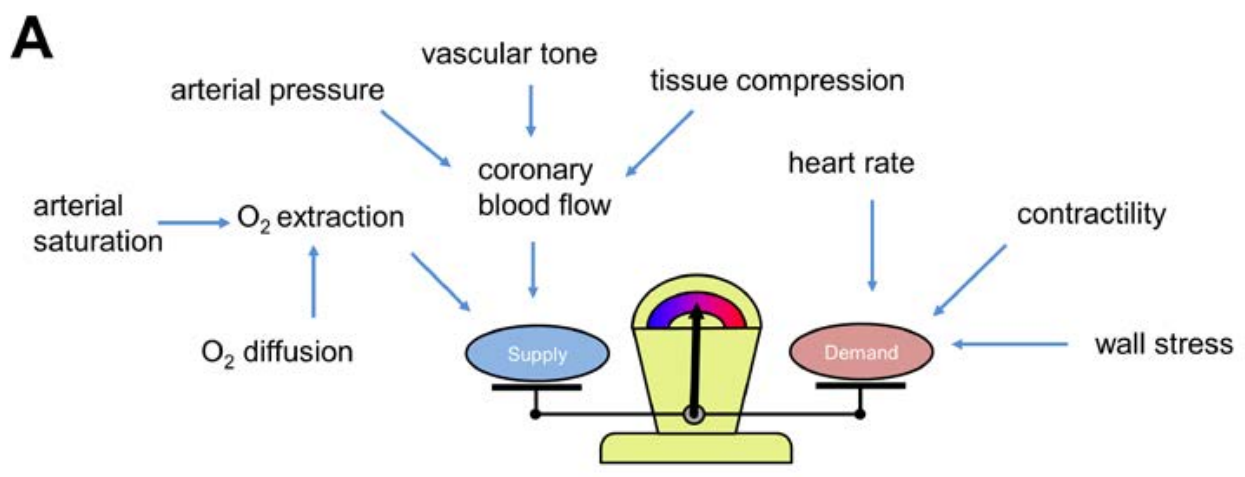

\section{B}
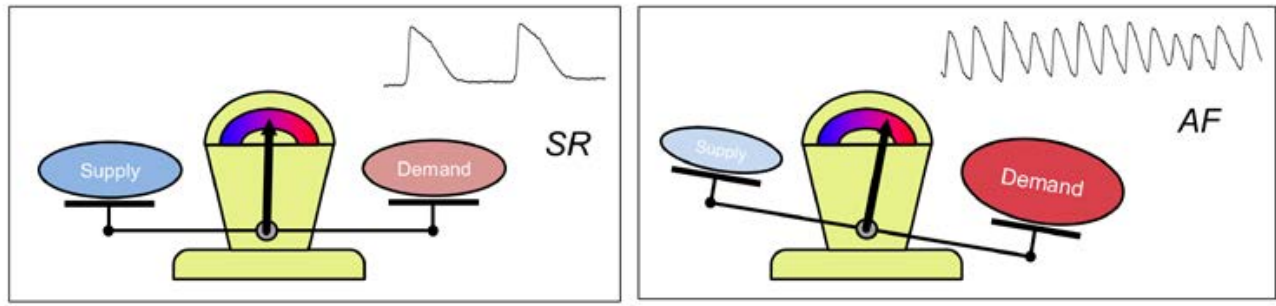

Figure 2. Atrial supply demand balance. (A) Determinants of atrial demand and supply. (B) In healthy atria, supply through the atrial coronary vasculature is in balance with demand by the atrial myocardium. With the 4-6-fold increase in the frequency of electrical activation and contraction, atrial demand will increase during AF. If the coronary blood supply does not show a commensurate increase, a state of supply/demand ischemia will develop.

The right atrium (RA) is mainly supplied by the right coronary artery, while the left atrium (LA) is mainly supplied by the left coronary artery ${ }^{16}$. The number and size of the atrial arteries $(0.5-1 \mathrm{~mm}$ in diameter), their branching points and the area they supply show 
considerable variation between individuals ${ }^{17}$. Atrial branches are often classified according to their point of origin as anterior, intermediate and posterior atrial branches ${ }^{18-20}$. The majority of atrial venous blood drains into to the coronary sinus, while a smaller part drains directly into the atrial cavities as Thebesian veins ${ }^{21}$. At rest during sinus rhythm, the atria receive about $5 \%$ of total coronary blood flow ${ }^{22,23}$. Blood flow in LA arteries measured with Doppler flow probes shows a phasic pattern, with a sharp decrease during atrial contraction ${ }^{24-26}$.

Atrial blood flow has been measured in conscious horses and dogs during rest and exercise. Exercise resulted in an increase of atrial blood flow depending on exercise intensity, with a larger increase in the RA than in the $\mathrm{LA}^{27,28}$. In anesthetized pigs, atrial pacing led to a ratedependent increase in LA blood flow that corresponded to the increase in atrial external work $^{26}$. In pigs, the LA coronary conductance reserve (the factor by which conductance can increase during full vasodilation in response to adenosine infusion) was smaller than in the LV (1.8 vs. 3.2$)^{8}$. In addition, a larger portion of this conductance reserve was mobilized during atrial pacing in the LA compared to the LV ( $75 \mathrm{vs.} 35 \%$ at a pacing cycle length of $400 \mathrm{~ms})$.

\subsection{Response to AF}

The response of atrial blood flow to acute AF has been investigated in several species. In anesthetized dogs, White at al. reported that the atrial flow increased 2- to 3-fold during acute $\mathrm{AF}^{29}$. Similarly, McHale et al. reported an $180 \%$ increase in atrial blood flow in conscious dogs during AF compared to sinus rhythm ${ }^{30}$. These authors also observed a further increase in atrial flow during AF after administration of a maximally vasodilating dose of adenosine, indicating that the atria had not reached its vascular conductance ${ }^{31}$. By contrast, in anesthetized open chest pigs, the maximal vascular conductance was reached after $1-5 \mathrm{~min}$ of acute $\mathrm{AF}^{8}$, and reactive hyperemia occurred after sinus rhythm was restored, suggesting that the LA has incurred an oxygen debt during $\mathrm{AF}^{26}$.

Another way in which an increase in oxygen demand can be accommodated is by increasing oxygen extraction, leading to a decrease in venous oxygen saturation. In dogs, oxygen consumption increases 3-fold during $A F$, but microspectrophotometry on frozen tissue did not reveal differences in venous $\mathrm{O}_{2}$-saturation ${ }^{29}$. In pigs, venous oxygen saturation was measured directly from $L A$ and $L V$ vein draining into the coronary sinus. Atrial $\mathrm{O}_{2}$ extraction increased from $26 \%$ during sinus rhythm to $63 \%$ after 5 min of $A F$, whereas $\mathrm{O}_{2}$ in the $\mathrm{LV}$ was not affected. Although both vascular conductance reserve and oxygen extraction reserve was mobilized in response to acute AF in pigs, supply/demand ischemia occurred in the LA, as evidenced by the increase in atrial lactate production (Figure 3$)^{8}$. Similarly, stretchrelated AF causes an immediate shift in high-energy phosphate levels in perfused rabbit hearts ${ }^{32}$. 


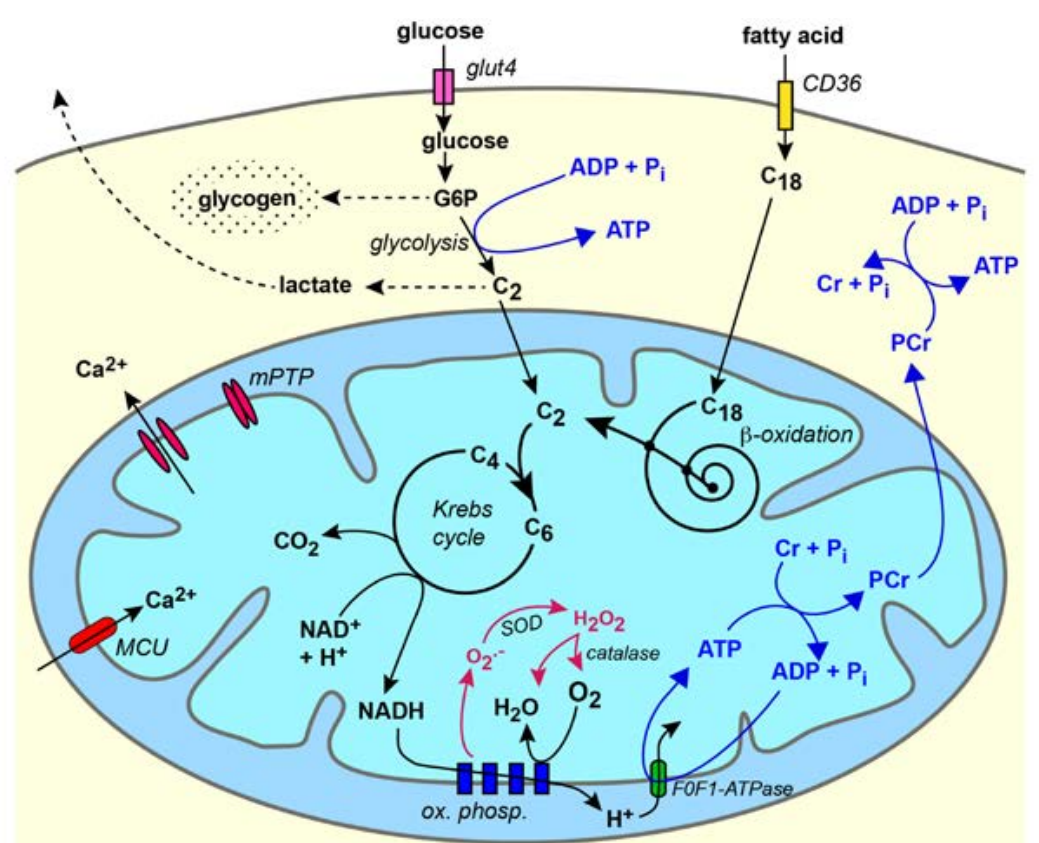

Figure 3. Overview of mitochondrial metabolism. In the Krebs cycle, C2 (acetyl-CoA) is coupled to C4 (oxaloacetate), and broken down, yielding $\mathrm{CO}_{2}$ as a waste product and $\mathrm{NADH}$ and $\mathrm{FADH}_{2}$ as energy carriers. The latter provide energy for the electron transport chain (oxidative phosphorylation) that produces an $\mathrm{H}^{+}$-gradient over the inner mitochondrial membrane. The FOF1-ATPase uses this gradient to synthesize ATP from ATP and $P_{i}$. The high-energy phosphate bond is exchanged with creatine to form creatine-phosphate, which diffuses throughout the cell and can serve as an energy buffer to replenish ATP levels wherever ATP is used. C2 to feed the Krebs cycle can be derived from beta-oxidation, in which fatty acids chains that have been imported by the transporter CD36 are broken down. Alternatively, glucose can be taken up via the glut4 transporter and converted to glucose-6-phospate (trapping it in the cell). G6P can be stored in the form of glycogen, or can be broken down in glycolysis, yielding a small amount of glycolytic ATP and C2. In the absence of $\mathrm{O}_{2^{\prime}} \mathrm{C} 2$ is converted to lactate. In the presence of $\mathrm{O}_{2^{\prime}} \mathrm{C} 2$ is used to drive the Krebs cycle. Activity of the electron transport chain can produce harmful oxygen radicals $\left(\mathrm{O}_{2}^{-}\right)^{-}$, that can be converted by superoxide dismutase (SOD) to $\mathrm{H}_{2} \mathrm{O}_{2}$, which can be further neutralized to $\mathrm{O}_{2}$ by catalase. The mitochondrial calcium uniporter (MCU) is the main entry mechanism of $\mathrm{Ca}^{2+}$ into mitochondria, allowing a role for mitochondria in calcium buffering and for $\mathrm{Ca}^{2+}$ in regulating metabolism. Multiple factors (e.g. high mitochondrial $\mathrm{Ca}^{2+}$ load) can trigger the opening of the mitochondrial permeability transition pore (mPTP), leading to collapse of the mitochondrial membrane potential and release of mitochondrial $\mathrm{Ca}^{2+}$ into the cytoplasm.

\section{Evidence for metabolic derangement and vascular alterations in AF}

\subsection{Metabolic alterations}

The energy required to perform the required electrical and mechanical work is provided as chemical energy in the form of ATP33. To maintain levels of ATP production and utilization of ATP have to be balanced. In the ventricles, of the total amount of ATP produced, $60-70 \%$ is used for contractility and remaining $30-40 \%$ for ion transport ${ }^{34}$. For the atria, no direct data have been reported, but this proportion may well be similar. As described above, 
there is evidence for supply/demand ischemia in the first minutes of AF. This subtle form of ischemia may persist in the important first weeks of AF pathogenesis. Activity of the mitochondrial ATP synthase (FOF1-ATPase) was increased in sheep after 2 hours of pacinginduced $\mathrm{AF}^{35}$. However, in a rabbit model, 7 days of rapid atrial pacing reduced F0F1-ATPase activity, down-regulated respiratory chain subunits and decreased atrial ATP content ${ }^{36}$. Goats with one week of AF have shown a decrease in creatine phosphate ( $\mathrm{PCr}$ ), the 'energy buffer' that can replenish local ATP levels (Figure 3), whereas ATP concentration itself was not affected ${ }^{37}$. A decrease in PCr is indicative of supply demand ischemia ${ }^{38}$. In the goat, the $\mathrm{PCr}$ level remained decreased by about $50 \%$ during the first two months of $\mathrm{AF}$, but levels had completely recovered at 4 months of $A F$, suggesting that the atrium eventually regains its energetic balance to some extent. In the same model, Hypoxia Inducible Factor $1 \mathrm{a}$ (HIF1a), the sensor that alters gene expression in hypoxic tissue, was elevated after 1 week of $A F$, but subsequently returned to its baseline level ${ }^{39}$.

HIF1a is a transcriptional activator of vascular endothelial growth factor (VEGF), which in turn stimulates angiogenesis. One study reported that increased LA levels VEGF were observed in patients with paroxysmal AF, but not in persistent AF patients ${ }^{40}$. This supports a transient supply/demand mismatch during the stabilization of AF. By contrast, Xu et al. reported a higher atrial HIF1 a content in permanent AF patient compared to patient with paroxysmal AF or sinus rhythm ${ }^{41}$, suggesting a more chronic, progressive hypoxic state in AF. Ogi et al. showed that AF increased HIFa and VEGF expression and that both proteins were predominantly produced and co-localized in the endothelium of atrial arteries in the $\mathrm{AF}$ group ${ }^{42}$. A detailed analysis of right atrial appendage biopsies of persistent $\mathrm{AF}$ patients also demonstrated an increase in hypoxic and angiogenic markers: protein levels of cytoplasmic HIF1a, HIF2a, vascular endothelial growth factor (VEGF), VEGF receptor 2 (KDR) and phosphorylated KDR (pKDR) proteins were increased ${ }^{43}$.

\subsection{Vascular alterations}

Given the pivotal role of VEGF in angiogenesis and arteriogenesis during myocardial ischemia 44,45 , the development of new atrial capillaries and arterioles during AF would be expected. Gramley et al. reported an increase in the size, but not in number, of atrial microvessels in AF patients ${ }^{43}$. Another study did not observe differences in capillary density between SR and AF patients ${ }^{46}$. However, several other studies have reported a decrease in capillary density in AF patients. Corradi et al. reported capillary rarefaction in the left atrial posterior wall of patients with mitral regurgitation and AF compared to patients with mitral regurgitation without a history of $A F^{47}, 48$. Similarly, Boldt et al. observed a lower LA capillary density in chronic AF patients ${ }^{49}$. A paradoxical loss of capillaries despite angiogenic signaling is not unprecedented; newly formed capillaries quickly disappear when not sufficiently stabilized through interaction with pericytes, as has been shown in renal fibrosis ${ }^{50}$. As a possible functional correlate to decreased capillary density, Skalidis et al. have observed a reduction in coronary flow reserve of left atrium coronary branch in patients with lone recurrent AF compared to sinus rhythm patients ${ }^{51}$. The flow reserve of the left circumflex coronary artery was comparable in both groups of patients, leading the authors to propose an isolated atrial microvascular dysfunction as a result of AF. The capillary density may vary between different populations of AF patients, but in 
patients with atrial capillary rarefaction, the capacity of the atrial vasculature to respond to fluctuations in demand would be reduced, increasing the vulnerability to supply/ demand ischemia. In analogy to changes in the ventricle during congestive heart failure $(\mathrm{CHF})^{52}$, endothelial dysfunction and increase $\mathrm{O}_{2}$ diffusion distances caused by fibrosis and myocyte hypertrophy may predispose to tissue hypoxia in the structurally remodeled atrium. In addition, atrial perfusion during AF will be affected by release of vasoactive mediators. In AF patients, atrial levels of the potent vasoconstrictor endothelin-1 (ET-1) were higher than in SR patients ${ }^{53,54}$. The expression of endothelin receptors may ${ }^{53}$ or may not $^{54}$ be reduced. To our knowledge, the implications of increased tissue ET-1 levels for atrial perfusion have not been assessed.

Few data are available on the effects of AF on ventricular metabolism and perfusion. In pigs, rapid atrial pacing (7 hours) increased oxidative stress in the ventricles and reduced ventricular coronary flow reserve, effects that could be inhibited by angiotensin II type 1 receptor blockade ${ }^{55,56}$.

In a broader sense, there is an association between AF and vascular disease. In many patients diagnosed with'lone AF', subclinical coronary artery disease is present (see section below) ${ }^{57,58}$. In addition, AF is associated with impaired both endothelium-dependent and -independent vasodilatation in peripheral arteries ${ }^{59-63}$. Endothelial function in peripheral arteries normalizes after restoration of sinus rhythm ${ }^{60,61,64,65}$. Asymmetric dimethylarginine (ADMA), an indicator of endothelial dysfunction, showed a rapid rise during an induced episode of AF (15 min) in patients ${ }^{66}$, and had decreased 6 months after successful catheter ablation in AF patients ${ }^{67}$. Several markers of endothelial remodeling are increased in the atria of patients in $A F$, particularly in the $L A^{68,69}$. These changes are relevant for formation of thrombi on the endocardial lining, but may also affect the atrial vasculature itself and thus atrial tissue perfusion.

\section{Metabolic remodeling caused by AF}

In AF patients, Mihm et al. demonstrated a reduction in myofibrillar creatine kinase (MMCK) activity that was correlated with the degree of protein nitration, supporting the role of oxidative damage to the contractile apparatus ${ }^{70}$. Decreased MM-CK activity would lead to impaired myofibrillar ATP generation. Possibly as a compensatory mechanism, the myosin isoform expression shifted from the high-velocity a-isoform to the slower, but more energy-efficient ${ }^{71}, \beta$-isoform.

A combined metabolomic and proteomic analysis was used to study patients undergoing coronary bypass or valve surgery. Patients with persistent AF displayed an increase in enzymes and metabolites involved in ketone body metabolism, including ketogenic amino acids ${ }^{72}$. Interestingly, the same study showed that in the SR group, the metabolic profile was predictive of postoperative AF occurrence. More specifically, a proteomic analysis demonstrated that correlates of increased oxidative stress and reduced glycolytic activity (i.e. reduced enolase and pyruvate dehydrogenase) predicted postoperative AF in patient undergoing coronary bypass surgery ${ }^{73}$. In a population of patients with metabolic 
syndrome undergoing coronary bypass, mitochondrial dysfunction (reduced respiration during $\beta$-oxidation, increased sensitivity of the mitochondrial permeability transition pore (mPTP) to $\mathrm{Ca}^{2+}$ and downregulation of genes involved in oxidative phosphorylation) was predictive of post-operative $A^{74}$. In patients with paroxysmal $A F$, the serine/threonine protein phosphatase type-1, a major determinant of the phosphorylation level of ion channels and proteins involved in $\mathrm{Ca}^{2+}$-handling, displayed altered interaction with its regulatory $\mathrm{R}$-subunits that are responsible for its subcellular localization and substrate specificity ${ }^{75}$.

Although animal studies have shown that AF leads to alterations in mitochondrial structure (see below), the effects of AF on mitochondrial physiology have not been studied extensively. Seppet et al. described alteration in respiratory chain activity (increased succinate-dependent respiration and augmented proton leak, which would decrease the efficiency of ATP synthesis) in mitochondria from AF patients ${ }^{76}$. In another study, mitochondrial DNA deletions that lead to impaired ATP synthesis were associated with AF prevalence in patients, although the causal relation was unclear ${ }^{77} \mathrm{Xu}$ et al. proposed that increased lactate signaling in AF patients, through mitochondrial MCT-1 (Monocarboxylate transporter 1) and ROS production could lead to increased activity of the mitochondrial apoptosis pathways ${ }^{78}$. A proteomic approach targeting mitochondrial proteins revealed differences between SR and AF patients, including a reduction in FHL2, a protein involved in coupling metabolic enzymes to sites of energy consumption in the sarcomere $^{79}$.

In the ventricle, the main source of ATP production is the oxidation of fatty acids (70 to $90 \%$ of the ATP generation). Glucose and lactate oxidation (and oxidation of small amounts of ketone bodies and amino acids) are responsible for generation of the remaining 10 to $30 \%{ }^{33}, 80$. During chronic hypoxia and heart failure, ventricular metabolism shifts from fatty acid to glucose utilization ${ }^{81}$. Fatty acid oxidation yields more ATP per gram of substrate under aerobic conditions, but costs 10-15\% more oxygen per amount of ATP than glucose $\mathrm{e}^{82}$. The substrate preference of healthy atria has not been investigated. It may not differ from that in the ventricles, although the glycolytic capacity appears to be higher in the atria than in the ventricles ${ }^{83}$. To which extent any such differences are attributable to differences in cellular composition (e.g. a larger abundance of fibroblasts in the atria) is not known.

AMP-activated protein kinase (AMPK) is an important sensor for the cellular energy status. Harada et al. recently showed that AMPK-phosphorylation (a measure for AMPK activation) was increased in dogs after one week of rapid atrial pacing ${ }^{84}$. AMPK phosphorylation was increased in patients with paroxysmal $A F$, but decreased in patients with longstanding persistent AF. In this study, AMPK activation was interpreted as an adaptive response to AF-induced metabolic stress, because it prevented a reduction in $\mathrm{I}_{\mathrm{CaL}^{\prime}}$ calcium transient amplitude and contractility ${ }^{84}$. In another recent study, irregular pacing of neonatal rat cardiomyocytes shortened the action potential duration (APD), compared to regular pacing at the same rate $(3 \mathrm{~Hz})$. Irregular pacing also elevated diastolic $\mathrm{Ca}^{2+}$ and activated $\mathrm{Ca}^{2+} /$ calmodulin-dependent protein kinase II (CaMKII) and $\mathrm{AMPK}^{85}$. This was associated 
with an increase in the levels of the fatty acid transporter CD36 and a decrease in the levels of the glucose transporter glut-4 in the membrane (Figure 3). Correspondingly, fatty acid uptake was augmented while glucose uptake was reduced. Parallel changes in metabolism were observed both in a mouse model of spontaneous AF (cardiac overexpression of the Rac1-GTPase) and in LA biopsies from AF patients ${ }^{85}$. These shifts were associated with intracellular accumulation of both lipids and glycogen, and by an activation of pro-apoptotic signaling pathways.

One metabolic phenomenon that has been investigated extensively is the production and consequences of reactive oxygen species (ROS) in $A F^{4,86,87}$. ROS are produced under physiological circumstances and can, by affecting the redox status of proteins, regulate ion channels and redox-sensitive transduction pathways ${ }^{4}$. However, persistent, excessive production of ROS (oxidative stress) can cause widespread modification of cellular proteins e.g. through formation of peroxynitrite and subsequent nitration of tyrosine residues and through S-glutathionylation of cysteine residues ${ }^{88}$, leading to alterations in function of e.g. oxidative phosphorylation, myofibrillar proteins ${ }^{70}$ and ions channels $s^{89}$. The sources of ROS production vary with the duration of the arrhythmia. At an early time point (1 week in pigs ${ }^{90}$, two weeks in goats ${ }^{91}$ ), atrial ROS production is increased (particularly in the LA) because of increased NAPDH oxidase activity. At later stages (6 months of AF in goats and AF patients with persistent AF), mitochondrial ROS production (Figure 3) and uncoupled nitric oxide synthase (NOS) accounted for the increased ROS production in both atria ${ }^{91}$. Under normal conditions, NOS produces nitric oxide (NO), a short-lived, rapidly diffusing molecule that, among many other effects, acts as a potent vasodilator ${ }^{92}$. NO bioavailability in the atria is decreased as a result of $\mathrm{AF}^{93}$. This may increase vascular tone and thus reduce atrial tissue perfusion, but this has not been investigated specifically. In its uncoupled state, NOS uses $\mathrm{O}_{2}$ as a substrate to produce the potent oxidant $\mathrm{O}_{2}-$ NOS uncoupling is favored by asymmetric dimethyl arginine (ADMA), an endogenous arginine analogue that is increased during $\mathrm{AF}^{94}$ and by depletion of the NOS cofactor tetrahydrobiopterin $(\mathrm{BH} 4)$, which has been demonstrated in the atria during $\mathrm{CHF}^{95}$.

\section{Impact of AF risk factors on atrial metabolism}

\section{1 'Metabolic diseases'}

Some important risk factors for AF can be considered metabolic diseases, including diabetes, obesity and abnormal thyroid function ${ }^{96}$. In most cases, very little is known about the mechanisms by which these'metabolic' risk factors lead to AF, whether through direct effects on atrial metabolism or a more indirect route. In atrial biopsies of patients with type 2 diabetes, tissue triglyceride content was increased and there was evidence of persistent oxidative stress compared to non-diabetic patients ${ }^{97}$. Mitochondrial respiration was lower in diabetic patients during oxidation of both glutamate and fatty acids, while mitochondrial $\mathrm{H}_{2} \mathrm{O}_{2}$ production was elevated for both substrates increased ${ }^{97}$. A recent study on diabetic rats compared groups in which diabetes was controlled or uncontrolled to a group in which glucose fluctuations were induced ${ }^{98}$. In the atria of rats with glucose fluctuations, profibrotic signaling, fibrosis, apoptosis and AF stability were increased compared to the other two groups. 
In a sheep model of obesity, infiltration of adipocytes, tissue levels of transforming growth factor $\beta 1$ (TGF $\beta 1$ ) and fibrosis are increased in the atria ${ }^{99,100}$. In this model, altered paracrine signaling between adipocytes, fibroblast and myocytes may contribute to the substrate for AF. In an exciting recent development, programs leading to weight loss and increased cardio-respiratory fitness led to a major reduction in AF burden in patients ${ }^{101-104}$.

With respect to abnormal thyroid function, it has been shown in a rat model that hypothyroidism increases atrial fibrosis, whereas hyperthyroidism leads to myocyte hypertrophy, while both increase AF stability ${ }^{105}$. However, both increase AF inducibility/ stability and both increased atrial sympathetic innervation ${ }^{105,106}$.

In patients undergoing cardiac surgery, atrial dilatation, an independent risk factor for $\mathrm{AF}^{107}$, correlated with alterations in mitochondrial metabolism ${ }^{108}$. Although (complex 1-dependent) mitochondrial respiration was impaired, activation of respiration by glucose was increased, indicating an enhanced coupling between glycolysis and oxidative phosphorylation.

\subsection{Congestive heart failure}

For several AF risk factors, such as hypertension and ageing, the effect on atrial metabolism are not known, although it is likely that for example increased atrial wall stress during hypertension also increases atrial energy expenditure. For congestive heart failure (CHF), another major independent risk factor for AF, effects on atrial metabolism have been described. The most extensively characterized animal model is a dog model of CHF as a result of rapid ventricular pacing. In this model, an early phase of atrial damage occurs, hallmarked by inflammatory infiltration, apoptosis and necrosis ${ }^{109}$. After 5 weeks of rapid ventricular pacing, end-stage CHF has developed, and pronounced atrial fibrosis is accompanied by conduction heterogeneity and increased AF stability ${ }^{15}$. Gene expression profiles revealed large changes in expression, both up- and down regulation, of genes involved in metabolism. The changes were present both after 24 hours and 2 weeks of ventricular pacing, indicating that they represent an early response $\mathrm{e}^{110}$. In a proteomic analysis of atrial tissue, 24 hours of rapid ventricular pacing in dogs already led to major shifts in expression of heat shock proteins and metabolic enzymes, whereas structural and contractile proteins were not yet affected. After 2 weeks of pacing, both metabolic and contractile protein levels were decreased and structural proteins showed fragmentation ${ }^{111}$. In the same study, metabolomic analysis revealed a pattern consistent with metabolic stress and impaired energy utilization, including a shift from glycolysis to alpha-ketoacid metabolism ${ }^{111}$, similar to that observed in patients with persistent $A^{72}$. After 5 weeks of rapid ventricular pacing in dogs, Cha et al. reported a profound disruption of atrial bioenergetics, with a substantial decrease in both PCr and ATP, along with a decrease in the activities of creatine kinase and adenylate cyclase, the main enzymes involved in the transfer of high-energy phosphate groups ${ }^{112}$. 


\section{Ischemic heart disease as a risk factor for AF}

Depressed ventricular function resulting from coronary artery disease/ischemic heart disease may affect the atria by mechanisms similar to those by which other forms of heart failure affect the atria (see previous section). However, ischemic heart disease is also likely to affect the atria directly. Acute myocardial infarction (MI) is a risk factor for $\mathrm{AF}^{113-115}$. AF is present in $10-20 \%$ of patients that are hospitalized with acute $\mathrm{Ml}$, of which $7-11 \%$ is new onset $\mathrm{AF}^{116-120}$. A study by Hod et al. on $214 \mathrm{Ml}$ patients included 7 (3\%) who developed $\mathrm{AF}$, all of whom had a coexisting occlusion of atrial arteries, confirming that acute atrial ischemia is a likely mechanism of new onset $\mathrm{AF}$ after $\mathrm{MI}^{121}$. In addition, atrial infarctions are regularly observed in post mortem studies after $\mathrm{MI}(17-42 \%)^{122-125}$, most often in the RA (appendage), and less frequently affecting the LA or both atria ${ }^{122,126,127}$. A study by Cushing et al. showed that $43 \%$ of patients with proven atrial infarctions had been in $\mathrm{AF}^{122}$.

AF and coronary artery disease (CAD) often coexist. In fact, AF patients are more likely to have underlying chronic coronary artery disease than their aged-matched controls in sinus rhythm ${ }^{57,115}$. Overall, the prevalence of overt coronary artery disease in AF patients is 6.4-19.2\% ${ }^{128-130}$. Manifestations of coronary artery disease, such as myocardial infarction and angina pectoris and even non-symptomatic ST segment abnormalities have been identified as independent risk factors for $\mathrm{AF}^{113}$. Even in patients who were originally diagnosed with "lone" AF, the prevalence of concealed, previously undiagnosed CAD is higher than in matched control patients ( 49 vs. $34 \%)^{57}$.

The mechanisms by which atrial ischemia leads to AF has been investigated in various animal models. In isolated perfused sheep hearts, acute regional ischemia, achieved by injection of microspheres in LA anterior artery, led to $\mathrm{I}_{\mathrm{KATP}}$-dependent APD shortening in both the ischemic and non-ischemic zone, but conduction velocity was reduced only in the ischemic zone ${ }^{131}$. In open-chest dogs, acute ischemia caused by complete ligation of an RA artery slowed conduction and increased conduction heterogeneity in the infarct zone and greatly increased the stability of AF with little or no effect on ERP'132, 133. The increase in AF stability in this setting could be prevented by rotagaptide, which enhances gap-junctional conductance ${ }^{134}$. Spontaneous AF episodes were observed in perfused sheep hearts ${ }^{131}$, but not in the studies on dogs with acute RA ischemia ${ }^{133,135,136}$. Chronically, ligation of the RA artery in dogs (1week) resulted in spontaneous atrial ectopic activity ${ }^{136}$. This was associated with an increased propensity to triggered activity and enhanced $\mathrm{Na}^{+} \mathrm{Ca}^{2+}$ exchange current in myocytes isolated from the border zone of the atrial infarct. In addition, fibrosis was increased in the (peri)-infarct zone and reentrant conduction was observed, indicating a combined role of ectopy and reentry in atrial infarction.

In summary, severe atrial ischemia/atrial infarction can create a substrate for AF. However, the extent and even the nature of changes in the atrial myocardium may be quite different in slowly developing coronary artery disease and in the supply/demand ischemia that is caused by AF itself. 


\section{Time course of atrial remodeling processes}

Both in any AF patients and in large animal models of AF, the stability of AF gradually increases; the duration of spontaneous or induced AF episodes becomes progressively longer. It is generally accepted that both electrical and structural remodeling of the atrial myocardium contribute to this progression of $\mathrm{AF}^{96}$. Electrical remodeling entails the shortening of the APD and concomitantly, the shortening of the effective refractory period (ERP). This allows faster re-activation rates and therefore an increased stability of reentry. Structural remodeling, most notably fibrosis, is thought to precipitate conduction heterogeneity, increasing to tortuosity of fibrillatory propagation and further stabilizing reentry. The time course of these changes has been studied most closely in the goat model of AF. Whereas electrical remodeling is a fast process, taking 1-2 days to complete, structural remodeling develops much more slowly over a time course of months ${ }^{14,137}$. In this goat model, it is interesting to note that the major part of AF stabilization takes place after APD shortening is complete and before changes in tissue structure becomes apparent. After 1-2 days of AF, electrical remodeling has increased AF episode duration from seconds to minutes. After 2-3 weeks of AF, the arrhythmia has become persistent, although no changes in tissue structure is apparent at that point ${ }^{137,138}$. In this model, endomysial fibrosis leads to the progressive loss of side-to-side connections between myocyte bundles over a time course of months, and a concomitant increase in the complexity of fibrillatory conduction, that has been proposed to explain the transition from persistent to permanent $\mathrm{AF}^{138,139}$. Over the same slow time course of months, $\mathrm{AF}$ causes myocyte hypertrophy ${ }^{140}$, that may also affect wavefront propagation ${ }^{141}$. The distribution pattern of fibrosis and hypertrophy is different, with hypertrophy occurring throughout the thickness of the atrial wall, whereas endomysial fibrosis is restricted to the outer millimeter of the epicardium ${ }^{138}$, suggesting that the mechanisms underlying these aspects of structural remodeling may be different.

The evidence described in the previous sections indicates that AF leads to acute metabolic derangement, leading to metabolic remodeling in the subsequent days and weeks (Figure 4). Although metabolic remodeling may be viewed as an adaptive process, leading to a decrease in energy demand, it may also lead to electrical instability and structural remodeling (Figure 1B), as detailed below. 


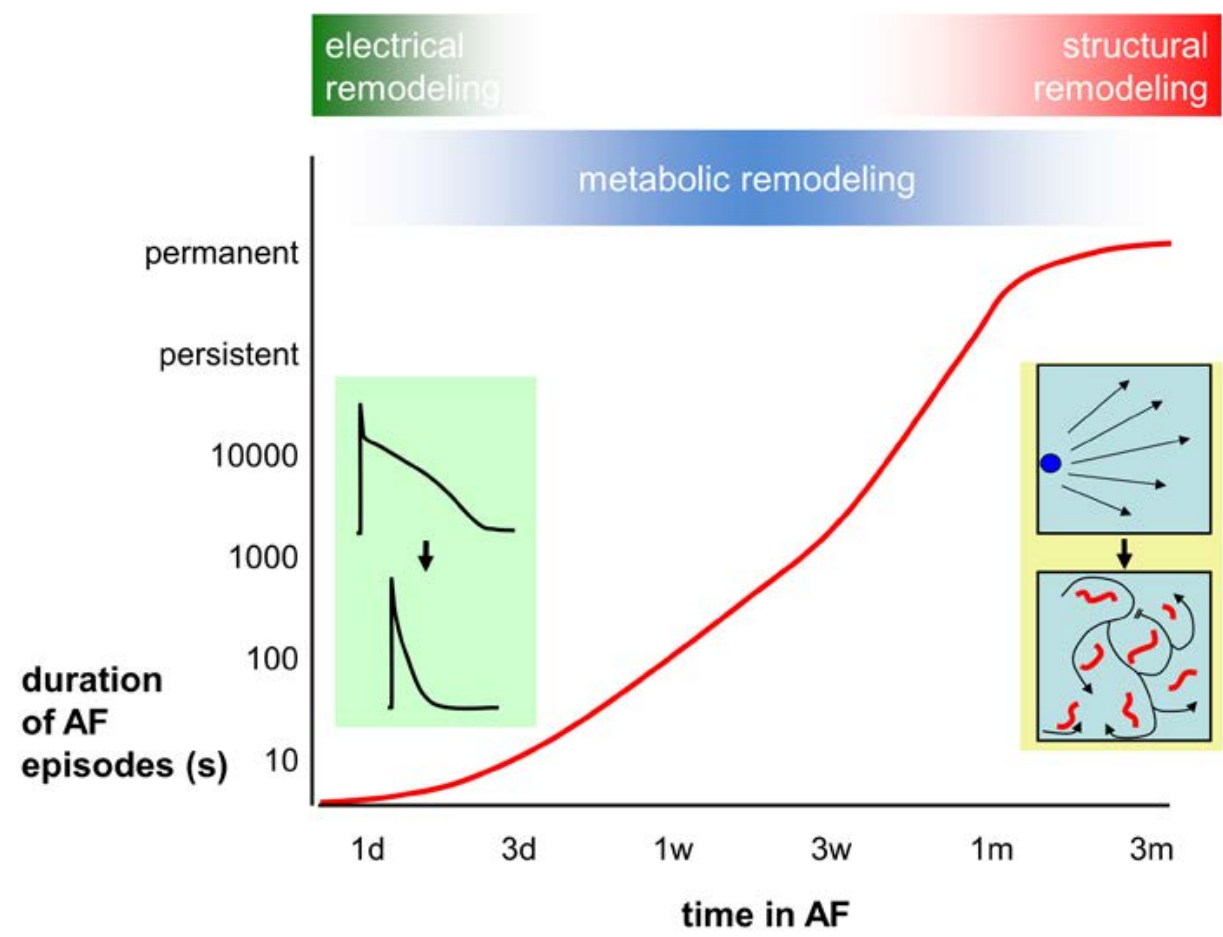

Figure 4. Proposed time course of atrial remodeling processes. Electrical remodeling in the strict sense, i.e. the shortening of APD and ERP takes places in the first 1-3 days of AF. The first signs of structural remodeling do not become apparent until several weeks later. The period in between (which coincides with a major increase in AF stabilization) is likely to be the most important phase of metabolic remodeling, hallmarked by chronic supply/ demand ischemia and hypoxia. Changing patterns of gene expression in this period reflect a reorientation of metabolism, regression to a fetal phenotype and hibernation.

\section{Relation of metabolism to electrical remodeling}

Even a short period of AF causes a (rapidly reversible) decline in atrial contractility, as has been reported in humans ${ }^{142}$ and in pigs $^{143}$. In humans, this correlates with an equally rapid decline in atrial refractory period ${ }^{144}$. In goats, the decrease in ERP and the loss of contractility follow exactly the same time course during the first days of $\mathrm{AF}^{145}$. The downregulation of the calcium current can be viewed as a protective mechanism against the calcium overload that occurs as a result of the rapid activation rates during $A F^{146}$. Indeed, a causative role for calcium overload is probable, because the calcium channel blocker verapamil can inhibit both the rapid loss in atrial contractility in humans ${ }^{142}$ and in pigs s $^{143}$ and the shortening of ERP in goats ${ }^{147}$. A positive side-effect of reduced contractility is that it will also ameliorate the supply/demand imbalance in the atria. On the other hand, APD shortening, in which the up-regulation of inward rectifier currents probably has a larger effect than down-regulation of the calcium current ${ }^{148}$, will increase activation frequency and thus energy consumption related to ion fluxes, including calcium cycling. 
There is an enormous variety of interactions between metabolic parameters and ion homeostasis, schematically and partially represented in Figure 5, with ROS/redox signaling, ATP/energetic status (AMPK) and the $\mathrm{Ca}^{2+}$ and $\mathrm{Na}^{+}$concentrations serving as nexuses between the metabolism and electrical activity.

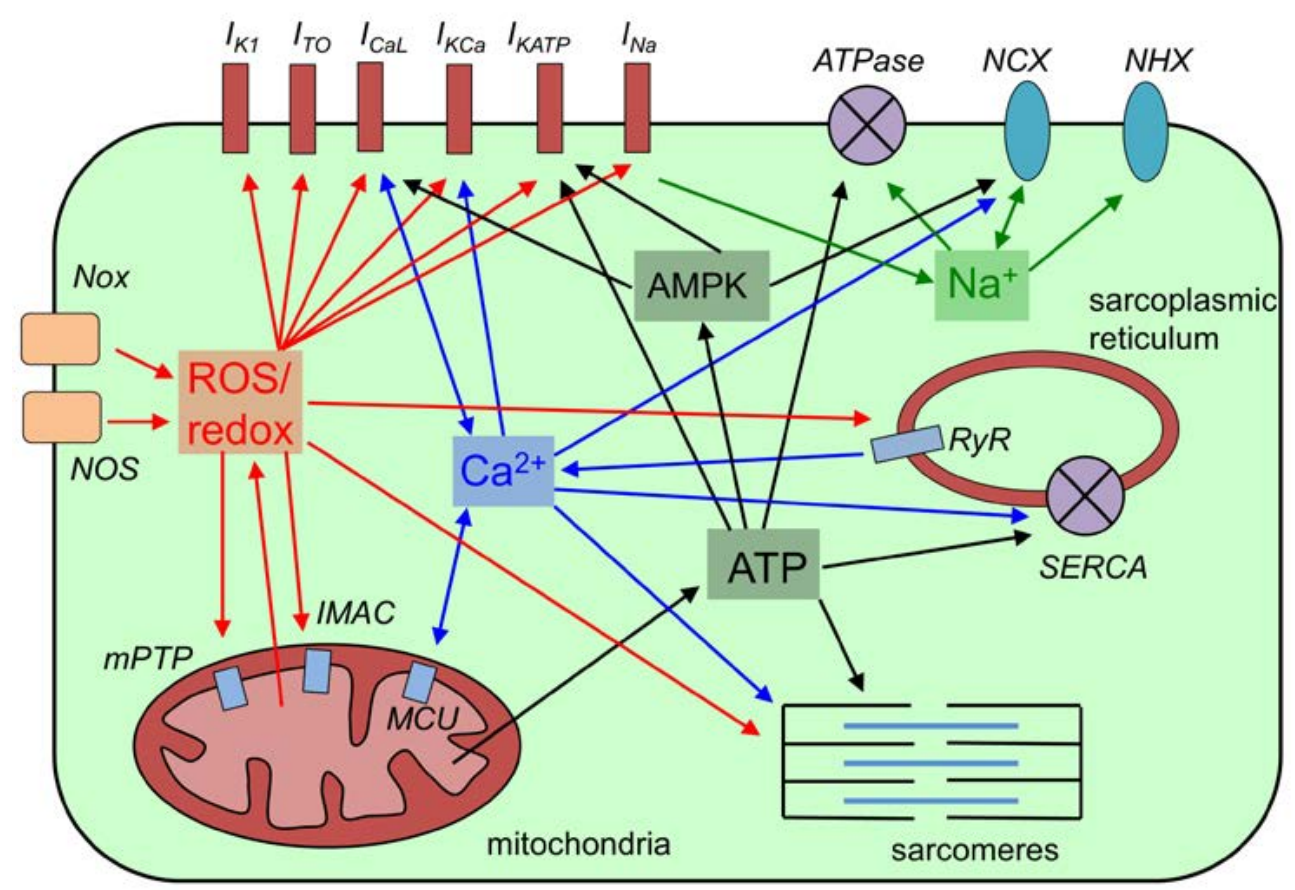

Figure 5. Interconnections between metabolism and electrical activity. This schematic representation (not intended to be comprehensive) shows a number of important of relations, with ROS, ATP/ energy status, $\mathrm{Ca}^{2+}$ and $\mathrm{Na}^{+}$serving as nexuses between cellular metabolism and electrophysiology. In several instances, these relations are bidirectional. For example, mitochondria play a role in buffering cytosolic calcium, and calcium is a vital regulator of energy production.

\subsection{Calcium handling}

'Electrical remodeling' is commonly used to refer to the shortening of the APD/ERP, but not to alterations in intracellular calcium handling. Abnormalities in calcium cycling may be proarrhythmic, leading to APD alternans, early or late afterdepolarizations and triggered activity. Although several factors involved in calcium cycling are known to be affected by AF, the time course of this form of 'electrical instability' has not been studied in detail. In isolated myocytes from AF patients, the frequency of spontaneous $\mathrm{Ca}^{2+}$ sparks and $\mathrm{Ca}^{2+}$ waves is increased ${ }^{149}$. In intact tissue, such calcium-dependent cellular proarrhythmic events could only give rise to propagating waves under specific conditions, for example in the presence of fibrosis or other factors that reduce electrical coupling ${ }^{150,151}$. This would lead to generation of new fibrillation waves characterized by focal spread of activation. However, the contribution of calcium-dependent proarrhythmic events to AF maintenance is unclear at present. Based on extensive activation mapping, one study reported that 
focal activity was the main mechanism of AF maintenance ${ }^{152}$. Another study indicated that EADs may play an important role in reinitiating $A^{153,154}$. Using simultaneous endo- and epicardial mapping in goats, Eckstein et al. have shown that although many instances of focal spread of activation can be explained by transmural propagation from the opposite side of the atrial wall, an estimated $13 \%$ could not, and these events could potentially have a pivotal contribution to AF maintenance ${ }^{155}$.

\subsection{Role of mitochondria}

All types of calcium-dependent proarrhythmic events, which could be collectively described as 'electrical instability' (Figure 1A), may be intimately linked with alterations in cellular metabolism. During metabolic stress (such as substrate deprivation or oxidative stress), metabolic oscillations can lead to oscillations in cytosolic $\mathrm{Ca}^{2+}$ and membrane currents $^{156,157}$. In ventricular myocytes, metabolic oscillations are mediated by the mitochondrial inner membrane anion channel (IMAC), activated under moderate oxidative stress ${ }^{158-160}$. Under strongly adverse conditions, high mitochondrial ROS production can also lead to opening of the MPTP (Figure 3), resulting in an irreversible depolarization of the mitochondrial membrane ${ }^{161}$, and which through to a wave of 'ROS-induced ROS release' in the network of mitochondria can lead to a cell-wide collapse of the mitochondrial membrane potential ${ }^{158-160,162}$. The extent to which this can occur during AF is unclear at present, but as described above, AF represents a significant stress on metabolism. Normally, matching of energy demand to mitochondrial energy production is regulated by the levels of adenosine di-phosphate (ADP) and $\mathrm{Ca}^{2+}$. ADP accumulation can increase ATP production by accelerating electron flux at the electron transport chain ${ }^{163}$. On the other hand, $\mathrm{Ca}^{2+}$ activates key enzymes in glucose oxidation (pyruvate dehydrogenase) and rate-limiting enzymes in Krebs cycle (isocitrate- and a-ketoglutarate dehydrogenase), stimulating oxidative phosphorylation and consequently ATP production ${ }^{163,164}$. Calcium is thought to be the most important under normal conditions ${ }^{165}$. This role appears to be inconsistent with the low affinity of the mitochondrial calcium uptake (MCU) uniporter. However, mitochondria are closely associated with the sarcoplasmic reticulum, with an average distance of 15-20 $\mathrm{nm}$ between mitochondria and the junctional sarcoplasmic reticulum ${ }^{166}$. Mitochondria can therefore be exposed to much higher local calcium concentrations, allowing a role for mitochondria in $\mathrm{Ca}^{2+}$-buffering and for $\mathrm{Ca}^{2+}$ in regulating mitochondrial metabolism ${ }^{167}$. Atrial myocytes have a more sparse T-tubular system than ventricular myocytes. Correspondingly, the calcium wave propagates more slowly and less completely into the central part of atrial myocytes ${ }^{168,169}$. In rat atrial myocytes, this partial extinction of the calcium wave has been attributed to calcium uptake by mitochondria and sarcoplasmic reticulum Ca2+-ATPase pumps ${ }^{168}$. In human atrial myocytes, calcium buffering due to increased myofilament $\mathrm{Ca}^{2+}$ sensitivity was identified as a potential contributor to the reduced calcium wave propagation resulting from atrial remodeling ${ }^{170}$. After 5 days of rapid atrial pacing in a rabbit model, the calcium wave failed to propagate into central part of the cell, although the amplitude of the subsarcolemmal calcium transient was unchanged compared to control atrial myocytes. Propagation failure of the calcium wave was associated with increased calcium buffering strength, but the possible contribution of mitochondria to this increase was not assessed ${ }^{169}$. 
Calcium overload during AF may explain some early changes in mitochondrial structure, since pacing of cultured human atrial tissue slices induced mitochondrial swelling and decreased mitochondrial respiration. These effects of pacing could be inhibited by treatment with the calcium channel blocker verapamil ${ }^{68}$.

In summary, normal and abnormal calcium handling affects mitochondria. Conversely, $\mathrm{Ca}^{2+}$ release by ryanodine channels (RyR) can be directly affected by a number of metabolites (e.g. stimulation by fructose-6-phosphate and inhibition by pyruvate) ${ }^{171}$. Cardiac alternans is a proarrhythmic factor ${ }^{172}$ that illustrates the interaction between metabolism and electrophysiology. In cat atrial myocytes, inhibition of glycolysis enhanced calcium alternans ${ }^{173}$. Between regions in individual myocytes, calcium alternans could be discordant, leading to gradients in calcium concentration that triggered propagating calcium waves $^{174}$.

In old rats, glycolytic inhibition induced EADs at the junction between LA and pulmonary veins, and $E A D$-induced triggered activity led to spontaneous $A F^{175}$. This response to glycolytic inhibition was not observed in young rats, suggesting that spontaneous AF in this model requires a conjunction of age-dependent changes in tissue structure (i.e. loss of transverse connections) $)^{176}$ and alterations in calcium handling resulting from glycolytic inhibition.

\subsection{Membrane currents}

Several ionic channels, pumps and exchangers are sensitive to the redox potential/ROS, including $\mathrm{I}_{\mathrm{Na}^{\prime}} \mathrm{I}_{\mathrm{to}^{\prime}} \mathrm{I}_{\mathrm{K} 1^{\prime}} \mathrm{I}_{\mathrm{KATP}} \mathrm{NCX}, \mathrm{RyR}$ and SERCA, conferring a link between the metabolic state and the electrical activity of myocytes (Figure 5, see ${ }^{4,89,177}$ for extensive reviews). In ventricular ischemia, several currents are increased, most notably $I_{\text {KATP }}$ the $\mathrm{Na}^{+} \mathrm{H}^{+}$exchanger (NHX) and the persistent sodium current $\mathrm{I}_{\mathrm{Na} \text {,late }}$. To a more limited extent, the contribution of these currents and the efficacy of their inhibition have been assessed during AF, but results are largely inconclusive. The persistent sodium current, $\mathrm{I}_{\mathrm{Na}}$, late , is increased under a number of pathological conditions in the ventricles, including ischemia ${ }^{178}$. It is also higher in AF patients compared to patients in SR ${ }^{179,180}$. Ranolazine blocks $\mathrm{I}_{\mathrm{Na}, \text { late }}{ }^{181}$. In pigs, ranolazine slightly decreased the stability of AF induced by acetylcholine infusion ${ }^{182}$, and decreased AF inducibility in a model of partial LCx occlusion, but only when applied in combination with dronaderone ${ }^{183}$. However, due to differences in inactivation kinetics of $\mathrm{I}_{\mathrm{Na}}$ in atria and ventricles, ranolazine has also been proposed as an atrium-specific blocker of peak $\mathrm{I}_{\mathrm{Na}}{ }^{184}$, and its efficacy in terminating AF may also be attributable to this effect.

The ATP-sensitive potassium current, $I_{\text {KATP }}$ is activated in response to falling ATP levels during severe ischemia, leading to a shortening of the APD. Wijffels et al. showed that $I_{\text {KATP }}$ blockade by glibencamide did not affect the AFCL in goats with sustained $A F^{185}$. This is consistent with the decrease in PCr, indicating supply-demand ischemia, while ATP levels are unaffected in this model at a similar point in time ${ }^{37}$.

Activity of the $\mathrm{NHX}$ is increased in response to intracellular acidification during ventricular ischemia. Excessive NHX activity can contribute to calcium overload. NHX blockade 
attenuates ischemia/reperfusion injury in the ventricle. Inhibition of the NHX inhibited atrial ERP shortening ${ }^{186}$ and contractile dysfunction ${ }^{187}$ in the first hours of rapid atrial pacing in a dog model, but did not prevent APD shortening in the goat model ${ }^{188}$.

\subsection{Reversibility of electrical remodeling}

Both in the goat model of $\mathrm{AF}^{145}$ and in $\mathrm{AF}$ patients ${ }^{189}$, electrical remodeling is completely reversible in a number days. By contrast, recovery from structural remodeling is slow and incomplete ${ }^{190,191}$. With recovery from electrical remodeling, contractility and therefore energy consumption would increase. This may be particularly relevant in paroxysmal AF. Each AF paroxysm may represent a renewed ischemic insult to the atrial myocardium, leading to an accumulation of (structural) damage. Alternatively however, repetitive AF paroxysms may induce ischemic 'preconditioning' 192 that would limit damage to the atria. Studies on animal models of episodic AF vary in the effect on AF stabilization. In goats, repetitive $A F$ episodes ( 5 days of $A F, 2$ days of $S R$ ) did not show a cumulative effect on $A F$ stability ${ }^{193}$. By contrast, episodes of AF (4 weeks of AF, one week of SR) in sheep lead to a gradual acceleration of AF stabilization, suggesting accumulating structural remodeling ${ }^{194}$.

\section{Relation of metabolism to structural remodeling}

'Structural remodeling' refers to any change in structure, both changes on the level of tissue structure (e.g. myocyte hypertrophy, fibrosis, fatty infiltrations) and changes within myocytes at the ultrastructural level. The former develop very slowly (months), and are likely to impact conduction directly, increasing the complexity of fibrillatory conduction and thereby the stability of $A F^{195}$. The latter ultrastructural changes, which are not likely to affect conduction directly, include glycogen accumulation, loss of contractile apparatus (myolysis) and changes in mitochondrial size and shape. Ultrastructural changes appear relatively early (1-3 weeks of AF), before changes in tissue structure become apparent, and are all related to energy production and consumption in atrial myocytes ${ }^{137}$.

In goats with 3-6 months of AF, almost all atrial myocytes showed a loss of myofibrils, accumulation of glycogen storage granules (Figure 3), fragmentation of the sarcoplasmic reticulum and dispersion of nuclear chromatin ${ }^{196}$. The number of mitochondria was increased, while their size was decreased ${ }^{37}$, which may indicate a shift towards increased mitochondrial fission ${ }^{197}$. However, the inner structure of mitochondria was largely normal (no loss of intramatrix granules, no clarification of mitochondrial matrices, no disruption of cristae). ${ }^{37}$

The phenomenon of hibernation coincides with dedifferentiation of atrial myocytes, i.e. regression to a fetal phenotype. This includes expression of a-smooth muscle actin, disappearance of cardiotin and an altered distribution pattern of titin ${ }^{140}$. A similar switch to a'fetal gene program' has been observed in the ventricles in a variety of pathophysiologic conditions, e.g. hypoxia, ischemia, hypertrophy and diabetes ${ }^{198}$. In general, the changes in ultrastructure and gene expression during prolonged AF are similar to those observed in the ventricular myocardium as a result of chronic low-flow ischemia ${ }^{199-201}$. 
Atrial structural remodeling correlates with broad changes in gene expression. In a dog model of AF with controlled ventricular rate, most genes in several categories were downregulated ${ }^{110}$. By contrast, in biopsies from AF patients, many genes were upregulated, including genes involved in metabolism, and altered gene expression was more pronounced in the LA than in the $\mathrm{RA}^{202,203}$. In pigs, rapid atrial pacing also led to more pronounced changes in the LA than in the RA, including a shift to the ventricular isoform of myosin regulatory light chain ${ }^{204}$. More broadly, Barth et al. described that in AF patients atrial-specific genes were down-regulated while ventricular-specific genes were up-regulated in the atrial myocardium ${ }^{205}$.

Dedifferentiation and hibernation represent an adaptation to chronic exposure to adverse circumstances e.g. increased wall stress and hypoxia, and have been described as an act of 'programmed cell survival'201. Indeed, rates of apoptosis are low in the goat model of $\mathrm{AF}^{200}$. By contrast, rates of apoptosis (and necrosis) are high in the canine CHF model in the first days of pacing ${ }^{109}$. Although it is not known which factors cause this acute damage, it is conceivable that they occur to rapidly in this model to allow a switch to a hibernation phenotype of atrial myocytes. The resulting loss of myocytes may explain the pronounced (replacement) fibrosis observed at later time points in this model ${ }^{15}$.

In animal models of 'lone' $\mathrm{AF}$, structural alterations may not be solely caused by the high atrial rate and concomitant calcium overload. In goats, ultrastructural changes were virtually absent when ventricular rate was controlled and only the atria were rapidly paced, and pronounced when both the atria and ventricles were rapidly paced ${ }^{206}$. In a sheep model with rapid atrial pacing, ventricular rate control (by His bundle ablation) prevented atrial tissue fibrosis and inhibited the development of persistent $A F$, but did not prevent myocyte hypertrophy ${ }^{207}$. Analogously, AF may have much larger consequences for atrial metabolism when ventricular role is not controlled. Indeed, genomic/proteomic analysis showed mainly down-regulation of metabolic genes in a dogs model of AF with complete rate control (AV block with ventricular pacing), whereas a similar (but not directly comparable) analysis in AF patients ${ }^{72}$ showed similarities in atrial metabolism with a dog model of $\mathrm{CHF}^{111}$.

At present, it is not clear to what extent metabolic derangement and remodeling (evidenced by ultrastructural changes and myocyte hibernation) in the first weeks of AF are eventually responsible for alterations in tissue structure (e.g. fibrosis and fatty infiltration) that affect conduction, but there are several (overlapping) candidate mechanisms. In analogy to the failing ventricle, energy starvation and/or oxidative stress can activate redox-sensitive signaling e.g. by oxidizing CaMKII, which has been linked to cell death and cardiomyopathy ${ }^{208,209}$. Expression of CaMKII is higher in AF patients than in SR patients ${ }^{210}$. As a general mechanism, AF and a number of AF risk factor are associated with inflammation, which can both produce and be triggered by oxidative stress ${ }^{211}$. The resulting production of inflammatory cytokines can lead to myocyte apoptosis, myocyte hypertrophy and fibroblast activation/collagen deposition ${ }^{211}$. Interestingly, a recent study has demonstrated that inflammatory lymphocytes were localized in fibro-fatty infiltrates in $\mathrm{AF}$ patients and in a sheep model of persistent $\mathrm{AF}^{212}$. 
In addition, endothelial dysfunction/damage and ischemia increase expression of tissue factor (TF) and thrombin, also by myocytes ${ }^{211,213}$. Apart from their role in blood coagulation, TF and thrombin also activate protease-activated receptor-1 and -2 (PAR-1 and -2) receptors on myocytes, fibroblasts and endothelial cells, which can lead to hypertrophy, fibrosis and further vascular damage (reviewed $\mathrm{in}^{214}$ ). Further evidence for a causal relation between metabolic derangement and structural remodeling will strengthen the rationale for early, aggressive treatment of AF in patients.

\section{Perspectives}

AF has a profound impact on the atrial metabolism, but our knowledge on these effects is still quite limited. On the whole, data in the literature are consistent with supply/demand ischemia and consequent metabolic and vascular remodeling in the important early phase of AF progression. At present, evidence that metabolic and vascular remodeling play a causative role in electrical and structural remodeling are largely circumstantial. Evidence for causation would be strengthened by intervention strategies that selectively target determinants of the atrial supply/demand balance. A possible approach is an 'improvement' of atrial metabolism ${ }^{81}$ to enhance oxygen efficiency and preserve atrial function. For example, a shift from fatty acid to glucose utilization would prove oxygen efficiency by an estimated 10-15\%, and may therefore ameliorate atrial oxygen shortage during AF. For the anti-anginal drug ranolazine, in addition to its effects on ion channels ${ }^{215}$, part of the beneficial long-term effects in AF patients ${ }^{216}$ may be explained by a shift in substrate preference ${ }^{81}$. A more specific strategy to cause a shift in substrate utilization may be attained by treatment with trimetazidine or perhexiline ${ }^{81,217}$. Alternatively, a treatment strategy could attempt to improve atrial perfusion. As discussed above, several studies show that atrial capillary rarefaction occurs during AF despite increased angiogenic signaling, indicating that newly formed capillaries are not sufficiently stabilized. One way to stabilize capillaries would be to target the balance between angiopoietins 1 and 2 , which has been proposed as an important determinant of capillary stability in other disease states ${ }^{50}$. If successful, such interventions could lead to new treatment options to prevent the progression of AF.

Conflict of interest: none declared.

\section{Funding}

This study was supported byt he Foundation Leducq (ENAFRA, 07CVD03), by the European Union; the European Network for Translational Research in Atrial Fibrillation (EUTRAF, No. 261057) and RADical reduction of OXidative stress in cardiovascular disease (RADOX, No. 316738) and by a grant from the Dutch Heart Foundation (CVON201409, RACE V: Reappraisal of Atrial Fibrillation: Interaction between hyperCoagulability, Electrical remodeling, and Vascular Destabilisation in the Progression of AF). 


\section{References}

1. Harris DA and Das AM. Control of mitochondrial ATP synthesis in the heart. Biochem J. 1991;280 (Pt 3):561-73.

2. Nattel S and Harada M. Atrial Remodeling and Atrial Fibrillation: Recent Advances and Translational Perspectives. J Am Coll Cardiol. 2014.

3. Hatem SN and Sanders P. Epicardial adipose tissue and atrial fibrillation. Cardiovasc Res. 2014;102:205-213.

4. Wolke C, Bukowska A, Goette A and Lendeckel U. Redox control of cardiac remodeling in atrial fibrillation. Biochim Biophys Acta. 2015;1850:1555-1565.

5. Simon JN, Duglan D, Casadei B and Carnicer R. Nitric oxide synthase regulation of cardiac excitation-contraction coupling in health and disease. J Mol Cell Cardiol. 2014;73:80-91.

6. Greiser $\mathrm{M}$ and Schotten U. Dynamic remodeling of intracellular $\mathrm{Ca}(2)(+)$ signaling during atrial fibrillation. J Mol Cell Cardiol. 2013;58:134-42.

7. Heijman J, Voigt N, Nattel S and Dobrev D. Cellular and molecular electrophysiology of atrial fibrillation initiation, maintenance, and progression. Circ Res. 2014;114:1483-99.

8. van Bragt KA, Nasrallah HM, Kuiper M, Luiken JJ, Schotten U and Verheule S. Atrial supplydemand balance in healthy adult pigs: coronary blood flow, oxygen extraction, and lactate production during acute atrial fibrillation. Cardiovasc Res. 2013.

9. Boerth RC, Covell JW, Seagren SC and Pool PE. High-energy phosphate concentrations in dog myocardium during stress. Am J Physiol. 1969;216:1103-1106.

10. Britman NA and Levine HJ. Contractile element work: a major determinant of myocardial oxygen consumption. J Clin Invest. 1964;43:1397-1408.

11. Graham TP, Covell JW, Sonnenblick EH, Ross J and Braunwald E. Control of myocardial oxygen consumption: relative influence of contractile state and tension development. J Clin Invest. 1968;47:375-385.

12. Bassenge $E$, Kucharczyk M, Holtz J and Stoian D. Treadmill exercise in dogs under -adrenergic blockade: adaptation of coronary and systemic hemodynamics. Pflügers Archiv : European journal of physiology. 1972;332:40-55.

13. Konings KT, Kirchhof CJ, Smeets JR, Wellens HJ, Penn OC and Allessie MA. High-density mapping of electrically induced atrial fibrillation in humans. Circulation. 1994;89:1665-80.

14. Wijffels $M$, Kirchhof $C$, Dorland $R$ and Allessie M. Atrial fibrillation begets atrial fibrillation. A study in awake chronically instrumented goats. Circulation. 1995;92:1954-1968.

15. Li D, Fareh S, Leung T and Nattel S. Promotion of atrial fibrillation by heart failure in dogs: atrial remodeling of a different sort. Circulation. 1999;100:87-95.

16. von Lüdinghausen $M$. The clinical anatomy of coronary arteries. Advances in anatomy, embryology, and cell biology. 2003;167:III-VIII, 1-111.

17. Busquet J, Fontan F, Anderson RH, Ho SY and Davies MJ. The surgical significance of the atrial branches of the coronary arteries. Int J Cardiol. 1984;6:223-236.

18. Smith GT. The anatomy of the coronary circulation. Am J Cardiol. 1962;9:327-42.

19. James TN and Burch GE. The atrial coronary arteries in man. Circulation. 1958;17:90-8.

20. Soderstrom. Some anatomical and functional data regarding the atria of the heart Acta medica scandinavica supplementum; 1948(217): 27-39.

21. Loukas M, Bilinsky S, Bilinsky E, el-Sedfy A and Anderson RH. Cardiac veins: a review of the literature. Clinical anatomy (New York, NY). 2009;22:129-145. 
22. Neill WA, Phelps NC, Oxendine JM, Mahler DJ and Sim DN. Effect of heart rate on coronary blood flow distribution in dogs. Am J Cardiol. 1973;32:306-312.

23. Neill WA, Sewell DH, Gosalia KP, Kingsley EM and Oxendine JM. Atrial coronary hyperemia and ischemia in response to variations in atrial pressure in dogs. Am Heart J. 1983;106:554-558.

24. Kajiya F, Tsujioka K, Ogasawara Y, Hiramatsu O, Wada Y, Goto M and Yanaka M. Analysis of the characteristics of the flow velocity waveforms in left atrial small arteries and veins in the dog. Circ Res. 1989;65:1172-1181.

25. Kimura A, Hiramatsu O, Wada Y, Yada T, Yamamoto T, Goto M, Ogasawara Y, Tsujioka K and Kajiya F. Atrial contractility affects phasic blood flow velocity of atrial small vessels in the dog. Cardiovasc Res. 1992;26:1219-1225.

26. van Bragt KA, Nasrallah HM, Kuiper M, van Hunnik A, Kuijpers NHL, Schotten U and Verheule S. Dynamic regulation of atrial coronary blood flow in healthy adult pigs. Heart Rhythm. 2015;12:991-1000.

27. Bauman RP, Rembert JC and Greenfield JC. Regional blood flow in canine atria during exercise. Am J Physiol. 1993;265:H629-32.

28. Manohar M, Goetz TE, Hutchens E and Coney E. Atrial and ventricular myocardial blood flows in horses at rest and during exercise. Am J Vet Res. 1994;55:1464-1469.

29. White CW, Kerber RE, Weiss HR and Marcus ML. The effects of atrial fibrillation on atrial pressure-volume and flow relationships. Circ Res. 1982;51:205-215.

30. McHale PA and Greenfield JC. Origin of atrial coving in canine phasic coronary artery blood flow. Am J Physiol. 1986;251:H774-8.

31. McHale PA, Rembert JC and Greenfield JC. Effect of atrial fibrillation on atrial blood flow in conscious dogs. Am J Cardiol. 1983;51:1722-1727.

32. Kalifa J, Maixent J-M, Chalvidan T, Dalmasso C, Colin D, Cozma D, Laurent P, Deharo J-C, Djiane $\mathrm{P}$, Cozzone $\mathrm{P}$ and Bernard $\mathrm{M}$. Energetic metabolism during acute stretch-related atrial fibrillation. Mol Cell Biochem. 2008;317:69-75.

33. Doenst T, Nguyen TD and Abel ED. Cardiac metabolism in heart failure: implications beyond ATP production. Circ Res. 2013;113:709-724.

34. Gibbs CL. Cardiac energetics. Physiol Rev. 1978;58:174-254.

35. Barbey O, Pierre S, Duran MJ, Sennoune S, Levy S and Maixent JM. Specific up-regulation of mitochondrial FOF1-ATPase activity after short episodes of atrial fibrillation in sheep. $J$ Cardiovasc Electrophysiol. 2000;11:432-438.

36. Dong J, Zhao J, Zhang M, Liu G, Wang X, Liu Y, Yang N, Liu Y, Zhao G, Sun J, Tian J, Cheng C, Wei L, Li Y and Li W. 33 -Adrenoceptor Impairs Mitochondrial Biogenesis and Energy Metabolism During Rapid Atrial Pacing-Induced Atrial Fibrillation. J Cardiovasc Pharmacol Ther. 2015.

37. Ausma J, Coumans WA, Duimel H, Van der Vusse GJ, Allessie MA and Borgers M. Atrial high energy phosphate content and mitochondrial enzyme activity during chronic atrial fibrillation. Cardiovasc Res. 2000;47:788-796.

38. Weiss RG, Mejia MA, Kass DA, DiPaula AF, Becker LC, Gerstenblith G and Chacko VP. Preservation of canine myocardial high-energy phosphates during low-flow ischemia with modification of hemoglobin-oxygen affinity. J Clin Invest. 1999;103:739-46.

39. Thijssen V, van der Velden $H$, van Ankeren E, Ausma J, Allessie M, Borgers M, van Eys $G$ and Jongsma $\mathrm{H}$. Analysis of altered gene expression during sustained atrial fibrillation in the goat. Cardiovasc Res. 2002;54:427-437. 
40. Scridon A, Morel E, Nonin-Babary E, Girerd N, Fernandez C and Chevalier P. Increased intracardiac vascular endothelial growth factor levels in patients with paroxysmal, but not persistent atrial fibrillation. Europace. 2012;14:948-953.

41. XuY, Sharma D, Du F and Liu Y.The role of Toll-like receptor 2 and hypoxia-induced transcription factor-1a in the atrial structural remodeling of non-valvular atrial fibrillation. Int J Cardiol. 2013;168:2940-2941.

42. Ogi H, Nakano Y, Niida S, Dote K, Hirai Y, Suenari K, Tonouchi Y, Oda N, Makita Y, Ueda S, Kajihara K, Imai K, Sueda T, Chayama K and Kihara Y. Is structural remodeling of fibrillated atria the consequence of tissue hypoxia? Circulation journal : official journal of the Japanese Circulation Society. 2010;74:1815-1821.

43. Gramley F, Lorenzen J, Jedamzik B, Gatter K, Koellensperger E, Münzel T and Pezzella F. Atrial fibrillation is associated with cardiac hypoxia. Cardiovasc Pathol. 2010;19:102-111.

44. Lee SH, Wolf PL, Escudero R, Deutsch R, Jamieson SW and Thistlethwaite PA. Early expression of angiogenesis factors in acute myocardial ischemia and infarction. NEng/ J Med. 2000;342:626-633.

45. Semenza GL. Angiogenesis in ischemic and neoplastic disorders. Annu Rev Med. 2003;54:17-28.

46. Olasinska-Wisniewska A, Mularek-Kubzdela T, Grajek S, Marszalek A, Sarnowski W, Jemielity M, Seniuk W, Lesiak M, Prech M and Podzerek T. Impact of atrial remodeling on heart rhythm after radiofrequency ablation and mitral valve operations. Ann Thorac Surg. 2012;93:1449-1455.

47. Corradi D, Callegari S, Maestri R, Benussi S, Bosio S, de Palma G, Alinovi R, Caglieri A, Goldoni M, Mozzoni P, Pastori P, Manotti L, Nascimbene S, Dorigo E, Rusconi R, Astorri E and Alfieri O. Heme oxygenase- 1 expression in the left atrial myocardium of patients with chronic atrial fibrillation related to mitral valve disease: its regional relationship with structural remodeling. Hum Pathol. 2008;39:1162-1171.

48. Corradi D, Callegari S, Maestri R, Ferrara D, Mangieri D, Alinovi R, Mozzoni P, Pinelli S, Goldoni M, Privitera YA, Bartoli V, Astorri E, Macchi E, Vaglio A, Benussi S and Alfieri O. Differential structural remodeling of the left-atrial posterior wall in patients affected by mitral regurgitation with or without persistent atrial fibrillation: a morphological and molecular study. J Cardiovasc Electrophysiol. 2012;23:271-279.

49. Boldt A, Scholl A, Garbade J, Resetar ME, Mohr F-W, Gummert JF and Dhein S. ACE-inhibitor treatment attenuates atrial structural remodeling in patients with lone chronic atrial fibrillation. Basic Res Cardiol. 2006;101:261-267.

50. Khairoun M, van der Pol P, de Vries DK, Lievers E, Schlagwein N, de Boer HC, Bajema IM, Rotmans JI, van Zonneveld AJ, Rabelink TJ, van Kooten C and Reinders MEJ. Renal ischemiareperfusion induces a dysbalance of angiopoietins, accompanied by proliferation of pericytes and fibrosis. Am J Physiol Renal Physiol. 2013;305:F901-10.

51. Skalidis El, Hamilos MI, Karalis IK, Chlouverakis G, Kochiadakis GE and Vardas PE. Isolated atrial microvascular dysfunction in patients with lone recurrent atrial fibrillation. J Am Coll Cardiol. 2008;51:2053-2057.

52. De Boer RA, Pinto YM and van Veldhuisen DJ. The imbalance between oxygen demand and supply as a potential mechanism in the pathophysiology of heart failure: the role of microvascular growth and abnormalities. Microcirculation (New York, NY: 1994). 2003;10:113-126.

53. Brundel BJ, Van Gelder IC, Tuinenburg AE, Wietses M, Van Veldhuisen DJ, Van Gilst WH, Crijns $\mathrm{HJ}$ and Henning $\mathrm{RH}$. Endothelin system in human persistent and paroxysmal atrial fibrillation. J Cardiovasc Electrophysiol. 2001;12:737-742. 
54. Mayyas F, Niebauer M, Zurick A, Barnard J, Gillinov AM, Chung MK and van Wagoner DR. Association of left atrial endothelin-1 with atrial rhythm, size, and fibrosis in patients with structural heart disease. Circ Arrhythmia Electrophysiol. 2010;3:369-379.

55. Goette A, Bukowska A, Dobrev D, Pfeiffenberger J, Morawietz H, Strugala D, Wiswedel I, Rohl FW, Wolke C, Bergmann S, Bramlage P, Ravens $U$ and Lendeckel U. Acute atrial tachyarrhythmia induces angiotensin II type 1 receptor-mediated oxidative stress and microvascular flow abnormalities in the ventricles. Eur Heart J. 2009;30:1411-20.

56. Goette A, Bukowska A, Lillig CH and Lendeckel U. Oxidative Stress and Microcirculatory Flow Abnormalities in the Ventricles during Atrial Fibrillation. Front Physiol. 2012;3:236.

57. Weijs B, Pisters R, Haest RJ, Kragten JA, Joosen IA, Versteylen M, Timmermans CC, Pison L, Blaauw $Y$, Hofstra L, Nieuwlaat R, Wildberger J and Crijns HJ. Patients originally diagnosed with idiopathic atrial fibrillation more often suffer from insidious coronary artery disease compared to healthy sinus rhythm controls. Heart Rhythm. 2012;9:1923-1929.

58. Weijs B, De Vos CB, Tieleman RG, Peeters FECM, Limantoro I, Kroon AA, Cheriex EC, Pisters $R$ and Crijns HJGM. The occurrence of cardiovascular disease during 5-year follow-up in patients with idiopathic atrial fibrillation. Europace : European pacing, arrhythmias, and cardiac electrophysiology : journal of the working groups on cardiac pacing, arrhythmias, and cardiac cellular electrophysiology of the European Society of Cardiology. 2013;15:18-23.

59. Takahashi N, Ishibashi Y, Shimada T, Sakane T, Ohata S, Sugamori T, Ohta Y, Inoue S, Nakamura K, Shimizu H, Katoh H, Sano K, Murakami $Y$ and Hashimoto M. Atrial fibrillation impairs endothelial function of forearm vessels in humans. J Card Fail. 2001;7:45-54.

60. Takahashi N, Ishibashi Y, Shimada T, Sakane T, Ohata S, Sugamori T, Ohta Y, Inoue S-i, Nakamura $\mathrm{K}$, Shimizu H, Katoh H and Murakami Y. Impaired exercise-induced vasodilatation in chronic atrial fibrillation--role of endothelium-derived nitric oxide. Circulation journal : official journal of the Japanese Circulation Society. 2002;66:583-588.

61. Skalidis El, Zacharis EA, Tsetis DK, Pagonidis K, Chlouverakis G, Yarmenitis S, Hamilos M, Manios EG and Vardas PE. Endothelial cell function during atrial fibrillation and after restoration of sinus rhythm. Am J Cardiol. 2007;99:1258-1262.

62. Freestone B, Chong AY, Nuttall S and Lip GYH. Impaired flow mediated dilatation as evidence of endothelial dysfunction in chronic atrial fibrillation: relationship to plasma von Willebrand factor and soluble E-selectin levels. Thromb Res. 2008;122:85-90.

63. Guazzi M and Arena R. Endothelial dysfunction and pathophysiological correlates in atrial fibrillation. Heart. 2009;95:102-106.

64. Shin SY, Na JO, Lim HE, Choi CU, Choi JI, Kim SH, Kim EJ, Park SW, Rha S-W, Park CG, Seo HS, Oh DJ and Kim Y-H. Improved endothelial function in patients with atrial fibrillation through maintenance of sinus rhythm by successful catheter ablation. J Cardiovasc Electrophysiol. 2011;22:376-382.

65. Guazzi M, Belletti S, Lenatti L, Bianco E and Guazzi MD. Effects of cardioversion of atrial fibrillation on endothelial function in hypertension or diabetes. Eur J Clin Invest. 2007;37:26-34.

66. Lim HS, Willoughby SR, Schultz C, Gan C, Alasady M, Lau DH, Leong DP, Brooks AG, Young GD, Kistler PM, Kalman JM, Worthley MI and Sanders P. Effect of atrial fibrillation on atrial thrombogenesis in humans: impact of rate and rhythm. J Am Coll Cardiol. 2013;61:852-860.

67. Lim HS, Willoughby SR, Schultz C, Chakrabarty A, Alasady M, Lau DH, Roberts-Thomson KC, Worthley MI, Young GD and Sanders P. Successful catheter ablation decreases platelet 
activation and improves endothelial function in patients with atrial fibrillation. Heart Rhythm. 2014;11:1912-1918.

68. Bukowska A, Schild L, Keilhoff G, Hirte D, Neumann M, Gardemann A, Neumann KH, Röhl F-W, Huth $C$, Goette $A$ and Lendeckel U. Mitochondrial dysfunction and redox signaling in atrial tachyarrhythmia. Exp Biol Med (Maywood). 2008;233:558-574.

69. Goette A, Bukowska A, Lendeckel U, Erxleben M, Hammwöhner M, Strugala D, Pfeiffenberger J, Röhl F-W, Huth C, Ebert MPA, Klein HU and Röcken C. Angiotensin II receptor blockade reduces tachycardia-induced atrial adhesion molecule expression. Circulation. 2008;117:732-742.

70. Mihm MJ, Yu F, Carnes CA, Reiser PJ, McCarthy PM, van Wagoner DR and Bauer JA. Impaired myofibrillar energetics and oxidative injury during human atrial fibrillation. Circulation. 2001;104:174-180.

71. Reggiani C, Bottinelli R and Stienen GJ. Sarcomeric Myosin Isoforms: Fine Tuning of a Molecular Motor. News Physiol Sci. 2000;15:26-33.

72. Mayr M, Yusuf S, Weir G, Chung Y-L, Mayr U, Yin X, Ladroue C, Madhu B, Roberts N, de Souza A, Fredericks S, Stubbs M, Griffiths JR, Jahangiri M, Xu Q and Camm AJ. Combined metabolomic and proteomic analysis of human atrial fibrillation. J Am Coll Cardiol. 2008;51:585-594.

73. Kourliouros A, Yin X, Didangelos A, Hosseini MT, Valencia O, Mayr M and Jahangiri M. Substrate modifications precede the development of atrial fibrillation after cardiac surgery: a proteomic study. Ann Thorac Surg. 2011;92:104-110.

74. Montaigne D, Marechal X, Lefebvre P, Modine T, Fayad G, Dehondt H, Hurt C, Coisne A, Koussa M, Remy-Jouet I, Zerimech F, Boulanger E, Lacroix D, Staels B and Neviere R. Mitochondrial dysfunction as an arrhythmogenic substrate: a translational proof-of-concept study in patients with metabolic syndrome in whom post-operative atrial fibrillation develops. $J \mathrm{Am}$ Coll Cardiol. 2013;62:1466-1473.

75. Chiang DY, Lebesgue N, Beavers DL, Alsina KM, Damen JM, Voigt N, Dobrev D, Wehrens XH and Scholten A. Alterations in the interactome of serine/threonine protein phosphatase type- 1 in atrial fibrillation patients. J Am Coll Cardiol. 2015;65:163-73.

76. Seppet E, Eimre M, Peet N, Paju K, Orlova E, Ress M, Kõvask S, Piirsoo A, Saks VA, Gellerich FN, Zierz $S$ and Seppet EK. Compartmentation of energy metabolism in atrial myocardium of patients undergoing cardiac surgery. Mol Cell Biochem. 2005;270:49-61.

77. Tsuboi M, Hisatome I, Morisaki T, Tanaka M, Tomikura Y, Takeda S, Shimoyama M, Ohtahara A, Ogino K, Igawa O, Shigemasa C, Ohgi S and Nanba E. Mitochondrial DNA deletion associated with the reduction of adenine nucleotides in human atrium and atrial fibrillation. Eur J Clin Invest. 2001;31:489-496.

78. Xu J, Xu X, Si L, Xue L, Zhang S, Qin J, Wu Y, Shao Y, Chen Y and Wang X. Intracellular lactate signaling cascade in atrial remodeling of mitral valvular patients with atrial fibrillation. $J$ Cardiothorac Surg. 2013;8:34.

79. Goudarzi M, Ross MM, Zhou W, Van Meter A, Deng J, Martin LM, Martin C, Liotta L, Petricoin $E$ and Ad N. Development of a novel proteomic approach for mitochondrial proteomics from cardiac tissue from patients with atrial fibrillation. J Proteome Res. 2011;10:3484-92.

80. Wisneski JA, Gertz EW, Neese RA, Gruenke LD and Craig JC. Dual carbon-labeled isotope experiments using $D-[6-14 C]$ glucose and L-[1,2,3-13C3] lactate: a new approach for investigating human myocardial metabolism during ischemia. J Am Coll Cardiol. 1985;5:1138-46.

81. Horowitz JD, Chirkov YY, Kennedy JA and Sverdlov AL. Modulation of myocardial metabolism: an emerging therapeutic principle. Curr Opin Cardiol. 2010;25:329-34. 
82. Liedtke AJ. Alterations of carbohydrate and lipid metabolism in the acutely ischemic heart. Prog Cardiovasc Dis. 1981;23:321-336.

83. Savabi $F$ and Kirsch A. Alteration of the phosphocreatine energy shuttle components in diabetic rat heart. J Mol Cell Cardiol. 1991;23:1323-1333.

84. Harada M, Tadevosyan A, Qi X, Xiao J, Liu T, Voigt N, Karck M, Kamler M, Kodama I, Murohara T, Dobrev D and Nattel S. Atrial Fibrillation Activates AMP-Dependent Protein Kinase and its Regulation of Cellular Calcium Handling: Potential Role in Metabolic Adaptation and Prevention of Progression. J Am Coll Cardiol. 2015;66:47-58.

85. Lenski M, Schleider G, Kohlhaas M, Adrian L, Adam O, Tian Q, Kaestner L, Lipp P, Lehrke M, Maack C, Böhm M and Laufs U. Arrhythmia causes lipid accumulation and reduced glucose uptake. Basic Res Cardiol. 2015;110:40.

86. van Wagoner DR. Oxidative stress and inflammation in atrial fibrillation: role in pathogenesis and potential as a therapeutic target. J Cardiovasc Pharmacol. 2008;52:306-313.

87. Sovari AA and Dudley SC. Reactive oxygen species-targeted therapeutic interventions for atrial fibrillation. Front Physiol. 2012;3:311.

88. Ho E, Karimi Galougahi K, Liu CC, Bhindi R and Figtree GA. Biological markers of oxidative stress: Applications to cardiovascular research and practice. Redox Biol. 2013;1:483-91.

89. Yang K-C, Bonini MG and Dudley SC. Mitochondria and arrhythmias. Free radical biology \&amp; medicine. 2014;71:351-361.

90. Dudley SC, Hoch NE, McCann LA, Honeycutt C, Diamandopoulos L, Fukai T, Harrison DG, Dikalov $\mathrm{SI}$ and Langberg J. Atrial fibrillation increases production of superoxide by the left atrium and left atrial appendage: role of the NADPH and xanthine oxidases. Circulation. 2005;112:1266-1273.

91. Reilly SN, Jayaram R, Nahar K, Antoniades C, Verheule S, Channon KM, Alp NJ, Schotten $\mathrm{U}$ and Casadei $\mathrm{B}$. Atrial sources of reactive oxygen species vary with the duration and substrate of atrial fibrillation: implications for the antiarrhythmic effect of statins. Circulation. 2011;124:1107-1117.

92. Bonilla IM, Sridhar A, Györke S, Cardounel AJ and Carnes CA. Nitric oxide synthases and atrial fibrillation. Front Physiol. 2012;3:105.

93. Cai H, Li Z, Goette A, Mera F, Honeycutt C, Feterik K, Wilcox JN, Dudley SC, Jr., Harrison DG and Langberg JJ. Downregulation of endocardial nitric oxide synthase expression and nitric oxide production in atrial fibrillation: potential mechanisms for atrial thrombosis and stroke. Circulation. 2002;106:2854-8.

94. Goette A, Hammwohner M, Bukowska A, Scalera F, Martens-Lobenhoffer J, Dobrev D, Ravens $U$, Weinert S, Medunjanin S, Lendeckel $U$ and Bode-Boger SM. The impact of rapid atrial pacing on ADMA and endothelial NOS. Int J Cardiol. 2012;154:141-6.

95. Nishijima Y, Sridhar A, Bonilla I, Velayutham M, Khan M, Terentyeva R, Li C, Kuppusamy P, Elton TS, Terentyev D, Györke S, Zweier JL, Cardounel AJ and Carnes CA. Tetrahydrobiopterin depletion and NOS2 uncoupling contribute to heart failure-induced alterations in atrial electrophysiology. Cardiovasc Res. 2011;91:71-79.

96. Schotten U, Verheule S, Kirchhof P and Goette A. Pathophysiological mechanisms of atrial fibrillation: a translational appraisal. Physiol Rev. 2011;91:265-325.

97. Anderson EJ, Kypson AP, Rodriguez E, Anderson CA, Lehr EJ and Neufer PD. Substrate-specific derangements in mitochondrial metabolism and redox balance in the atrium of the type 2 diabetic human heart. J Am Coll Cardiol. 2009;54:1891-1898. 
98. Saito S, Teshima Y, Fukui A, Kondo H, Nishio S, Nakagawa M, Saikawa T and Takahashi N. Glucose fluctuations increase the incidence of atrial fibrillation in diabetic rats. Cardiovasc Res. 2014;104:5-14.

99. Abed HS, Samuel CS, Lau DH, Kelly DJ, Royce SG, Alasady M, Mahajan R, Kuklik P, Zhang Y, Brooks AG, Nelson AJ, Worthley SG, Abhayaratna WP, Kalman JM, Wittert GA and Sanders P. Obesity results in progressive atrial structural and electrical remodeling: implications for atrial fibrillation. Heart Rhythm. 2013;10:90-100.

100. Mahajan R, Lau DH, Brooks AG, Shipp NJ, Manavis J, Wood JPM, Finnie JW, Samuel CS, Royce SG, Twomey DJ, Thanigaimani S, Kalman JM and Sanders P. Electrophysiological, Electroanatomical, and Structural Remodeling of the Atria as Consequences of Sustained Obesity. J Am Coll Cardiol. 2015;66:1-11.

101. Abed HS, Wittert GA, Leong DP, Shirazi MG, Bahrami B, Middeldorp ME, Lorimer MF, Lau DH, Antic NA, Brooks AG, Abhayaratna WP, Kalman JM and Sanders P. Effect of weight reduction and cardiometabolic risk factor management on symptom burden and severity in patients with atrial fibrillation: a randomized clinical trial. JAMA. 2013;310:2050-60.

102. Pathak RK, Middeldorp ME, Meredith M, Mehta AB, Mahajan R, Wong CX, Twomey D, Elliott AD, Kalman JM, Abhayaratna WP, Lau DH and Sanders P. Long-Term Effect of Goal-Directed Weight Management in an Atrial Fibrillation Cohort: A Long-Term Follow-Up Study (LEGACY). J Am Coll Cardiol. 2015;65:2159-69.

103. Pathak RK, Elliott A, Middeldorp ME, Meredith M, Mehta AB, Mahajan R, Hendriks JM, Twomey D, Kalman JM, Abhayaratna WP, Lau DH and Sanders P. Impact of CARDIOrespiratory FITness on Arrhythmia Recurrence in Obese Individuals With Atrial Fibrillation:The CARDIO-FIT Study. J Am Coll Cardiol. 2015;66:985-96.

104. Nalliah CJ, Sanders P, Kottkamp H and Kalman JM. The role of obesity in atrial fibrillation. Eur Heart J. 2015.

105. Zhang Y, Dedkov El, Teplitsky D, Weltman NY, Pol CJ, Rajagopalan V, Lee B and Gerdes AM. Both hypothyroidism and hyperthyroidism increase atrial fibrillation inducibility in rats. Circ Arrhythmia Electrophysiol. 2013;6:952-959.

106. Liu L, Yun F, Zhao H, Zhang S, Liu Z, Wang X, Wang D, Peng W, Li S, Xiu C, Tan X and Li Y. Atrial sympathetic remodeling in experimental hyperthyroidism and hypothyroidism rats. Int $J$ Cardiol. 2015;187:148-150.

107. Eckstein J, Verheule S, de Groot NM, Allessie M and Schotten U. Mechanisms of perpetuation of atrial fibrillation in chronically dilated atria. Prog Biophys Mol Biol. 2008;97:435-51.

108. Roosimaa M, Põdramägi T, Kadaja L, Ruusalepp A, Paju K, Puhke R, Eimre M, Orlova E, Piirsoo A, Peet N, Gellerich FN and Seppet E. Dilation of human atria: increased diffusion restrictions for ADP, overexpression of hexokinase 2 and its coupling to oxidative phosphorylation in cardiomyocytes. Mitochondrion. 2013;13:399-409.

109. Cardin S, Li D, Thorin-Trescases N, Leung T-K, Thorin E and Nattel S. Evolution of the atrial fibrillation substrate in experimental congestive heart failure: angiotensin-dependent and -independent pathways. Cardiovasc Res. 2003;60:315-325.

110. Cardin S, Libby E, Pelletier P, Le Bouter S, Shiroshita-Takeshita A, Le Meur N, Léger J, Demolombe $S$, Ponton A, Glass L and Nattel S. Contrasting gene expression profiles in two canine models of atrial fibrillation. Circ Res. 2007;100:425-433. 
111. De Souza Al, Cardin S, Wait R, Chung Y-L, Vijayakumar M, Maguy A, Camm AJ and Nattel S. Proteomic and metabolomic analysis of atrial profibrillatory remodelling in congestive heart failure. J Mol Cell Cardiol. 2010;49:851-863.

112. Cha Y, Dzeja P, Shen W, Jahangir A, Hart C, Terzic A and Redfield M. Failing atrial myocardium: energetic deficits accompany structural remodeling and electrical instability. Am J Physiol Heart Circ Physiol. 2003;284:H1313-20.

113. Krahn AD, Manfreda J, Tate RB, Mathewson FA and Cuddy TE. The natural history of atrial fibrillation: incidence, risk factors, and prognosis in the Manitoba Follow-Up Study. Am J Med. 1995;98:476-484.

114. Kannel WB, Wolf PA, Benjamin EJ and Levy D. Prevalence, incidence, prognosis, and predisposing conditions for atrial fibrillation: population-based estimates. Am J Cardiol. 1998;82:2N-9N.

115. Kannel WB and Benjamin EJ. Status of the epidemiology of atrial fibrillation. The Medical clinics of North America. 2008;92:17-40- ix.

116. Goldberg RJ, Seeley D, Becker RC, Brady P, Chen ZY, Osganian V, Gore JM, Alpert JS and Dalen JE. Impact of atrial fibrillation on the in-hospital and long-term survival of patients with acute myocardial infarction: a community-wide perspective. Am Heart J. 1990;119:996-1001.

117. Madias JE, Patel DC and Singh D. Atrial fibrillation in acute myocardial infarction: a prospective study based on data from a consecutive series of patients admitted to the coronary care unit. Clin Cardiol. 1996;19:180-186.

118. Sakata K, Kurihara H, Iwamori K, Maki A, Yoshino H, Yanagisawa A and Ishikawa K. Clinical and prognostic significance of atrial fibrillation in acute myocardial infarction. Am J Cardiol. 1997;80:1522-1527.

119. Rathore SS, Berger AK, Weinfurt KP, Schulman KA, Oetgen WJ, Gersh BJ and Solomon AJ. Acute myocardial infarction complicated by atrial fibrillation in the elderly: prevalence and outcomes. Circulation. 2000;101:969-974.

120. Berton G, Cordiano R, Cucchini F, Cavuto F, Pellegrinet M and Palatini P. Atrial fibrillation during acute myocardial infarction: association with all-cause mortality and sudden death after 7-year of follow-up. Int J Clin Pract. 2009;63:712-721.

121. Hod H, Lew AS, Keltai M, Cercek B, Geft IL, Shah PK and Ganz W. Early atrial fibrillation during evolving myocardial infarction: a consequence of impaired left atrial perfusion. Circulation. 1987;75:146-150.

122. Cushing EH, Feil HS, Stanton EJ and Wartman WB. Infarction of the cardiac auricles (atria): clinical pathological, and experimental studies. Br Heart J. 1942;4:17-34.

123. Wartman WB and SOUDERS JC. Localization of myocardial infarcts with respect to the muscle bundles of the heart. Arch Pathol. 1950;50:329-346.

124. Lazar EJ, Goldberger J, Peled H, Sherman M and Frishman WH. Atrial infarction: diagnosis and management. Am Heart J. 1988;116:1058-1063.

125. Shakir DK and Arafa SOE. Right atrial infarction, atrial arrhythmia and inferior myocardial infarction form a missed triad: a case report and review of the literature. Can J Cardiol. 2007;23:995-997.

126. Flowers NC and Horan LG. Atrial infarction. Dis Chest. 1966;49:638-640.

127. Gardin JM and Singer DH. Atrial infarction. Importance, diagnosis, and localization. Arch Intern Med. 1981;141:1345-1348. 
128. Akao $M$, Chun $\mathrm{YH}$, Wada $\mathrm{H}$, Esato $\mathrm{M}$, Hashimoto $T$, Abe $\mathrm{M}$, Hasegawa $\mathrm{K}$, Tsuji $\mathrm{H}$, Furuke $\mathrm{K}$ and Fushimi AFRI. Current status of clinical background of patients with atrial fibrillation in a community-based survey: the Fushimi AF Registry. J Cardiol. 2013;61:260-6.

129. Senoo K, Suzuki S, Sagara K, Otsuka T, Matsuno S, Uejima T, Oikawa Y, Yajima J, Nagashima K, Kirigaya H, Sawada H, Aizawa T, Lip GY and Yamashita T. Coronary artery diseases in Japanese patients with nonvalvular atrial fibrillation. J Cardiol. 2014;63:123-7.

130. Kakkar AK, Mueller I, Bassand JP, Fitzmaurice DA, Goldhaber SZ, Goto S, Haas S, Hacke W, Lip GY, Mantovani LG, Turpie AG, van Eickels M, Misselwitz F, Rushton-Smith S, Kayani G, Wilkinson $P$, Verheugt FW and Investigators GR. Risk profiles and antithrombotic treatment of patients newly diagnosed with atrial fibrillation at risk of stroke: perspectives from the international, observational, prospective GARFIELD registry. PloS one. 2013;8:e63479.

131. Yamazaki M, Avula UMR, Bandaru K, Atreya A, Boppana VSC, Honjo H, Kodama I, Kamiya K and Kalifa J. Acute regional left atrial ischemia causes acceleration of atrial drivers during atrial fibrillation. Heart Rhythm. 2013;10:901-909.

132. Sakabe M, Shiroshita-Takeshita A, Maguy A, Brundel BJ, Fujiki A, Inoue $H$ and Nattel S. Effects of a heat shock protein inducer on the atrial fibrillation substrate caused by acute atrial ischaemia. Cardiovasc Res. 2008;78:63-70.

133. Sinno H, Derakhchan K, Libersan D, Merhi Y, Leung T-K and Nattel S. Atrial ischemia promotes atrial fibrillation in dogs. Circulation. 2003;107:1930-1936.

134. Shiroshita-Takeshita A, Sakabe M, Haugan K, Hennan JK and Nattel S. Model-dependent effects of the gap junction conduction-enhancing antiarrhythmic peptide rotigaptide (ZP123) on experimental atrial fibrillation in dogs. Circulation. 2007;115:310-8.

135. Rivard L, Sinno H, Shiroshita-Takeshita A, Schram G, Leung T-Kand Nattel S. The pharmacological response of ischemia-related atrial fibrillation in dogs: evidence for substrate-specific efficacy. Cardiovasc Res. 2007;74:104-113.

136. Nishida K, Qi X-Y, Wakili R, Comtois P, Chartier D, Harada M, Iwasaki Y-K, Romeo P, Maguy A, Dobrev D, Michael G, Talajic M and Nattel S. Mechanisms of atrial tachyarrhythmias associated with coronary artery occlusion in a chronic canine model. Circulation. 2011;123:137-146.

137. Ausma J, Litjens N, Lenders MH, Duimel H, Mast F, Wouters L, Ramaekers F, Allessie $M$ and Borgers M. Time course of atrial fibrillation-induced cellular structural remodeling in atria of the goat. J Mol Cell Cardiol. 2001;33:2083-2094.

138. Verheule S, Tuyls E, Gharaviri A, Hulsmans S, van Hunnik A, Kuiper M, Serroyen J, Zeemering S, Kuijpers NHL and Schotten U. Loss of Continuity in the Thin Epicardial Layer Due to Endomysial Fibrosis Increases the Complexity of Atrial Fibrillatory Conduction. Circ Arrhythmia Electrophysiol. 2013.

139. Verheule S, Eckstein J, Linz D, Maesen B, Bidar E, Gharaviri A and Schotten U. Role of endoepicardial dissociation of electrical activity and transmural conduction in the development of persistent atrial fibrillation. Prog Biophys Mol Biol. 2014;115:173-185.

140. Ausma J, Wijffels M, Thone F, Wouters L, Allessie M and Borgers M. Structural changes of atrial myocardium due to sustained atrial fibrillation in the goat. Circulation. 1997;96:3157-3163.

141. Spach MS, Heidlage JF, Dolber PC and Barr RC. Electrophysiological effects of remodeling cardiac gap junctions and cell size: experimental and model studies of normal cardiac growth. Circ Res. 2000;86:302-11. 
142. Daoud EG, Marcovitz P, Knight BP, Goyal R, Man KC, Strickberger SA, Armstrong WF and Morady F. Short-term effect of atrial fibrillation on atrial contractile function in humans. Circulation. 1999;99:3024-3027.

143. Leistad E, Aksnes G, Verburg E and Christensen G. Atrial contractile dysfunction after shortterm atrial fibrillation is reduced by verapamil but increased by BAY K8644. Circulation. 1996;93:1747-1754.

144. Daoud E, Bogun F, Goyal R, Harvey M, Man K, Strickberger S and Morady F. Effect of atrial fibrillation on atrial refractoriness in humans. Circulation. 1996;94:1600-1606.

145. Schotten U, Duytschaever M, Ausma J, Eijsbouts S, Neuberger $\mathrm{H}$ and Allessie M. Electrical and contractile remodeling during the first days of atrial fibrillation go hand in hand. Circulation. 2003;107:1433-1439.

146. Ausma J, Dispersyn GD, Duimel H, Thone F, ver Donck L, Allessie MA and Borgers M. Changes in ultrastructural calcium distribution in goat atria during atrial fibrillation. J Mol Cell Cardiol. 2000;32:355-364.

147. Tieleman RG, De Langen CDJ, Van Gelder IC, de Kam PJ, Grandjean J, Bel KJ, Wijffels MCEF, Allessie MA and Crijns HJGM. Verapamil Reduces Tachycardia-Induced Electrical Remodeling of the Atria. Circulation. 1997;95:1945-1953.

148. Zhang H, Garratt CJ, Zhu J and Holden AV. Role of up-regulation of IK1 in action potential shortening associated with atrial fibrillation in humans. Cardiovasc Res. 2005;66:493-502.

149. Hove-Madsen L, Llach A, Tibbits GF and Tort L. Triggering of sarcoplasmic reticulum Ca2+ release and contraction by reverse mode $\mathrm{Na}+/ \mathrm{Ca} 2+$ exchange in trout atrial myocytes. $\mathrm{Am} \mathrm{J}$ Physiol Regul Integr Comp Physiol. 2003;284:R1330-9.

150. Xie Y, Sato D, Garfinkel A, Qu Z and Weiss JN. So little source, so much sink: requirements for afterdepolarizations to propagate in tissue. Biophys J. 2010;99:1408-15.

151. Karagueuzian HS, Nguyen TP, Qu Z and Weiss JN. Oxidative stress, fibrosis, and early afterdepolarization-mediated cardiac arrhythmias. Front Physiol. 2013;4:19.

152. Lee S, Sahadevan J, Khrestian CM, Durand DM and Waldo AL. High density mapping of atrial fibrillation during vagal nerve stimulation in the canine heart: restudying the Moe hypothesis. J Cardiovasc Electrophysiol. 2013;24:328-35.

153. Burashnikov A and Antzelevitch C. Reinduction of atrial fibrillation immediately after termination of the arrhythmia is mediated by late phase 3 early afterdepolarization-induced triggered activity. Circulation. 2003;107:2355-60.

154. Burashnikov A and Antzelevitch C. Late-phase 3 EAD. A unique mechanism contributing to initiation of atrial fibrillation. Pacing Clin Electrophysiol. 2006;29:290-295.

155. Eckstein J, Zeemering S, Linz D, Maesen B, Verheule S, van Hunnik A, Crijns H, Allessie MA and Schotten $U$. Transmural conduction is the predominant mechanism of breakthrough during atrial fibrillation: evidence from simultaneous endo-epicardial high-density activation mapping. Circ Arrhythm Electrophysiol. 2013;6:334-41.

156. O'Rourke B, Ramza B and Marban E. Oscillations of membrane current and excitability driven by metabolic oscillations in heart cells. Science (New York, NY). 1994;265:962-966.

157. O'Rourke B, Ramza B, Romashko D and Marban E. Metabolic oscillations in heart cells. Adv Exp Med Biol. 1995;382:165-174.

158. Aon MA, Cortassa $S$ and $O^{\prime}$ Rourke B. Mitochondrial oscillations in physiology and pathophysiology. Adv Exp Med Biol. 2008;641:98-117. 
159. Aon MA, Cortassa S, Akar FG, Brown DA, Zhou L and O'Rourke B. From mitochondrial dynamics to arrhythmias. The international journal of biochemistry \&amp; cell biology. 2009;41:1940-1948.

160. Brown DA and O'Rourke B. Cardiac mitochondria and arrhythmias. Cardiovasc Res. 2010;88:241249.

161. Akar FG, Aon MA, Tomaselli GF and O'Rourke B. The mitochondrial origin of postischemic arrhythmias. J Clin Invest. 2005;115:3527-35.

162. Zorov DB, Filburn CR, Klotz LO, Zweier JL and Sollott SJ. Reactive oxygen species (ROS)-induced ROS release: a new phenomenon accompanying induction of the mitochondrial permeability transition in cardiac myocytes. J Exp Med. 2000;192:1001-14.

163. Cortassa S, Aon MA, Marban E, Winslow RL and O'Rourke B. An integrated model of cardiac mitochondrial energy metabolism and calcium dynamics. Biophys J. 2003;84:2734-55.

164. Kohlhaas $M$ and Maack C. Adverse bioenergetic consequences of $\mathrm{Na}+\mathrm{Ca} 2+$ exchangermediated Ca2+ influx in cardiac myocytes. Circulation. 2010;122:2273-2280.

165. Dorn GW and Maack C. SR and mitochondria: calcium cross-talk between kissing cousins. J Mol Cell Cardiol. 2013;55:42-49.

166. Chen Y, Csordás G, Jowdy C, Schneider TG, Csordás N, Wang W, Liu Y, Kohlhaas M, Meiser M, Bergem S, Nerbonne JM, Dorn GW and Maack C. Mitofusin 2-containing mitochondrialreticular microdomains direct rapid cardiomyocyte bioenergetic responses via interorganelle $\mathrm{Ca}(2+)$ crosstalk. Circ Res. 2012;111:863-875.

167. Kohlhaas M and Maack C. Calcium release microdomains and mitochondria. Cardiovasc Res. 2013;98:259-268.

168. Mackenzie L, Roderick HL, Berridge MJ, Conway SJ and Bootman MD. The spatial pattern of atrial cardiomyocyte calcium signalling modulates contraction. J Cell Sci. 2004;117:6327-37.

169. Greiser M, Kerfant BG, Williams GS, Voigt N, Harks E, Dibb KM, Giese A, Meszaros J, Verheule S, Ravens U, Allessie MA, Gammie JS, van der Velden J, Lederer WJ, Dobrev D and Schotten U. Tachycardia-induced silencing of subcellular Ca2+ signaling in atrial myocytes. J Clin Invest. 2014;124:4759-72.

170. Belus A, Piroddi N, Ferrantini C, Tesi C, Cazorla O, Toniolo L, Drost M, Mearini G, Carrier L, Rossi A, Mugelli A, Cerbai E, van der Velden J and Poggesi C. Effects of chronic atrial fibrillation on active and passive force generation in human atrial myofibrils. Circ Res. 2010;107:144-52.

171. Kockskämper J, Zima AV and Blatter LA. Modulation of sarcoplasmic reticulum Ca2+ release by glycolysis in cat atrial myocytes. The Journal of physiology. 2005;564:697-714.

172. Weiss JN, Karma A, Shiferaw Y, Chen P-S, Garfinkel A and Qu Z. From pulsus to pulseless: the saga of cardiac alternans. Circ Res. 2006;98:1244-1253.

173. Huser J, Wang YG, Sheehan KA, Cifuentes F, Lipsius SL and Blatter LA. Functional coupling between glycolysis and excitation-contraction coupling underlies alternans in cat heart cells. The Journal of physiology. 2000;524 Pt 3:795-806.

174. Kockskämper J and Blatter LA. Subcellular Ca2+ alternans represents a novel mechanism for the generation of arrhythmogenic Ca2+ waves in cat atrial myocytes. The Journal of physiology. 2002;545:65-79.

175. Ono N, Hayashi H, Kawase A, Lin S-F, Li H, Weiss JN, Chen P-S and Karagueuzian HS. Spontaneous atrial fibrillation initiated by triggered activity near the pulmonary veins in aged rats subjected to glycolytic inhibition. American journal of physiology Heart and circulatory physiology. 2007;292:H639-48. 
176. Koura T, Hara M, Takeuchi S, Ota K, Okada Y, Miyoshi S, Watanabe A, Shiraiwa K, Mitamura $\mathrm{H}$, Kodama I and Ogawa $\mathrm{S}$. Anisotropic conduction properties in canine atria analyzed by high-resolution optical mapping: preferential direction of conduction block changes from longitudinal to transverse with increasing age. Circulation. 2002;105:2092-2098.

177. Yang K-C, Kyle JW, Makielski JC and Dudley SC. Mechanisms of sudden cardiac death: oxidants and metabolism. Circ Res. 2015;116:1937-1955.

178. Remme CA and Wilde AAM. Late sodium current inhibition in acquired and inherited ventricular (dys)function and arrhythmias. Cardiovascular drugs and therapy/sponsored by the International Society of Cardiovascular Pharmacotherapy. 2013;27:91-101.

179. Sossalla S, Kallmeyer B, Wagner S, Mazur M, Maurer U, Toischer K, Schmitto JD, Seipelt $\mathrm{R}$, Schöndube FA, Hasenfuss $\mathrm{G}$, Belardinelli $L$ and Maier LS. Altered $\mathrm{Na}(+)$ currents in atrial fibrillation effects of ranolazine on arrhythmias and contractility in human atrial myocardium. J Am Coll Cardiol. 2010;55:2330-2342.

180. Poulet C, Wettwer E, Grunnet M, Jespersen T, Fabritz L, Matschke K, Knaut M and Ravens U. Late Sodium Current in Human Atrial Cardiomyocytes from Patients in Sinus Rhythm and Atrial Fibrillation. PLoS One. 2015;10:e0131432.

181. Antzelevitch C, Belardinelli L, Zygmunt AC, Burashnikov A, Di Diego JM, Fish JM, Cordeiro $J M$ and Thomas $G$. Electrophysiological effects of ranolazine, a novel antianginal agent with antiarrhythmic properties. Circulation. 2004;110:904-10.

182. Kumar K, Nearing BD, Carvas M, Nascimento BCG, Acar M, Belardinelli L and Verrier RL. Ranolazine exerts potent effects on atrial electrical properties and abbreviates atrial fibrillation duration in the intact porcine heart. J Cardiovasc Electrophysiol. 2009;20:796-802.

183. Verrier RL, Pagotto VPF, Kanas AF, Sobrado MF, Nearing BD, Zeng D and Belardinelli L. Low doses of ranolazine and dronedarone in combination exert potent protection against atrial fibrillation and vulnerability to ventricular arrhythmias during acute myocardial ischemia. Heart Rhythm. 2013;10:121-127.

184. Burashnikov A, Di Diego JM, Zygmunt AC, Belardinelli L and Antzelevitch C. Atrium-selective sodium channel block as a strategy for suppression of atrial fibrillation: differences in sodium channel inactivation between atria and ventricles and the role of ranolazine. Circulation. 2007;116:1449-1457.

185. Wijffels MCEF, Kirchhof CJHJ, Dorland R, Power J and Allessie MA. Electrical remodeling due to atrial fibrillation in chronically instrumented conscious goats: roles of neurohumoral changes, ischemia, atrial stretch, and high rate of electrical activation. 1997;96:3710-3720.

186. Jayachandran JV, Zipes DP, Weksler J and Olgin JE. Role of the $\mathrm{Na}(+) / \mathrm{H}(+)$ exchanger in shortterm atrial electrophysiological remodeling. Circulation. 2000;101:1861-1866.

187. Altemose GT, Zipes DP, Weksler J, Miller JM and Olgin JE. Inhibition of the $\mathrm{Na}(+) / \mathrm{H}(+)$ exchanger delays the development of rapid pacing-induced atrial contractile dysfunction. Circulation. 2001;103:762-768.

188. Blaauw $Y$, Beier N, van der Voort P, van Hunnik A, Schotten $U$ and Allessie M. Inhibitors of the $\mathrm{Na}+\mathrm{H}+$ exchanger cannot prevent atrial electrical remodeling in the goat. $J$ Cardiovasc Electrophysiol. 2004;15:440-446.

189. Yu WC, Lee SH, Tai CT, Tsai CF, Hsieh MH, Chen CC, Ding YA, Chang MS and Chen S-A. Reversal of atrial electrical remodeling following cardioversion of long-standing atrial fibrillation in man. Cardiovasc Res. 1999;42:470-476. 
190. Ausma J, van der Velden $H$, Lenders $M$, van Ankeren $E$, Jongsma H, Ramaekers F, Borgers $M$ and Allessie M. Reverse structural and gap-junctional remodeling after prolonged atrial fibrillation in the goat. Circulation. 2003;107:2051-8 Epub 2003 Apr 7.

191. Shinagawa K, Shi Y-F, Tardif J-C, Leung T-K and Nattel S. Dynamic nature of atrial fibrillation substrate during development and reversal of heart failure in dogs. Circulation. 2002;105:26722678.

192. Kloner RA and Jennings RB. Consequences of brief ischemia: stunning, preconditioning, and their clinical implications: part 1. Circulation. 2001;104:2981-9.

193. Garratt C, Duytschaever M, Killian M, Dorland R, Mast F and Allessie M. Repetitive electrical remodeling by paroxysms of atrial fibrillation in the goat: no cumulative effect on inducibility or stability of atrial fibrillation. J Cardiovasc Electrophysiol. 1999;10:1101-1108.

194. Todd D, Fynn S, Walden A, Hobbs W, Arya S and Garratt C. Repetitive 4-week periods of atrial electrical remodeling promote stability of atrial fibrillation: time course of a second factor involved in the self-perpetuation of atrial fibrillation. Circulation. 2004;109:1434-9 Epub 2004 Mar 15.

195. Verheule S, Tuyls E, van Hunnik A, Kuiper M, Schotten U and Allessie M. Fibrillatory conduction in the atrial free walls of goats in persistent and permanent atrial fibrillation. Circ Arrhythmia Electrophysiol. 2010;3:590-599.

196. Ausma J, Wijffels M, van Eys G, Koide M, Ramaekers F, Allessie Mand Borgers M. Dedifferentiation of atrial cardiomyocytes as a result of chronic atrial fibrillation. Am J Pathol. 1997;151:985-997.

197. Shirihai OS, Song M and Dorn GW. How mitochondrial dynamism orchestrates mitophagy. Circ Res. 2015;116:1835-1849.

198. Taegtmeyer $\mathrm{H}$, Sen $\mathrm{S}$ and Vela $\mathrm{D}$. Return to the fetal gene program: a suggested metabolic link to gene expression in the heart. Ann N Y Acad Sci. 2010;1188:191-198.

199. Ausma J, Thone F, Dispersyn GD, Flameng W, Vanoverschelde JL, Ramaekers FC and Borgers M. Dedifferentiated cardiomyocytes from chronic hibernating myocardium are ischemiatolerant. Mol Cell Biochem. 1998;186:159-168.

200. Dispersyn GD, Ausma J, Thone F, Flameng W, Vanoverschelde JL, Allessie MA, Ramaekers FC and Borgers M. Cardiomyocyte remodelling during myocardial hibernation and atrial fibrillation: prelude to apoptosis. Cardiovasc Res. 1999;43:947-957.

201. Thijssen VL, Ausma J and Borgers M. Structural remodelling during chronic atrial fibrillation: act of programmed cell survival. Cardiovasc Res. 2001;52:14-24.

202. Modrego J, Maroto L, Tamargo J, Azcona L, Mateos-Cáceres P, Segura A, Moreno-Herrero R, Pérez-Castellanos N, Delpón E, Pérez-Villacastín J, Rodríguez E, Macaya C and López-Farré AJ. Comparative expression of proteins in left and right atrial appendages from patients with mitral valve disease at sinus rhythm and atrial fibrillation. J Cardiovasc Electrophysiol. 2010;21:859-868.

203. Tu T, Zhou S, Liu Z, Li X and Liu Q. Quantitative proteomics of changes in energy metabolismrelated proteins in atrial tissue from valvular disease patients with permanent atrial fibrillation. Circulation journal : official journal of the Japanese Circulation Society. 2014;78:993-1001.

204. Lai L-P, Lin J-L, Lin C-S, Yeh H-M, Tsay Y-G, Lee C-F, Lee H-H, Chang Z-F, Hwang J-J, Su M-J, Tseng $Y-Z$ and Huang SKS. Functional genomic study on atrial fibrillation using CDNA microarray and two-dimensional protein electrophoresis techniques and identification of the myosin regulatory light chain isoform reprogramming in atrial fibrillation. J Cardiovasc Electrophysiol. 2004;15:214-223. 
205. Barth AS, Merk S, Arnoldi E, Zwermann L, Kloos P, Gebauer M, Steinmeyer K, Bleich M, Kääb S, Hinterseer M, Kartmann H, Kreuzer E, Dugas M, Steinbeck G and Näbauer M. Reprogramming of the human atrial transcriptome in permanent atrial fibrillation: expression of a ventricularlike genomic signature. Circ Res. 2005;96:1022-1029.

206. Schoonderwoerd BA, Ausma J, Crijns HJGM, van Veldhuisen DJ, Blaauw EH and van Gelder IC. Atrial ultrastructural changes during experimental atrial tachycardia depend on high ventricular rate. J Cardiovasc Electrophysiol. 2004;15:1167-1174.

207. AnnéW, Willems R, Holemans P, Beckers F, Roskams T, Lenaerts I, Ector H and Heidbüchel H. Selfterminating $\mathrm{AF}$ depends on electrical remodeling while persistent $\mathrm{AF}$ depends on additional structural changes in a rapid atrially paced sheep model. J Mol Cell Cardiol. 2007;43:148-158.

208. Nickel A, Loffler J and Maack C. Myocardial energetics in heart failure. Basic Res Cardiol. 2013;108:358.

209. Anderson ME. Oxidant stress promotes disease by activating CaMKII. J Mol Cell Cardiol. 2015;89:160-7.

210. Tessier S, Karczewski P, Krause EG, Pansard Y, Acar C, Lang-Lazdunski M, Mercadier JJ and Hatem SN. Regulation of the transient outward $\mathrm{K}(+)$ current by $\mathrm{Ca}(2+) /$ calmodulin-dependent protein kinases II in human atrial myocytes. Circ Res. 1999;85:810-9.

211. Harada $M$, Van Wagoner DR and Nattel S. Role of inflammation in atrial fibrillation pathophysiology and management. Circ J. 2015;79:495-502.

212. Haemers P, Hamdi H, Guedj K, Suffee N, Farahmand P, Popovic N, Claus P, LePrince P, Nicoletti A, Jalife J, Wolke C, Lendeckel U, Jais P, Willems R and Hatem SN. Atrial fibrillation is associated with the fibrotic remodelling of adipose tissue in the subepicardium of human and sheep atria. Eur Heart J. 2015.

213. Chong AJ, Pohlman TH, Hampton CR, Shimamoto A, Mackman N and Verrier ED. Tissue factor and thrombin mediate myocardial ischemia-reperfusion injury. Ann Thorac Surg. 2003;75:S649-55.

214. Spronk HM, de Jong AM, Crijns HJ, Schotten U, Van Gelder IC and Ten Cate H. Pleiotropic effects of factor Xa and thrombin: what to expect from novel anticoagulants. Cardiovasc Res. 2014;101:344-51.

215. Maier LS. Ranolazine for atrial fibrillation: buy one get three beneficial mechanisms! Eur J Heart Fail. 2012;14:1313-5.

216. Mihos CG, Krishna RK, Kherada N, Larrauri-Reyes M, Tolentino A and Santana O. The use of ranolazine in non-anginal cardiovascular disorders: A review of current data and ongoing randomized clinical trials. Pharmacol Res. 2015;103:49-55.

217. Lopatin YM, Rosano GM, Fragasso G, Lopaschuk GD, Seferovic PM, Gowdak LH, Vinereanu D, Hamid MA, Jourdain P and Ponikowski P. Rationale and benefits of trimetazidine by acting on cardiac metabolism in heart failure. Int J Cardiol. 2016;203:909-15. 



\section{Chapter III}

Effect of ranolazine in a goat model of lone atrial fibrillation

Dragan Opačić, Arne van Hunnik, Stef Zeemering, Arvinder Dhalla, Luiz Belardinelli, Ulrich Schotten and Sander Verheule 


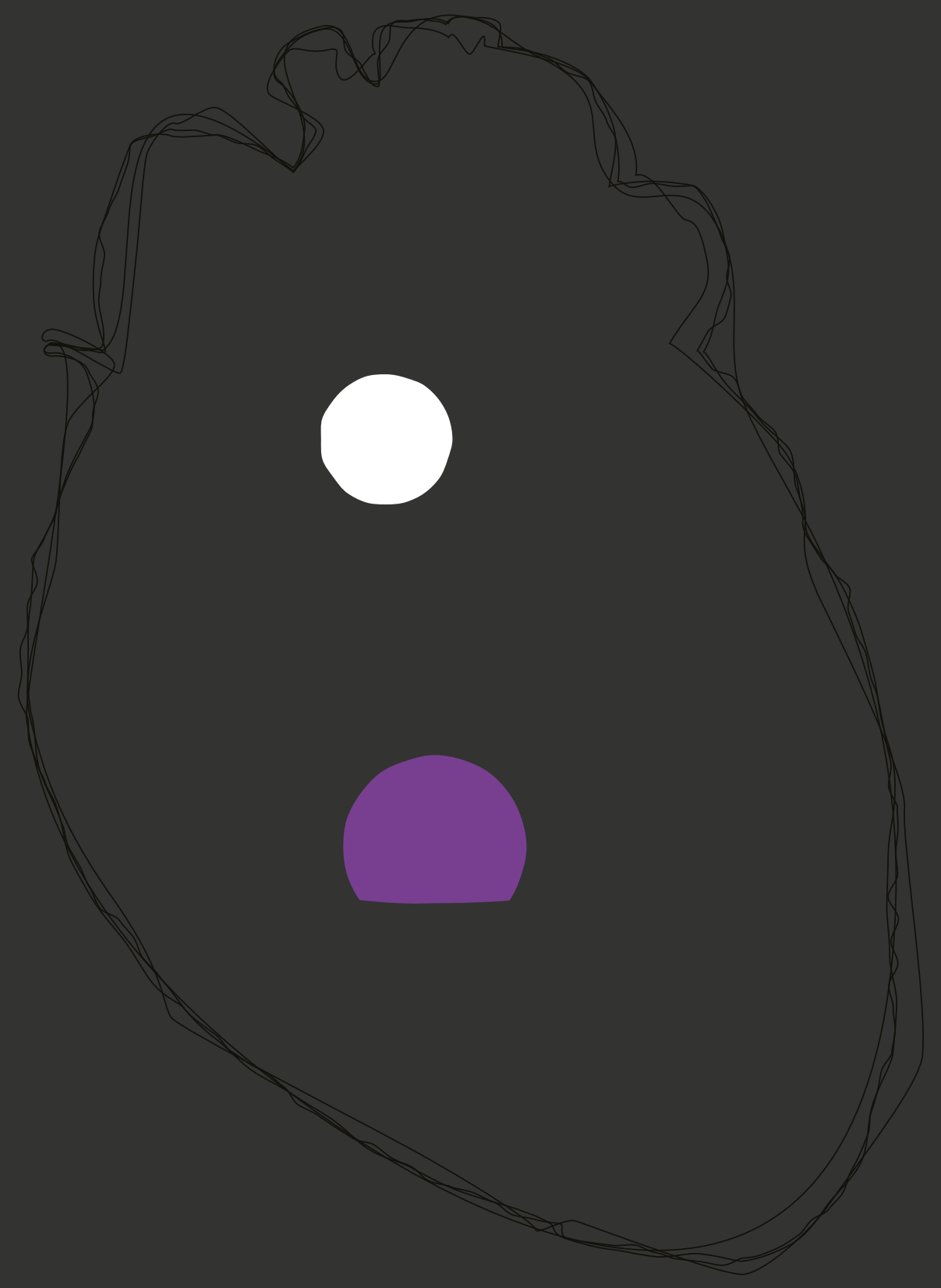




\begin{abstract}
Background: There is still an unmet need for pharmacological treatment options of atrial fibrillation (AF). Here, in an awake model of lone AF, we investigate the effects of ranolazine, an antiarrhythmic drug reported to have atrial selectivity.
\end{abstract}

Methods: Electrode patches were implanted on the atrial epicardium of 8 Dutch milk goats. Experiments were performed at baseline and after 2 and 14 days of electrically maintained AF. At these timepoints, surface ECG parameters, atrial refractory period (AERP), atrial conduction velocity (CV), AF cycle length (AFCL), and AF episode duration were measured during the infusion of vehicle and low, medium, and high doses ranolazine (approximate plasma levels $4 \mu \mathrm{M}, 8 \mu \mathrm{M}$ and $16 \mu \mathrm{M}$, respectively).

Results: The highest administered dose of ranolazine significantly prolonged AERP and decreased atrial CV both at baseline and after 2 days of AF. After 2 days of $A F$, the lowest dose significantly prolonged AF episode duration (143.8 \pm 63.4 s vs. $236.27 \pm 70.79$ s vs. $143.20 \pm 70.47$ s vs. $117.89 \pm 71.92 s ; p<0.01$ ). After 2 weeks of $A F$, ranolazine prolonged the p5 and p50 of the AFCL distribution in a dose-dependent manner but was not effective in restoring sinus rhythm. The medium and highest doses of ranolazine prolonged $P Q$, RR, QRS and QTc intervals but, no adverse ventricular arrhythmic events, i.e. premature ventricular beats or signs of hemodynamic instability were observed during the infusion of ranolazine at any point in this study.

Conclusion: The lowest investigated dose of ranolazine, which is expected to block both late $\mathrm{I}_{\mathrm{Na}}$ and atrial peak $\mathrm{I}_{\mathrm{Na}}$ has no effect on the investigated electrophysiological parameters. The highest dose affected both atrial and ventricular parameters at different stages of AF-induced remodeling but was not efficacious in cardioverting AF to sinus rhythm in a goat model of lone AF.

Keywords: ranolazine, atrial fibrillation, goat, remodeling, antiarrhythmic drugs 


\section{Introduction}

Atrial fibrillation (AF) is the most common sustained tachy-arrhythmia in clinical practice. Numerous available antiarrhythmic drugs used in the treatment of AF are often insufficiently atrial selective and therefore frequently associated with ventricular arrhythmias' Identifying antiarrhythmic agents that selectively affect atrial electrophysiology, thus avoiding any deleterious effects on the ventricles, is of the utmost importance in the treatment of patients with AF.

Ranolazine, a well-known antianginal drug, at clinically used doses (2-6 $\mu \mathrm{mol} / \mathrm{l})$ blocks peak $\mathrm{Na}^{+}$current $\left(\mathrm{I}_{\mathrm{Na}}\right)$ with remarkable atrial selectivity ${ }^{2-5}$. At the same concentration, ranolazine in ventricles inhibits mainly late $\mathrm{I}_{\mathrm{Na}^{\prime}}$, while at higher concentrations, it also blocks rapid delayed rectifier $\mathrm{K}^{+}$current $\left(\mathrm{I}_{\mathrm{Kr}^{\prime}} \mathrm{IC}_{50}=12 \mu \mathrm{mol}\right)$, slow delayed rectifier $\mathrm{K}^{+}$current $\left(\mathrm{I}_{\mathrm{Ks}}, 17 \%\right.$ at $\left.\mathrm{IC}_{50}=30 \mu \mathrm{mol}\right)$ and L-type $\mathrm{Ca}^{2+}$ current $\left(\mathrm{I}_{\mathrm{CaL}^{\prime}}, \mathrm{IC}_{50}=50 \mu \mathrm{mol}\right)$ to similar extent both in atrial and ventricular myocytes ${ }^{4,5}$. In addition to its atrial selectivity in peak $\mathrm{I}_{\mathrm{Na}}$ blockade, ranolazine has been described as an effective antiarrhythmic agent for AF. Initially, in the large MERLIN TIMI-36 clinical trial (Metabolic Efficiency With Ranolazine for Less Ischemia in Non-ST-Elevation Acute Coronary Syndromes-Thrombolysis In Myocardial Infarction 36) ranolazine showed a strong tendency to decrease the incidence of supraventricular arrhythmias and prevented the onset of new AF episodes in patients with non-ST-segment elevation acute myocardial syndrome ${ }^{6}$. The potential role for rhythm control treatment of patients with AF is later confirmed in a meta-analysis by Guerra et al ${ }^{7}$. In addition, ranolazine decreased AF inducibility and AF duration in various models of acutely induced AF both in isolated heart preparations ${ }^{2,8-10}$ and in intact animals ${ }^{11-14}$. This effect of ranolazine on $A F$ is mainly attributed to its effect on the sodium current, and is characterized by prolongation of post-repolarization refractoriness, a decrease in conduction velocity, and by a decrease in the occurrence of both early and delayed afterdepolarizations $s^{3,15}$. Additionally, Sossalla et al. reported that ranolazine suppresses the upregulated late $\mathrm{I}_{\mathrm{Na}}$ in atrial cardiomyocytes isolated from patients with $\mathrm{AF}$ and also prevents $\mathrm{Ca}^{2+}$ and isoprenaline-induced premature atrial contractions in isolated trabeculae from both patients in sinus rhythm and $\mathrm{AF}^{16}$. These findings indicate that ranolazine also has antiarrhythmic properties in diseased human cells and tissue. Furthermore, recent clinical trials suggest that ranolazine should be considered as a drug for the management of AF with fewer ventricular side effects especially in patients with structural heart disease ${ }^{6,17-19}$.

However, to our knowledge, the effects of ranolazine on electrophysiology in atria with 'electrical remodeling', i.e. atria that have undergone alterations in expression and function of various ion channels induced by AF mainly manifested by shortening of the action potential duration (APD) have not been studied. Therefore, we investigated the effects of ranolazine in an awake goat model of lone AF at different stages of AF-induced atrial remodeling. 


\section{Methods}

\section{Animal model}

All animal experiments were conducted according to the 'European Directive for the Protection of Vertebrate animals used for Experimental and Scientific Purpose, European Community Directive for the Protection of Vertebrate animals used for Experimental and Scientific Purpose, European Community Directive 86/609/CEE' and approved by Local Ethical Committee for Experiments on Animals of the Maastricht University, The Netherlands.

In total, 8 Dutch milk goats were used. During general anesthesia (isoflurane, and a 1:2 mixture of $\mathrm{O}_{2}$ and $\mathrm{N}_{2} \mathrm{O}$ )) patches with $5 \times 6$ silver electrodes were sutured to the epicardium of both atria (figure 1). A patch with $2 \times 12$ electrodes was sutured to the bundle of Bachmann (BB), the main connection between the right atrium (RA) and left atrium (LA). The interelectrode distance of all atrial electrode patches was $4 \mathrm{~mm}$. An additional patch of 3 electrodes was sutured to the ventricle and three silver reference electrodes were placed subcutaneously. All leads were tunneled to the neck of the animal, externalized and connected to the custom-made fibrillation pacemaker, as described before ${ }^{20}$.

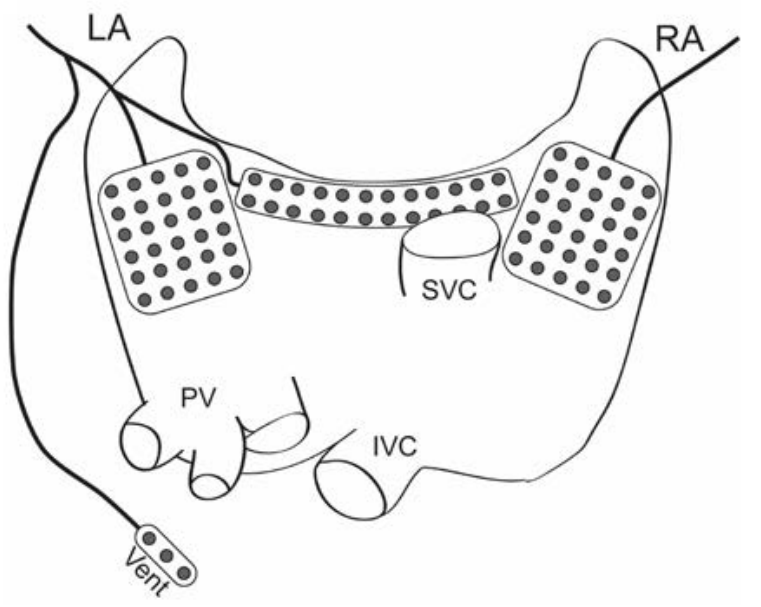

Figure 1. Position of the three atrial electrode plaques. The BB plaque was inserted along the bundle of Bachmann from the posterior side of the LA appendage to the posterior side of the RA appendage. The plaques on the RA and LA covered the majority of the atrial free walls from the anterior sides of the appendages to the posterior. PV - Pulmonary veins, SVC - Superior vena cava, IVC - Inferior vena cava. Vent Ventricular electrodes.

\section{Experimental protocol}

Two weeks after surgery, baseline electrophysiological parameters including atrial refractory period (AERP), atrial conduction velocity (CV), AF episode duration and surface ECG parameters were determined in awake goats during the infusion of solvent and various doses of ranolazine through venous lines in one of the superficial hind leg veins. Subsequently, the atrial pacemaker was turned on, applying 1-second bursts of $50 \mathrm{~Hz}$ every 2 seconds to artificially maintain AF.

At 2 and 14 days of maintained AF, the atrial pacemaker was disconnected, and venous lines were inserted for blood sampling and administration of ranolazine. At 2 days of maintained $A F$, the same parameters as at baseline were determined during the infusion 
of solvent and different doses of ranolazine. After the measurements, the atrial burst pacemaker was turned back on to maintain AF. At 14 days of maintained AF the effect of different doses of ranolazine during persistent AF was investigated. The experimental protocol is depicted schematically in Figure 2A.

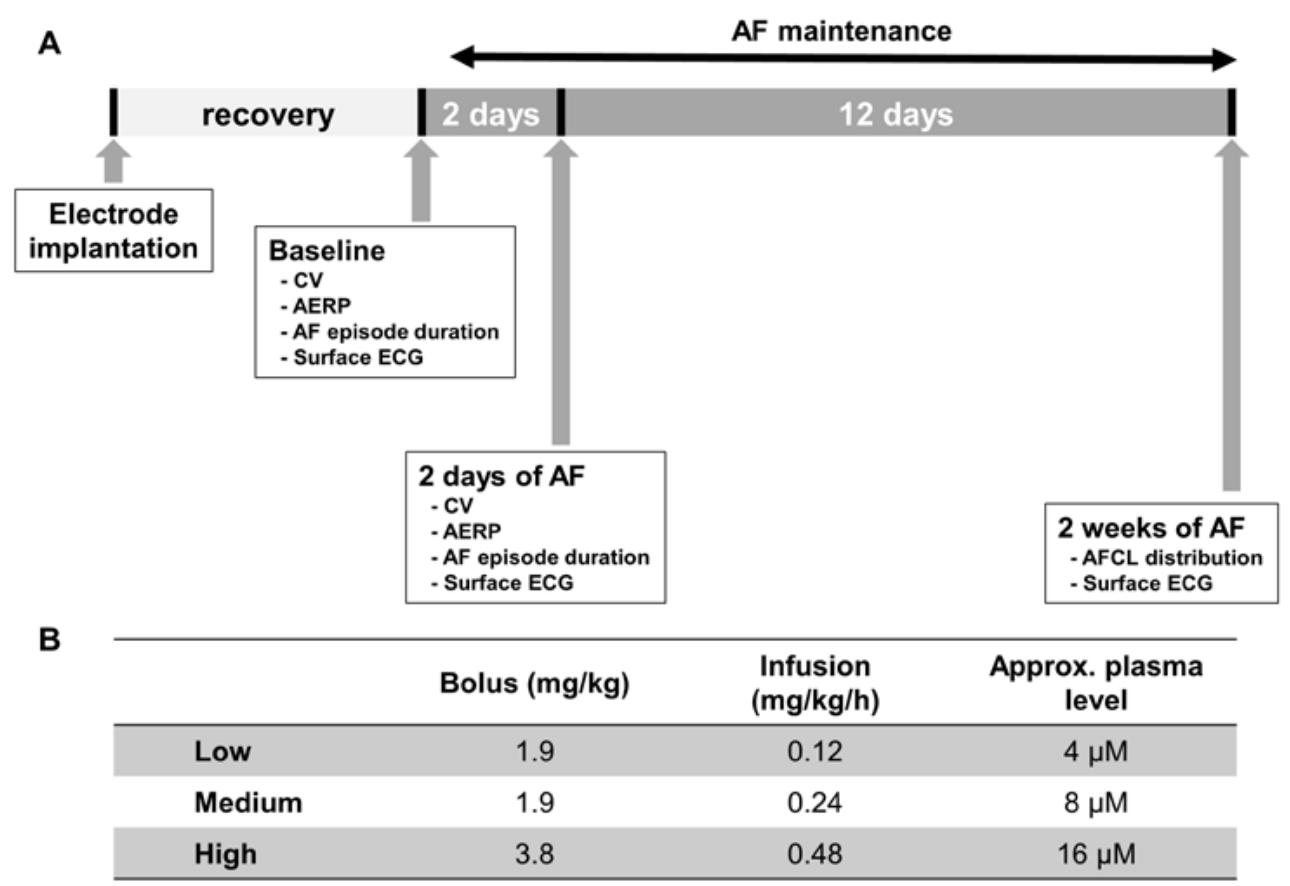

Figure 2. (A) Study protocol. CV - conduction velocity, AERP - atrial effective refractory period, AFCL - atrial fibrillation cycle length. (B) Infusion schemes used and approximate plasma concentrations reached.

All experiments were performed in awake goats. In each experiment, a venous line was inserted in one hind leg for drug infusion. Another venous line was inserted in the other hind leg for blood sampling. Baseline measurements were performed during infusion of the solvent (saline $+0.5 \%$ ascorbic acid, $\mathrm{pH} 5$ ) followed by administration of increasing doses of ranolazine as represented in Figure 2B. Blood samples were taken before administration of the bolus, and at 1, 3, 5, 10, 15, 20 and 25 minutes after the bolus. For a number of goats, samples were used for determination of plasma concentrations. The low and medium doses were tested in all 8 goats. In the last 4 goats, the additional higher dose was tested.

\section{Electrophysiological parameters}

At baseline and at 2 days of maintained AF during programmed electrical stimulation at a stimulus amplitude of $2 x$ the diastolic threshold and basic cycle lengths (BCL) of 450,400 , $350,300,250,225$ and $200 \mathrm{~ms}$ the AERP was determined. In each experiment, stimulation sites on RA, LA, and BB were tested. AERP was determined by delivering premature stimuli 
in decreasing interval duration after the train of 10 beats at every investigated BCL. The shortest interval of premature beats that resulted in propagating wave was taken as the AERP.

Conduction velocity was determined in $\mathrm{BB}$ during programmed electrical stimulation of RA at basic cycle lengths 400, 350, 300, 275, 250, 225, and 200ms.

In addition, 5-second bursts of $50 \mathrm{~Hz}$ were applied, and the duration of induced AF episodes was measured to determine the stability of AF.

At baseline and after 2 days of AF, the PR interval, QRS duration, RR interval, QT time, and corrected QT time (QTC) were determined from the surface ECG during infusion of solvent and various doses of ranolazine. QTc was calculated with goat-specific modified Bazett's formula $\mathrm{QTc}=\mathrm{QT} /(\mathrm{RR} / 1000)^{0.6}$ according to Mohan et al. ${ }^{21}$

At 14 days of maintained $A F$, the arrhythmia was persistent (no spontaneous cardioversions were observed during a 60-minute monitoring period). During infusion of solvent and incremental doses of ranolazine, the median atrial fibrillation cycle length (AFCL), RR intervals and QRS durations were determined. As a surrogate parameter for AERP during $A F$ we used the fifth percentile (p5) of the AFCL distribution ${ }^{22}$.

\section{Signal analysis}

The $\mathrm{CV}$ in $\mathrm{BB}$ during pacing and $\mathrm{AFCL}$ distribution was determined using a custommade analysis software (MATLAB 8.1, The Mathworks, Inc., Natick, Massachusetts, USA) as described before ${ }^{23}$. Surface ECG parameters were analyzed with custom software (PaceMap, developed by Dr. M.A. Allessie at Maastricht University).

\section{Data analysis and statistics}

Electrophysiological parameters were analyzed with a marginal linear mixed effects model using either the first order autoregressive or compound symmetry covariance structure and Fisher's Least Significant Difference post hoc analysis. Fixed variables were $\mathrm{BCL}$ (for AERP and CV measurements), pacing/signal acquisition site, drug dose and relevant interactions, while the individual animal was included as a random variable. Results are presented as the estimated mean \pm standard error of the mean. A p-value $<0.05$ was considered statistically significant. Statistical analysis was performed with IBM SPSS Statistics for Windows, version 23 (IBM Corp., Armonk, N.Y., USA) and GraphPad Prism version 6.00 for Windows (GraphPad Software, La Jolla California USA).

\section{Results}

\section{Effects of ranolazine on atrial electrophysiology}

Ranolazine significantly prolonged AERP in goats at baseline only at the highest tested dose. At that dose, AERP could no longer be measured at the shortest BCL of $200 \mathrm{msec}$, because of loss of 1 to 1 capture (Figure 3A). 
After two days of maintained AF, all goats had undergone electrical remodeling, i.e. a decrease in AERP. At this time point also, the AERP was only significantly prolonged during the administration of the highest dose (Figure $3 \mathrm{~B}$ ).

At baseline, conduction velocity was decreased at the highest investigated dose of ranolazine. This effect was rate-dependent, because the decrease in conduction velocity was observed mainly at shorter BCLs (Figure 3C). In electrically remodeled goats after 2 days of maintained $A F$, ranolazine, both at medium and high concentration, significantly decreased conduction velocity at all investigated BCLs (Figure 3D).

Under baseline conditions, the duration of AF episodes induced by burst pacing was very short. The highest tested dose of ranolazine significantly reduced the duration of AF episodes further compared to control and to the two lower doses tested (Figure 3E). As expected, after 2 days of AF, the episodes of AF induced by burst pacing were markedly longer. However, all goats still spontaneously cardioverted to sinus rhythm. Interestingly, the lowest dose of ranolazine significantly prolonged the duration of the AF episodes, whereas the medium and the highest dose did not affect the duration of the AF episodes (Figure 3F).
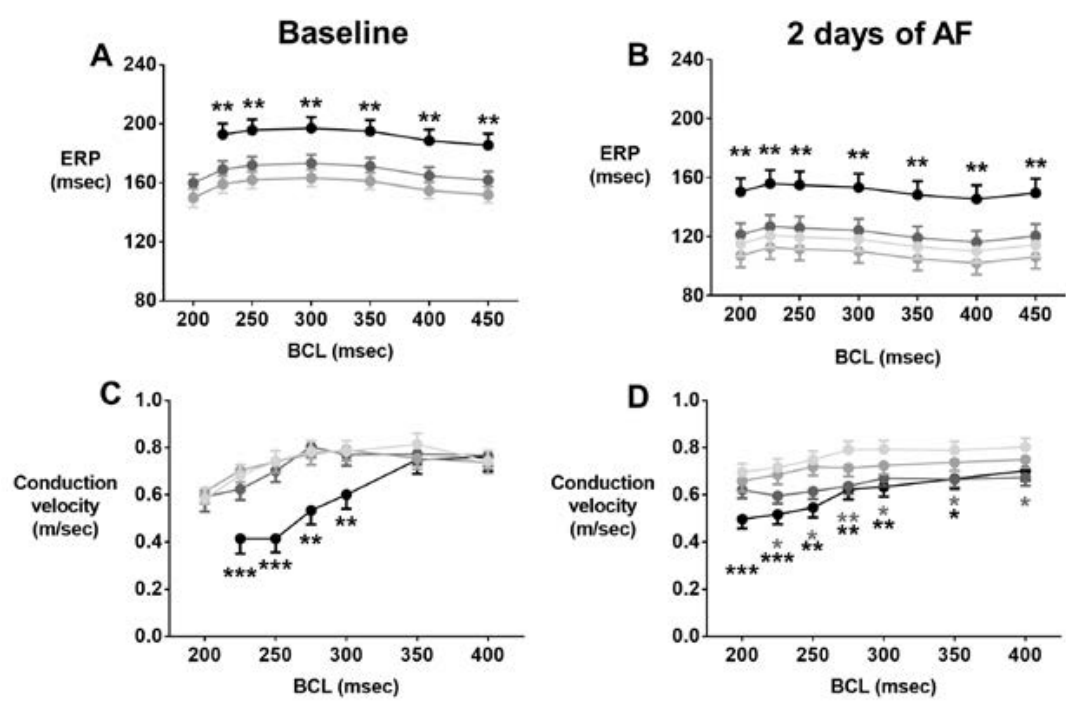

\section{2 days of $A F$}
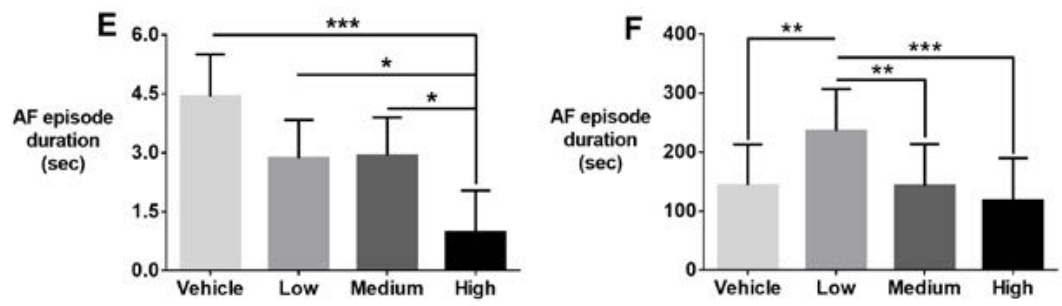

Figure 3. Effects of ranolazine in normal and electrically remodeled atria. Conduction velocity at baseline (A) and after two days of atrial fibrillation (B). Atrial effective refractory period (AERP) at baseline (C) and after two days of $A F(D)$. AF episode duration at baseline (E) and after two days of $A F(\mathbf{F})$ 


\section{Effect of ranolazine during persistent atrial fibrillation}

After two weeks of AF maintenance, the arrhythmia was sustained in all animals, i.e. no spontaneous cardioversions were observed after turning the pacemaker off. Ranolazine caused a dose-dependent prolongation in AFCL $(103.1 \pm 4.4 \mathrm{~ms}$ vs. $109.2 \pm 4.4 \mathrm{~ms}$ vs. $117.5 \pm 4.2 \mathrm{~ms}$ vs. $135.7 \pm 4.3 \mathrm{~ms} ; \mathrm{p}<0.01, \mathrm{p}<0.001, \mathrm{p}<0.001$ compared to $A F C L$ during solvent infusion) (Figure $4 C$ ). This increase in AFCL was accompanied with the similar increase in p5 AFCL, a surrogate parameter for AERP during AF $(68.9 \pm 5.5 \mathrm{~ms}$ vs. $77.2 \pm 5.4 \mathrm{~ms}$ vs. $85.1 \pm 5.4 \mathrm{~ms}$ vs. $101.1 \pm 5.4 \mathrm{~ms} ; \mathrm{p}<0.001, \mathrm{p}<0.001, \mathrm{p}<0.001$ compared to $\mathrm{p} 5 \mathrm{AFCL}$ during solvent infusion) (Figure 4D). In none of the goats AF cardioverted to the sinus rhythm during the infusion of the lower doses of ranolazine. Only in one goat the AF cardioverted to sinus rhythm, after the administration of the highest investigated dose.
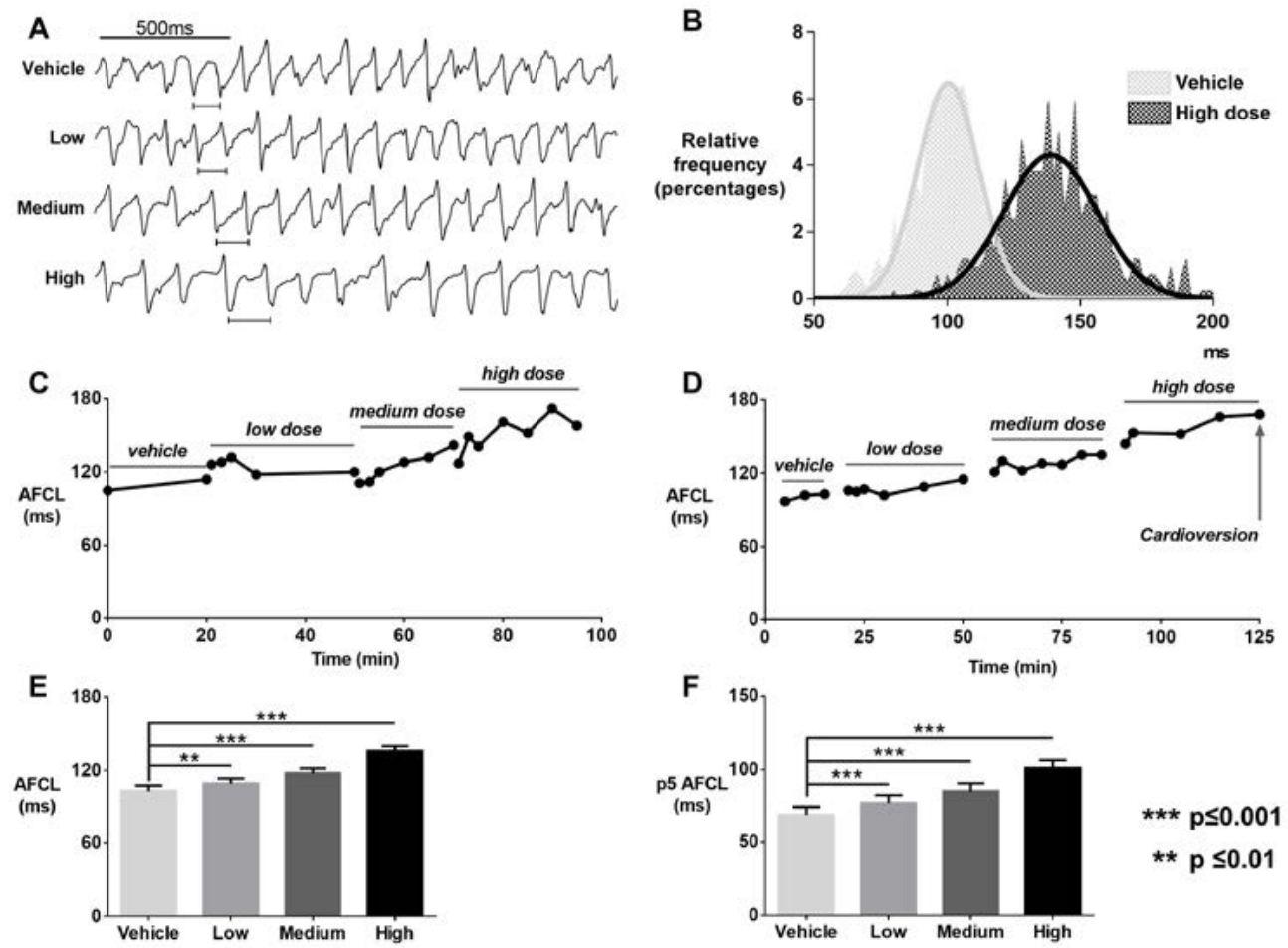

Figure 4. Effects of ranolazine during persistent atrial fibrillation. (A) A single unipolar atrial electrogram during the infusion of vehicle and increasing doses of ranolazine, (B) AFCL frequency distribution during vehicle infusion and during administration of the highest dose of ranolazine, (C, D) Time course of changes in AFCL during administration of increasing doses of ranolazine in two individual goats, (E) Calculated mean AFCL of all goats during administration of increasing doses of ranolazine, (F) Mean p5 AFCL of all goats during administration of increasing doses of ranolazine.

\section{Body surface ECG parameters}

Both at baseline and after 2 days of AF, ranolazine had dose-dependent effects on several surface ECG parameters (Figure 5). The medium and high dose of ranolazine significantly prolonged the $\mathrm{PQ}$ interval compared to the period during solvent infusion $(83.9 \pm 4.6 \mathrm{~ms}$ 
vs. $96.6 \pm 4.6 \mathrm{~ms} ; \mathrm{p}<0.05$ and $83.9 \pm 4.6 \mathrm{~ms}$ vs. $104.4 \pm 5.3 \mathrm{~ms} ; \mathrm{p}<0.01$, respectively). $\mathrm{PQ}$ interval duration in goats after two days of AF was also prolonged in the presence of medium and high dose of ranolazine $(84.7 \pm 2.9 \mathrm{~ms}$ vs. $87.3 \pm 3.1 \mathrm{~ms}$ vs. $93.3 \pm 2.85$ vs. $109.8 \pm 3.4 \mathrm{~ms} ; \mathrm{p}=\mathrm{ns}$, $p<0.05, p<0.001$, respectively) (Figure $5 A$ ).

Ranolazine did not significantly affect QRS duration in normal goats. In goats after 2 days and 2 weeks of $A F$, the highest ranolazine dose prolonged QRS complex duration $(66.7 \pm 2.2 \mathrm{~ms}$ vs. $78.9 \pm 2.5 \mathrm{~ms}, \mathrm{p}<0.001 ; 75.8 \pm 3.3 \mathrm{~ms}$ vs. $87.6 \pm 3.5 \mathrm{~ms}, \mathrm{p}<0.001$; respectively) (Figure 5B).
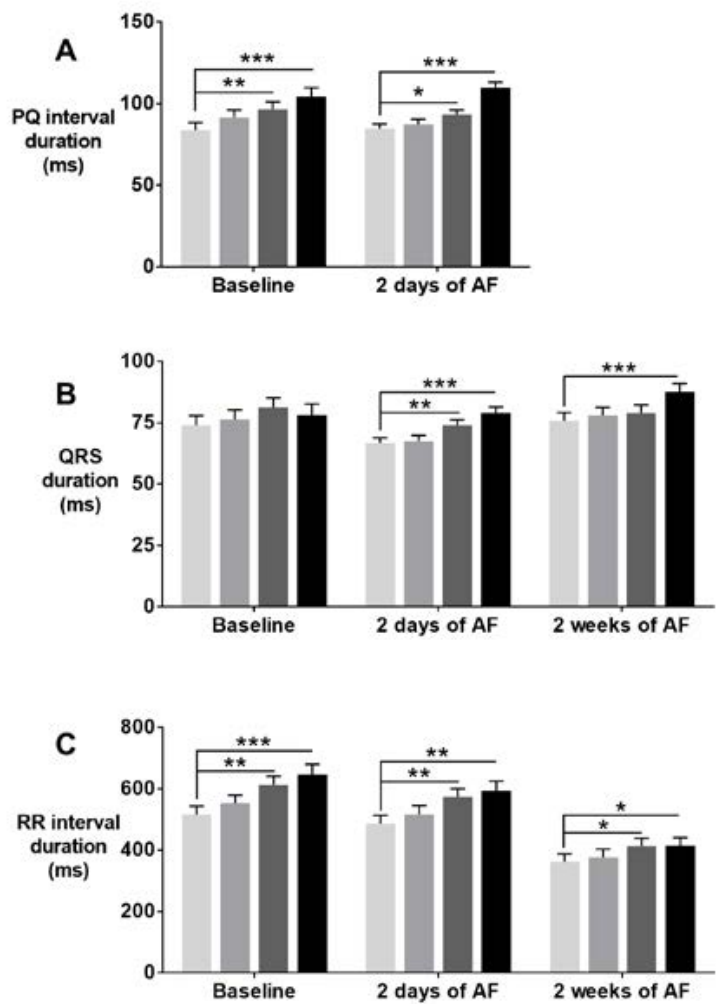
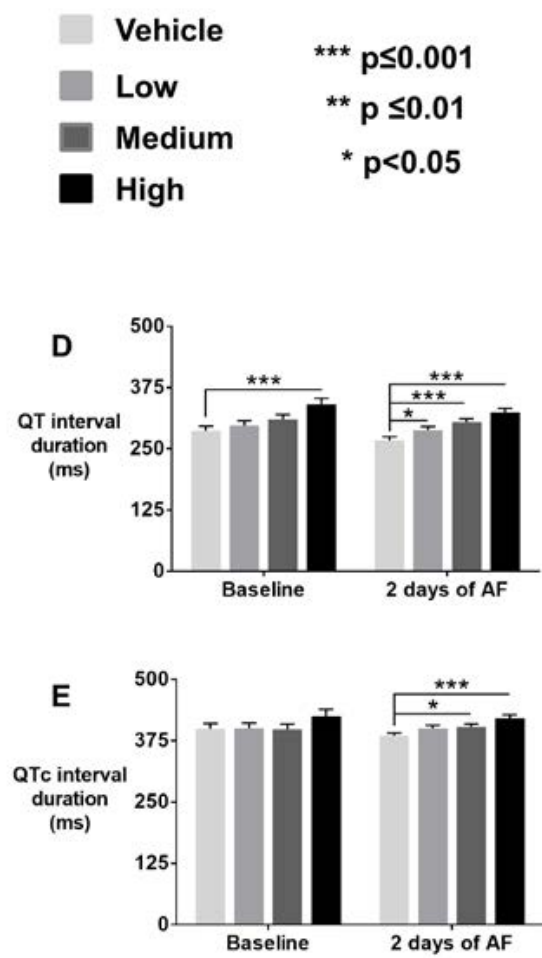

Figure 5. Effects of ranolazine on the following surface ECG intervals (A) PQ interval, (B) QRS complex, (C) RR interval, (D) QT interval, (E) QT interval.

Ranolazine, both at low and high dose, increased the RR interval in sinus rhythm goats at baseline and after 2 days of AF $(516.3 \pm 26.7 \mathrm{~ms}$ vs. $613.6 \pm 26.7 \mathrm{~ms}(p<0.01)$ vs. $646.8 \pm 32.6 \mathrm{msec}(\mathrm{p}<0.001)$ and $486.3 \pm 27.0 \mathrm{~ms}$ vs. $573.0 \pm 27.0 \mathrm{~ms}$ ( $p<0.01)$ vs. $594.2 \pm 31.0 \mathrm{~ms}$ $(p<0.01)$. RR intervals during persistent AF were as well slightly prolonged in a presence of medium and the highest ranolazine dose $(362.3 \pm 25.6 \mathrm{~ms}$ vs. $413.4 \pm 25.6 \mathrm{~ms}(p<0.05)$ and $362.3 \pm 25.6 \mathrm{~ms}$ vs. $414.3 \pm 26.5 \mathrm{~ms}$ ( $p<0.05)$, respectively) (Figure $5 \mathrm{C}$ ). 
The QT interval during sinus rhythm in goats at baseline and after 2 days of AF was increased during high dose administration compared to solvent infusion. Although this trend remained, the corrected QT duration was not significantly prolonged during the infusion of the highest ranolazine at baseline, while prolongation of QTc interval in goats after 2 days of AF was statistically significant $(385.1 \pm 5.7 \mathrm{~ms}$ vs. $400.5 \pm 6.2 \mathrm{~ms}, \mathrm{p}=\mathrm{ns}$; $385.1 \pm 5.7 \mathrm{~ms}$ vs. $403.6 \pm 5.7 \mathrm{~ms}, \mathrm{p}<0.05 ; 385.1 \pm 5.7 \mathrm{~ms}$ vs. $421.1 \pm 6.9, \mathrm{p}<0.001$ ) (Figure $5 \mathrm{D}$, E). No adverse ventricular arrhythmic events i.e. premature ventricular beats or signs of hemodynamic instability were observed during the infusion of ranolazine at any point in this study.

\section{Discussion}

Our results show that the effects of ranolazine on atrial electrophysiology are not affected by electrical remodeling. Both in normal and electrically remodeled atria, at the highest investigated dose, ranolazine decreased conduction velocity and prolonged AERP. However, the shortening of AF episode duration by ranolazine in normal atria was no longer observed in the electrically remodeled atria after 2 days of AF. In addition, at the 2-week time-point ranolazine increased the AFCL and the p5 of AFCL distribution in a dose-dependent manner, but still was not effective in cardioverting AF to sinus rhythm. No significant adverse ventricular pro-arrhythmic effects were observed.

Ranolazine is a multichannel blocker that dose-dependently blocks different ion channels both in the atria and in the ventricles ${ }^{2-5}$. Based on the dose-response curves observed in earlier studies, the two lower doses of ranolazine used in our experiment (approx. $4 \mu \mathrm{M}$ and $8 \mu \mathrm{M})$ are expected to block late $I_{\mathrm{Na}}$ and atrial peak $\mathrm{I}_{\mathrm{Na}}{ }^{2,4,5}$. In addition, the highest investigated dose, that reached approximate plasma concentration of $16 \mu \mathrm{M}$, is also expected to block $\mathrm{I}_{\mathrm{Kr}}$ in both atria and ventricle ${ }^{4,5}$.

\section{Electrophysiological effects of ranolazine in the atrium}

Prolongation of the AERP in the presence of the highest investigated concentration of ranolazine at baseline and after two days of AF may be attributable both to $\mathrm{I}_{\mathrm{Kr}}$ blockade and to peak $\mathrm{I}_{\mathrm{Na}}$ blockade and consequent prolongation of post repolarization refractoriness ${ }^{2}$. Post repolarization refractoriness refers to the effect of $I_{\mathrm{Na}}$ blockers to prolong the ERP to a larger extent than the APD. Burashnikov et al. demonstrated in isolated atrial myocytes and in superfused canine pulmonary vein sleeves that ranolazine prolongs ERP much more than APD, showing that a major effect of ranolazine on ERP is actually due to post repolarization refractoriness ${ }^{2}$. Ranolazine's effect on peak $I_{\mathrm{Na}}$ in our experiments is further supported by the fact that the highest ranolazine dose also decreased CV in a ratedependent manner in normal goat atria. Similar observations were made in cells, organ preparations and in intact animals ${ }^{2,11,24}$. After two days of $A F$, the medium ranolazine dose also decreased CV in the atria, while the rate-dependency of CV slowing became less prominent.

There is ongoing discussion whether ranolazine has a greater affinity for binding to $\mathrm{Na}^{+}$ in the open ${ }^{25,26}$ or inactivated state ${ }^{27}$. Poulet et al. reported that ranolazine at doses of 
$3 \mu \mathrm{M}$ and $10 \mu \mathrm{M}$ depressed upstroke velocity $\left(\mathrm{dV} / \mathrm{dt}_{\mathrm{max}}\right)$, which depends on peak $\mathrm{I}_{\mathrm{Na}^{\prime}}$ only in trabecula from AF patients but not from sinus rhythm patients ${ }^{28}$. This increase in sensitivity was explained by the decrease in atrial $I_{\mathrm{Na}}$ density ${ }^{16,29-31}$ and an increase in open state fraction of $\mathrm{Na}^{+}$channels of AF-remodeled atrial cardiomyocytes ${ }^{32}$ that together resulted in a higher percentage of blocked $\mathrm{Na}^{+}$channels by ranolazine. By contrast, Sossalla et al. observed a reduction in peak $I_{\mathrm{Na}}$ current inhibition by ranolazine in cardiomyocytes from AF patients compared to sinus rhythm patients, attributing this phenomenon to preferential binding of ranolazine to inactivated $\mathrm{Na}^{+}$channels ${ }^{16,27}$. Whereas Sossalla et al. reported that ranolazine loses its effect to inhibit peak $I_{\mathrm{Na}}$ in cardiomyocytes from $A F$ patients, we found that the class I effect of ranolazine (i.e. the reduction in CV) is preserved in atria after short term electrical remodeling. Based on our current results, we propose that the effect of ranolazine on atrial electrophysiology in normal and AF remodeled atria can be explained by its effect on peak $I_{\mathrm{Na} \text {. }}$ However, we cannot exclude a contribution of IKr blockade (with an $\mathrm{IC}_{50}$ of $12 \mu \mathrm{M}$ in canine atrial myocytes ${ }^{4,5}$ ) to the ERP prolongation we observed.

Poulet et al. reported that significant $A \mathrm{PD}_{90}$ prolongation was observed in trabeculae from AF patients, but not in the patients with sinus rhythm at a dose of $10 \mu \mathrm{M}^{28}$. Although we studied an early stage of electrical remodeling, the prolongation of the ERP by ranolazine was similar in normal and electrically remodeled goat atria.

The contribution of late $\mathrm{I}_{\mathrm{Na}}$ to AF pathophysiology is still a matter of debate. The integral of late $I_{\mathrm{Na}}$ in atrial cardiomyocytes from the persistent AF patients is reported to be increased by $26 \%$ compared to sinus rhythm patients ${ }^{16}$. Enhancement of late $I_{\mathrm{Na}}$ in atrial cardiomyocytes from persistent AF patients was later confirmed also by Poulet et al. ${ }^{28}$. An anti-arrhythmic effect of late $\mathrm{I}_{\mathrm{Na}}$ inhibition by ranolazine could also be attributable to the prevention of $\mathrm{Na}^{+}$overload, and thereby indirectly $\mathrm{Ca}^{2+}$ overload and the suppression of delayed afterdepolarizations ${ }^{33}$. Still, the contribution of an increased current density of late $I_{\mathrm{Na}}$ in remodeled atria may be diminished by the shorter APD, decreasing the integral of late $\mathrm{I}_{\mathrm{Na}}{ }^{15}$.

\section{The effects of ranolazine on AF stability}

The highest investigated dose of ranolazine caused a significant decrease in the AF episode duration in normal goat atria. Similarly, ranolazine reduced AF episode duration in a pig model of acetylcholine induced $\mathrm{AF}^{11}$ and increased atrial fibrillation threshold (the lowest stimulus intensity that evokes AF) in the intact porcine model of vagal stimulation ${ }^{12}$. In addition, ranolazine suppressed acetylcholine-mediated AF inducibility in rabbits ${ }^{13}$. Models of acetylcholine-mediated AF are hallmarked by a pronounced shortening of atrial APD, and are not completely comparable to the electrical remodeling that occurs as a result of AF. Therefore, evaluating the effects of ranolazine on AF stability in atria with AF-induced remodeling is more representative of the situation in patients with AF. The ability of ranolazine to decrease AF duration was diminished in remodeled goat atria after two days of AF. Actually, the lowest administered dose of ranolazine, which is expected to specifically affect late $I_{\mathrm{Na}^{\prime}}$, significantly prolonged AF episode duration. If indeed late $I_{\mathrm{Na}}$ is 
enhanced in goat atria with AF-induced remodeling, it is conceivable that blockade of late $\mathrm{I}_{\mathrm{Na}}$ would further shorten the APD and could therefore be pro-arrhythmic.

After two weeks of AF maintenance, during sustained AF, ranolazine caused a dosedependent prolongation of both $A F C L$ and the $\mathrm{p} 5$ of the $A F C L$ distribution (a surrogate parameter for $A E R P$ during $A^{22}$ ) but was not effective in terminating $A F$. Compared with the different classes of antiarrhythmic drugs previously studied in this model, the degree of AFCL prolongation was the most similar to AFCL prolongation by class I antiarrhythmic drugs $^{34,35}$. AFCL was significantly prolonged already after the administration of the lowest dose, supporting the notion that $\mathrm{Na}^{+}$channel blockade by ranolazine increases at high activation frequencies. However, the efficacy of ranolazine to cardiovert AF to sinus rhythm was still much lower compared to that the class I blockers Hydroquinidine, Cibezoline and Flecainide, and the class III blockers d-Sotalol or AVE0118+Dofetilide after similar AF duration in the same animal model ( $83 \%$ vs. $78 \%$ vs. $33 \%$ vs. $100 \%$ vs. $80 \%$, respectively ${ }^{34-36}$ ). It is important to note that, in these animal experiments drug infusion was continuous and was limited by safety endpoints that included QRS prolongation or ventricular proarrhythmia, which resulted in a higher drug dosage than in clinical practice. For example, in a study by Eijsbouts et al. neither flecainide nor cibenzoline were effective in cardioverting any animal after one week of maintained AF at clinically used doses, and the minimal dose that caused cardioversion was 2-3 fold higher ${ }^{35}$. In our study, dosing was based on the effects on atrial electrophysiology observed in prior experimental studies. We did not observe any adverse ventricular arrhythmic events and thus, the endpoints used in previous studies in the goat model were not reached. Therefore, an exact comparison of the efficacy of different antiarrhythmic agents, although within the same animal model, cannot be made.

Therefore, in spite the low efficacy in AF termination, ranolazine affected atrial electrophysiological parameters in electrically remodeled atria, and hence it can be considered as a treatment option for AF with good safety properties, perhaps in combination with other antiarrhythmic drugs $^{19}$.

Beneficial effects of ranolazine on AF prevalence is showed in previous clinical studies ${ }^{6,7,17}$, ${ }^{19}$, but based on our studies with acute administration of ranolazine, these effects cannot be explained by direct channel blockade and concomitant cardioversion. However, in these clinical trials, ranolazine was administered chronically, over periods of weeks to months ${ }^{7}$. Therefore, the reported beneficial effects of ranolazine may be attributable to pathophysiological mechanisms operative on a longer time scale, such as prevention of calcium overload ${ }^{29,37}$ and a shift from fatty acid oxidation to more oxygen-efficient glucose oxidation ${ }^{38,39}$. The latter effect has been used to explain the anti-anginal effect of ranolazine in the setting of ischemic heart disease ${ }^{40}$. However, whether ranolazine causes a metabolic shift was later challenged, leaving the anti-anginal properties of ranolazine still not completely understood ${ }^{41}$. We have previously shown that in pigs, the high metabolic demand imposed by $\mathrm{AF}$ leads to a state of supply demand ischemia in acute $\mathrm{AF}^{42}$ and there is evidence of chronic atrial ischemia as a result of $\mathrm{AF}^{43}$. Long-term administration of ranolazine, which did not cause ventricular proarrhythmia in our study, may represent a 
novel strategy to prevent deleterious consequences of AF-induced metabolic compromise for the atrial myocardium.

\section{Limitations}

A thorough investigation of the effects of ranolazine on cardiac cellular electrophysiology has been performed in isolated cardiomyocytes from dogs $s^{4,5}$.The dosing regimen in our study was based on these observations. However, the pharmacology of channel blockade may differ between species. For unknown reasons, and despite extensive efforts, it has proven difficult to isolate viable myocytes from the goat atrial myocardium. Therefore, we cannot be certain that ranolazine affects the same currents with the same dosedependency in goat atria. However, taken together, the large body of previous studies on AF-induced remodeling and the effects of antiarrhythmic drugs suggest that goat and dog atria are similar electrophysiologically, and comparable to human atria. 


\section{References}

1. Zimetbaum P. Antiarrhythmic drug therapy for atrial fibrillation. Circulation. 2012;125:381-9.

2. Burashnikov A, Di Diego JM, Zygmunt AC, Belardinelli L and Antzelevitch C. Atrium-selective sodium channel block as a strategy for suppression of atrial fibrillation: differences in sodium channel inactivation between atria and ventricles and the role of ranolazine. Circulation. 2007;116:1449-1457.

3. Antzelevitch $C$ and Burashnikov A. Atrial-selective sodium channel block as a novel strategy for the management of atrial fibrillation. Ann N Y Acad Sci. 2010;1188:78-86.

4. Antzelevitch C, Belardinelli L, Wu L, Fraser H, Zygmunt AC, Burashnikov A, Di Diego JM, Fish JM, Cordeiro JM, Goodrow RJ, Scornik F and Perez G. Electrophysiologic properties and antiarrhythmic actions of a novel antianginal agent. J Cardiovasc Pharmacol Ther. 2004;9 Suppl 1:S65-83.

5. Antzelevitch C, Belardinelli L, Zygmunt AC, Burashnikov A, Di Diego JM, Fish JM, Cordeiro $J M$ and Thomas $G$. Electrophysiological effects of ranolazine, a novel antianginal agent with antiarrhythmic properties. Circulation. 2004;110:904-910.

6. Scirica BM, Morrow DA, Hod H, Murphy SA, Belardinelli L, Hedgepeth CM, Molhoek P, Verheugt FWA, Gersh BJ, McCabe $\mathrm{CH}$ and Braunwald E. Effect of ranolazine, an antianginal agent with novel electrophysiological properties, on the incidence of arrhythmias in patients with non ST-segment elevation acute coronary syndrome: results from the Metabolic Efficiency With Ranolazine for Less Ischemia in Non ST-Elevation Acute Coronary Syndrome Thrombolysis in Myocardial Infarction 36 (MERLIN-TIMI 36) randomized controlled trial. Circulation. 2007;116:1647-1652.

7. Guerra F, Romandini A, Barbarossa A, Belardinelli L and Capucci A. Ranolazine for rhythm control in atrial fibrillation: A systematic review and meta-analysis. Int J Cardiol. 2017;227:284-291.

8. Zou D, Geng N, Chen Y, Ren L, Liu X, Wan J, Guo S and Wang S. Ranolazine improves oxidative stress and mitochondrial function in the atrium of acetylcholine- $\mathrm{CaCl} 2$ induced atrial fibrillation rats. Life Sci. 2016;156:7-14.

9. Burashnikov A, Di Diego JM, Barajas-Martinez H, Hu D, Cordeiro JM, Moise NS, Kornreich BG, Belardinelli $L$ and Antzelevitch $C$. Ranolazine effectively suppresses atrial fibrillation in the setting of heart failure. Circ Heart Fail. 2014;7:627-33.

10. Frommeyer G, Schmidt M, Clauss C, Kaese S, Stypmann J, Pott C, Eckardt L and Milberg P. Further insights into the underlying electrophysiological mechanisms for reduction of atrial fibrillation by ranolazine in an experimental model of chronic heart failure. Eur J Heart Fail. 2012;14:1322-31.

11. Kumar K, Nearing BD, Carvas M, Nascimento BCG, Acar M, Belardinelli L and Verrier RL. Ranolazine exerts potent effects on atrial electrical properties and abbreviates atrial fibrillation duration in the intact porcine heart. J Cardiovasc Electrophysiol. 2009;20:796-802.

12. Carvas $M$, Nascimento $B C$, Acar $M$, Nearing BD, Belardinelli $L$ and Verrier RL. Intrapericardial ranolazine prolongs atrial refractory period and markedly reduces atrial fibrillation inducibility in the intact porcine heart. J Cardiovasc Pharmacol. 2010;55:286-91.

13. Aidonidis I, Doulas K, Hatziefthimiou A, Tagarakis G, Simopoulos V, Rizos I, Tsilimingas N and Molyvdas PA. Ranolazine-induced postrepolarization refractoriness suppresses induction of atrial flutter and fibrillation in anesthetized rabbits. J Cardiovasc Pharmacol Ther. 2013;18:94101. 
14. Bhimani AA, Yasuda T, Sadrpour SA, Khrestian CM, Lee S, Zeng D, Belardinelli L and Waldo AL. Ranolazine terminates atrial flutter and fibrillation in a canine model. Heart Rhythm. 2014;11:1592-9.

15. Burashnikov A and Antzelevitch C. Role of late sodium channel current block in the management of atrial fibrillation. Cardiovasc Drugs Ther. 2013;27:79-89.

16. Sossalla S, Kallmeyer B, Wagner S, Mazur M, Maurer U, Toischer K, Schmitto JD, Seipelt $\mathrm{R}$, Schondube FA, Hasenfuss $\mathrm{G}$, Belardinelli $L$ and Maier LS. Altered $\mathrm{Na}(+)$ currents in atrial fibrillation effects of ranolazine on arrhythmias and contractility in human atrial myocardium. J Am Coll Cardiol. 2010;55:2330-42.

17. De Ferrari GM, Maier LS, Mont L, Schwartz PJ, Simonis G, Leschke M, Gronda E, Boriani G, Darius H, Guillamon Toran L, Savelieva I, Dusi V, Marchionni N, Quintana Rendon M, Schumacher K, Tonini G, Melani L, Giannelli S, Alberto Maggi C, Camm AJ and Investigators R. Ranolazine in the treatment of atrial fibrillation: Results of the dose-ranging RAFFAELLO (Ranolazine in Atrial Fibrillation Following An ELectricaL CardiOversion) study. Heart Rhythm. 2015;12:872-8.

18. Morrow DA, Scirica BM, Karwatowska-Prokopczuk E, Murphy SA, Budaj A, Varshavsky S, Wolff AA, Skene A, McCabe CH, Braunwald E and Investigators M-TT. Effects of ranolazine on recurrent cardiovascular events in patients with non-ST-elevation acute coronary syndromes: the MERLIN-TIMI 36 randomized trial. JAMA. 2007;297:1775-1783.

19. Reiffel JA, Camm AJ, Belardinelli L, Zeng D, Karwatowska-Prokopczuk E, Olmsted A, Zareba W, Rosero S, Kowey P and Investigators H. The HARMONY Trial: Combined Ranolazine and Dronedarone in the Management of Paroxysmal Atrial Fibrillation: Mechanistic and Therapeutic Synergism. Circ Arrhythm Electrophysiol. 2015;8:1048-56.

20. Wijffels MC, Kirchhof $C J$, Dorland R and Allessie MA. Atrial fibrillation begets atrial fibrillation. A study in awake chronically instrumented goats. Circulation. 1995;92:1954-68.

21. Mohan N, Nliyogi D and Singh H. Analysis of relationship between Q-T and R-R interval in the electrocardiogram of goats. Indian J Anim Sci. 2009;79:362-365.

22. Duytschaever M, Mast F, Killian M, Blaauw $Y$, Wijffels $M$ and Allessie M. Methods for determining the refractory period and excitable gap during persistent atrial fibrillation in the goat. Circulation. 2001;104:957-62.

23. Zeemering S, Maesen B, Nijs J, Lau DH, Granier M, Verheule S and Schotten U. Automated quantification of atrial fibrillation complexity by probabilistic electrogram analysis and fibrillation wave reconstruction. Conf Proc IEEE Eng Med Biol Soc. 2012;2012:6357-60.

24. Sicouri S, Glass A, Belardinelli $L$ and Antzelevitch $C$. Antiarrhythmic effects of ranolazine in canine pulmonary vein sleeve preparations. Heart Rhythm. 2008;5:1019-1026.

25. Rajamani S, Shryock JC and Belardinelli L. Block of tetrodotoxin-sensitive, $\mathrm{Na}(\mathrm{V}) 1.7$ and tetrodotoxin-resistant, $\mathrm{Na}(\mathrm{V}) 1.8, \mathrm{Na}+$ channels by ranolazine. Channels (Austin). 2008;2:449-60.

26. Wang GK, Calderon J and Wang S-Y. State- and use-dependent block of muscle Nav1.4 and neuronal Nav1.7 voltage-gated $\mathrm{Na}+$ channel isoforms by ranolazine. Mol Pharmacol. 2008;73:940-948.

27. Undrovinas Al, Maltsev VA and Sabbah HN. Repolarization abnormalities in cardiomyocytes of dogs with chronic heart failure: role of sustained inward current. Cell Mol Life Sci. 1999;55:494-505.

28. Poulet C, Wettwer E, Grunnet M, Jespersen T, Fabritz L, Matschke K, Knaut M and Ravens U. Late Sodium Current in Human Atrial Cardiomyocytes from Patients in Sinus Rhythm and Atrial Fibrillation. PLoS One. 2015;10:e0131432. 
29. Sossalla S, Wagner S, Rasenack ECL, Ruff H, Weber SL, Schöndube FA, Tirilomis T, Tenderich G, Hasenfuss G, Belardinelli L and Maier LS. Ranolazine improves diastolic dysfunction in isolated myocardium from failing human hearts--role of late sodium current and intracellular ion accumulation. J Mol Cell Cardiol. 2008;45:32-43.

30. Yagi T, Pu J, Chandra P, Hara M, Danilo P, Jr., Rosen MR and Boyden PA. Density and function of inward currents in right atrial cells from chronically fibrillating canine atria. Cardiovasc Res. 2002;54:405-15.

31. Gaspo R, Bosch RF, Bou-Abboud E and Nattel S. Tachycardia-induced changes in Na+ current in a chronic dog model of atrial fibrillation. Circ Res. 1997;81:1045-52.

32. Bosch RF, Zeng X, Grammer JB, Popovic K, Mewis C and Kuhlkamp V. Ionic mechanisms of electrical remodeling in human atrial fibrillation. Cardiovascular research. 1999;44:121-31.

33. Antzelevitch C, Burashnikov A, Sicouri S and Belardinelli L. Electrophysiologic basis for the antiarrhythmic actions of ranolazine. Heart Rhythm. 2011;8:1281-90.

34. Wijffels MC, Dorland R and Allessie MA. Pharmacologic cardioversion of chronic atrial fibrillation in the goat by class IA, IC, and III drugs: a comparison between hydroquinidine, cibenzoline, flecainide, and d-sotalol. Journal of cardiovascular electrophysiology. 1999;10:178-93.

35. Eijsbouts S, Ausma J, Blaauw Y, Schotten U, Duytschaever $M$ and Allessie MA. Serial cardioversion by class IC Drugs during 4 months of persistent atrial fibrillation in the goat. $J$ Cardiovasc Electrophysiol. 2006;17:648-54.

36. Verheule S, Tuyls E, van Hunnik A, Kuiper M, Schotten U and Allessie M. Fibrillatory conduction in the atrial free walls of goats in persistent and permanent atrial fibrillation. Circ Arrhythm Electrophysiol. 2010;3:590-9.

37. Fraser $\mathrm{H}$, Belardinelli L, Wang L, Light PE, McVeigh JJ and Clanachan AS. Ranolazine decreases diastolic calcium accumulation caused by ATX-II or ischemia in rat hearts. J Mol Cell Cardiol. 2006;41:1031-1038.

38. McCormack JG, Barr RL, Wolff AA and Lopaschuk GD. Ranolazine stimulates glucose oxidation in normoxic, ischemic, and reperfused ischemic rat hearts. Circulation. 1996;93:135-142.

39. Clarke B, Spedding M, Patmore L and McCormack JG. Protective effects of ranolazine in guinea-pig hearts during low-flow ischaemia and their association with increases in active pyruvate dehydrogenase. Br J Pharmacol. 1993;109:748-750.

40. Jaswal JS, Keung W, Wang W, Ussher JR and Lopaschuk GD. Targeting fatty acid and carbohydrate oxidation--a novel therapeutic intervention in the ischemic and failing heart. Biochim Biophys Acta. 2011;1813:1333-50.

41. Wang P, Fraser H, Lloyd SG, McVeigh JJ, Belardinelli L and Chatham JC. A comparison between ranolazine and CVT-4325, a novel inhibitor of fatty acid oxidation, on cardiac metabolism and left ventricular function in rat isolated perfused heart during ischemia and reperfusion. $J$ Pharmacol Exp Ther. 2007;321:213-220.

42. van Bragt KA, Nasrallah HM, Kuiper M, Luiken JJ, Schotten $U$ and Verheule S. Atrial supplydemand balance in healthy adult pigs: coronary blood flow, oxygen extraction, and lactate production during acute atrial fibrillation. Cardiovasc Res. 2014;101:9-19.

43. Opacic D, van Bragt KA, Nasrallah HM, Schotten U and Verheule S. Atrial metabolism and tissue perfusion as determinants of electrical and structural remodeling in atrial fibrillation. Cardiovasc Res. 2016. 



\section{Chapter IV}

\section{The inward rectifier current inhibitor PA-6 terminates atrial fibrillation and does not cause ventricular arrhythmias in dedicated goat and dog models}

Yuan $\mathrm{Ji}^{*}$, Rosanne Varkevisser*, Dragan Opačić, Alexandre Bossu, Marion Kuiper, Jet D M Beekman, Sihyung Yang, Azinwi Phina Khan, Dobromir Dobrev, Niels Voigt, Michael Zhuo Wang, Sander Verheule, Marc A Vos, Marcel A G van der Heyden 


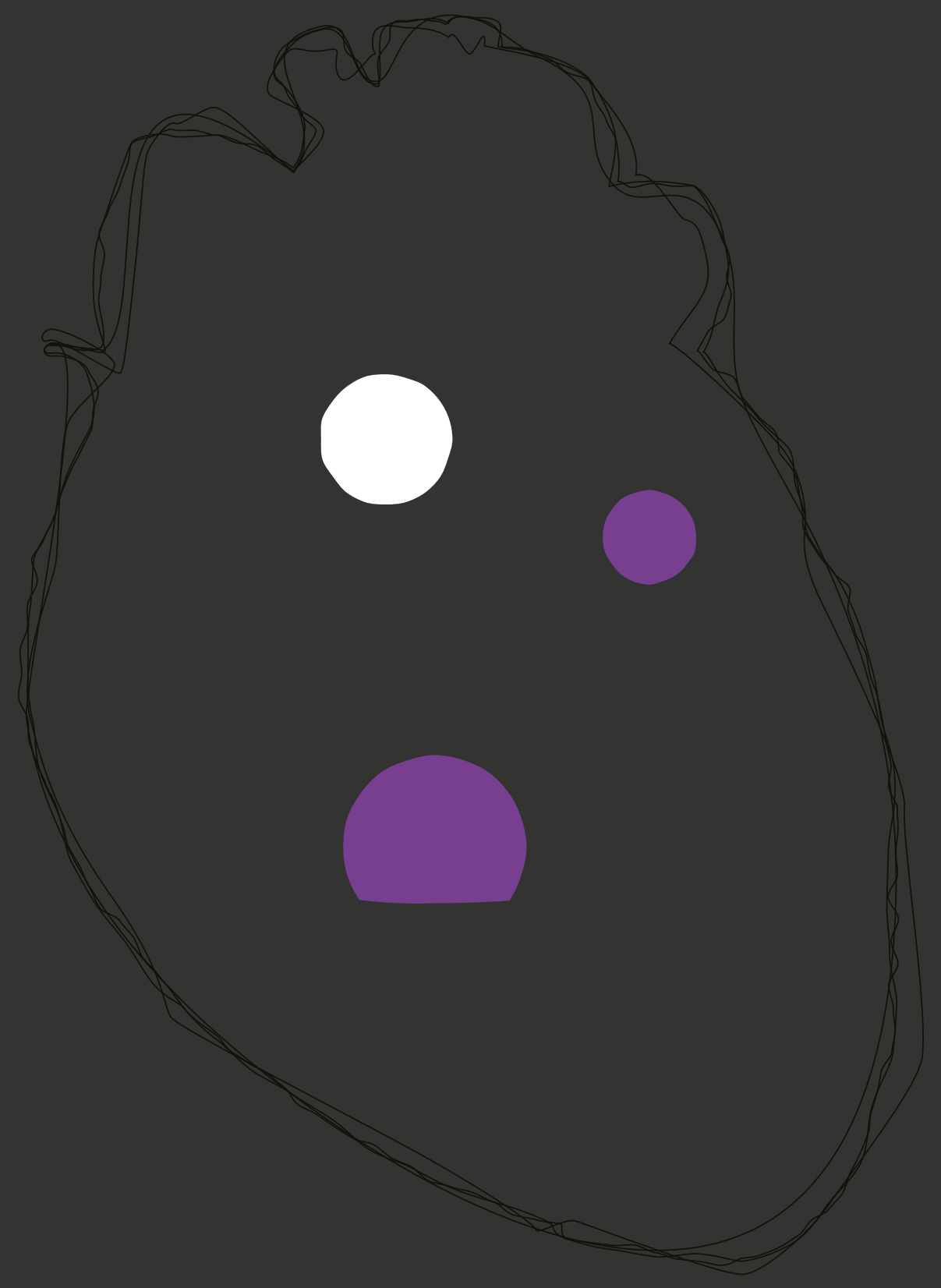




\section{Abstract}

Background and Purpose: Inward rectifier current $\left(\mathrm{I}_{\mathrm{K} 1}\right)$ density increases in atrial fibrillation (AF), shortening effective refractory period and thus promotes atrial reentry. Pentamidine-Analogue 6 (PA-6) is a selective and potent $\mathrm{I}_{\mathrm{K} 1}$ inhibitor. We tested PA-6 for anti-AF efficacy and potential proarrhythmia, in established large animal models.

Experimental Approach: PA-6 was applied i.v. in anaesthetized goats with rapid pacing induced $A F$ and anaesthetized chronic AV block dogs. Electrophysiological and pharmacological parameters were determined.

Key Results: PA-6 (2.5 mg. kg-1.10 $\left.\mathrm{min}^{-1}\right)$ induced cardioversion to sinus rhythm (SR) in 5/6 goats. PA-6 prolonged AF cycle length (LA:139.0 23.2 vs. $152.1 \pm 22.1 \mathrm{~ms}, \mathrm{p}<0.05 ; \mathrm{RA}: 111.7 \pm 29.1$ vs. $129.5 \pm 26.6 \mathrm{~ms}, \mathrm{p}<0.05)$. AF complexity decreased significantly prior to cardioversion. PA-6 accumulated in cardiac tissue with ratios between skeletal muscle:atrial muscle:ventricular muscle of approximately 1:8:21. In SR dogs, PA-6 peak plasma levels 10min post infusion were $5.5 \pm 0.9 \mu \mathrm{M}, \mathrm{PA}-6$ induced mild QTc prolongation (306 \pm 21 vs. $326 \pm 16 \mathrm{~ms},+7 \%(\mathrm{~ns}))$, but had no effect on heart rate (RR:601 \pm 54 vs. $605 \pm 55 \mathrm{~ms}), \mathrm{PQ}$ ( $129 \pm 20$ vs. $125 \pm 18 \mathrm{~ms})$ or QRS ( $75 \pm 5$ vs. $75 \pm 4 \mathrm{~ms})$ duration. In chronic AV block dogs, PA- 6 did not affect QRS ( $117 \pm 9$ vs. $118 \pm 8 \mathrm{~ms})$ but lengthened QTc $(384 \pm 40$ vs. $465 \pm 89 \mathrm{~ms},+21 \%, \mathrm{P}<0.05)$ during the experiment, but not chronically. PA-6 did not induce TdP arrhythmias in nine animals (0/9) in contrast to Dofetilide (5/9). PA-6 (200nM) inhibited $I_{\mathrm{K} 1}$, but not $\mathrm{I}_{\mathrm{K}, \mathrm{ACh}}$ in isolated human atrial cardiomyocytes.

Conclusion and Implications: PA- 6 restored SR in goats with persistent AF. PA-6 prolonged QT interval in CAVB dogs, without TdP arrhythmia occurrence. Our results demonstrate cardiac safety and good anti-AF properties for PA-6.

Key words: atrial fibrillation; inward rectifier current; arrhythmia; chronic AV block dog; PA-6

Abbreviations: $A E R P$, atrial effective refractory period; $A F$, atrial fibrillation; $\mathrm{AP}$, action potential; $C A V B$, chronic atrio-ventricular block; $C \mathrm{Ch}$, carbachol; $I_{K} 1^{\prime}$ inward rectifier $\mathrm{K}^{+}$current; $I_{K, A c h^{\prime}}$ acetylcholine sensitive inward rectifier $\mathrm{K}^{+}$ current; $L A$, left atrium; LV, left ventricle; MAPD; monophasic action potential duration; $\mathrm{PA}-6$, pentamidine analogue 6; $\mathrm{PQ}, \mathrm{PQ}$ interval on $\mathrm{ECG}$; $\mathrm{RA}$, right atrium; RR, RR interval on ECG; RV, right ventricle; $\mathrm{QRS}, \mathrm{QRS}$ interval on ECG; QTc, heart rate corrected ECG QT-interval; SR, sinus rhythm; STV, short term variability of repolarization duration; $\mathrm{TdP}$, torsade de pointes 


\section{Introduction}

The $\mathrm{K}^{+}$inward rectifier $\mathrm{K}^{+}$current $\left(\mathrm{I}_{\mathrm{K} 1}\right)^{1}$ is found in many excitable tissues, including the heart ${ }^{2} . I_{K 1}$ channels are composed of four $\mathrm{K}_{\mathrm{ir}} 2 . x$ subunits, either in a homo- or heteromeric configuration. In ventricles, $\mathrm{K}_{\mathrm{ir}} 2.1$ is the major constituent, whereas in atria $\mathrm{K}_{\mathrm{ir}} 2.1, \mathrm{~K}_{\mathrm{ir}} 2.2$ and $\mathrm{K}_{\mathrm{ir}} 2.3$ are more equally contributing to functional channels $\mathrm{s}^{2,3}$. Atrial cardiomyocytes have a six- to ten-fold lower $I_{\mathrm{K} 1}$ density than ventricular cardiomyocytes ${ }^{3,4}$. Nodal tissues lack functional $\mathrm{I}_{\mathrm{K} 1}{ }^{5}$. Due to their conductive state around the potassium equilibrium potential and strong rectification behavior, $\mathrm{I}_{\mathrm{K} 1}$ currents contribute to the resting membrane potential and its stability, but allow proper action potential (AP) formation ${ }^{6}$. Furthermore, the outward component of $\mathrm{I}_{\mathrm{K} 1}$ significantly contributes to phase 3 repolarization of the action potential $(\mathrm{AP})^{7-9}$.

Atrial fibrillation (AF) is the most common arrhythmia observed in humans ${ }^{10}$. Clinically, AF associates with increased risks for heart failure, stroke and death ${ }^{11-13}$. In a significant proportion of patients, AF progresses ${ }^{14}$, as a result of electrical and structural atrial remodeling ${ }^{15}$. Both processes increase the duration of AF episodes, a phenomenon known as "AF begets $A F$ " ${ }^{16}$. Electrical remodeling results in shortened atrial effective refractory period (AERP) which facilitates atrial reentry ${ }^{17}$. Current guidelines indicate anticoagulation therapy and rate control or rhythm control (including catheter ablation) ${ }^{18,19}$, but the present treatment regimens often are inadequate ${ }^{20}$, and especially rhythm control suffers from lack of efficacy and the occurrence of adverse effects, including cardiac proarrhythmia ${ }^{21}$. Since $I_{\mathrm{K} 1}$ densities increase in AF atria ${ }^{22-24}$, and may play a major role in AERP shortening ${ }^{25}$, $\mathrm{I}_{\mathrm{K} 1}$ inhibitors are potential new drugs in the antiarrhythmic pharmacotherapy repertoire ${ }^{26}$.

Starting off with pentamidine for which we demonstrated $\mathrm{I}_{\mathrm{K} 1}$ inhibiting capacity ${ }^{27}$, we selected a pentamidine-analogue (PA), PA-6, with a highly favorable $I_{\mathrm{K} 1}$ inhibiting profile ${ }^{28}$. PA- 6 inhibited both the inward and outward component of the current carried by $\mathrm{K}_{\mathrm{ir}} 2 . \mathrm{x}$ with an $\mathrm{IC}_{50}$ of 12-15 $\mathrm{nM}$ for the different cardiac $\mathrm{K}_{\mathrm{ir}} 2 . \mathrm{x}$ isoforms, as determined in the inside-out orientation of the patch-clamp method. Furthermore, in isolated canine ventricular cardiomyocytes, 200 nM PA-6 prolonged ventricular AP duration by $34 \%$, without the occurrence of proarrhythmia. Finally, $200 \mathrm{nM}$ of PA- 6 did not affect $\mathrm{I}_{\mathrm{Kv} 11.1}, \mathrm{I}_{\mathrm{Kv} 7.1 /}$ ${ }_{\text {Mink' }} \mathrm{I}_{\mathrm{Kv} 4.3^{\prime}} \mathrm{I}_{\mathrm{C},-\mathrm{L}}$ or $\mathrm{I}_{\mathrm{Nav} 1.5}{ }^{28}$.

In order to test efficacy and safety of PA- 6 in vivo, we used two established large animal models to circumvent creating and validating a single large animal model for both purposes. We used the goat model of AF induced by rapid atrial pacing ${ }^{16,29}$, and determined the effect of PA- 6 infusion on the efficacy of cardioversion and on several electrophysiological parameters. To determine cardiac safety of PA- 6 , especially the absence of ventricular arrhythmias, we used the dog model of chronic AV block ${ }^{30}$. Furthermore, we determined the relation between PA- 6 dosing and plasma and tissue concentration, as well as PA- 6 plasma protein binding. Finally, we demonstrated that PA- 6 is able to unmask the precise contribution of $\mathrm{I}_{\mathrm{K} 1}$ to inward rectifier $\mathrm{K}^{+}$current human atrial cardiomyocytes. 


\section{Methods}

\section{Ethics statement}

Animal care and management were in adherence to the guidelines from Directive 2010/63/ EU of the European Parliament. All animal experiments were approved by the Committee for Experiments on Animals of the Utrecht and Maastricht University, The Netherlands, for dog and goat experiments, respectively. For human atrial cells, the study was approved by the local ethics committee of the University Duisburg Essen (No: 12-5268-BO) and each patient gave written informed consent. The investigation conforms to the principles outlined in the Declaration of Helsinki. Animal studies are reported in compliance with the ARRIVE and BJP guidelines ${ }^{31,32}$. The current study has no implications for replacement, refinement or reduction.

\section{Animal preparation and experiments}

\section{Goats}

Eight female Dutch white milk goats weighing between 52.0 and $62.4(56.7 \pm 6.2) \mathrm{kg}$, age 16-24 (21.5 \pm 2.6$)$ months, obtained from a local farmer were used to evaluate the effect of PA-6 in an animal model of persistent AF. Goats were housed in pairs in conventional metal cages (approx. $8 \mathrm{~m}^{2}$ ) on straw at a constant temperature and humidity with the 12 hours light/dark cycle and free access to food (hay and pellets) and water. Animal welfare was checked daily and body weight was measured once a week. All animals were instrumented with an atrial lead (Medtronic Capsurefix ${ }^{\circledast}$ ) implanted transjugularly and fixed in the right atrial appendage. The pacemaker lead was connected to a subcutaneously implanted neurostimulator (Medtronic Itrel $^{\circledR}$ ). AF was induced and maintained by repetitive $50 \mathrm{~Hz}$ burst stimulation every other second, at 4 times the threshold, for three weeks ${ }^{33}$.

Anesthesia, both for implantation procedures and for follow up experiments, was induced with Sodium-Thiopental (20mg kg $\left.{ }^{-1}\right)$ and maintained with Sufentanil $\left(6 \mu \mathrm{g} \mathrm{kg}^{-1} \mathrm{~h}^{-1}\right)$ and Propofol $\left(10 \mathrm{mg} \mathrm{kg}^{-1} \mathrm{~h}^{-1}\right)$. In follow up experiments, the muscle relaxant Pavulon $\left(0.3 \mathrm{mg} \mathrm{kg}^{-1}\right.$ $\left.\mathrm{h}^{-1}\right)$ was added.

All animals $(n=8)$ underwent sacrifice experiment 3 weeks after the AF initiation, when electrical remodeling is complete without significant structural remodeling. Following termination of atrial pacing and anesthesia induction, the heart was exposed through a leftsided thoracotomy. Subsequently the animals were allowed to stabilize for 1 hour. AF was considered as stable if it did not terminate spontaneously during this stabilization period.

Unipolar atrial electrograms were recorded with two custom-made high-density mapping electrodes $(\varnothing 4 \mathrm{~cm}, 247$ electrodes, interelectrode distance $2.4 \mathrm{~mm}$ ) that were placed on the free walls of right and left atria. Electrograms were recorded with a custom-made 256 channel mapping amplifier (filtering bandwidth $0.1-408 \mathrm{~Hz}$, sampling rate $1 \mathrm{kHz}, \mathrm{A} / \mathrm{D}$ resolution 16 bits). The surface ECG was obtained from standard limb leads. 
PA-6 (2.5 mg kg-1) was infused over 10 minutes as a bolus, followed by continuous infusion $\left(0.04 \mathrm{mg} \mathrm{kg} \mathrm{min}^{-1}\right)$ for 50 minutes. Blood samples were taken at baseline before drug infusion, after the PA- 6 bolus administration ( $\mathrm{t}=10 \mathrm{~min}$ ), and at 15, 20, 30, 40, 60, 70 and 90 minutes after the start of infusion. Skeletal muscle biopsies from the left hind limb were taken at baseline (before the start of PA- 6 infusion), at end of the bolus administration, at 20 and 60 minutes after start of the infusion. Left ventricular (LV), right ventricular (RV), left atrial (LA) and right atrial (RA) tissues were harvested at the end of the experiment.

Surface ECG traces were analyzed using IDEE-Q software (Instrument Development Engineering and Evaluation, Maastricht University, Maastricht, The Netherlands). QRS, RR, QT(c) intervals were analyzed for 1 minute periods at baseline, directly following the start of administration of the bolus, directly prior to and after cardioversion. The heart ratecorrected QT $\left(\mathrm{QT}_{\mathrm{C}}\right)$ intervals were calculated by using the modified Bazett's formula $\mathrm{QTC}=\mathrm{QT} /$ (RR) ${ }^{0.6}$ according to Mohan et al..$^{34}$.

For periods of $1 \mathrm{~min}$, local atrial activation times were determined, and fibrillation waves were reconstructed using custom-made analysis software (MATLAB 8.1, The Mathworks, Inc., Natick, Massachusetts, USA) as described before ${ }^{35,36}$. AF complexity was quantified as the total number of waves and the number of breakthrough (BT) waves per AF cycle, mean wave size expressed as number of electrodes per wave, mean fractionation index defined as the ratio of subsidiary to dominant deflections, and the mean wave conduction velocity ${ }^{35-39}$. All parameters were assessed at baseline (before PA- 6 infusion), during the first minute of maintenance and during the last minute preceding cardioversion to sinus rhythm.

Atrial Fibrillation Cycle Length (AFCL) was calculated as median AFCL value during $60 \mathrm{sec}$ recordings for both atria independently, and was assessed at three time points during stabilization period as a baseline, for every other minute during PA- 6 infusion. The fifth percentile $(\mathrm{p} 5)$ of the $A F C L$ distribution was used as a surrogate parameter for the AERP during $\mathrm{AF}^{37}$.

\section{Dogs}

A total of ten adult mongrel dogs (7 females; $24.0 \pm 2.3 \mathrm{~kg} ; 2.6 \pm 0.5$ year; Marshall, New York, USA) were included in this study. Dogs were housed in pairs in conventional dog kennels (approx. $8 \mathrm{~m}^{2}$ ) containing wooden bedding material. Animals had access to water ad lib. and received dog food pellets twice a day. Cages were enriched with playing tools and animals were allowed to play in groups in an outdoor pen $\left(50 \mathrm{~m}^{2}\right)$ once a day. Dogs were checked for comfort and health every day, and body weight was established once a week. Dose finding was performed during four experiments in four normal sinus rhythm dogs. Yokoyama et al. ${ }^{40}$ infused pentamidine at $4 \mathrm{mg} / \mathrm{kg} / 40 \mathrm{~min}$ in anesthetized sinus rhythm dogs resulting in a QTc increase of approximately $8 \%$ at 40 min. Given the 11 -fold difference in $I_{K 1} I C_{50}$ values between pentamidine and PA- 6 in inside-out measurements ${ }^{28}$, we initially anticipated a PA- 6 dose between 0.5 and $2.5 \mathrm{mg} / \mathrm{kg}$ to be given in a period of 10-30 minutes that was subsequently adjusted to a time period of $10 \mathrm{~min}$. Arrhythmia inducibility by PA-6 and dofetilide was tested serially in nine CAVB dogs. AV block was induced by radiofrequency ablation, which methods were as described previously ${ }^{41}$. In cAVB dog experiments, the 
animal was paced from the right ventricular apex at $60 \mathrm{bpm}$. All dog experiments were performed under general anesthesia, which was induced with sodium pentobarbital ( $25 \mathrm{mg}$ $\mathrm{kg}^{-1}$ i.v.) and maintained by isoflurane (1.5\% in $\mathrm{O}_{2}: \mathrm{NO}_{2} 1: 2$ ). Premedication, pacing protocols and data analysis were as described previously ${ }^{41}$. ECG parameters, monophasic action potentials (MAP) from left and right ventricular endocardial sites were recorded.

PA-6 was dissolved in Milli-Q water and tested at two doses $\left(0.5 \mathrm{mg} \mathrm{kg}^{-1}\right.$ and $\left.2.5 \mathrm{mg} \mathrm{kg}^{-1}\right)$. Before administration of PA-6, 10 minutes baseline was recorded. A continuous infusion of the low dose of PA- $6\left(0.5 \mathrm{mg} \mathrm{kg}^{-1}\right)$ was given as a bolus during 10 minutes followed by an additional 20 minutes recording only period. Subsequently, the high dose of PA- 6 ( $2.5 \mathrm{mg}$ $\mathrm{kg}^{-1}$ ) was infused as a bolus over 10 minutes and recordings were continued for another 20 minutes. Blood samples were collected before, directly after infusion of PA- 6 , and every 5 minutes during the measurement periods. In sinus rhythm animals, awake ECG recordings were taken at regular intervals for up to 16 days. In cAVB dogs, dofetilide (Procter \& Gamble Pharmaceuticals) was applied at $0.025 \mathrm{mg} \mathrm{kg}^{-1} 5 \mathrm{~min}^{-1}$ and recordings were continued for another 20 minutes. When TdP arrhythmias were observed during the dofetilide infusion period, infusion was terminated immediately.

ECG data were recorded by the EPTracer program (Cardiotek,Maastricht,TheNetherlands). ECG parameters were quantified at baseline period and every 5 minutes after PA- 6 administration. For each time point, RR, PQ, QRS and QT intervals were averaged from 5 successive beats. LV and RV monophasic APD at $80 \%$ repolarization $\left(\mathrm{LV}_{\text {MAPD80 }}\right.$ and $\left.\mathrm{RV}_{\text {MAPD80 }}\right)$ were analyzed by MATLAB 8.3. Beat-to-beat variability of repolarization was quantified as short term variability (STV) from 30 consecutive $L_{\text {MAPD }}$ recordings according to the formula $\mathrm{STV}=\Sigma \mid \mathrm{D}_{\mathrm{n}+1}+\mathrm{D}_{\mathrm{n}}-2 \mathrm{D}_{\text {mean }} / /[30 \times \sqrt{2}]$.

\section{Dog cell isolation and patch clamp recordings}

Experiments were all performed in adult ventricular cardiomyocytes $(n=8)$ isolated from two CAVB dogs (see above) using rupture patch configuration as described earlier ${ }^{28}$. The isolation procedure has been already described previously ${ }^{42}$. Patch clamp data were acquired and analyzed with pCLAMP 10 software (Molecular Device, Sunnyvale, CA, USA).

\section{Tissue binding assays and UPLC-MS/MS analysis}

The binding of PA- 6 with both goat plasma and tissues were evaluated using rapid equilibrium dialysis devices (Thermo Scientific Pierce, Rockford, IL, USA) as previously described ${ }^{43}$. Thawed goat tissue samples were mixed with two volumes (vol/wt) of water (3-fold dilution) and homogenized. Blank (untreated) plasma and tissue samples were taken from baseline period. PA- 6 concentrations were determined as described below. For each sample, technical triplicates were used.

To prepare samples for ultra-performance liquid chromatography-tandem mass spectrometry (UPLC-MS/MS) analysis, plasma $(5 \mu \mathrm{l})$, tissue homogenate $(10 \mu \mathrm{l})$ or samples from tissue binding assays were mixed with $200 \mu \mathrm{l}$ of 7:1 (vol/vol) methanol-water containing $0.1 \%$ trifluoroacetic acid and internal standard ( $20 \mathrm{nM}$ pentamidine) and then vortex mixed for $30 \mathrm{~s}$, followed by centrifugation $(2,800 \times \mathrm{g}, 15 \mathrm{~min})$ to pellet precipitated proteins. The 
supernatants were dried using a 96-well microplate evaporator (Apricot Designs Inc., Covina, CA, USA) under $\mathrm{N}_{2}$ at $50^{\circ} \mathrm{C}$ and reconstituted with $150 \mu \mathrm{L} 15 \%$ methanol containing $0.1 \%$ trifluoroacetic acid before UPLC-MS/MS analysis.

The reconstituted samples ( $2 \mu \mathrm{l}$ injection volume) were analyzed for drug concentration using a Waters Xevo TQ-S triple quadrupole mass spectrometer (Foster City, CA, USA) coupled with a Waters Acquity UPLC I-Class system. Compounds were separated on a Waters UPLC BEH C $_{18}$ column $(2.1 \times 50 \mathrm{~mm}, 1.7 \mu \mathrm{m})$ equilibrated at $50^{\circ} \mathrm{C}$. UPLC mobile phases consisted of water containing $0.1 \%(\mathrm{v} / \mathrm{v})$ formic acid $(\mathrm{A})$ and methanol containing $0.1 \%(\mathrm{v} / \mathrm{v})$ formic acid (B). Analytical conditions for PA- 6 and pentamidine were the same as those previously described for diamidines ${ }^{44}$. The characteristic multiple reaction monitoring transitions for PA-6 were $m / z$ 492.3 $\longrightarrow 372.3$ (for quantification) and $492.3 \longrightarrow 196.1$ (for confirmation), and the characteristic single reaction monitoring transitions for pentamidine was $m / z 341.4$ $>120.1$, under positive electrospray ionization mode. The calibration curves for PA- 6 ranged from 0.005 to $50 \mu \mathrm{M}$ for plasma samples and from 0.1 to $100 \mu \mathrm{M}$ for tissue homogenates. The interday coefficient of variation and accuracy were within $\pm 15 \%$.

\section{Human atrial cardiomyocyte isolation and electrophysiological recordings}

Right atrial appendages were obtained from 12 patients with SR. Atrial cardiomyocytes were isolated using a standard protocol ${ }^{45}$, suspended in storage solution $(\mathrm{mM}: \mathrm{KCl} 20$, $\mathrm{KH}_{2} \mathrm{PO}_{4} 10$, glucose 10 , $\mathrm{K}$-glutamate 70 , $\beta$-hydroxybutyrate 10 , taurine 10 , EGTA 10 , albumin $1, \mathrm{pH}=7.4$ ) and investigated within 6 hours. Only well-striated, rod-shaped myocytes were used for current-recordings.

Membrane currents were measured with standard whole-cell voltage-clamp technique ${ }^{46,}$ ${ }^{47}$. Borosilicate glass microelectrodes had tip resistances of 2-5 $\mathrm{M} \Omega$ when filled with pipette solution (in mM: K-aspartate 80, $\mathrm{NaCl} 8, \mathrm{KCl} 40, \mathrm{Mg}$-ATP 5, EGTA 2, GTP-Tris 0.1, HEPES 10, $\mathrm{pH}=7.4$ ). Cardiomyocytes were superfused with a solution containing (in $\mathrm{mM}$ ): $\mathrm{NaCl} 120$, $\mathrm{KCl} 20, \mathrm{MgCl}_{2} 1, \mathrm{CaCl}_{2} 2$, glucose $10, \mathrm{HEPES} \mathrm{10,} \mathrm{pH}=7.4$ at $22-24^{\circ} \mathrm{C}$. Seal resistances were 4-8 $\mathrm{G} \Omega$. Series resistance and cell capacitance were compensated.

Drugs were applied via an additional rapid solution exchange system (ALA Scientific Instruments, Long Island, NY, USA). Data were not corrected for the calculated liquid junction potential (-12 mV, software JPCalc, version 2.2). To control for cardiomyocyte-size variability, the currents are expressed as densities (pA/pF).

\section{Statistics}

Groups were not randomized, and operators and data analysts were not blinded. Data were analyzed using GraphPad Prism version 6.00 for Windows (GraphPad Software, La Jolla California USA). For normally distributed data, a Student t test or ANOVA for paired samples with Tukey's HSD post-hoc or Bonferroni correction for multiple comparisons were used, while nonparametric data were analyzed using Wilcoxon rank-sum test and Friedman's test with Dunn's multiple comparison test. For human atrial cardiomyocytes differences between group means were compared by unpaired Student's $t$-test. Results are presented as mean \pm SD unless mentioned otherwise. Values of $p<0.05$ were considered 
significant. The data and statistical analysis comply with the recommendations on experimental design and analysis in pharmacology.

\section{Nomenclature of Targets and Ligands}

Key protein targets and ligands in this article are hyperlinked to corresponding entries in http://www.guidetopharmacology.org, the common portal for data from the IUPHAR/ BPS Guide to PHARMACOLOGY ${ }^{48}$, and are permanently archived in the Concise Guide to PHARMACOLOGY 2015/1649.

\section{Results}

\section{PA-6 in goat model of atrial fibrillation}

\section{Cardioversion success rate}

At 3 weeks after AF induction, 6 of the 8 goats (75.0\%) were in stable AF (not terminating spontaneously for $60 \mathrm{~min}$ ). Of these 6 goats, 5 animals cardioverted to SR during PA- 6 infusion at the end of bolus $\left(2.5 \mathrm{mg} \mathrm{kg}^{-1} 10 \mathrm{~min}^{-1}\right)$ or briefly thereafter during maintenance $\left(0.04 \mathrm{mg} \mathrm{kg}^{-1} \mathrm{~min}^{-1}\right)$ administration $(\mathrm{n}=5,83 \%$, Figure 1$)$, with a mean time to cardioversion of $13.2 \pm 4.9 \mathrm{~min}$ (6-19 $\mathrm{min})$. The other animal cardioverted 11 minutes after the end of PA-6 infusion (71 min from start of infusion). Compared to baseline, PA-6 prolonged RR and QT times following cardioversion but did not affect QRS duration in AF goats (Table 1).

In 2 SR goats, PA- 6 administration ( $2.5 \mathrm{mg} \mathrm{kg}^{-1} 10 \mathrm{~min}^{-1}$ ) tended to prolong QTc (349 vs. 432 ms for goat \#1 and 356 vs. 376 ms for goat \#2) and QRS width (59 vs. 71 ms and 59 vs. 69 $\mathrm{ms}$ ) at the end of infusion, but did not consistently affect RR duration (683 vs. $542 \mathrm{~ms}$ and 665 vs. $613 \mathrm{~ms})$.

Table 1. Electrophysiological parameters (in ms) in AF goats $(n=5)$ that cardioverted during PA-6 application

\begin{tabular}{lllll}
\hline & Baseline & Bolus (0-1 min) & Pre-conversion & Post-conversion \\
RR & $310 \pm 49$ & $323 \pm 40$ & $334 \pm 41$ & $583 \pm 75^{*}$ \\
QRS & $41 \pm 1$ & $40 \pm 3$ & $41 \pm 4$ & $40 \pm 2$ \\
QT & $241 \pm 33$ & $240 \pm 29$ & $257 \pm 30$ & $341 \pm 34^{*}$ \\
QTc & n.d. ${ }^{a}$ & n.d. ${ }^{\text {a }}$ & n.d. ${ }^{\text {a }}$ & $472 \pm 29$ \\
${ }^{*}$ P $<0.05$ vs. baseline & & & \\
aQTc correction cannot be derived in AF conditions & &
\end{tabular}


A

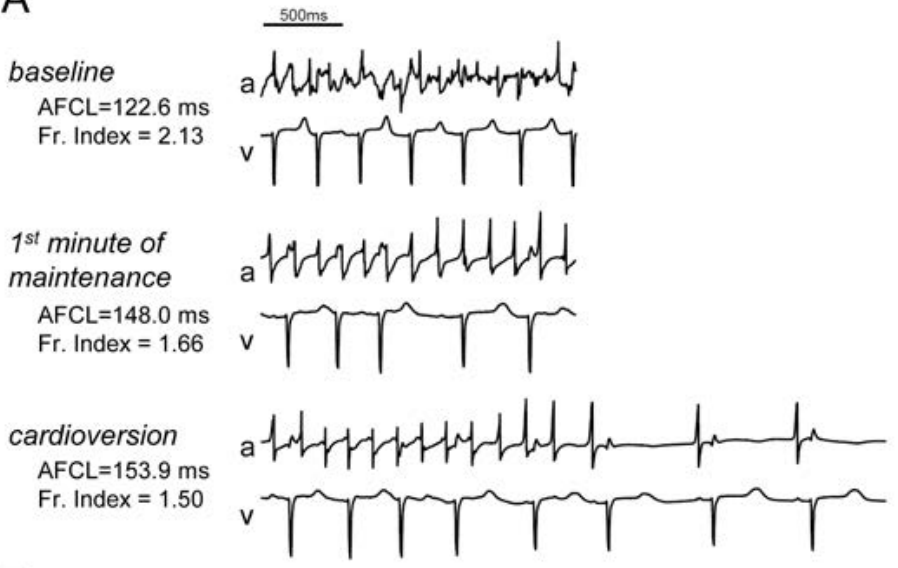

B

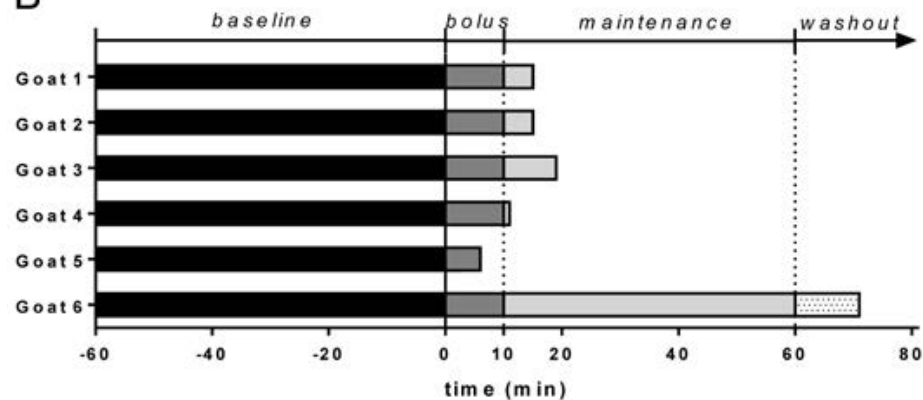

Figure 1. AF termination during PA-6 administration in goats with rapid pacing induced AF ( $n=6$ ). (A) Left atrial electrogram (a) and unipolar ventricular electrogram (v) recordings of goat \#1 goat demonstrating AF and irregular ventricular rhythm (baseline), decrease in AF complexity (1 ${ }^{\text {st }}$ minute of maintenance) and finally cardioversion resulting in SR (cardioversion). AFCL and Fractionation index for each stage are indicated. (B) The end of each bar represents the moment of cardioversion. Baseline: 60 minutes of stabilization period after turning off the pacemaker and preceding the start of the PA- 6 infusion; Bolus: administration of 2.5 mg.kg- PA-6 over 10min; Maintenance: administration of $0.04 \mathrm{mg} \mathrm{kg}^{-1} \mathrm{~min}^{-1} \mathrm{PA}-6$ over the next 50 minutes; Washout: washout period after the end of PA-6 infusion.

\section{PA-6 increases AFCL}

During PA-6 infusion, the AFCL gradually prolonged, as shown for two goats in Figure $2 \mathrm{~A}$ and $2 \mathrm{~B}$. The median $\mathrm{AFCL}$ was stable during stabilization period in all animals and significantly higher in the LA than in the RA (139 \pm 23 vs. $111.7 \pm 29 \mathrm{~ms} ; \mathrm{p}<0.05)$. The significant difference in AFCL between the atria remained throughout the whole protocol.

The largest increase in AFCL duration occurred during bolus infusion, and this prolongation was significant compared to baseline AFCL for both atria (LA: $139.0 \pm 23.2$ vs. $152.1 \pm 22.1$ ms, $p<0.05 ; R A: 111.7 \pm 29.1$ vs. $129.5 \pm 26.6 \mathrm{~ms}, \mathrm{p}<0.05$, respectively). After infusion of the PA- 6 bolus, the AFCL did not show a significant further increase during the maintenance period (Figure $2 \mathrm{C}$ ). The prolongation of $\mathrm{AFCL}$ was somewhat more pronounced in the RA, but the difference in AFCL prolongation between the atria was not significant (Figure 2D). 
P5 AFCL values, a surrogate marker for the refractory period, also had significantly lower baseline values in the RA compared to LA $(74.0 \pm 4.6$ vs. $96.9 \pm 13.0 \mathrm{~ms}, \mathrm{p}<0.05)$, and this difference became more pronounced after drug administration (Figure 2E). However, the relative increases in $\mathrm{p} 5$ of the AFCL caused by PA- 6 were not significantly different between LA and RA (Figure 2F).
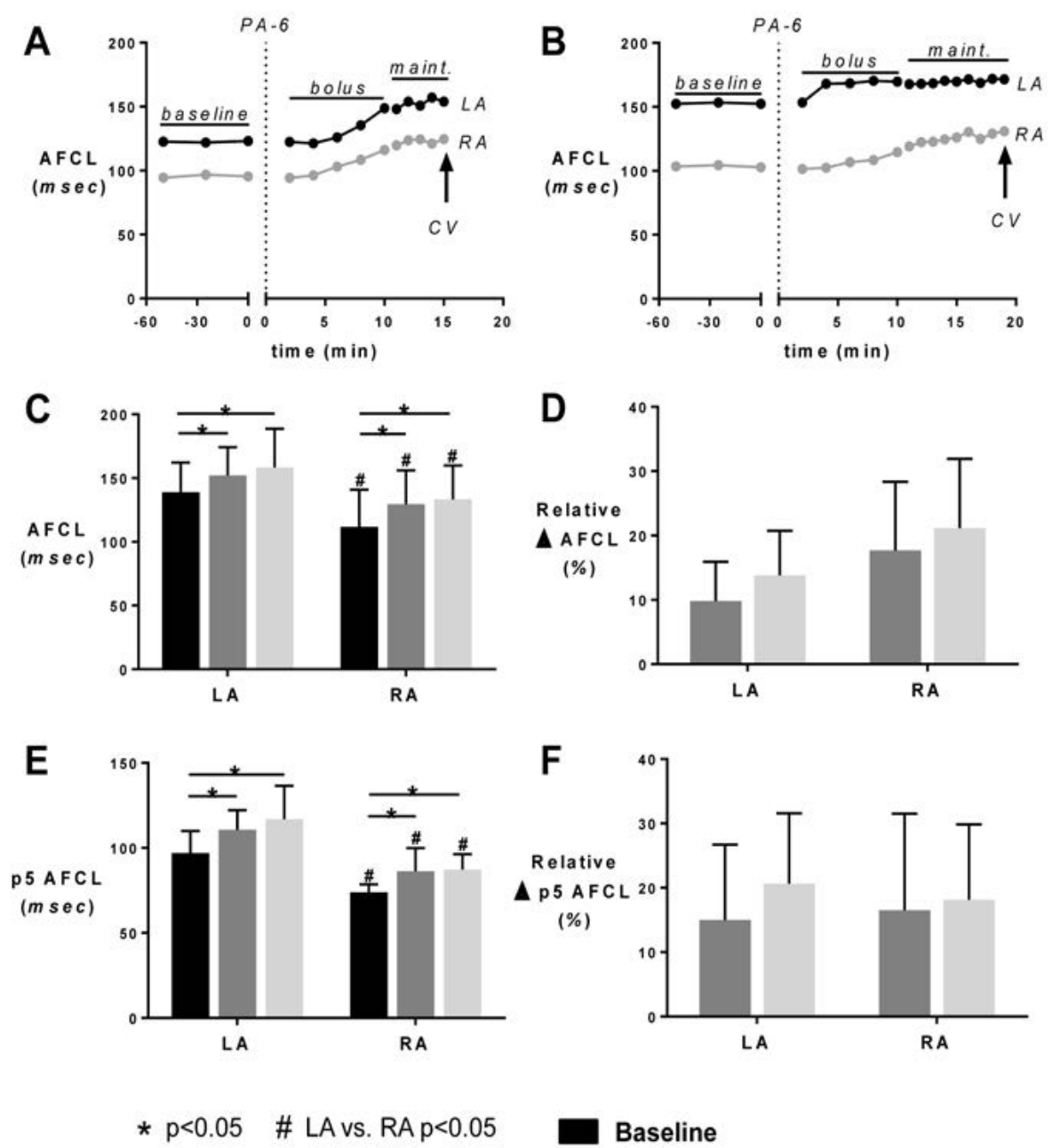

\section{Baseline}

First minute of maintenance dose

\section{Last minute preceding cardioversion}

Figure 2. PA-6 lengthens the AFCL. (A,B) Time course for AFCL in both atria during PA-6 infusion until the moment of cardioversion to SR in two goats. CV: cardioversion to SR. (C) AFCL for the LA and RA, (D) relative change in AFCL, (E) $\mathrm{p} 5$ of the AFCL. (F) Relative change of $\mathrm{p} 5$ of the AFCL. All parameters were calculated for the baseline (blsn), the first minute of maintenance period (Maint. Start), and the last minute preceding cardioversion (Pre CV). ${ }^{*} p<0.05$. Data for $n=5$ goats displaying cardioversion are depicted 


\section{PA-6 decreases the complexity of AF}

Representative wave maps of three consecutive beats of AF at baseline, during the first minute of maintenance and during the last minute preceding cardioversion are presented in the Figure 3A (Left panel). These wave maps show the number of waves, the origin of waves (peripheral or breakthrough) and the size of waves. PA-6 infusion decreased the number of (peripheral and breakthrough) waves, while simultaneously increasing wave size. The right panel of Figure 3A illustrates the concomitant decrease in fractionation index during PA-6 infusion.

The parameters related to AF pattern and complexity confirm that PA- 6 decreased AF complexity equally in both atria, by reducing the total number of fibrillation waves and the number of BT waves per AF cycle (Figure $3 \mathrm{~B}$ and C). This was associated with an increase in wave size (Figure 3D) and a decrease in mean fractionation index (Figure 3E). However, the conduction velocity of fibrillation waves was not affected by PA-6 (Figure 3F). The decrease in AF complexity was comparable in both atria. A tendency toward organization of AF was present already during the first minute of PA- 6 maintenance, and a significant difference compared to baseline values was present during the last minute preceding the cardioversion.

\section{PA-6 lengthens QTc in dogs but does not induce TdP arrhythmias}

In sinus rhythm dogs, PA- 6 infused at a dose of either 0.5 or $2.5 \mathrm{mg}^{\mathrm{kg}} \mathrm{kg}^{-1} 10 \mathrm{~min}^{-1}$, did not cause significant effects on RR, PQ, QRS, QTC and LV $_{\text {MAPD80 }}$ duration, nor on the proarrhythmic marker STV as determined on the $\mathrm{LV}_{\text {MAP }}\left(\mathrm{STV}_{\text {LVMAPD80 }}\right)$ (Table 2, Supplementary Figure S1).

In isolated ventricular cardiomyocytes from cAVB dogs, 200 nM PA-6 inhibited both inward and outward $I_{\mathrm{K} 1}$ (Figure 4A). In CAVB dogs, PA-6 administration at $2.5 \mathrm{mg} \cdot \mathrm{kg}^{-1} 10 \mathrm{~min}^{-1}$ did not significantly alter QRS or STV, but prolonged QTC and LV ${ }_{\text {MAPD80 }}$ durations (Table 2, supplementary Figure S2). PA-6 did not induce TdP arrhythmias in 9 CAVB dogs (Figure 4B and D). In contrast, the $\mathrm{I}_{\mathrm{Kr}}$ blocker dofetilide induced TdP arrhythmias in 5 dogs using the same set of 9 animals (Figure 4C and D). Furthermore, dofetilide resulted in more pronounced QTC and LV ${ }_{\text {MAPD80 }}$ prolongation than PA-6 (Table 2).

Table 2. Electrophysiological parameters (in ms) in sinus rhythm and CAVB dogs in control conditions and upon drug application

\begin{tabular}{|c|c|c|c|c|c|c|}
\hline & \multicolumn{2}{|c|}{ Sinus Rhythm ( $n=4)$} & \multicolumn{2}{|c|}{ CAVB $(n=9)$} & \multicolumn{2}{|c|}{ CAVB $(n=9)$} \\
\hline & Baseline & PA-6 & Baseline & PA-6 & Baseline & Dofetilide \\
\hline $\mathrm{RR}^{\mathrm{a}}$ & $601 \pm 54$ & $605 \pm 55$ & 1000 & 1000 & 1000 & 1000 \\
\hline $\mathrm{PQ}^{\mathrm{b}}$ & $129 \pm 20$ & $125 \pm 18$ & n.a. & n.a. & n.a. & n.a. \\
\hline QRS & $75 \pm 5$ & $75 \pm 4$ & $117 \pm 9$ & $118 \pm 8$ & $115 \pm 10$ & $115 \pm 11$ \\
\hline QTC & $306 \pm 21$ & $326 \pm 16$ & $384 \pm 40$ & $465 \pm 89 *$ & $381 \pm 26$ & $600 \pm 33^{*}$ \\
\hline STV & $0.29 \pm 0.02$ & $0.39 \pm 0.17$ & $0.60 \pm 0.22$ & $1.20 \pm 0.68$ & $0.77 \pm 0.23$ & $1.82 \pm 0.88$ \\
\hline $\mathrm{LV}_{\text {MAPD80 }}$ & $197 \pm 21$ & $216 \pm 28$ & $236 \pm 20$ & $285 \pm 52 *$ & $249 \pm 18$ & $400 \pm 64^{*}$ \\
\hline
\end{tabular}


A

Baseline
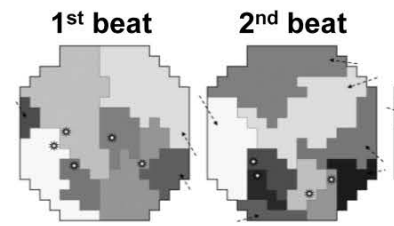

$3^{\text {rd }}$ beat

Fractionation index (Fi)

Baseline

First minute of maintenance
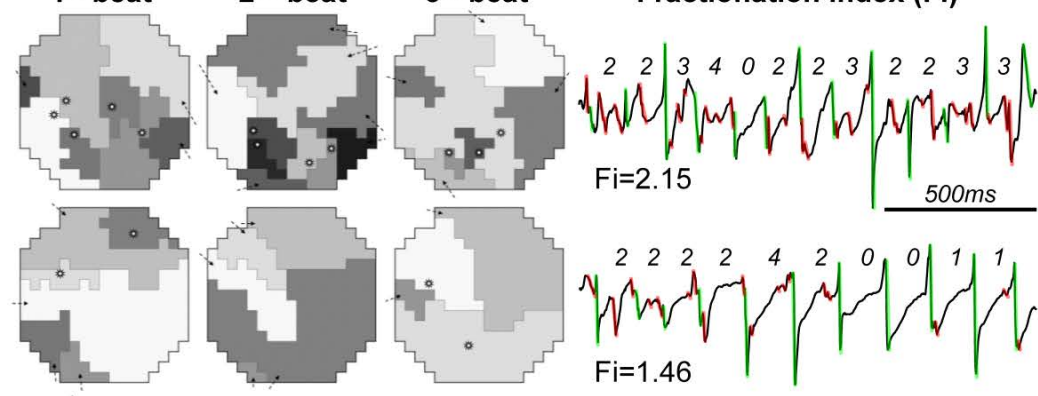

$\mathrm{Fi}=2.15$

$500 \mathrm{~ms}$
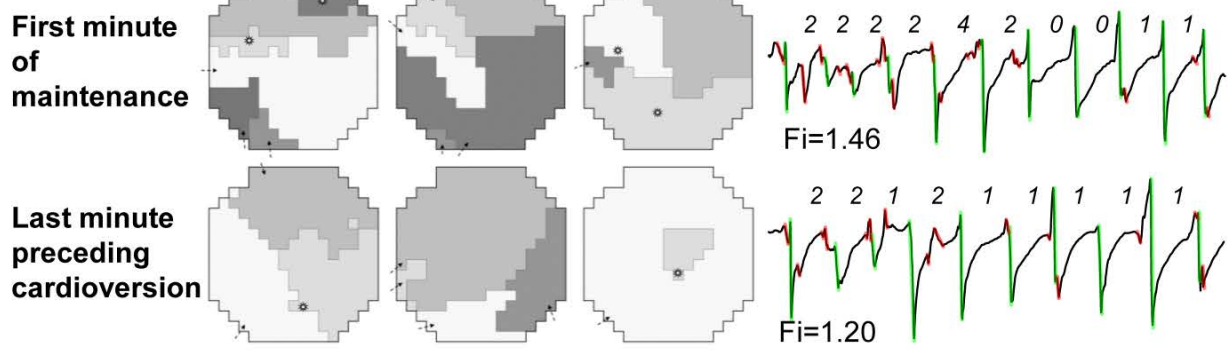

\section{$\mathrm{Fi}=1.46$}

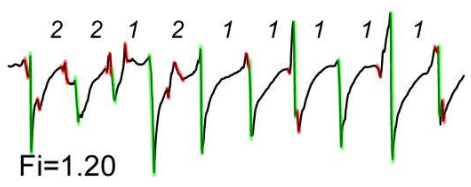

.... Peripheral wave

Breakthrough wave

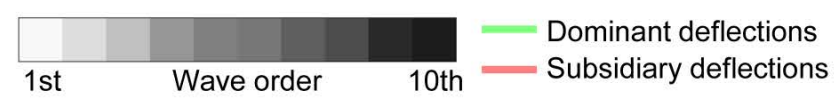

B

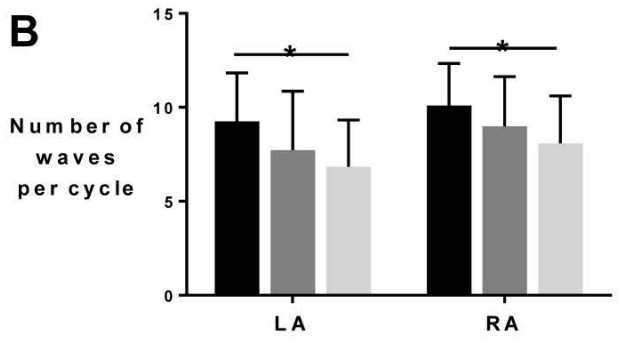

D

D
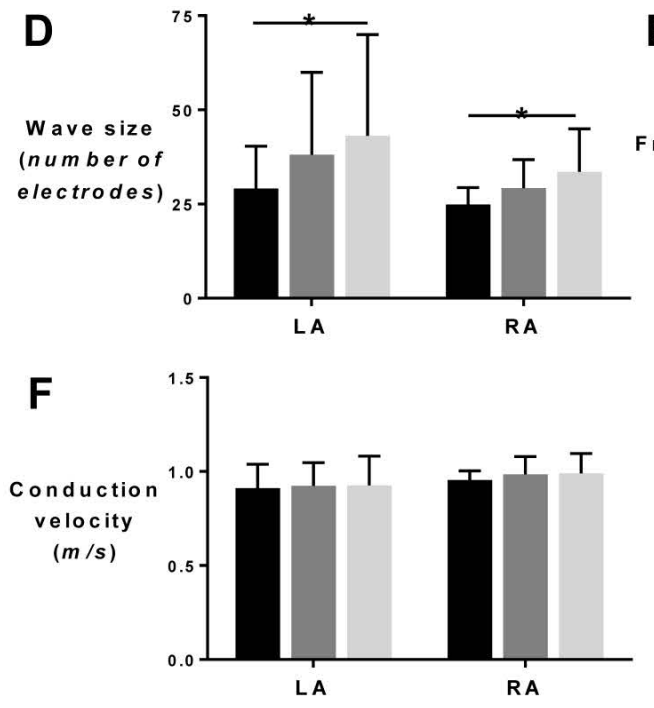

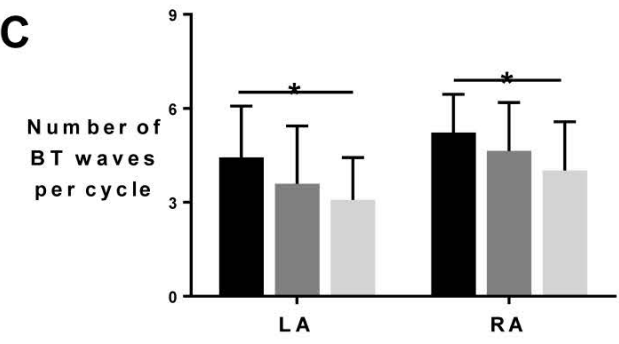

E

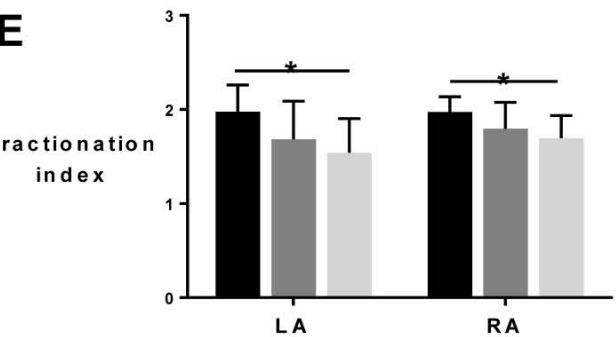

* $p \leq 0.05$

Baseline

First minute of maintenance dose

Last minute preceding cardioversion 
Figure 3. PA-6 decreases the complexity of atrial fibrillation for LA and RA. (A) Fibrillation patterns. Wave maps of three consecutive AF beats at baseline, at the first minute of maintenance and at the last minute preceding cardioversion (Left panel) reconstructed based on the mapping data acquired with LA spoon electrode ( $\varnothing 4 \mathrm{~cm}, 247$ electrodes, interelectrode distance $2.4 \mathrm{~mm}$ ). Wave maps depict the total number of waves, origin of the waves (peripheral and breakthrough), wave size and wave order. The right panel depicts the calculation method of the unipolar fractionation indexes at one electrode for three different time points according to dominant activations. The fractionation index is calculated as the ratio between the number of dominant (green) and subsidiary (red) deflections. (B) Total number of waves per cycle, (C) number of epicardial breakthrough waves per cycle, (D) wave size expressed as mean number of electrodes assigned to one wave, (E) fractionation index (mean values of ratios of remote to local deflections per electrode), (F) mean conduction velocity for each electrode. Data for $\mathrm{n}=5$ goats displaying cardioversion are depicted in panel $B-F$.
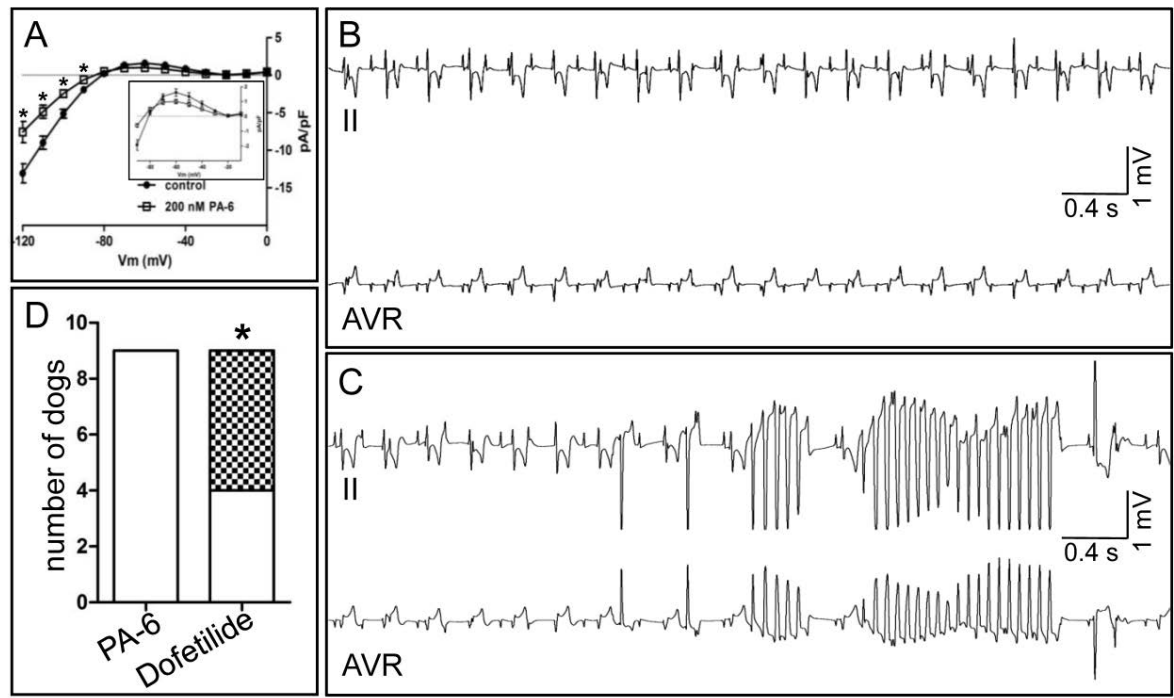

Figure 4. Absence of pro-arrhythmia upon PA-6 application in cAVB dogs. $(A) I_{\mathrm{K} 1}$ current-voltage relationships from isolated ventricular cAVB cardiomyocytes $(n=8)$ for control (closed circles) and $200 \mathrm{nM}$ PA-6 (open squares) treatment. Inset: enlargements of currents from -90 to $-10 \mathrm{mV}$. (B) Electrocardiogram (leads II and AVR) displaying normal paced CAVB rhythm following PA-6 (2.5 mg.kg-1 $\left.10 \mathrm{~min}^{-1}\right)$ application. (C) Electrocardiogram (leads II and AVR) from the same animal as in panel A, showing TdP arrhythmia episode following dofetilide ( $25 \mathrm{mg}^{\mathrm{kg}} \mathrm{kg}^{-1} 5 \mathrm{~min}$ $\left.{ }^{1}\right)$ application. (D) Quantification of TdP arrhythmias in 9 CAVB animals tested serially with dofetilide and PA-6 (in random order). Non-filled: normal CAVB rhythm, checkered pattern: TdP arrhythmia inducible (3 or more TdP arrhythmias). ${ }^{*} \mathrm{p}<0.05$.

\section{PA-6 pharmacokinetics in goats and dogs}

Figure 5 A provides PA- 6 plasma profile in AF goats. $C_{\max }(6.7 \pm 1.3 \mu \mathrm{M})$ was obtained at the end of the bolus. During maintenance infusion, plasma PA- 6 concentrations gradually dropped $(1.7 \pm 0.5 \mu \mathrm{M})$. Thirty minutes following the end of maintenance infusion, PA- 6 
plasma levels were $(0.5 \pm 0.2 \mu \mathrm{M})$. Goat plasma spiked with PA- 6 at $0.5,1,5$ and $50 \mu \mathrm{M}$ resulted in a PA-6 unbound fraction of $0.59 \pm 0.06 \%$ (3.0 nM), 0.67 $\pm 0.14 \%(6.7 \mathrm{nM}), 1.54 \pm 0.35 \%$ (77 $\mathrm{nM})$ and $7.41 \pm 0.54 \%(3.7 \mu \mathrm{M})$, respectively. During the experiment, skeletal muscle PA-6 levels increased to $3.6 \mu \mathrm{M}$. Atrial and ventricular PA- 6 concentrations were approximately 8 and 21 fold higher, respectively (Table 3 ).

PA- 6 administration to SR $(n=2)$ and $C A V B(n=2)$ dogs at the low and high dose resulted in a two peaked PA-6 plasma profile (Figure $5 B$ ). $C_{\max }$ at low dose was $0.41 \pm 0.18$ and $0.47 \pm 0.17 \mu \mathrm{M}$ for SR and CAVB respectively, whereas $C_{\max }$ at the high dose was $5.75 \pm 1.30$ and $5.33 \pm 0.63 \mu \mathrm{M}$, respectively. Thirty minutes following start of administration of the high dose, PA-6 plasma concentration of $0.30 \pm 0.12$ and $0.44 \pm 0.32 \mu \mathrm{M}$ were achieved for $\mathrm{SR}$ and CAVB dogs respectively.

Follow-up QTc measurements in awake CAVB dogs for more than two weeks after PA-6 administration at the high dose indicated absence of QTC changes when compared to predosing, either at idioventricular rhythm, nor when paced from the right ventricle at 1 $\mathrm{Hz}$ (Figure 6). Therefore, the observed QTc prolongation during the experiment $(\mathrm{t}=30 \mathrm{~min}$ ) (Table 2, Supplemental Figure S2) was not persistent during follow up, suggesting rapid clearance from cardiac tissue.

Table 3. PA-6 tissue concentrations $(\mu \mathrm{M})$ after start of infusion

\begin{tabular}{llll}
\hline Tissue & $\mathbf{1 0}$ minutes & $\mathbf{2 0}$ minutes & $\mathbf{6 0}$ minutes \\
Skeletal Muscle & $23.2 \pm 2$ & $2.6 \pm 1$ & $3.6 \pm 2$ \\
Right Ventricle & n.a. & n.a. & $78 \pm 14$ \\
Left ventricle & n.a. & n.a. & $70 \pm 21$ \\
Right Atrium & n.a. & n.a. & $29 \pm 4$ \\
Left Atrium & n.a. & n.a. & $30 \pm 6$
\end{tabular}


A

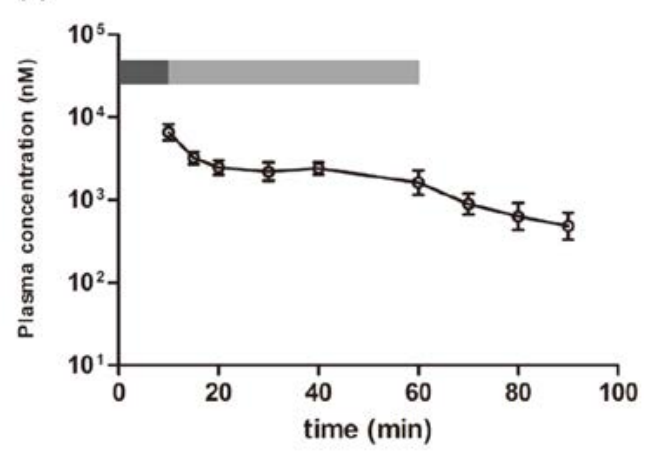

B
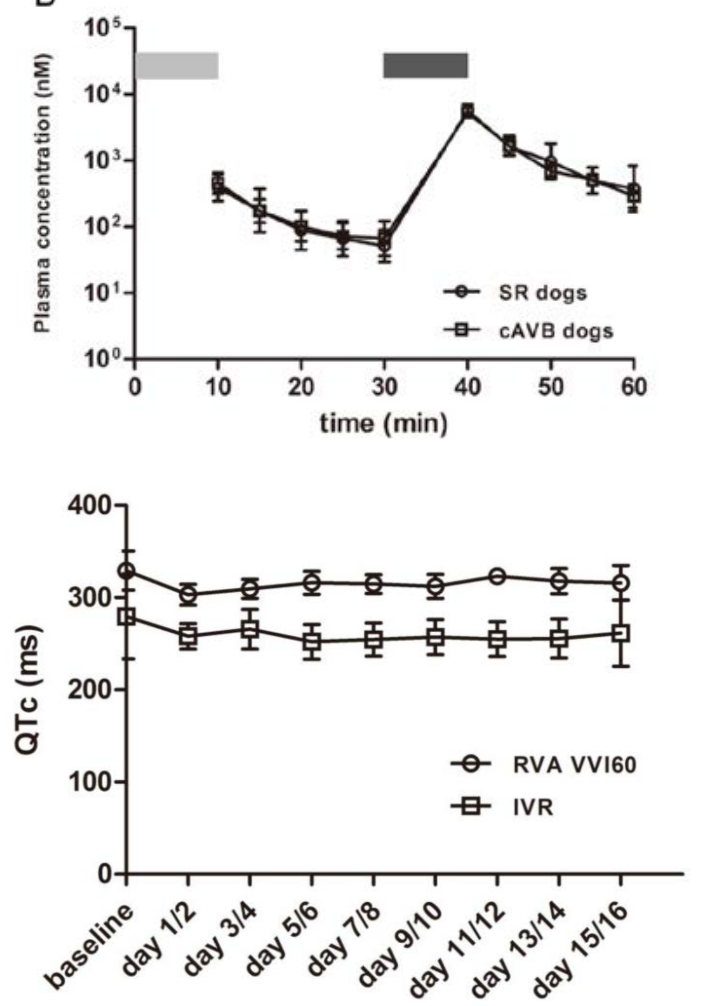

Figure 5. PA-6 plasma concentrations in AF goats and CAVB dogs. (A) PA-6 plasma concentrations $(\mathrm{nM})$ in cardioverted AF goats $(\mathrm{n}=5)$ following PA-6 infusion (0-10 min bolus (2.5 mg.kg-1 $10 \mathrm{~min}^{-1}$, dark gray bar), 10-60 min maintenance $\left(0.04 \mathrm{mg}^{\mathrm{kg}}{ }^{-1} \mathrm{~min}^{-1}\right.$, light grey bar), 60-90 min (washout)). (B) PA-6 plasma concentrations in SR $(n=2)$ and CAVB dogs $(n=2)$ following a low dose (0-10 min. $\left(0.5\right.$ mg. $\mathrm{kg}^{-1}$ $10 \mathrm{~min}^{-1}$, light gray bar)) and a high dose (30$40 \mathrm{~min} 2.5 \mathrm{mg}^{\mathrm{kg}}{ }^{-1} 10 \mathrm{~min}^{-1}$, dark grey bar)) bolus. Washout between 10-30 and 40-60 min, respectively.

Figure 6. Absence of chronic QTC interval prolongation in CAVB dogs $(n=9)$ upon 16 days post-infusion. ECG recordings were taken in awake animals during idioventricular rhythm (IVR) or right ventricular apex pacing at $1 \mathrm{~Hz}$ (RVA VVI60). 


\section{PA-6 inhibits basal $\mathrm{I}_{\mathrm{K} 1}$ in human atrial cardiomyocytes}

Typical current traces and current amplitudes at $-100 \mathrm{mV}$ in the time course of an experiment are shown in Figure 7A,B. Cell capacitances averaged 107.0 $17.2 \mathrm{pF}(\mathrm{n}=26)$. Agonist-independent basal current was measured by applying a depolarizing ramp pulse from -100 to $+40 \mathrm{mV}$ (holding potential $-80 \mathrm{mV} ; 112[\mathrm{mV} / \mathrm{s}$ ]; see inset in Figure 7A and C). $\mathrm{Ba}^{2+}(1 \mathrm{mM})$ was applied at the end of each experiments in each cardiomyocyte and the inward rectifier $\mathrm{K}^{+}$currents were analyzed after subtraction of the resulting leak currents.

Application of $2 \mu \mathrm{M}$ carbachol (CCh) resulted in rapid initial increase („Peak") of $\mathrm{I}_{\mathrm{K}, \mathrm{ACh}}$ amplitude followed by a decrease to a quasi-steady-state level („QSS“) despite continuous presence of CCh ("desensitisation ${ }^{446}$, Figure 7B). I K,ACh $_{\text {, }}$ was defined as the CCh-sensitive current increase ${ }^{46,50}$. PA-6 (200 nM) was applied after 1 minute washout of CCh and resulted in an immediate and maintained block of IK1 (Figure 7B and D). CCh $(2 \mu \mathrm{M})$ was applied a second time with the first (S1) application serving as internal control, the second (S2) being measured in the presence of PA-6 (Figure 7A). $I_{K, A C h}$ was smaller during $S 2$ than $S 1$ suggesting incomplete recovery from desensitization, but the degrees of $I_{K, A C h}$ desensitization, expressed as S2/S1 ratio, were similar in PA-6 experiments and in timematched controls (Figure 7B and E).

A
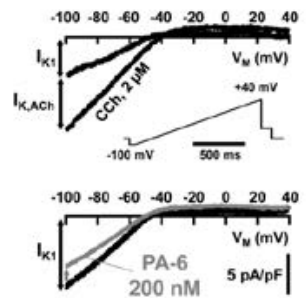

C

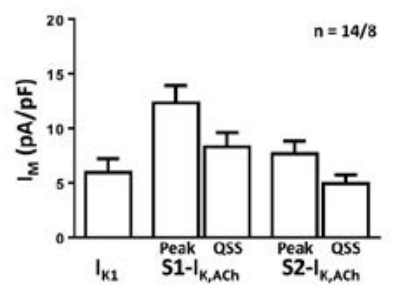

B
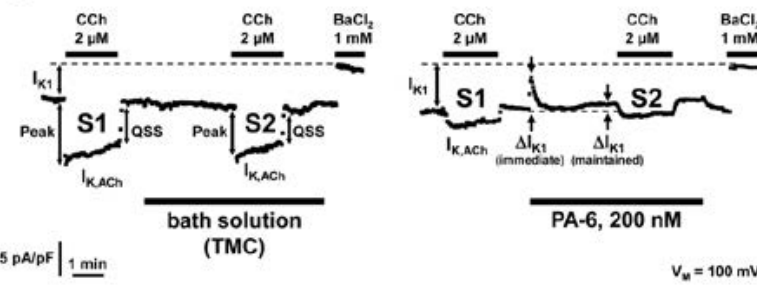

E

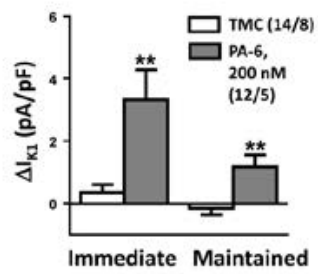

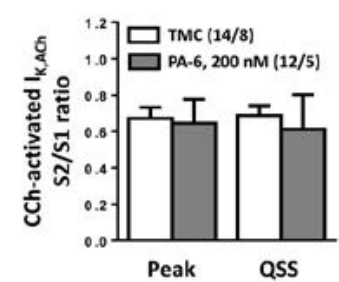

Figure 7. Effect of PA-6 (200 nM) on inward rectifier $\mathrm{K}^{+}$currents in human atrial cardiomyocytes. (A) Original recording of basal current with response to $2 \mu \mathrm{M}$ carbachol (upper panel, $\mathrm{I}_{\mathrm{K}, \mathrm{ACh}}$ was defined as $\mathrm{CCh}$-sensitive current) and response to $200 \mathrm{nM}$ PA-6 (lower panel). (B) Time course of $I_{\mathrm{K} 1}$ and $I_{\mathrm{K}, \mathrm{ACh}}$ during 2 successive CCh applications (S1, S2, 4 minutes apart). During activation the initial increase („Peak“) of $I_{K, A C h}$ faded (,rapid desensitization") to a quasi-steady-state level ("QSS"). PA-6 (200 nM) was applied 1 minute after the first CCh application (right panel) and compared to application of bath solution only (left panel, time-matched controls, TMC). (C) Basal current and CCh-activated I $I_{K, A C h}$ at "Peak" and "QSS". (D, E) Effects of PA-6 (200 nM) on basal current and on the S2/S1 ratio of $\mathrm{I}_{K, A C h}$ at "Peak" and "QSS". Data are expressed as mean \pm SEM. ${ }^{*} \mathrm{P}<0.05$ vs. corresponding TMC values. Numbers indicate cardiomyocytes/patients. 


\section{Discussion}

Here we demonstrated, by using two established large animal models for efficacy and safety testing, the validity of $\mathrm{I}_{\mathrm{K} 1}$ as a safe drug target in AF therapy. We showed that the specific $I_{K 1}$ inhibitor PA- 6 is indeed able to inhibit AF in a goat model of pacing induced AF. Our results demonstrate that cardioversion is preceded by prolongation of AF cycle length and an increase in atrial refractoriness, and a concomitant decrease in AF complexity. The conduction velocity of atrial fibrillation waves was not affected.

Among the many changes that occur during AF progression, increases in $\mathrm{K}_{\mathrm{ir}} 2.1$ function, protein and mRNA expression were found in several studies comparing AF patients of different etiology with matched controls ${ }^{51}$. For this reason, pharmacological inhibition of $\mathrm{I}_{\mathrm{K} 1}$ was suggested as a new treatment option ${ }^{26,52}$, although the potential side effects of neurologic, ventricular-, skeletal- and smooth-muscle related complications may have hampered development of specific $\mathrm{I}_{\mathrm{K} 1}$ inhibiting compounds for this purpose.

In Langendorff perfused sheep heart, chloroquine, which inhibits IK1 $\left(\mathrm{IC}_{50}=0.69 \mu \mathrm{M}\right)$, $\mathrm{I}_{\text {KACh }}\left(\mathrm{IC}_{50}=0.38 \mu \mathrm{M}\right)$, and $\mathrm{I}_{\text {KATP }}\left(\mathrm{IC}_{50}=0.51 \mu \mathrm{M}\right)$ channels, terminated stretch-induced $\mathrm{AF}$ at concentrations between 1 and $4 \mu M^{53}$, and cholinergically induced $A F$ at $10 \mu M^{54}$. The authors reported that chloroquine decreased AF frequency and the number of breakthrough waves just before AF termination, similar as in our in vivo PA-6 experiments in goats. We show that PA- 6 increases the AFCL and AERP (as evidenced by the surrogate parameter of the $\mathrm{p} 5$ of the AFCL histogram ${ }^{37}$. The decrease in the total number of waves and breakthrough waves per AF cycle as well as an increase in the size of fibrillation waves indicate that PA- 6 makes the fibrillation pattern more simple. Previously, we showed that progressive atrial electrical and structural remodeling make the fibrillation pattern more complex and thereby make AF more stable ${ }^{33,38,55}$. Conversely, a decrease in AF complexity, as observed during PA- 6 infusion, would make AF less stable and therefore AF termination more likely.

$\mathrm{I}_{\mathrm{K} 1}$ may have a pivotal role in rotor stability ${ }^{56,57}$ and we would expect that PA- 6 impairs rotor stability. We have not observed stable rotors in the mapped atrial regions. However, rotors may have been present outside our field of view, such as the posterior left atrium, which in the goat is not accessible for epicardial mapping. Nevertheless, our results are fully compatible with a decrease in rotor stability with $\mathrm{I}_{\mathrm{K} 1}$ blockade. With decreased rotor stability and frequency, break-up into 'daughter waves ${ }^{\prime 58}$ and therefore the complexity of fibrillatory patterns at more distant sites would also be reduced. Therefore, irrespective of the mechanism responsible for AF maintenance, multiple wavelets or rotors with 'daughter waves', the decrease in AF complexity would be related to a decrease in AF stability.

Class IC and III anti-arrhythmic drugs were evaluated earlier in the same goat model used here. In general, Class IC blockers primarily cause a reduction in conduction velocity, whereas class III inhibitors increase AERP, but all drugs that can successfully terminate AF reduce the complexity of $A F$, regardless of the observed prolongation in $A F C L$. Following three to four weeks of pacing induced persistent $A F$, cibenzoline resulted in cardioversion 
rates of $78 \%{ }^{59}$, Flecainide in $33 \%$ and $67 \%{ }^{59}, 60, \mathrm{~d}$-Sotalol in $92 \%{ }^{60}$, and the combination of AVE0118+Dofetilide in 100\% ${ }^{61}$. PA-6 administration, at similar times following AF induction, resulted in a cardioversion rate of $83 \%$ and thereby performs better than Flecainide, comparable to cibenzoline and combined AVE0118+dofetilide application, but less efficient than d-sotalol. Direct comparison of these drugs, even in the same animal model, is not straightforward, because of the different dosages used. However, all studies used up to the highest tolerated dose and had similar safety endpoints with respect to QRS duration and ventricular proarrhythmia. Importantly, the efficacy of cardioversion of a particular drug can be species-specific. For example, although d-sotalol was highly successful in restoring SR in goats, it was less effective than flecainide in humans and therefore is not used in clinical practice for pharmacological cardioversions ${ }^{62,63}$.

The present study reflects an early point in the development of AF induced remodeling. A decrease of cardioversion rate upon AF progression in the AF goat model, measured in awake goats, was observed for flecainide $(60 \%, 33 \%, 33 \%$ and $17 \%$ at $1,4,8$ and 16 weeks of $\mathrm{AF}$, respectively), cibenzoline $(80 \%, 78 \%, 67 \%$ and $63 \%$ at $1,4,8$ and 16 weeks of $\mathrm{AF}$, respectively $)^{59}$, and AVE0118+dofetilide $(80 \%, 33 \%, 50 \%, 0 \%, 0 \%$ and $0 \%$ at $1,2,3,4,5$ and 6 months of AF, respectively) ${ }^{33}$. Follow-up studies with PA- 6 are required to determine efficacy at later time points during AF-induced remodeling.

We used the CAVB dog to investigate the potential pro-arrhythmic actions of PA- 6 . Previously, we used this model to investigate the pro-arrhythmic and antiarrhythmic actions of various clinical drugs and experimental compounds, including anti-AF drugs $^{30,41,64-66}$. This is the first study that investigates specific $I_{K 1}$ inhibition in this model. In sinus rhythm animals, no reduction in conduction velocity was evidenced by either PQ or QRS interval changes, whereas QTc prolongation was less than 7\%. The CAVB dog, with its compromised repolarization reserve (Oros et al., 2008), showed a more severe QTc prolongation (21\%), whereas also here ventricular activation (QRS width) was not impaired. Moreover, no pro-arrhythmia was observed in contrast to dofetilide application in the serially tested animals. $I_{\mathrm{K} 1}$ inhibition was proposed to be pro-arrhythmic ${ }^{67}$.This view is mainly based on experiments in which $\mathrm{BaCl}_{2}$ was applied to small and large animal models. As argued by us earlier, specific inhibition of $\mathrm{I}_{\mathrm{K} 1}$ by $\mathrm{BaCl}_{2}$ is not pro-arrhythmic and has only minor effects on the resting membrane potential in various animal models and isolated tissues ${ }^{6}$. Only at higher concentrations of $\mathrm{BaCl}_{2}(>10 \mu \mathrm{M})$, when $\mathrm{I}_{\mathrm{K}, \mathrm{Ach}}$ and $\mathrm{I}_{\mathrm{K}, \mathrm{ATP}}$ channels become affected also, resting membrane depolarization and arrhythmic events become evident. In classical experiments performed by Roza and Berman ${ }^{68}$, infusion of 1 mmol kg- min- $^{-1}$ of $\mathrm{BaCl}_{2}$ in normal dogs under anesthesia resulted in a course of events that eventually resulted in hypotension, flaccid paralysis of skeletal muscles, ventricular tachycardia and fibrillation. Finally, hypokalemia occurred, most likely resulting from an extra-intracellular potassium shift. These findings strongly reflect the course seen in barium poisoning cases in $\operatorname{man}^{69}$. Interestingly, potassium administration to dogs counteracted most of the clinical signs ${ }^{68}$. No serum potassium levels were measured in our canine experiments, although we expect these to be low already as previously studies demonstrated serum potassium concentrations of $2.8 \mathrm{mM}$ in the experimental setting of the $C A V B$ dogs ${ }^{66}$. 
It cannot be excluded that the effects of PA- 6 are species dependent, but when we compare PA- 6 mediated block between human and white bream (fish) $\mathrm{K}_{\mathrm{ir}} 2.1$, that share 82.9\% sequence identity at the protein level, no differences in blockade were obtained (Supplementary Figure S3). Amino acid sequence identities for $\mathrm{K}_{\mathrm{ir}} 2.1, \mathrm{~K}_{\mathrm{ir}} 2.2$ and $\mathrm{K}_{\mathrm{ir}} 2.3$ between human, dog and goat are significantly higher (95-99\%) (Supplementary Figure S4). As demonstrated before, PA- 6 sensitivity for $\mathrm{K}_{\mathrm{ir}} 2.1, \mathrm{~K}_{\mathrm{ir}} 2.2$ and $\mathrm{K}_{\mathrm{ir}} 2.3$ are similar ${ }^{28}$. For these reasons, we do not anticipate that channel differences due to isoform expression alterations or sequence variation between species would affect outcome. However, species dependent differences in $\mathrm{I}_{\mathrm{K} 1}$ density may have an impact on pro- and antiarrhythmic effects. In a direct comparison, ventricular $\mathrm{I}_{\mathrm{K} 1}$ density in canine ventricular cells is two- to three-fold higher than in human ventricular cardiomyocytes ${ }^{70}$ which may increase the sensitivity of the human ventricle for $I_{\mathrm{K} 1}$ inhibition compared to dog. Furthermore, $I_{\mathrm{K} 1}$ densities found in the atrium are ten-fold ${ }^{3}$ or five-fold ${ }^{4}$ lower than in the ventricle of dogs and humans respectively, which may provide a safety margin for antiarrhythmic $\mathrm{I}_{\mathrm{K} 1}$ inhibition in the atrium and pro-arrhythmic activity in the ventricle. Finally, we provided evidence that also human atrial $\mathrm{I}_{\mathrm{K} 1}$ is a target for PA-6. For the goat, $\mathrm{K}_{\mathrm{ir}} 2 . \mathrm{x}$ isoform expression data and accompanying $\mathrm{I}_{\mathrm{K} 1}$ densities are currently not available and deserves further attention.

Recently, the effects of PA-6 application to Langendorff perfused rat hearts were reported $^{71}$. In contrast to our findings, no lengthening of the atrial ERP was observed. The authors observed prolongation of the ventricular AP and ventricular fibrillation occurred in two out of six hearts assessed. Several factors may explain the differences between our findings and those of Skarsfeldt et al. ${ }^{71}$. The relative contribution of $\mathrm{I}_{\mathrm{K} 1}$ to atrial and ventricular repolarization and resting membrane potential stability is likely to differ between murine and many other animal models, as well as its blockade by PA-6 may result in different proarrhythmic liability, as brought forward in the Skarsfeldt report ${ }^{71}$. Interestingly, a recent paper involving the same research group, on Langendorff perfused guinea pig hearts did not report any pro-arrhythmia of PA- $6^{72}$. The authors emphasized that the relative contribution of $\mathrm{I}_{\mathrm{K} 1}$ to repolarization is lower in guinea pig than in rat. Secondly, our in vivo models include factors like autonomic regulation, mechanical function and anesthesia, which all affect cardiac function differently than in an ex vivo Langendorff heart model that lacks these factors.

The lipophilic PA- 6 accumulates in cardiac tissues as established here, especially in the ventricle. Currently, we cannot provide a clear explanation for this phenomenon. It is however tempting to speculate that strong expression of $\mathrm{I}_{\mathrm{K} 1}$ channels, especially in the canine ventricle $\mathrm{e}^{3}$ may be the basis of this finding.

Our current results, obtained from goats and dogs, demonstrate cardiac safety and good anti-AF properties for PA-6. Furthermore, PA- 6 is able to target human atrial $\mathrm{I}_{\mathrm{K} 1}$. Therefore, PA-6 might be considered as an interesting compound for further clinical evaluation as a potential antiarrhythmic drug for AF. 


\section{Limitations}

An important limitation of our study is that cardioversion efficacy of PA- 6 in the goat model of AF was tested in animals under the general anesthesia. The anesthesia regimen contained thiopental which is a known $\mathrm{I}_{\mathrm{K} 1}$ inhibitor that most likely acts via $\mathrm{PIP}_{2}$ interference ${ }^{73}$. Furthermore, conversion was tested at 3 weeks of pacing-induced AF only. Given the current study setup, we cannot exclude that potential PA- 6 activity outside the heart contributes to the anti-arrhythmic efficacy, nor can we exclude that additional potassium currents within the goat atrium are involved.

Current safety studies focused on cardiac arrhythmias in the CAVB dog only. At this point, no statements can be made on skeletal muscle, including respiratory muscle, and neurologic effects and these questions await further analysis.

This study made use of a single dose regimen for efficacy and safety testing in large animal studies. A full dose-response relationship, both with respect to efficacy and toxicity, should be performed prior to considering any human clinical testing.

\section{Acknowledgments}

The authors thank Monika Hagedorn for excellent technical assistance.

Y.J. is the recipient of a scholarship from the Chinese Scholarship Council. This study received funding from the UMC Utrecht holding b.v. (Octopus valorization grant). D.D. is supported by the National Institutes of Health (R01-HL131517), the German Research Foundation DFG (Do 769/4 1) and DZHK (German Center for Cardiovascular Research). N.V. is supported by the DZHK, by the German Research Foundation (DFG VO 1568/3-1 and IRTG1816 RP12) and by the Else Kröner-Fresenius Stiftung (EKFS 2016_A20). S.V. is supported by the European Union; EUTRAF (No. 261057) and the Dutch Heart Foundation; RACE-V (CVON201409). D.O. is supported by a scholarship from the Serbian Ministry of Youth and Sports; Fund for Young Talents - Dositeja.S.V.and D.Oare both supported by RADOX (No. 316738).

\section{Author contributions}

Y.J., R.V., D.O., A.B., A.P.K. and M.Z. planned and performed experiments and analyzed data, M.K. and J.D.M.B. performed experiments and analyzed data, M.Z.W., S.V., D.D., N.V., M.V. and M.A.G.v.d.H. designed the study, planned the experiments and analyzed data. Y.J., S.V., M.Z.W., N.V. and M.A.G.v.d.H wrote the manuscript.

\section{Conflict of interest}

The authors declare no conflicts of interest.

\section{Declaration of transparency and scientific rigour}

This Declaration acknowledges that this paper adheres to the principles for transparent reporting and scientific rigour of preclinical research recommended by funding agencies, publishers and other organizations engaged with supporting research. 


\section{References}

1. Hibino $\mathrm{H}$, Inanobe A, Furutani K, Murakami S, Findlay I and Kurachi Y. Inwardly rectifying potassium channels: their structure, function, and physiological roles. Physiol Rev. 2010;90:291-366.

2. de Boer TP, Houtman MJ, Compier M and van der Heyden MA. The mammalian K(IR)2.x inward rectifier ion channel family: expression pattern and pathophysiology. Acta Physiol (Oxf). 2010;199:243-56.

3. Cordeiro JM, Zeina T, Goodrow R, Kaplan AD, Thomas LM, Nesterenko VV, Treat JA, Hawel L, 3rd, Byus C, Bett GC, Rasmusson RL and Panama BK. Regional variation of the inwardly rectifying potassium current in the canine heart and the contributions to differences in action potential repolarization. J Mol Cell Cardiol. 2015;84:52-60.

4. Wang Z, Yue L, White M, Pelletier G and Nattel S. Differential distribution of inward rectifier potassium channel transcripts in human atrium versus ventricle. Circulation. 1998;98:2422-8.

5. Satoh H. Sino-atrial nodal cells of mammalian hearts: ionic currents and gene expression of pacemaker ionic channels. J Smooth Muscle Res. 2003;39:175-93.

6. van der Heyden MA and Jespersen T. Pharmacological exploration of the resting membrane potential reserve: Impact on atrial fibrillation. Eur J Pharmacol. 2016;771:56-64.

7. Biliczki P, Virag L, lost N, Papp JG and Varro A. Interaction of different potassium channels in cardiac repolarization in dog ventricular preparations: role of repolarization reserve. $\mathrm{Br} J$ Pharmacol. 2002;137:361-8.

8. Nagy N, Acsai K, Kormos A, Sebok Z, Farkas AS, Jost N, Nanasi PP, Papp JG, Varro A and Toth A. $[\mathrm{Ca}(2)(+)]$ i-induced augmentation of the inward rectifier potassium current (IK1) in canine and human ventricular myocardium. Pflugers Arch. 2013;465:1621-35.

9. Wang $\mathrm{L}, \mathrm{Chiamvimonvat} \mathrm{N}$ and Duff HJ. Interaction between selected sodium and potassium channel blockers in guinea pig papillary muscle. J Pharmacol Exp Ther. 1993;264:1056-62.

10. Krijthe BP, Kunst A, Benjamin EJ, Lip GY, Franco OH, Hofman A, Witteman JC, Stricker BH and Heeringa J. Projections on the number of individuals with atrial fibrillation in the European Union, from 2000 to 2060. Eur Heart J. 2013;34:2746-51.

11. Benjamin EJ, Wolf PA, D'Agostino RB, Silbershatz H, Kannel WB and Levy D. Impact of atrial fibrillation on the risk of death: the Framingham Heart Study. Circulation. 1998;98:946-52.

12. Krahn AD, Manfreda J, Tate RB, Mathewson FA and Cuddy TE. The natural history of atrial fibrillation: incidence, risk factors, and prognosis in the Manitoba Follow-Up Study. The American journal of medicine. 1995;98:476-84.

13. Wolf PA, Abbott RD and Kannel WB. Atrial fibrillation as an independent risk factor for stroke: the Framingham Study. Stroke. 1991;22:983-8.

14. Potpara TS, Stankovic GR, Beleslin BD, Polovina MM, Marinkovic JM, Ostojic MC and Lip GYH. A 12-year follow-up study of patients with newly diagnosed lone atrial fibrillation: implications of arrhythmia progression on prognosis: the Belgrade Atrial Fibrillation study. Chest. 2012;141:339-347.

15. Heijman J, Voigt N, Nattel S and Dobrev D. Cellular and molecular electrophysiology of atrial fibrillation initiation, maintenance, and progression. Circ Res. 2014;114:1483-99.

16. Wijffels MC, Kirchhof CJ, Dorland R and Allessie MA. Atrial fibrillation begets atrial fibrillation. A study in awake chronically instrumented goats. Circulation. 1995;92:1954-68.

17. Schotten U, Verheule S, Kirchhof P and Goette A. Pathophysiological mechanisms of atrial fibrillation: a translational appraisal. Physiol Rev. 2011;91:265-325. 
18. European Heart Rhythm A, European Association for Cardio-Thoracic S, Camm AJ, Kirchhof P, Lip GY, Schotten U, Savelieva I, Ernst S, Van Gelder IC, Al-Attar N, Hindricks G, Prendergast B, Heidbuchel H, Alfieri O, Angelini A, Atar D, Colonna P, De Caterina R, De Sutter J, Goette A, Gorenek B, Heldal M, Hohloser SH, Kolh P, Le Heuzey JY, Ponikowski P and Rutten FH. Guidelines for the management of atrial fibrillation: the Task Force for the Management of Atrial Fibrillation of the European Society of Cardiology (ESC). Eur Heart J. 2010;31:2369-429.

19. Camm AJ, Lip GY, De Caterina R, Savelieva I, Atar D, Hohnloser SH, Hindricks G, Kirchhof P and Guidelines ESCCFP. 2012 focused update of the ESC Guidelines for the management of atrial fibrillation: an update of the 2010 ESC Guidelines for the management of atrial fibrillation. Developed with the special contribution of the European Heart Rhythm Association. Eur Heart J. 2012;33:2719-47.

20. Gillis $A M$, Krahn AD, Skanes AC and Nattel S. Management of atrial fibrillation in the year 2033: new concepts, tools, and applications leading to personalized medicine. Can J Cardiol. 2013;29:1141-6.

21. Chinitz JS, Halperin JL, Reddy VY and Fuster V. Rate or rhythm control for atrial fibrillation: update and controversies. Am J Med. 2012;125:1049-56.

22. Bosch RF, Zeng X, Grammer JB, Popovic K, Mewis C and Kuhlkamp V. Ionic mechanisms of electrical remodeling in human atrial fibrillation. Cardiovascular research. 1999;44:121-31.

23. Dobrev D, Graf E, Wettwer E, Himmel HM, Hala O, Doerfel C, Christ T, Schuler S and Ravens $U$. Molecular basis of downregulation of G-protein-coupled inward rectifying $\mathrm{K}(+)$ current $(\mathrm{I}(\mathrm{K}, \mathrm{ACh})$ in chronic human atrial fibrillation: decrease in GIRK4 mRNA correlates with reduced $\mathrm{I}(\mathrm{K}, \mathrm{ACh})$ and muscarinic receptor-mediated shortening of action potentials. Circulation. 2001;104:2551-7.

24. Dobrev D, Wettwer E, Kortner A, Knaut M, Schuler S and Ravens U. Human inward rectifier potassium channels in chronic and postoperative atrial fibrillation. Cardiovasc Res. 2002;54:397404.

25. Zhang H, Garratt CJ, Zhu J and Holden AV. Role of up-regulation of IK1 in action potential shortening associated with atrial fibrillation in humans. Cardiovasc Res. 2005;66:493-502.

26. Ehrlich JR. Inward rectifier potassium currents as a target for atrial fibrillation therapy. $J$ Cardiovasc Pharmacol. 2008;52:129-35.

27. de Boer TP, Nalos L, Stary A, Kok B, Houtman MJ, Antoons G, van Veen TA, Beekman JD, de Groot $B L$, Opthof T, Rook MB, Vos MA and van der Heyden MA. The anti-protozoal drug pentamidine blocks KIR2.x-mediated inward rectifier current by entering the cytoplasmic pore region of the channel. Br J Pharmacol. 2010;159:1532-41.

28. Takanari H, Nalos L, Stary-Weinzinger A, de Git KC, Varkevisser R, Linder T, Houtman MJ, Peschar M, de Boer TP, Tidwell RR, Rook MB, Vos MA and van der Heyden MA. Efficient and specific cardiac IK(1) inhibition by a new pentamidine analogue. Cardiovasc Res. 2013;99:203-14.

29. Verheule S, Tuyls E, Gharaviri A, Hulsmans S, van Hunnik A, Kuiper M, Serroyen J, Zeemering $S$, Kuijpers NH and Schotten U. Loss of continuity in the thin epicardial layer because of endomysial fibrosis increases the complexity of atrial fibrillatory conduction. Circulation Arrhythmia and electrophysiology. 2013;6:202-11.

30. Oros A, Beekman JD and Vos MA. The canine model with chronic, complete atrio-ventricular block. Pharmacol Ther. 2008;119:168-78.

31. Kilkenny C, Browne W, Cuthill IC, Emerson M, Altman DG and Group NCRRGW. Animal research: reporting in vivo experiments: the ARRIVE guidelines. Br J Pharmacol. 2010;160:1577-9. 
32. McGrath JC and Lilley E. Implementing guidelines on reporting research using animals (ARRIVE etc.): new requirements for publication in BJP. Br J Pharmacol. 2015;172:3189-93.

33. Verheule S, Tuyls E, van Hunnik A, Kuiper M, Schotten U and Allessie M. Fibrillatory conduction in the atrial free walls of goats in persistent and permanent atrial fibrillation. Circ Arrhythm Electrophysiol. 2010;3:590-9.

34. Mohan N, Nliyogi D and Singh H. Analysis of relationship between Q-T and R-R interval in the electrocardiogram of goats. Indian J Anim Sci. 2009;79:362-365.

35. Lau DH, Maesen B, Zeemering S, Kuklik P, van Hunnik A, Lankveld TA, Bidar E, Verheule S, Nijs J, Maessen J, Crijns H, Sanders P and Schotten U. Indices of bipolar complex fractionated atrial electrograms correlate poorly with each other and atrial fibrillation substrate complexity. Heart Rhythm. 2015;12:1415-23.

36. Zeemering S, Maesen B, Nijs J, Lau DH, Granier M, Verheule S and Schotten U. Automated quantification of atrial fibrillation complexity by probabilistic electrogram analysis and fibrillation wave reconstruction. Conf Proc IEEE Eng Med Biol Soc. 2012;2012:6357-60.

37. Duytschaever M, Mast F, Killian M, Blaauw Y, Wijffels M and Allessie M. Methods for determining the refractory period and excitable gap during persistent atrial fibrillation in the goat. Circulation. 2001;104:957-62.

38. Eckstein J, Maesen B, Linz D, Zeemering S, van Hunnik A, Verheule S, Allessie M and Schotten $\mathrm{U}$. Time course and mechanisms of endo-epicardial electrical dissociation during atrial fibrillation in the goat. Cardiovascular research. 2011;89:816-24.

39. Eckstein J, Zeemering S, Linz D, Maesen B, Verheule S, van Hunnik A, Crijns H, Allessie MA and Schotten $U$. Transmural conduction is the predominant mechanism of breakthrough during atrial fibrillation: evidence from simultaneous endo-epicardial high-density activation mapping. Circ Arrhythm Electrophysiol. 2013;6:334-41.

40. Yokoyama H, Nakamura $Y$, Iwasaki H, Nagayama $Y$, Hoshiai K, Mitsumori $Y$ and Sugiyama A. Effects of acute intravenous administration of pentamidine, a typical hERG-trafficking inhibitor, on the cardiac repolarization process of halothane-anesthetized dogs. J Pharmacol Sci. 2009;110:476-82.

41. Varkevisser R, van der Heyden MA, Tieland RG, Beekman JD and Vos MA. Vernakalant is devoid of proarrhythmic effects in the complete AV block dog model. Eur JPharmacol. 2013;720:49-54.

42. Nalos $L$, Varkevisser R, Jonsson MK, Houtman MJ, Beekman JD, van der Nagel R, Thomsen MB, Duker G, Sartipy P, de Boer TP, Peschar M, Rook MB, van Veen TA, van der Heyden MA and Vos MA. Comparison of the IKr blockers moxifloxacin, dofetilide and E-4031 in five screening models of pro-arrhythmia reveals lack of specificity of isolated cardiomyocytes. Br JPharmacol. 2012;165:467-78.

43. Yang S, Wenzler T, Miller PN, Wu H, Boykin DW, Brun R and Wang MZ. Pharmacokinetic comparison to determine the mechanisms underlying the differential efficacies of cationic diamidines against first- and second-stage human African trypanosomiasis. Antimicrob Agents Chemother. 2014;58:4064-74.

44. Wenzler T, Yang S, Braissant O, Boykin DW, Brun R and Wang MZ. Pharmacokinetics, Trypanosoma brucei gambiense efficacy, and time of drug action of DB829, a preclinical candidate for treatment of second-stage human African trypanosomiasis. Antimicrob Agents Chemother. 2013;57:5330-43.

45. Voigt N, Pearman CM, Dobrev D and Dibb KM. Methods for isolating atrial cells from large mammals and humans. J Mol Cell Cardiol. 2015;86:187-98. 
46. Dobrev D, Friedrich A, Voigt N, Jost N, Wettwer E, Christ T, Knaut M and Ravens U. The G protein-gated potassium current $\mathrm{I}(\mathrm{K}, \mathrm{ACh})$ is constitutively active in patients with chronic atrial fibrillation. Circulation. 2005;112:3697-706.

47. Voigt N, Trausch A, Knaut M, Matschke K, Varro A, Van Wagoner DR, Nattel S, Ravens U and Dobrev D. Left-to-right atrial inward rectifier potassium current gradients in patients with paroxysmal versus chronic atrial fibrillation. Circ Arrhythm Electrophysiol. 2010;3:472-80.

48. Southan C, Sharman JL, Benson HE, Faccenda E, Pawson AJ, Alexander SP, Buneman OP, Davenport AP, McGrath JC, Peters JA, Spedding M, Catterall WA, Fabbro D, Davies JA and NC I. The IUPHAR/BPS Guide to PHARMACOLOGY in 2016: towards curated quantitative interactions between 1300 protein targets and 6000 ligands. Nucleic Acids Res. 2016;44:D1054-68.

49. Alexander SP, Catterall WA, Kelly E, Marrion N, Peters JA, Benson HE, Faccenda E, Pawson AJ, Sharman JL, Southan C, Davies JA and Collaborators C. The Concise Guide to PHARMACOLOGY 2015/16: Voltage-gated ion channels. Br J Pharmacol. 2015;172:5904-41.

50. Voigt N, Friedrich A, Bock M, Wettwer E, Christ T, Knaut M, Strasser RH, Ravens U and Dobrev $D$. Differential phosphorylation-dependent regulation of constitutively active and muscarinic receptor-activated IK,ACh channels in patients with chronic atrial fibrillation. Cardiovasc Res. 2007;74:426-37.

51. Veldhuis MG, Y. J and van der Heyden MA. A little too much: cardiac electrophysiological effects of elevated inward rectifying current carried by the KIR2.1 ion channel protein. Adaptive Medicine. 2015;7:1-8.

52. Bhave G, Lonergan D, Chauder BA and Denton JS. Small-molecule modulators of inward rectifier K+ channels: recent advances and future possibilities. Future Med Chem. 2010;2:757-74.

53. Filgueiras-Rama D, Martins RP, Mironov S, Yamazaki M, Calvo CJ, Ennis SR, Bandaru K, Noujaim SF, Kalifa J, Berenfeld $\mathrm{O}$ and Jalife J. Chloroquine terminates stretch-induced atrial fibrillation more effectively than flecainide in the sheep heart. Circulation Arrhythmia and electrophysiology. 2012;5:561-70.

54. Noujaim SF, Stuckey JA, Ponce-Balbuena D, Ferrer-Villada T, Lopez-Izquierdo A, Pandit SV, Sanchez-Chapula JA and Jalife J. Structural bases for the different anti-fibrillatory effects of chloroquine and quinidine. Cardiovasc Res. 2011;89:862-9.

55. Verheule S, Eckstein J, Linz D, Maesen B, Bidar E, Gharaviri A and Schotten U. Role of endoepicardial dissociation of electrical activity and transmural conduction in the development of persistent atrial fibrillation. Prog Biophys Mol Biol. 2014;115:173-85.

56. Beaumont J, Davidenko N, Davidenko JM and Jalife J. Spiral waves in two-dimensional models of ventricular muscle: formation of a stationary core. Biophys J. 1998;75:1-14.

57. Noujaim SF, Pandit SV, Berenfeld O, Vikstrom K, Cerrone M, Mironov S, Zugermayr M, Lopatin AN and Jalife J. Up-regulation of the inward rectifier K+ current (I K1) in the mouse heart accelerates and stabilizes rotors. J Physiol. 2007;578:315-26.

58. Everett THt and Olgin JE. Basic mechanisms of atrial fibrillation. Cardiol Clin. 2004;22:9-20.

59. Eijsbouts S, Ausma J, Blaauw Y, Schotten U, Duytschaever M and Allessie MA. Serial cardioversion by class IC Drugs during 4 months of persistent atrial fibrillation in the goat. $J$ Cardiovasc Electrophysiol. 2006;17:648-54.

60. Wijffels MC, Dorland R and Allessie MA. Pharmacologic cardioversion of chronic atrial fibrillation in the goat by class IA, IC, and III drugs: a comparison between hydroquinidine, cibenzoline, flecainide, and d-sotalol. Journal of cardiovascular electrophysiology. 1999;10:178-93. 
61. Blaauw Y, Schotten U, van Hunnik A, Neuberger HR and Allessie MA. Cardioversion of persistent atrial fibrillation by a combination of atrial specific and non-specific class III drugs in the goat. Cardiovasc Res. 2007;75:89-98.

62. Kirchhof P, Benussi S, Kotecha D, Ahlsson A, Atar D, Casadei B, Castella M, Diener HC, Heidbuchel H, Hendriks J, Hindricks G, Manolis AS, Oldgren J, Popescu BA, Schotten U, Van Putte B, Vardas P, Authors/Task Force M and Document R. 2016 ESC Guidelines for the management of atrial fibrillation developed in collaboration with EACTS: The Task Force for the management of atrial fibrillation of the European Society of Cardiology (ESC)Developed with the special contribution of the European Heart Rhythm Association (EHRA) of the ESCEndorsed by the European Stroke Organisation (ESO). Eur Heart J. 2016.

63. Reisinger J, Gatterer E, Heinze G, Wiesinger K, Zeindlhofer E, Gattermeier M, Poelzl G, Kratzer $\mathrm{H}$, Ebner A, Hohenwallner W, Lenz K, Slany J and Kuhn P. Prospective comparison of flecainide versus sotalol for immediate cardioversion of atrial fibrillation. Am J Cardiol. 1998;81:1450-4.

64. Antoons G, Oros A, Beekman JD, Engelen MA, Houtman MJ, Belardinelli L, Stengl M and Vos MA. Late na(+) current inhibition by ranolazine reduces torsades de pointes in the chronic atrioventricular block dog model. J Am Coll Cardiol. 2010;55:801-9.

65. Bourgonje VJ, Vos MA, Ozdemir S, Doisne N, Acsai K, Varro A, Sztojkov-Ivanov A, Zupko I, Rauch E, Kattner L, Bito V, Houtman M, van der Nagel R, Beekman JD, van Veen TA, Sipido KR and Antoons G. Combined $\mathrm{Na}(+) / \mathrm{Ca}(2+)$ exchanger and L-type calcium channel block as a potential strategy to suppress arrhythmias and maintain ventricular function. Circ Arrhythm Electrophysiol. 2013;6:371-9.

66. Thomsen MB, Volders PG, Beekman JD, Matz J and Vos MA. Beat-to-Beat variability of repolarization determines proarrhythmic outcome in dogs susceptible to drug-induced torsades de pointes. J Am Coll Cardiol. 2006;48:1268-76.

67. Escande D, Coraboeuf E, Planche $C$ and Lacour-Gayet F. Effects of potassium conductance inhibitors on spontaneous diastolic depolarization and abnormal automaticity in human atrial fibers. Basic Res Cardiol. 1986;81:244-57.

68. Roza O and Berman LB. The pathophysiology of barium: hypokalemic and cardiovascular effects. J Pharmacol Exp Ther. 1971;177:433-9.

69. Bhoelan BS, Stevering $\mathrm{CH}$, van der Boog AT and van der Heyden MA. Barium toxicity and the role of the potassium inward rectifier current. Clin Toxicol (Phila). 2014;52:584-93.

70. Jost N, Virag L, Comtois P, Ordog B, Szuts V, Seprenyi G, Bitay M, Kohajda Z, Koncz I, Nagy N, Szel T, Magyar J, Kovacs M, Puskas LG, Lengyel C, Wettwer E, Ravens U, Nanasi PP, Papp JG, Varro A and Nattel $\mathrm{S}$. Ionic mechanisms limiting cardiac repolarization reserve in humans compared to dogs. J Physiol. 2013;591:4189-206.

71. Skarsfeldt MA, Carstensen H, Skibsbye L, Tang C, Buhl R, Bentzen BH and Jespersen T. Pharmacological inhibition of IK1 by PA- 6 in isolated rat hearts affects ventricular repolarization and refractoriness. Physiol Rep. 2016;4.

72. Hoeker GS, Skarsfeldt MA, Jespersen T and Poelzing S. Electrophysiologic effects of the IK1 inhibitor PA-6 are modulated by extracellular potassium in isolated guinea pig hearts. Physiol Rep. 2017;5.

73. van der Heyden MA, Stary-Weinzinger A and Sanchez-Chapula JA. Inhibition of cardiac inward rectifier currents by cationic amphiphilic drugs. Curr Mol Med. 2013;13:1284-98. 


\section{Supplementary Methods}

\section{AF Substrate Complexity}

\section{The quantification of wave size, conduction velocity and fractionation index}

AF complexity was quantified as the total number of waves and the number of breakthrough (BT) waves per AF cycle, mean wave size, mean fractionation index and the mean wave conduction velocity ${ }^{1-5}$.

The number of waves was expressed as a number of waves per AF cycle and was calculated as a total number of waves normalized to the number of AF cycles within a recording.

$$
\text { No. of waves per } A F \text { cycle }=\frac{\text { total number of waves }}{\text { recording duration } / A F C L}
$$

$B T$ waves are waves emerging within the mapping area whose origin cannot be attributed to any other propagating wave on the epicardium. The number of BT waves was also expressed as the number of BT waves per AF cycle and was calculated as a total number of BT waves during the recording divided by the number of AF cycles within the recording.

$$
\text { No. of BT waves per } A F \text { cycle }=\frac{\text { total number of } B T \text { waves }}{\text { recording duration } / A F C L}
$$

The wave size was determined by the number of electrodes that were allocated to the same AF wave and expressed as the mean wave size of all waves within the recording.

The fractionation index was defined as the ratio between subsidiary and main deflections (marked red and green in figure $3 \mathrm{~A}$ of the manuscript) for each electrode and reported as a mean value of all electrodes within the recording.

$$
\text { Fractionation index }=\frac{(2+2+3+4+0+2+2+3+2+2+3+3)}{13}=2.15
$$


The wave conduction velocity was calculated for each electrode activation within a wave by fitting a plane to activation times at neighboring electrodes belonging to the same wave ( $3 \times 3$ electrodes). The reciprocal value of the steepness of the fitted plane was then used to determine conduction velocity at each electrode. The conduction velocity was expressed as the mean conduction velocity of all electrodes within the wave.
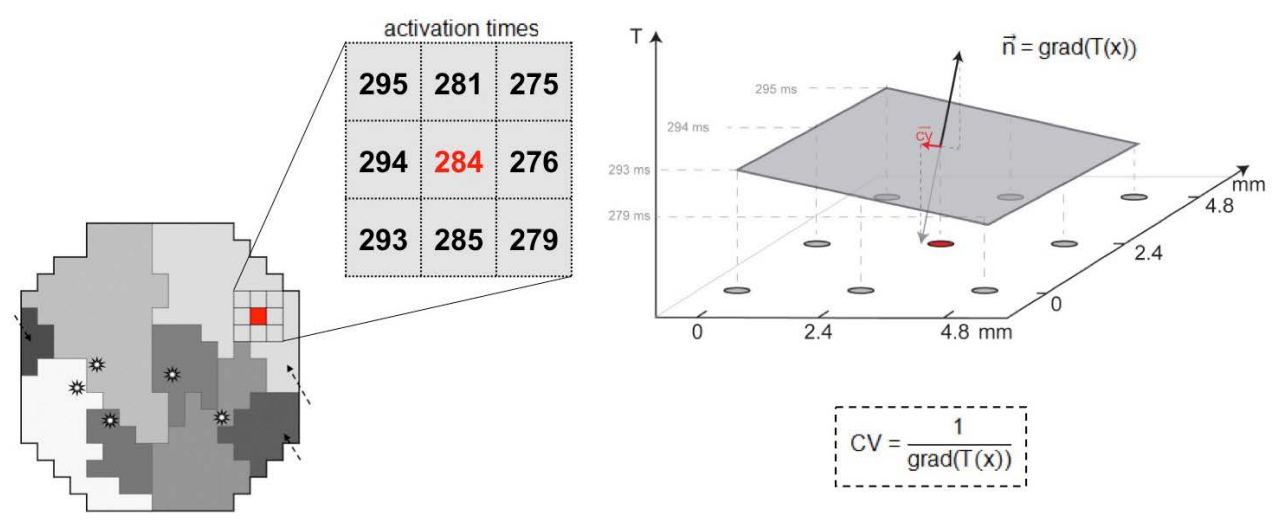

\section{Inside/out patch clamp electrophysiology}

Inside-out measurements of human and white bream IKir2.1 expressed in HEK293 cell membrane patches was performed as described previously ${ }^{6}$. 


\section{Supporting information}

The supporting information provides a complete view of the electrophysiological responses up to 30 minutes following PA- 6 application in SR and CAVB dogs, and thereby supplements the data presented in Table 2 that presents the maximal response in time. PA-6 sensitivity is similar for evolutionary distinct ( $82.9 \%$ amino acid sequence identity) fish and human $\mathrm{K}_{\mathrm{ir}} 2.1$ channels, whereas $\mathrm{K}_{\mathrm{ir}} 2 . x$ differences between human, dog and goat are $94.9 \%$ or higher at the amino acid level, and thereby provide (experimental) support for statements made in the discussion section of the manuscript. 
A
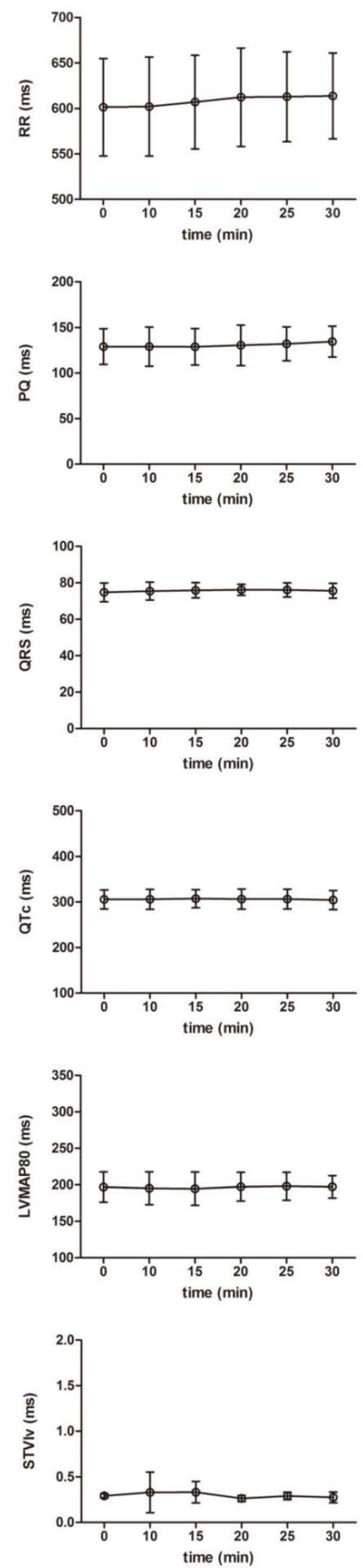

B
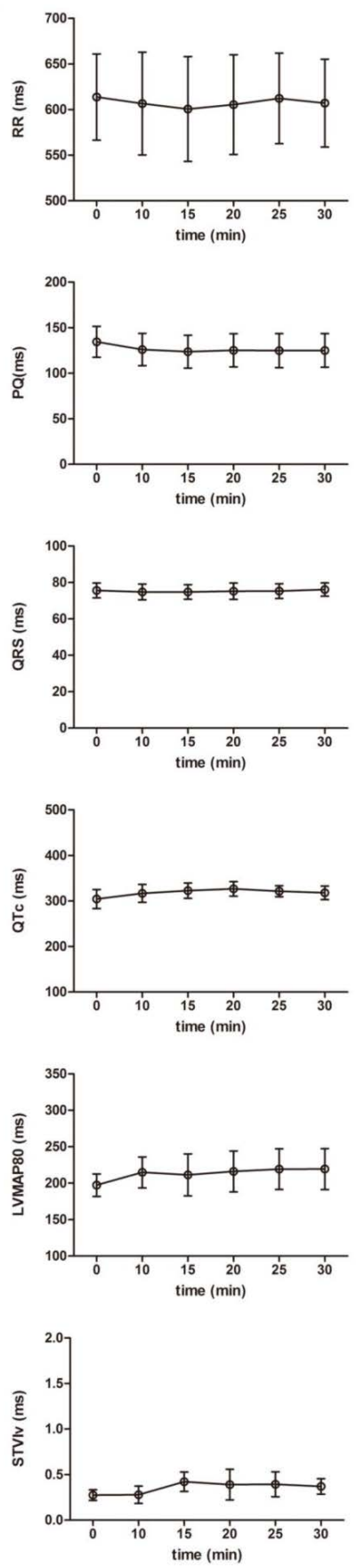

Figure S1. Electrophysiological parameters in sinus rhythm dogs $(n=4)$ upon low dose bolus $\left(0.5 \mathrm{mg} \cdot \mathrm{kg}^{-1} 10 \mathrm{~min}^{-1}\right)$ (A) or high dose bolus (2.5 mg.kg-1 10 $\mathrm{min}^{-1}$ ) (B) up to thirty mins following start of infusion. RR, $\mathrm{PQ}, \mathrm{QRS}$, QTc values are derived from ECG recordings. $\mathrm{LV}_{\text {MAP80 }}$ and STVlv are derived from monophasic action potential recordings from the left ventricle. 
A

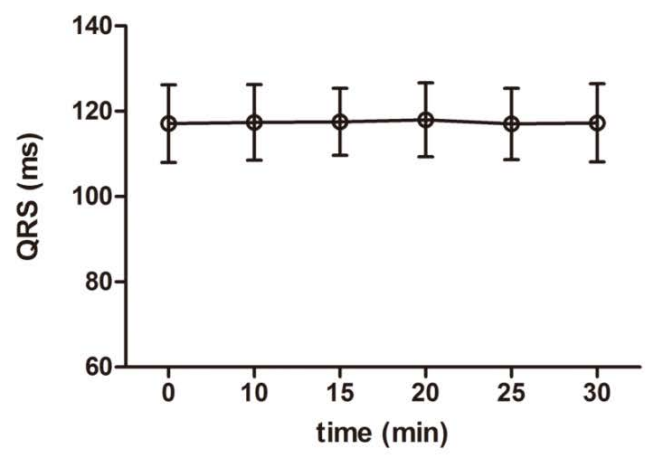

B

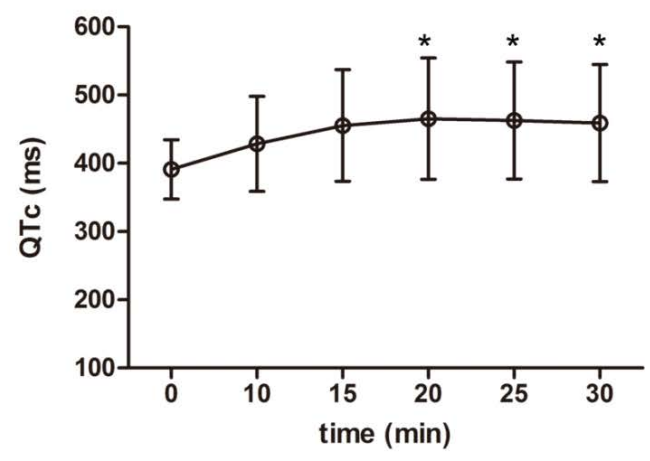

C

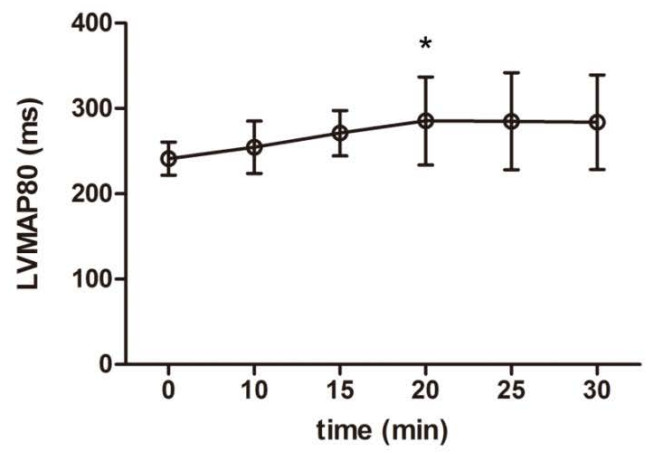

Figure S2. Electrophysiological parameters in CAVB dogs ( $\mathrm{n}=9$ ) upon high dose bolus $\left(2.5 \mathrm{mg} \cdot \mathrm{kg}^{-1} 10 \mathrm{~min}^{-1}\right)$ infusion up to thirty mins following start of infusion. QRS and QTC values are derived from ECG recordings. $\mathrm{LV}_{\text {MAPBO }}$ values are derived from monophasic action potential recordings from the left ventricle. 

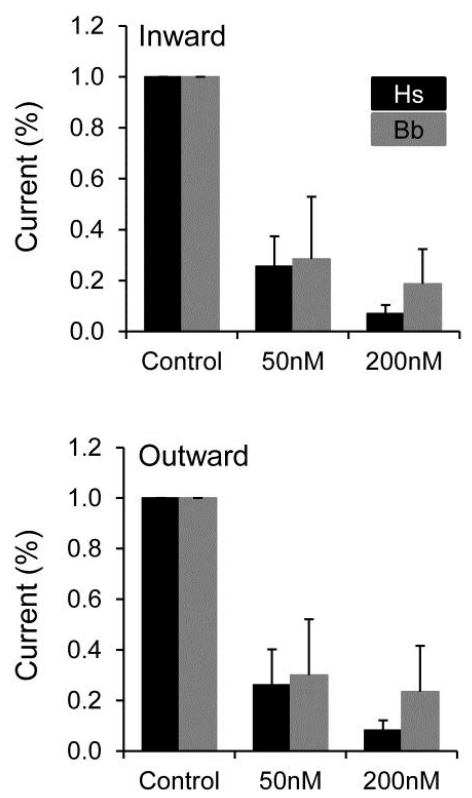

Figure S3. PA-6 mediated inhibition ( 50 and $200 \mathrm{nM}$ ) of human (Hs, human sapiens) and fish (Bb, Blicca bjoerkna (white bream)) $I_{\text {Kir.1 }}$ determined by patch-clamp electrophysiology in the inside-out orientation. Percentage amino acid sequence identity between $\mathrm{Hs}$ and $\mathrm{Bb}$ is $82.9 \%$. 

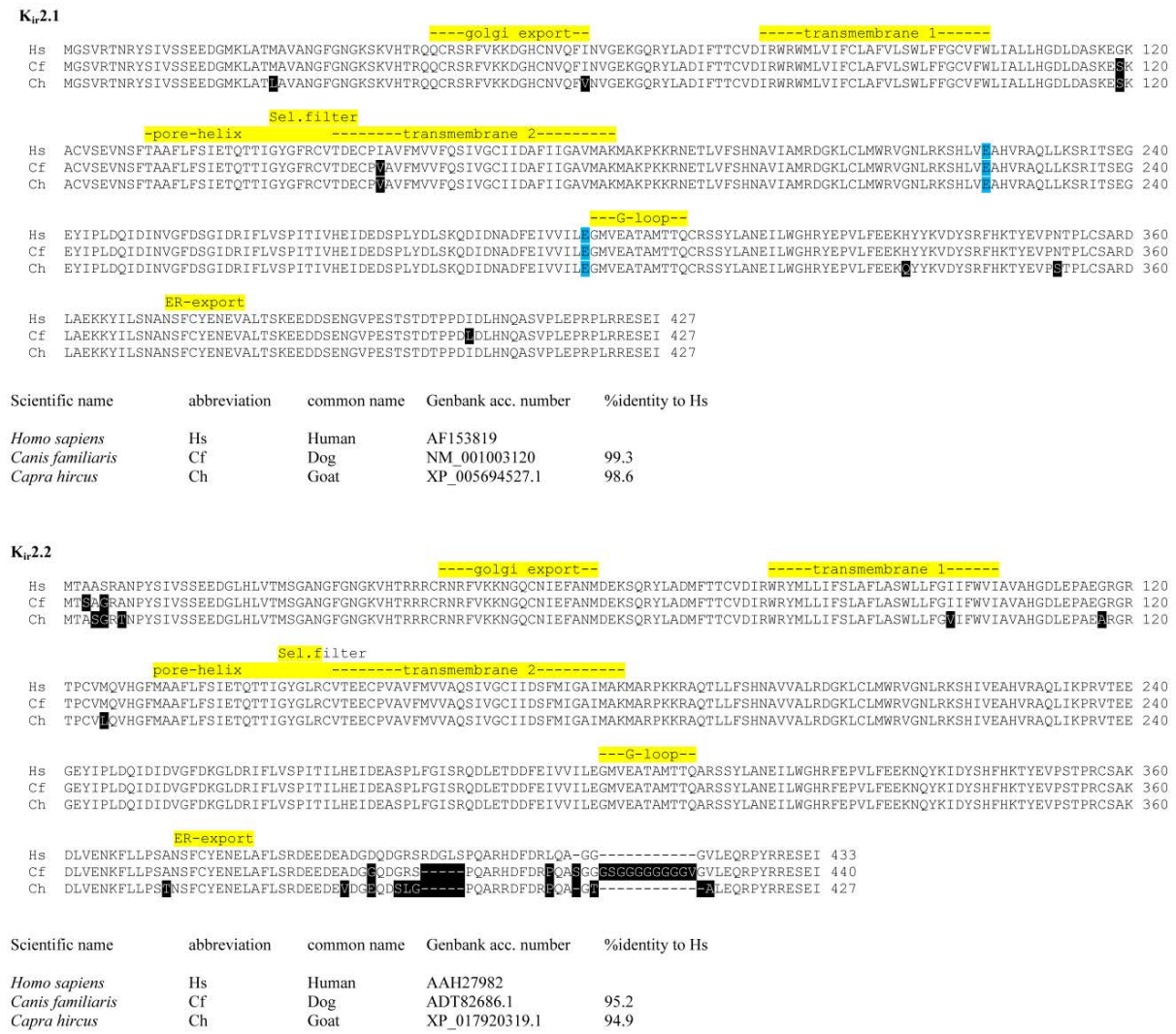

$\mathbf{K}_{\mathrm{ir}} \mathbf{2 . 3}$

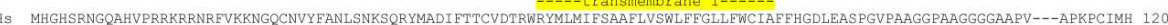

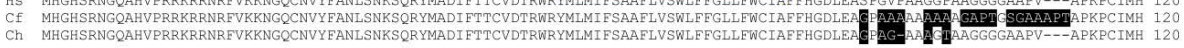
Sel.filter ----transmembrane 2---

As VNGELGAFLESVETOTTIGYGFRCVTEECPLAVIAVVVOSIVGCVIDSFMIGTIMAKMARPKKRAOTLLFSHHAVISVRDGKLCLMWRVGNLRKSHIVEAHVRAOLIKPYMTOEGEYLPL 240 CF VNGLLGAFLFSVETQTTIGYGFRCVTEECPLAVIAVVVQSIVGCVIDSFMI GT IMAKMARPKKRAQTLLFSHHAVISVRDGKLCLMWRVGNLRKSHIVEAHVRAQIIKPYMTQEGEYLPL 240
Ch VNGELGAFLFSVETQTTIGYGFRCVTEECPLAVIAVVVQSIVGCVI DSFMIGTIMAKMARPKKRAQTLILSHHAVISVRDGKLCLMWRVGNLRKSHIVEAHVRAQIIKPYMTQEGEYLPL 240

HS DQRDLNVGYDIGLDRIFLVSPI I IVHEI DEDSPLYGMGKEELESEDFEIVVILEGMVEATAMTTQARSSYLASEILWGHREEPVVFEEKSHYKVDYSRFHKTYEVAGTPCCSARELQESK 360 Cf DQRDLNVGYDIGLDRIFLVSPI I IVHE I DEDSPLYGMGKEELESEDFEIVVILEGMVEATAMTTOARSSYLASE I LVGHREE PVVEEEKSHYKVDYSRFHKTYEVAGTPCCSARELQESK 360

Hs ITVLPAPPPPPSAFCYENELALMSOEEQEMEEEAAAARAVAAGLGLEAGSKEEAGIIRUIEFGSHLDLERMQASLPLDNISYRRESAI 445 Cf. ITVLPAPPPPPSAFCYENELALIMSOEEEEMEEEAAAARAVAAGLGLEAGSKEEAGIIRMLEFGSHLDLERMQATLPLDNISYRRESAI 448

Ch ITVLPAPEPPPSAFCYENELALMSQEEEMEEEAAAARAVAAGLGLEAGSKEEAGIIRMIEFGSHLDLERMQAILPLDNISYRRESAI 444

$\begin{array}{lllll}\text { Scientific name } & \text { abbreviation } & \text { common name } & \text { Genbank acc. number } & \text { \%identity to Hs } \\ & & & & \\ \text { Homo sapiens } & \text { Hs } & \text { Human } & \text { NP_004972 } & \\ \text { Canisfamiliaris } & \text { Cf } & \text { Dog } & \text { XP_005625940 } & 95.7 \\ \text { Capra hircus } & \text { Ch } & \text { Goat } & \text { XP_017904253 } & 98.4\end{array}$

Figure S4. Amino acid alignment of human (Hs, Homo sapiens), dog (Cf, canis familiaris) and goat (Ch, Capra hircus) $\mathrm{K}_{\mathrm{ir}} 2.1, \mathrm{~K}_{\mathrm{ir}} 2.2$ and $\mathrm{K}_{\mathrm{ir}} 2.3$ amino acid sequences in single letter code. Non-identical residues with respect to the human sequence are depicted in white font on a black background. Transmembrane region 1 and 2, selectivity filter, G-loop, Golgi and ER export signals are indicated in yellow. Blue shaded residues are involved in PA-6 mediated blockade. Genbank accession numbers and percentages of amino acid identity are given below the alignments. 


\section{References}

1. Zeemering S, Maesen B, Nijs J, Lau DH, Granier M, Verheule S and Schotten U. Automated quantification of atrial fibrillation complexity by probabilistic electrogram analysis and fibrillation wave reconstruction. Conf Proc IEEE Eng Med Biol Soc. 2012;2012:6357-60.

2. Lau DH, Maesen B, Zeemering S, Kuklik P, Hunnik A, Lankveld TA, Bidar E, Verheule S, Nijs J, Maessen J, Crijns H, Sanders P and Schotten U. Indices of bipolar complex fractionated atrial electrograms correlate poorly with each other and atrial fibrillation substrate complexity. Heart rhythm : the official journal of the Heart Rhythm Society. 2015;12:1415-23.

3. Duytschaever M, Mast F, Killian M, Blaauw Y, Wijffels M and Allessie M. Methods for determining the refractory period and excitable gap during persistent atrial fibrillation in the goat. Circulation. 2001;104:957-62.

4. Eckstein J, Maesen B, Linz D, Zeemering S, van Hunnik A, Verheule S, Allessie M and Schotten $\mathrm{U}$. Time course and mechanisms of endo-epicardial electrical dissociation during atrial fibrillation in the goat. Cardiovascular research. 2011;89:816-24.

5. Eckstein J, Zeemering S, Linz D, Maesen B, Verheule S, van Hunnik A, Crijns H, Allessie MA and Schotten U. Transmural conduction is the predominant mechanism of breakthrough during atrial fibrillation: evidence from simultaneous endo-epicardial high-density activation mapping. Circ Arrhythm Electrophysiol. 2013;6:334-41.

6. de Boer TP, Nalos L, Stary A, Kok B, Houtman MJ, Antoons G, van Veen TA, Beekman JD, de Groot $B L$, Opthof T, Rook MB, Vos MA and van der Heyden MA. The anti-protozoal drug pentamidine blocks KIR2.x-mediated inward rectifier current by entering the cytoplasmic pore region of the channel. Br J Pharmacol. 2010;159:1532-41. 


\section{Chapter}

The effect of chronic atrial fibrillation on responsiveness of isolated left atrial and ventricular resistance arteries in goats

Dragan Opačić, Paul Schiffers, Ger Janssen, Marion Kuiper, Stef Zeemering, Ulrich Schotten, Sander Verheule 


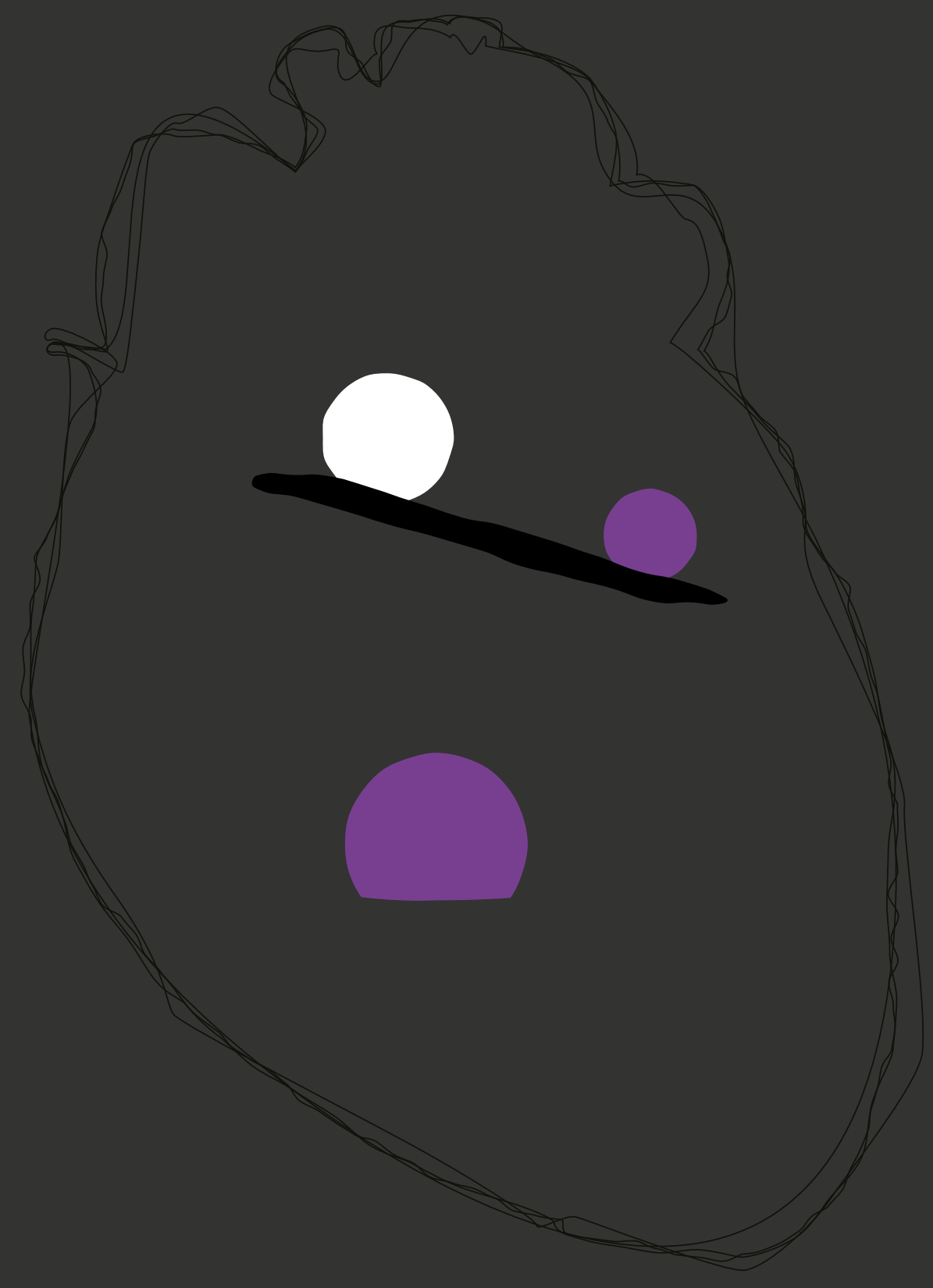




\begin{abstract}
Background: A mismatch between atrial coronary blood supply and atrial demand during atrial fibrillation (AF) may trigger proarrhythmic atrial remodeling. The objective of our study was to determine whether chronic AF in goats alters the function of isolated atrial and ventricular resistance arteries.
\end{abstract}

Methods: Vasomotor studies were performed in left atrial (LA) and ventricular (LV) resistance arteries obtained from 7 AF goats (16 weeks of $\mathrm{AF}$ ) and 7 sham-operated goats using wire myography. Vessels were pre-contracted with thromboxane A2 analog U-46619. Subsequently, endothelium-dependent and endothelium-independent relaxation were quantified using Bradykinin (BK) and the NO donor sodium nitroprusside (SNP). In addition, endothelium-dependent relaxation was investigated in the presence of L-NAME and Indomethacin.

Results: After 16 weeks of $A F$, endothelium-dependent vasodilation in response to $B K$ was increased in $L A$ vessels of $A F$ goats. The $L A$ pEC50 for BK in the AF group was significantly lower than in sham ( $8.19 \pm 0.12$ vs. $8.77 \pm 0.10$, $\mathrm{p}<0.01)$. This difference was further increased in the presence of L-NAME and Indomethacin $(7.42 \pm 0.11$ vs. $8.41 \pm 0.11, \mathrm{p}<0.01)$. Endothelium-independent vasodilation was comparable between the groups for both $L A$ and LV vessels ( $p E C 50=5.88 \pm 0.16$ vs. $6.15 \pm 0.09, p=n s ; p E C 50=5.89 \pm 0.10$ vs. $5.66 \pm 0.06$, $\mathrm{p}=\mathrm{ns}$; respectively). The $\mathrm{U}-46619$-induced maximal contraction $\left(\mathrm{E}_{\max }\right)$ of $L A$ and LV vessels was similar for both groups $(2.24 \pm 0.22 \mathrm{vs} .2 .22 \pm 0.29 \mathrm{mN} / \mathrm{mm}$, $\mathrm{p}=n s ; 2.18 \pm 0.43$ vs. $2.15 \pm 0.24 \mathrm{mN} / \mathrm{mm}, \mathrm{p}=\mathrm{ns}$, respectively).

Conclusions: Our findings demonstrate that chronic AF causes changes in the vascular function of LA resistance arteries. These changes may affect coronary flow regulation in fibrillating atria and therefore affect atrial supply/demand balance during AF. 


\section{Introduction}

Atrial fibrillation (AF) is the most common sustained arrhythmia in clinical practice. The natural time course of atrial fibrillation is characterized by gradual prolongation of AF episode duration until the arrhythmia becomes sustained. One of the underlying processes primarily considered responsible for the progressive nature of AF is atrial structural remodeling, which includes endomysial fibrosis, myocyte hypertrophy, myocyte dedifferentiation, etc. ${ }^{1-4}$. However, the exact factors that trigger and perpetuate AF-associated atrial structural remodeling are still not completely understood.

Recently, we have shown that acute AF in pigs causes a supply-demand mismatch between atrial coronary blood supply and atrial demand that is evidenced by an increase in atrial lactate production ${ }^{5}$. Skalidis et al. reported a decrease in coronary flow reserve of the atria in patients with lone recurrent $A F$, suggesting a contribution of atrial microvascular dysfunction in the pathophysiology of $\mathrm{AF}^{6}$. To preserve sufficient coronary blood perfusion during increased demand, the appropriate vasomotor reactivity of the coronary vasculature is of utmost importance. Vascular endothelium represents one of the most important factors involved in the regulation of vascular tone. A properly functioning endothelium releases substances that cause the relaxation of the vascular smooth muscle cells. These substances include NO synthesized by the endothelial NOS (eNOS), a release of different prostaglandins, and activation of other mechanisms usually described as Endothelium-Derived Hyperpolarizing Factors (EDHF) ${ }^{7}$.

Our group has shown that long-lasting AF in goats and humans is associated with uncoupling of eNOS ${ }^{8}$, which is a major cause of endothelial dysfunction ${ }^{9}$. Therefore, the observed microvascular dysfunction and impaired atrial perfusion associated with AF could be a consequence of endothelial dysfunction.

We have designed this study to characterize the effect of lone chronic AF in goats on isolated atrial and ventricular resistance arteries, and to investigate whether AF causes endothelial dysfunction.

\section{Material and methods}

\section{Animal model}

Animal experiments were approved by the Committee for Experiments on Animals of the Maastricht University, The Netherlands and performed according to 'European Directive for the Protection of Vertebrate Animals used for Experimental and Scientific Purpose, European Community Directive for the Protection of Vertebrate animals used for Experimental and Scientific Purpose, European Community Directive 86/609/CEE'.

In total 14 Dutch white milk goats were divided into two groups, an AF group, $\mathrm{n}=7$ and a sham group, $n=7$. All goats were implanted with one exteriorized custom-made electrode and one internal electrode connected to a subcutaneously implanted neurostimulator (Medtronic Itrel $\left.{ }^{\circledR}\right)$. Anesthesia was induced with Sodium-Thiopental $(20 \mathrm{mg} / \mathrm{kg})$ and 
maintained with Sufentanil $(6 \mu \mathrm{g} / \mathrm{kg} / \mathrm{h})$ and Propofol $(10 \mathrm{mg} / \mathrm{kg} / \mathrm{h})$ while the muscle relaxant Pavulon $(0.3 \mathrm{mg} / \mathrm{kg} / \mathrm{h})$ was added in the follow-up experiment.

AF in goats was induced as described previously ${ }^{10,11}$. Briefly, after a recovery period, in the AF animals, the exteriorized electrode was connected to an external custom-made electrical stimulator which was used for AF initiation and continuous monitoring of AF stabilization until a single AF episode duration was longer than 24 hours. Afterward, a subcutaneously implanted neurostimulator connected to the internal electrode was used for AF maintenance. AF was induced and maintained in 7 goats for 16 weeks by repetitive $50 \mathrm{~Hz}$ burst stimulation at 4 times diastolic threshold. The control group consisted of 7 sham animals implanted in the same manner, but in which AF was never induced.

\section{Tissue harvesting and vessel isolation}

After anesthesia induction, a left-sided thoracotomy was performed, and the heart was exposed. In none of the animals, there were signs of infection or adhesions within the pericardial sac. After a stabilization period of at least 30 minutes, the heart was excised and a region of left atrial and left ventricular tissue surrounding the left circumflex artery was collected and stored in a $4^{\circ} \mathrm{C}$ HEPES solution. Using a dissection microscope, both LA and $L V$ resistance arteries were isolated from the tissue and stored overnight in HEPES solution that contained (in mM): $\mathrm{NaCl} 144, \mathrm{KCl} 4.7, \mathrm{CaCl}_{2} 2.5, \mathrm{MgSO}_{4} 1.2, \mathrm{KH}_{2} \mathrm{PO}_{4} 1.2, \mathrm{HEPES}$ 14.9 and glucose 5.5 with a $\mathrm{pH}$ set to 7.4 .

\section{Vasomotor studies}

The next day, isolated LA and LV arterial segments were mounted on multi-channel wire myographs (Multi-channel wire myograph system, DMT, Denmark) and isometric force development was recorded as previously described ${ }^{12}$. Briefly, after mounting, the vessel segments were equilibrated for 60 minutes at $37^{\circ} \mathrm{C}$ in an oxygenated Krebs-Ringer bicarbonate buffer containing (in $\mathrm{mM}$ ): $\mathrm{NaCl}$ : 118.5; $\mathrm{KCL}: 4.7 ; \mathrm{CaCl}_{2}: 2.5 ; \mathrm{KH}_{2} \mathrm{PO}_{4}: 1.2 ; \mathrm{NaHCO}_{3}$ : 25.0 and glucose: 5.5 . Following equilibration, the arterial segments were distended to a lumen diameter corresponding to $90 \%$ of the passive lumen diameter at a transmural pressure of $100 \mathrm{mmHg}\left(0.9 * \mathrm{~d}_{100}\right)$ and left to equilibrate for additional 30 minutes ${ }^{12,13}$. Vessels were precontracted with the Thromboxane A2 analog U46119 in incrementing doses from $10^{-9} \mathrm{M}$ to $10^{-5.5} \mathrm{M}$ to determine the dose-response curve. Dose-response curves for Bradykinin (BK, $10^{-10} \mathrm{M}$ to $10^{-6} \mathrm{M}$, endothelium-dependent vasodilatation) and the NO donor Sodium Nitroprusside (SNP, $10^{-8} \mathrm{M}$ to $10^{-4.5} \mathrm{M}$, endothelium-independent vasodilation) were recorded in the presence of $10^{-5.5} \mathrm{M}$ U46619. Finally, the vessels were incubated with L-NAME $\left(10^{-1} \mathrm{M}\right)$ and Indomethacin $\left(10^{-2} \mathrm{M}\right)$ for 30 minutes after which the Bradykinin dose-response curve was again recorded in the presence of $10^{-5.5} \mathrm{M} U 46619$. The protocol and a typical wire-myography trace are depicted in the figure 1. 


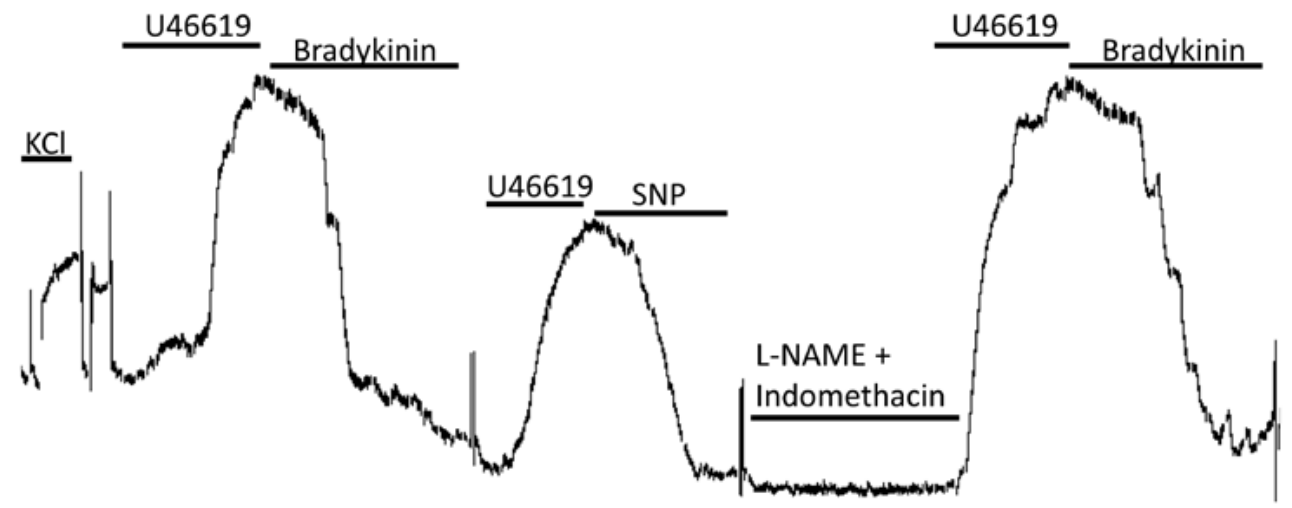

Figure 1. The protocol and a typical wire myography trace.

\section{Chemicals}

U46619 (Cayman Chemical \#16450) and Indomethacin (Sigma-Aldrich 17378) were dissolved in 100\% ethanol. Bradykinin acetate salt (Sigma-Aldrich B3259), SNP (SigmaAldrich S0501) and L-NAME (Sigma-Aldrich N5751) were dissolved in distilled water.

\section{Statistical analysis}

GraphPad Prism version 7.00 for Windows (GraphPad Software, La Jolla California USA) and IBM SPSS Statistics for Windows, version 23 (IBM Corp., Armonk, N.Y., USA) were used for data analysis and presentation. Individual concentration-response curves were fitted to a nonlinear sigmoid regression curve from which pEC50 (negative logarithm of the molar concentration that elicits $50 \%$ of the maximal effect of the agonist or antagonist) were obtained. The maximal effect $\left(\mathrm{E}_{\max }\right)$ of $\mathrm{U} 46119$ was calculated as the maximal force produced at the highest investigated concentration of $U 46619\left(10^{5.5} \mathrm{M}\right)$, while $\mathrm{E}_{\max }$ for Bradykinin and SNP were expressed as the percentage of relaxation normalized to the maximal contraction with U46619. All results are expressed as mean \pm SEM. A random intercept mixed model with Bonferroni post hoc correction was used to test the difference in $E_{\max }$ and pEC50 between the groups. A difference with $p<0.05$ was considered statistically significant.

\section{Results}

\section{Passive properties of the left atrial and left ventricular resistance size arteries}

In total 65 isolated vessels (LA: 21 from 7 sham and 23 from 6 AF animals; LV: 9 from 5 sham and 12 from $6 \mathrm{AF}$ animals) were included in the study. The average optimal lumen diameter $\left(0.9 * \mathrm{~d}_{100}\right)$ of all isolated arteriolar segments was $296 \pm 10.9 \mu \mathrm{m}$ and it was comparable between the groups both for the LA and LV vessels (Figure 2A). The passive wall tension was plotted against vessel displacement and a straight line was fitted at the linear part of the curve. The slope of the fitted linear function was used to quantify vessel stiffness. The vessel stiffness was similar between the groups both for LA $(17.8 \pm 1.5 \mathrm{vs} .17 .7 \pm 1.9 \mathrm{mN} /$ $\left.\mathrm{mm}^{2}, \mathrm{p}=0.689\right)$ and for $\mathrm{LV}\left(18.7 \pm 1.5\right.$ vs. $\left.19.5 \pm 2.2 \mathrm{mN} / \mathrm{mm}^{2}, \mathrm{p}=0.557\right)$ vessels (Figure $2 B$ ). 

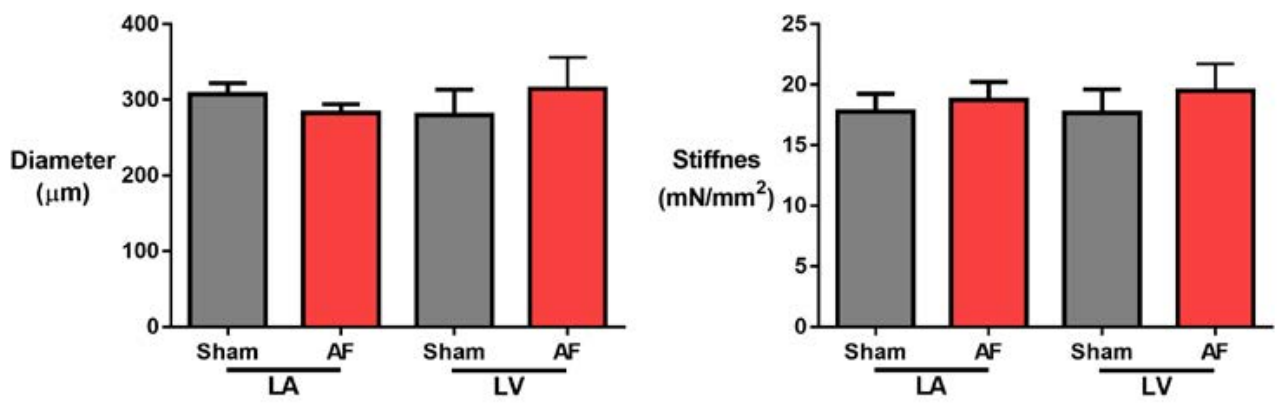

Figure 2. Passive properties of the left atrial (LA) and left ventricular (LV) resistance size arteries. (A) Optimal lumen diameter $\left(0.9^{*}\right.$ d100) of resistance arteries for LA sham $(n=7)$ and AF $(n=6)$ and for LV sham $(n=5)$ and $\mathrm{AF}(\mathrm{n}=6)$ and $(\mathbf{B})$ passive vascular stiffness.

\section{Receptor-dependent vasoconstriction}

The thromboxane A2 analog U46619 caused stable, dose-dependent vasoconstriction in both LA and LV resistance arteries. Maximal wall tension produced in response to the highest $\mathrm{U} 46619$ concentration $\left(\mathrm{E}_{\max }\right)$ was comparable between the sham and AF group for both LA $(2.24 \pm 0.22$ vs. $2.22 \pm 0.29 \mathrm{mN} / \mathrm{mm}, \mathrm{p}=0.883)$ and $\mathrm{LV}$ resistance arteries $(2.18 \pm 0.43$ vs. $2.15 \pm 0.24 \mathrm{mN} / \mathrm{mm}, \mathrm{p}=0.982$ ). Similarly, the concentration with half-maximal effect ( $p E C 50$ ) did not differ between the groups, independently of the vascular bed investigated (6.98 \pm 0.09 vs. $6.90 \pm 0.06, p=0.862$ for the $L A$ and $6.76 \pm 0.33$ vs. $6.71 \pm 0.19, p=0.665$ for the LV) (Figure $3 \mathrm{~A}, \mathrm{~B}$; Table 1.). These findings suggest that the contractile properties of $L A$ and $\mathrm{LV}$ resistance arteries were not altered by AF.
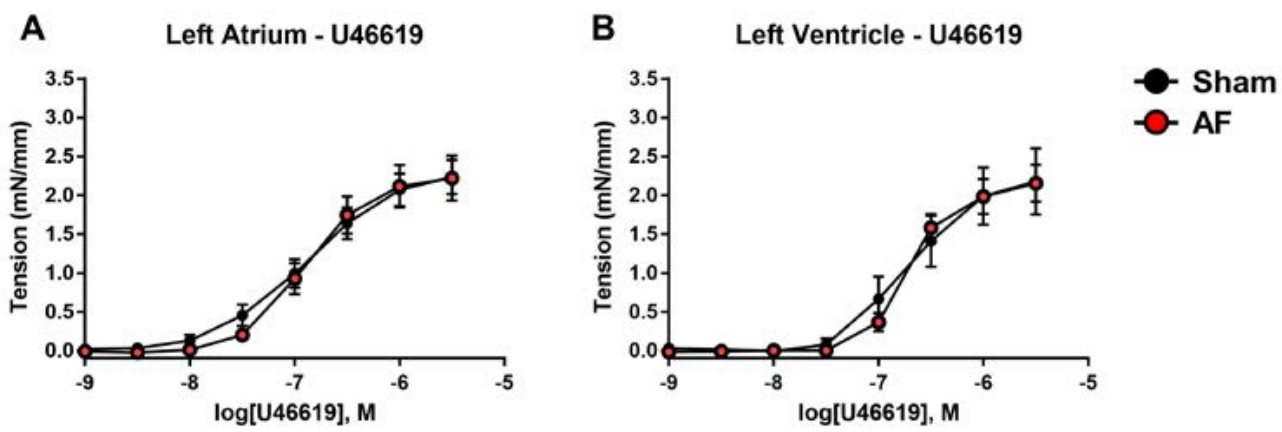

Figure 3. Receptor-dependent vasoconstriction. (A) U466619 dose-response curve showing the vascular wall tension of LA arteries in sham ( $n=7)$ and AF animals $(n=6),(B)$ U466619 dose-response curve showing the vascular wall tension of $L V$ arteries in sham $(n=4)$ and $A F$ animals $(n=6)$. 
Table 1. Values of the pEC50 (negative logarithm of the molar concentration that elicits $50 \%$ of maximal effect of the agonist or antagonist) and maximal effect $\left(E_{\max }\right)$ in the presence of the highest concentration of the investigated compounds.

\begin{tabular}{|c|c|c|c|c|c|c|}
\hline $\begin{array}{l}\text { pEC50 } \\
(-\log M)\end{array}$ & & Sham & AF & $\begin{array}{l}\text { Sham + } \\
\text { L-NAME \& } \\
\text { Indometacin }\end{array}$ & $\begin{array}{l}\text { AF + } \\
\text { L-NAME \& } \\
\text { Indometacin }\end{array}$ & $\mathbf{p}$ \\
\hline \multirow{2}{*}{ U46619 } & LA & $6.98 \pm 0.09$ & $6.90 \pm 0.06$ & & & 0.862 \\
\hline & LV & $6.76 \pm 0.33$ & $6.71 \pm 0.19$ & & & 0.665 \\
\hline \multirow{2}{*}{ BK } & LA & $8.19 \pm 0.12$ & $8.77 \pm 0.10 \dagger$ & $7.42 \pm 0.11 \S$ & $8.41 \pm 0.11^{*} \ddagger$ & 0.001 \\
\hline & LV & $8.60 \pm 0.17$ & $8.80 \pm 0.16$ & $8.12 \pm 0.26$ & $8.18 \pm 0.10 \neq$ & 0.001 \\
\hline \multirow{2}{*}{ SNP } & LA & $5.88 \pm 0.16$ & $6.15 \pm 0.09$ & & & 0.495 \\
\hline & LV & $5.89 \pm 0.10$ & $5.66 \pm 0.06$ & & & 0.059 \\
\hline$E_{\max }$ & & Sham & AF & $\begin{array}{l}\text { Sham + } \\
\text { L-NAME \& } \\
\text { Indometacin }\end{array}$ & $\begin{array}{l}\text { AF + } \\
\text { L-NAME \& } \\
\text { Indometacin }\end{array}$ & p \\
\hline \multirow{2}{*}{$\begin{array}{l}10^{-5.5} \mathrm{M} \mathrm{U} 46619 \\
(\mathrm{mN} / \mathrm{mm})\end{array}$} & LA & $2.24 \pm 0.22$ & $2.22 \pm 0.29$ & & & 0.883 \\
\hline & LV & $2.18 \pm 0.43$ & $2.15 \pm 0.24$ & & & 0.982 \\
\hline \multirow{2}{*}{$\begin{array}{l}10^{-6} \mathrm{M} \mathrm{BK} \\
(\%)\end{array}$} & LA & $98.8 \pm 4.4$ & $92.8 \pm 4.5$ & $85.1 \pm 8.5$ & $90.2 \pm 6.1$ & n.s. \\
\hline & LV & $100.7 \pm 3.2$ & $96.2 \pm 1.9$ & $102.3 \pm 3.3$ & $95.8 \pm 5.0$ & n.s. \\
\hline \multirow{2}{*}{$\begin{array}{l}10^{-4.5} \text { SNP } \\
(\%)\end{array}$} & LA & $82.2 \pm 3.9$ & $93.1 \pm 4.3$ & & & 0.234 \\
\hline & LV & $87.0 \pm 6.9$ & $84.2 \pm 2.7$ & & & 0.610 \\
\hline
\end{tabular}

$+p \leq 0.01$ Sham vs. AF

$\S \mathrm{p} \leq 0.001$ bsln vs. L-NAME + Indomethacin

* $\mathrm{p} \leq 0.01$ bsin vs. L-NAME + Indomethacin

$\neq p \leq 0.001$ Sham vs. AF in a presence of L-NAME + Indomethacin

\section{Endothelium-dependent and -independent vasodilatation}

Dose-response curves for BK (endothelium-dependent vasodilatation) and SNP (endothelium-independent vasodilation) were determined in precontracted vessels at the highest investigated concentration of U46619 $\left(10^{-5.5} \mathrm{M}\right)$.

Endothelium-independent vasodilatation was similar between the groups. Maximal dilation $\left(\mathrm{E}_{\max }\right)$ was achieved only with the highest investigated concentration of SNP $\left[10^{-4.5} \mathrm{M}\right]$ both for the LA and LV $(82.2 \pm 3.9$ vs. $93.1 \pm 4.3 \%, p=0.234 ; 87.0 \pm 6.9$ vs. $84.2 \pm 2.7$, $\mathrm{p}=0.715$; respectively). In addition, the dose-response curves did not differ between the groups both for the LA and LV vessels, as confirmed by similar pEC50 in each group (5.88 \pm 0.16 vs. $6.15 \pm 0.09, p=0.495$ for the $L A$ and $5.89 \pm 0.10$ vs. $5.66 \pm 0.06, p=0.059$ for the LV) (Figure 4A, B; Table 1.). 

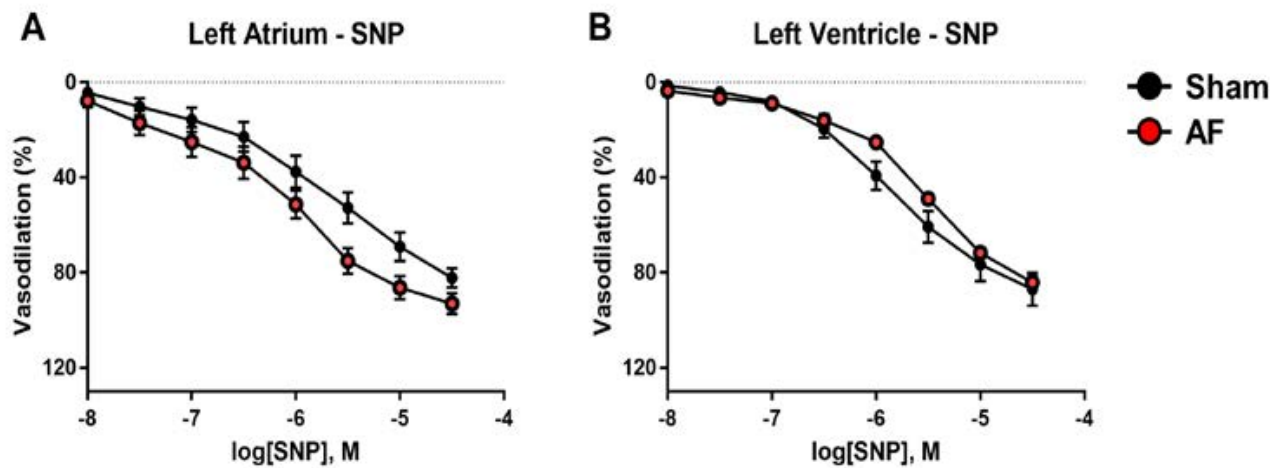

Figure 4. Endothelium-independent vasodilatation. (A) SNP mediated vasodilation dose-response curve of LA arteries in sham $(n=7)$ and AF animals $(n=6),(B)$ SNP mediated vasodilation dose-response of LV arteries in sham $(n=4)$ and AF animals $(n=4)$.

On the other hand, the dose-response curve for BK was shifted to the left in LA vessels in the AF group compared to Sham, implying increased sensitivity of these vessels to endothelium-dependent vasodilatation. Comparing the $\mathrm{pEC50}$ values acquired from the dose-response curves of the LA vessels of the sham and AF goats, this leftward shift was statistically significant ( $8.19 \pm 0.12$ vs. $8.77 \pm 0.10, p<0.01)$ (Figure $5 A$; Table 1.). Interestingly, BK dose-response curves of the LV vessels from the AF animals were similar to the ones from the sham group, with a pEC50 of $8.60 \pm 0.17$ for sham LV and $8.80 \pm 0.16$ for AF LV $(p=0.186)$ (Figure 5B; Table 1.).

After the incubation of the vessels with the L-NAME and Indomethacin to block both eNOS-mediated and prostaglandin-mediated vasodilatory pathways, the sensitivity to the BK-induced vasodilation was reduced in all vessels (Figure 5C-D; Table 1.). However, the leftward shift of the LA vessels isolated from AF animals compared to the vessels isolated from sham animals was actually increased (Sham $\mathrm{pEC} 50=7.42 \pm 0.11 \mathrm{vs}$. AF $\mathrm{pEC} 50=8.41 \pm 0.11, \mathrm{p}<0.001$ ) (Figure $5 \mathrm{C}$; Table 1.). The responsiveness of LV resistance arteries to BK remained comparable between the groups, ( $8.12 \pm 0.26$ vs $8.41 \pm 0.11$, $\mathrm{p}=0.596$ ) (Figure 5D; Table 1.).

The maximal effect of $B K\left(E_{\max }\right)$ was similar between the groups both before and after the incubation with L-NAME and Indomethacin (Figure 5A-D; Table 1.). 

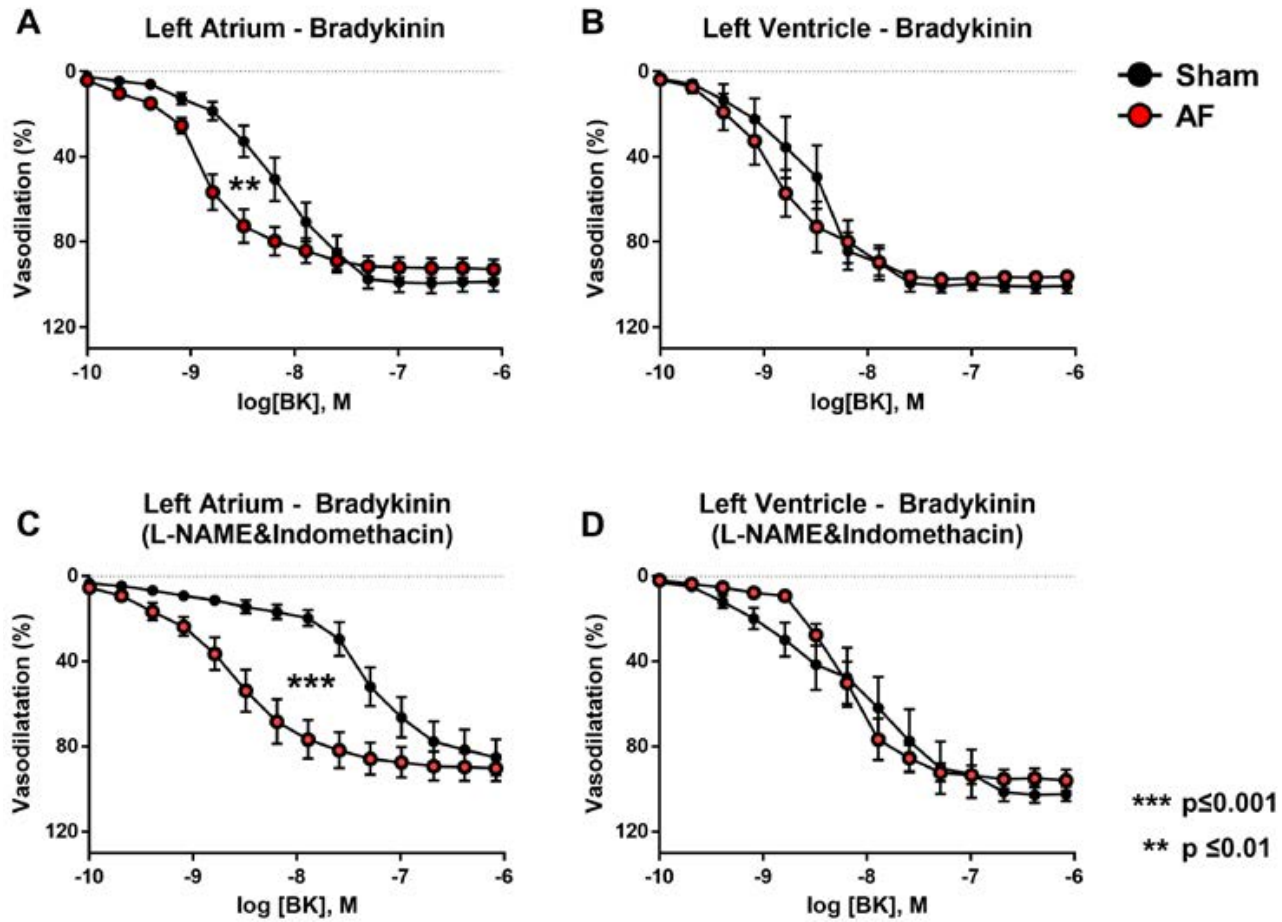

Figure 5. Endothelium-dependent vasodilatation. BK-mediated vasodilation dose-response curve at baseline of $L A$ arteries $(A)$ in sham $(n=5)$ and AF animals $(n=6)$ and of $L V$ arteries $(B)$ in sham $(n=3)$ and AF animals $(n=5)$. BK-mediated vasodilation dose-response curve after the incubation with L-NAME (10-1M) and Indomethacin (10-2M) of LA arteries $(\mathbf{C})$ in sham $(n=4)$ and AF animals $(n=6)$ and of $L V$ arteries $(\mathbf{D})$ in sham $(n=5)$ and AF animals $(n=5) .{ }^{*} P<0.01 ;{ }^{* * *} p<0.001$ sham vs. AF arteries.

\section{Discussion}

The interplay between inadequate atrial perfusion and the pathophysiology of AF has received growing attention ${ }^{14}$, but it is not known whether AF by itself leads to vascular remodeling. We have designed this study to investigate the effect of long-term AF without preexisting structural heart disease on the behavior of isolated LA and LV resistance arteries. Our results show that long term AF does not affect the contractile response of LA and LV vessels to U46619. Similarly, endothelium-independent vasodilatation was not significantly altered due to chronic AF. Contrary to our expectations, we have observed that $L A$ resistance arteries show increased responsiveness to BK-mediated endotheliumdependent vasodilatation. This increased responsiveness to BK was observed exclusively in LA vessels and was further augmented in the presence of L-NAME and Indomethacin.

Both acute and chronic AF can cause supply/demand ischemia ${ }^{5,15-17}$. The blood flow required for adequate tissue perfusion is determined by the perfusion pressure and the resistance of the vascular bed ${ }^{18}$. In normal, healthy hearts coronary vascular resistance is mainly determined by small resistance arteries ${ }^{19}$. Impaired perfusion may result from 
changes in vascular structure or altered responsiveness of vascular smooth muscle cells, either an increased response to vasoconstrictors or a decreased response to vasodilators.

Several studies in different species showed that acute AF increases atrial blood flow significantly $y^{5,20,21}$, but effects of long term AF on vascular structure and function have scarcely been studied ${ }^{14}$. In patients with lone AF, Skalidis et al. reported a reduction in coronary flow reserve of the left atrial coronary branch, but not in the left circumflex coronary artery ${ }^{6}$. To our knowledge, this is the only study in which a functional assessment of the atrial coronary vasculature of AF patients has been performed. However, based on those findings, it is not possible to discriminate whether this isolated atrial vascular dysfunction of AF patients was a result of structural or functional alterations of the atrial vasculature. One of the possible causes of decreased coronary flow reserve could be a decrease in capillary density which has indeed been observed both in AF patients with mitral regurgitation and in patients with lone chronic $\mathrm{AF}^{16,22}$. Another possible explanation could be alterations in the regulation of atrial coronary resistance arteries i.e. impaired endothelial function ${ }^{8,9}$. In our study, AF did not cause increased contractile response to the thromboxane A2 analog U46619 in either LA and LV vessels. In addition, the vessel wall stiffness was also not altered by $A F$, indicating that $A F$ does not cause significant changes in the passive properties of coronary resistance arteries.

Contrary to our expectations, the sensitivity to $\mathrm{BK}$, an endothelium-dependent vasodilator was significantly increased in resistance arteries from the $L A$, but not $L V$, indicating that despite to the observed eNOS uncoupling in long-term AF, endothelial function seems to be preserved. BK can produce its effect through several signaling pathways, including nitric oxide (NO), prostaglandin E2 (PGE2) and endothelium-derived hyperpolarizing factor $(\mathrm{EDHF})^{23}$. The increase in sensitivity to $\mathrm{BK}$ was further enhanced after incubation of vessels with L-NAME (blocking NO-dependent dilatation) and Indomethacin (blocking PGE2-dependent dilatation), which indicates that the observed increase in responsiveness to BK was mainly mediated by EDHF. The importance of EDHF in vasodilatation in our experiments was also confirmed by the fact that the maximal degree of vasodilatation of all vessel groups was achieved during incubation with L-NAME and Indomethacin. A similar increase in BK-mediated vasodilatation of resistance-sized coronary arteries of exercise-trained pigs was reported by Muller et al. ${ }^{24}$. The authors in that study propose that the enhancement in vasodilatory response to BK is an increased production of EDHF, but also increased production of NO. In addition, an absence of a significant change in endothelium-independent vasodilation observed in experiments, further strengthening the point that changes in vasodilatory response in LA vessels derive mainly from endothelium-dependent pathways.

Importantly, EDHF does not represent a single substance, but rather a number of substances secreted by endothelial cells that lead to hyperpolarization of arterial smooth muscle cells, thereby resulting in vasodilation ${ }^{25}$. EDHF-mediated relaxation pathways include diffusible factors and contact-mediated pathways. Diffusible factors are epoxyeicosatrienoic acids, hydrogen peroxide, endothelium-derived potassium ions, and C-type natriuretic peptide, while contact-mediated pathways are mediated by both homocellular and myoendothelial 
gap junctions ${ }^{25}$. Interestingly, Lee et al. reported significantly elevated levels of C-type natriuretic peptide in patients with acute coronary syndrome presenting with $\mathrm{AF}^{26}$. The C-type natriuretic peptide is secreted from vessel walls and has beneficial effects both on the endothelium and on the heart by preventing neointimal hyperplasia and by inhibiting myocardial fibrosis and hypertrophy respectively ${ }^{27}$.

Based on our results, we suggest that the decreased coronary flow reserve observed by Skalidis et al. ${ }^{6}$ may result not only from atrial microvascular dysfunction but also from a decrease in coronary flow reserve attributable to increased basal vasodilatation. This increased basal vasodilatation could represent an adaptive response of the atrial coronary vasculature to the increased metabolic demand during episodes of AF.

\section{Limitations}

The major limitation of our study is the fact that all experiments were performed ex vivo in isolated vessels. Although this approach, which is widely used to study vascular function, allows a direct assessment of alterations in the behavior of vessels, it excludes paracrine interactions with surrounding tissues. The vascular tone in vivo not only depends on the responsiveness of vessels to vasodilators and vasoconstrictors but also on the levels of these substances the vessels are exposed to in the intact tissue. Further investigation of the (dys)regulation of vascular tone in AF and its role in myocardial tissue perfusion will require in vivo experiments.

\section{Conflict of interest}

None

\section{Funding}

This study was supported by the European Union (RADical reduction of OXidative stress in cardiovascular disease (RADOX, No. 316738)) and by a grant from the Dutch Heart Foundation (CVON2014-09, RACE V: Reappraisal of Atrial Fibrillation: Interaction between hyperCoagulability, Electrical remodeling, and Vascular Destabilisation in the Progression of $A F$ ). 


\section{References}

1. Eckstein J, Zeemering S, Linz D, Maesen B, Verheule S, van Hunnik A, Crijns H, Allessie MA and Schotten $U$. Transmural conduction is the predominant mechanism of breakthrough during atrial fibrillation: evidence from simultaneous endo-epicardial high-density activation mapping. Circ Arrhythm Electrophysiol. 2013;6:334-41.

2. Ausma J, Wijffels M, van Eys G, Koide M, Ramaekers F, Allessie Mand Borgers M. Dedifferentiation of atrial cardiomyocytes as a result of chronic atrial fibrillation. Am J Pathol. 1997;151:985-97.

3. Charbel FT, Hoffman WE, Misra M, Hannigan K and Ausman Jl. Cerebral interstitial tissue oxygen tension, $\mathrm{pH}, \mathrm{HCO} 3, \mathrm{CO}$. Surgical neurology. 1997;48:414-7.

4. Schotten U, Verheule S, Kirchhof P and Goette A. Pathophysiological mechanisms of atrial fibrillation: a translational appraisal. Physiol Rev. 2011;91:265-325.

5. van Bragt KA, Nasrallah HM, Kuiper M, Luiken JJ, Schotten $U$ and Verheule S. Atrial supplydemand balance in healthy adult pigs: coronary blood flow, oxygen extraction, and lactate production during acute atrial fibrillation. Cardiovascular research. 2014;101:9-19.

6. Skalidis El, Hamilos MI, Karalis IK, Chlouverakis G, Kochiadakis GE and Vardas PE. Isolated atrial microvascular dysfunction in patients with lone recurrent atrial fibrillation. J Am Coll Cardiol. 2008;51:2053-7.

7. Durand MJ and Gutterman DD. Diversity in mechanisms of endothelium-dependent vasodilation in health and disease. Microcirculation. 2013;20:239-47.

8. Reilly SN, Jayaram R, Nahar K, Antoniades C, Verheule S, Channon KM, Alp NJ, Schotten U and Casadei $B$. Atrial sources of reactive oxygen species vary with the duration and substrate of atrial fibrillation: implications for the antiarrhythmic effect of statins. Circulation. 2011;124:1107-17.

9. Vallet B. Endothelial cell dysfunction and abnormal tissue perfusion. Crit Care Med. 2002;30:S229-34.

10. Wijffels MC, Kirchhof CJ, Dorland R and Allessie MA. Atrial fibrillation begets atrial fibrillation. A study in awake chronically instrumented goats. Circulation. 1995;92:1954-68.

11. Verheule S, Tuyls E, van Hunnik A, Kuiper M, Schotten U and Allessie M. Fibrillatory conduction in the atrial free walls of goats in persistent and permanent atrial fibrillation. Circ Arrhythm Electrophysiol. 2010;3:590-9.

12. Mulvany MJ and Halpern W. Contractile properties of small arterial resistance vessels in spontaneously hypertensive and normotensive rats. Circ Res. 1977;41:19-26.

13. Halpern W, Mulvany MJ and Warshaw DM. Mechanical properties of smooth muscle cells in the walls of arterial resistance vessels. J Physiol. 1978;275:85-101.

14. Opacic D, van Bragt KA, Nasrallah HM, Schotten U and Verheule S. Atrial metabolism and tissue perfusion as determinants of electrical and structural remodeling in atrial fibrillation. Cardiovasc Res. 2016.

15. Gramley F, Lorenzen J, Jedamzik B, Gatter K, Koellensperger E, Munzel T and Pezzella F. Atrial fibrillation is associated with cardiac hypoxia. Cardiovasc Pathol. 2010;19:102-11.

16. Corradi D, Callegari S, Maestri R, Ferrara D, Mangieri D, Alinovi R, Mozzoni P, Pinelli S, Goldoni M, Privitera YA, Bartoli V, Astorri E, Macchi E, Vaglio A, Benussi S and Alfieri O. Differential structural remodeling of the left-atrial posterior wall in patients affected by mitral regurgitation with or without persistent atrial fibrillation: a morphological and molecular study. J Cardiovasc Electrophysiol. 2012;23:271-9. 
17. Ausma J, Coumans WA, Duimel H, Van der Vusse GJ, Allessie MA and Borgers M. Atrial high energy phosphate content and mitochondrial enzyme activity during chronic atrial fibrillation. Cardiovasc Res. 2000;47:788-96.

18. Duncker DJ, Koller A, Merkus D and Canty JM, Jr. Regulation of coronary blood flow in health and ischemic heart disease. Prog Cardiovasc Dis. 2015;57:409-22.

19. Chilian WM, Eastham CL and Marcus ML. Microvascular distribution of coronary vascular resistance in beating left ventricle. Am J Physiol. 1986;251:H779-88.

20. White CW, Kerber RE, Weiss HR and Marcus ML. The effects of atrial fibrillation on atrial pressure-volume and flow relationships. Circ Res. 1982;51:205-15.

21. McHale PA, Rembert JC and Greenfield JC, Jr. Effect of atrial fibrillation on atrial blood flow in conscious dogs. Am J Cardiol. 1983;51:1722-7.

22. Boldt A, Scholl A, Garbade J, Resetar ME, Mohr FW, Gummert JF and Dhein S. ACE-inhibitor treatment attenuates atrial structural remodeling in patients with lone chronic atrial fibrillation. Basic research in cardiology. 2006;101:261-7.

23. Vanhoutte PM. Endothelium-dependent hyperpolarizations: the history. Pharmacol Res. 2004;49:503-8.

24. Muller JM, Myers PR and Laughlin MH. Vasodilator responses of coronary resistance arteries of exercise-trained pigs. Circulation. 1994;89:2308-14.

25. Luksha L, Agewall S and Kublickiene K. Endothelium-derived hyperpolarizing factor in vascular physiology and cardiovascular disease. Atherosclerosis. 2009;202:330-44.

26. Lee J, Than M, Aldous S, Troughton R, Richards M and Pemberton CJ. CNP Signal Peptide in Patients with Cardiovascular Disease. Front Cardiovasc Med. 2015;2:28.

27. Federico C. Natriuretic Peptide system and cardiovascular disease. Heart Views. 2010;11:10-5. 


\section{Chapter VI}

\section{The metabolic modulator trimetazidine inhibits AF-induced atrial structural remodeling}

Dragan Opačić, Philippe Pasdois, Stephanie Reid, Jorik Simons, Antje Weseler, Patrick Schönleitner, Arne van Hunnik, Marion Kuiper, Wil Coumans, Marie Jose Drittij, Ioannis Akomianakis, Joost Luiken, Charalambos Antoniades, Ulrich Schotten, Sander Verheule 



\begin{abstract}
Introduction: Atrial fibrillation (AF) is a progressive disease. We have recently shown that AF leads to metabolic derangement in the first minutes to weeks of AF. As a treatment to redress this metabolic derangement, we have investigated the effect of treatment with Trimetazidine (TMZ). TMZ has pleiotropic effects, including improved oxygen efficiency, decreased ROS production and mitochondrial protection.
\end{abstract}

Purpose: We have investigated whether improving atrial energy production and inhibiting ROS production with TMZ treatment inhibits AF stabilization and AF-induced atrial remodeling.

Methods: Dutch female white milk goats were instrumented with pericardial electrodes and AF was maintained by burst pacing for 16 weeks. Eight goats were treated with $20 \mathrm{mg} / \mathrm{kg}$ of TMZ two times per day from 7 days before AF initiation until sacrifice, while 10 untreated animals with AF were used as controls (UAF). Ten sham animals received the same instrumentation, but AF was never induced.

Results: TMZ treatment abolished AF-induced increase in left atrial (LA) resting superoxide production that mainly originated from mitochondrial oxidases (LA Resting O- $47.1 \pm 2.8$ vs. $79.7 \pm 7.4$ vs. $40.0 \pm 6.5 \mathrm{RLU} / \mathrm{sec} / \mathrm{mg}$ of protein, $\mathrm{p}<0.05$; Rotenone stimulated $181.0 \pm 27.9$ vs. $309.0 \pm 24.0$ vs. $173.30 \pm 28.77 \mathrm{RLU} / \mathrm{sec} / \mathrm{mg}$ of protein, $\mathrm{P}<0.05$; for sham, UAF and TMZ treated AF respectively). However, the markers of oxidative stress (LA GSH/GSSG ratio: $50.8 \pm 9.3$ vs. $66.8 \pm 6.9$ vs. $74.9 \pm 16.0, p=$ n.s.) and oxidative damage in the left atrium (LA Malondialdehyde (MDA): $9.6 \pm 1.3$ vs. $9.2 \pm 0.9$ vs. $8.0 \pm 0.7 \mathrm{pmol}$ of MDA per mg heart tissue, $\mathrm{p}=$ n.s.) were not affected either in untreated or treated animals. This suggests increased ROS neutralizing capacity, which was indeed reflected in increased levels of the glutathione system (536 140 vs. $1034 \pm 91$ vs. $1130 \pm 178$ pmol GSH+GSSG per mg heart tissue, $p<0.05)$.

TMZ treatment did not affect early AF stabilization (time to $24 \mathrm{~h}$ AF episode 74.1 \pm 9.1 vs. $79.7 \pm 28.9 \mathrm{~h} ; \mathrm{p}=\mathrm{ns}$ ), but it inhibited structural remodeling, as reflected by inhibited atrial cardiomyocyte hypertrophy (cardiomyocyte diameter: $11.4 \pm 0.2$ vs. $13.3 \pm 0.2$ vs. $12.7 \pm 0.3 \mu \mathrm{m} ; \mathrm{p}<0.05)$, decreased cell to cell distance in the LA subepicardium ( $3.5 \pm 0.1$ vs. $3.9 \pm 0.1$ vs. $3.6 \pm 0.1 \mu \mathrm{m}, \mathrm{p}<0.05$;) and by preserved mitochondrial structure (area of individual mitochondria: $124.5 \pm 6.7$ vs. $92.3 \pm 6.7$ vs. $119.5 \pm 6.7$ pixels; $p<0.05$;).

Conclusion: TMZ did not affect early AF stabilization, but did reduce AFinduced ROS production and attenuated several hallmarks of structural remodeling. Adjunctive therapy with $\mathrm{TMZ}$ may be useful in preserving atrial structure and function during AF. 


\section{Introduction}

Atrial fibrillation (AF) is the most common sustained arrhythmia in clinical practice and is associated with numerous complications that decrease the quality of life and increase healthcare costs ${ }^{1}$. AF often begins with short episodes (paroxysms) that spontaneously revert to sinus rhythm $(\mathrm{SR})^{2}$. However, over time both in humans and in animal models, AF episodes tend to become longer, and restoration of SR becomes more difficult ${ }^{2,3}$. The underlying mechanisms responsible for this progression of AF include changes both in electrical and structural properties of the atria ${ }^{4}$. 'Electrical remodeling' is mainly responsible for initial AF stabilization and is characterized by a shortening of the action potential duration, which favors reentry ${ }^{5,6}$. On the other hand, structural remodeling, which involves cellular hypertrophy, increased endomysial fibrosis, and a hibernating phenotype of atrial cardiomyocytes is a much slower process and considered to be the main determinant of the long-term stabilization of $\mathrm{AF}^{6,7}$. Although these remodeling processes have been described extensively ${ }^{4}$, the exact causative mechanisms that lead to these changes are not fully elucidated.

We have recently shown that acute AF causes a mismatch in the supply/demand balance that results in increased lactate production ${ }^{8}$. In addition, during the first months of AF, the content of phosphocreatine is decreased, indicative of supply/demand ischemia, and that the mitochondrial structure changes ${ }^{9}$. In fact, some of the previously mentioned hallmarks of AF-induced structural remodeling resemble the hibernating phenotype of ventricular myocardium observed in the regions of low flow ischemia ${ }^{10}$. These observations suggest the possible involvement of metabolism and energy production in structural remodeling in AF.

As an important metabolic parameter, increased reactive oxygen species (ROS) production is often associated with alterations in myocyte metabolism and impaired mitochondrial function ${ }^{11}$. Excessive ROS production has also been proposed to lead to structural damage to proteins, and can therefore, represent a driving force for structural remodeling ${ }^{12,13}$. In previous work of our group, we have shown that in our goat model, AF is associated with increased ROS production and that the sources of ROS differ over the duration of $A F$, shifting from increased NADPH oxidase in the first weeks to increased mitochondrial ROS production and uncoupled NOS in the ensuing months ${ }^{14}$.

At the moment, it is not clear whether the observed supply/demand mismatch and increased ROS production indeed play a causative role in AF-induced structural remodeling. Therefore, identifying an intervention that would improve energy production, preserve mitochondrial function and structure would further clarify the role of metabolic derangement in AF. Trimetazidine, 1-(2,3,4-Trimethoxybenzyl) piperazine dihydrochloride (TMZ) is an established antianginal drug with pleiotropic effects. Trimetazidine is a socalled 'metabolic shifter' which inhibits fatty acid oxidation by blocking 3-KAT (3-ketoacylCoA thiolase), consequently favoring glucose utilization ${ }^{15}$. Although fatty acid oxidation is more 'substrate-efficient', yielding a larger number of high-energy phosphate bonds per substrate molecule (129 or 106 vs. 32 or 30), glucose utilization is more oxygen-efficient, 
yielding more high-energy bonds per $\mathrm{O}_{2}$ molecule ${ }^{16}$. Therefore, under conditions of oxygen shortage, a shift from the normal myocardial preference for fatty acid to glucose would be advantageous. Indeed, ventricular substrate preference shifts from fatty acids to glucose during low-flow ischemia ${ }^{17}$. This metabolic shift prevents the development of intracellular acidosis and ameliorates mitochondrial ATP production in settings of limited oxygen supply or during ischemia/reperfusion ${ }^{18-20}$. In addition to its protective role on mitochondrial function, TMZ also has direct anti-oxidative properties, by inhibiting NADPH oxidase, thereby decreasing cardiac fibrosis in a pressure overload mouse model, and by improving endothelial dysfunction in patients with chronic heart failure ${ }^{19,21-23}$.

Therefore, due to its numerous beneficial effects not only on the redox status of the cells but also on mitochondrial function and energy production we hypothesized that chronic TMZ treatment can prevent AF-induced metabolic alterations and decrease ROS production and thus slow down AF-associated atrial structural remodeling and AF progression. With the background of the AF-induced increased mitochondrial ROS and altered mitochondrial structure, we have also investigated how AF affects mitochondrial function, and whether changes in mitochondrial structure and function can be prevented by $T M Z$ treatment.

\section{Methods}

\section{Experimental protocol}

In total 28 female Dutch milk goats (average age 38.9 \pm 2.9 (13-62) months and weight $64.2 \pm 1.9(45-81) \mathrm{kg}$ ) were included in the study. AF was maintained for 16 weeks, after which a sacrifice experiment was performed. In 18 goats, AF was induced and maintained for 4 months. 8 of these goats were treated with subcutaneous injections of TMZ 20mg/ kg (Sigma-Aldrich, No. 653322) two times a day, starting 7 days before the initiation of AF till the end of the protocol. Sham animals $(n=10)$ were instrumented in the same manner, but in these animals, AF was never induced. The study protocol is depicted in Figure 1.

s.c. administration of $20 \mathrm{mg} / \mathrm{kg} T M Z$ twice daily or not

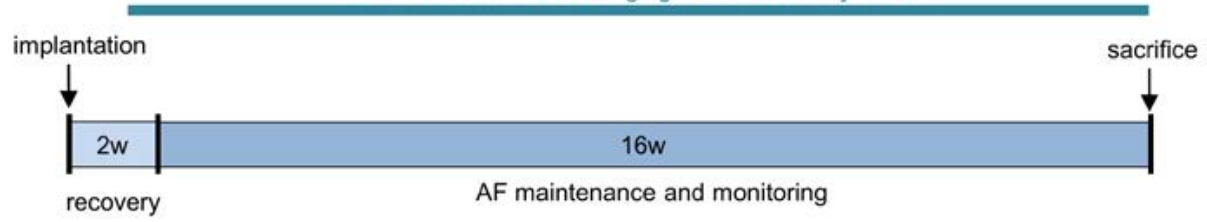

Figure 1. Study protocol

\section{Implantation procedure and AF maintenance}

Anesthesia was induced with Sodium-Thiopental $(20 \mathrm{mg} / \mathrm{kg})$ and maintained with Sufentanil $(6 \mu \mathrm{g} / \mathrm{kg} / \mathrm{h})$, and Propofol $(10 \mathrm{mg} / \mathrm{kg} / \mathrm{h})$. The muscle relaxant Pavulon $(0.3 \mathrm{mg} /$ $\mathrm{kg} / \mathrm{h}$ ) was added at follow-up experiments. A left-sided thoracotomy through the $4^{\text {th }}$ intercostal space was performed and a custom-made electrode plaque containing 10 electrodes was sutured to the pericardium on top of the left atrial free wall. In addition, two small electrode plaques with 2 electrodes were sutured to the pericardium on top of 
the left and right ventricle. The cable connected to these electrodes was then tunneled below the skin and exteriorized at the back of the animal between shoulder blades. $A$ bifurcated Bipolar Epicardial lead (Medtronic CapSure Epi) was sutured to the pericardium on top of the left free atrial wall and connected to a subcutaneously implanted pacemaker (Medtronic Itrel). After a recovery period of 2-3 weeks, goats were placed in separate cages and connected to a custom-made setup for AF induction and continuous monitoring of atrial electrical activity as described before ${ }^{5}$. In short, AF was maintained by burst pacing $(1 \mathrm{~s}, 50 \mathrm{~Hz}, 4$ times diastolic threshold) every time SR was detected (as an isoelectric line longer than $250 \mathrm{~ms}$ ) and the duration of each AF episode was recorded. Animals remained connected to this setup until a single AF episode was longer than 24 hours. Subsequently, the internal pacemaker was turned on and programmed to deliver burst stimuli $(1 \mathrm{~s}, 50 \mathrm{~Hz}$ at 4 times threshold) every minute until the end of the first 5 weeks, every 5 minutes during the second 5 weeks and every 10 minutes until the end of the protocol.

\section{Hemodynamic measurements}

After anesthesia induction and preceding opening of the chest, hemodynamic measurements were performed. Aortic and left ventricular pressures were measured with a catheter (Sentron Europe BV, Roden, the Netherlands), while cardiac output was measured using thermodilution (Swan Ganz catheter $(7.5$ FR, 110cm) from Edward Lifesciences and a Sat-2 Oximeter/Cardiac output computer Baxter). From the pressure signals obtained in the LV, we calculated end-diastolic and end-systolic LV pressures as well as left ventricular $\mathrm{dP} / \mathrm{dt}$, max and $\mathrm{dP} / \mathrm{dt}$, min using IDEE-Q software (Instrument Development Engineering and Evaluation, University of Maastricht, Maastricht, The Netherlands). In addition, diastolic, systolic and mean aortic pressures were determined from the aortic pressure signals. All hemodynamic measurements were performed during AF in untreated AF (UAF) and TMZ-treated AF group, and during SR in SHAM group.

\section{Mapping and AF complexity quantification}

Following the hemodynamic measurements, a left-sided thoracotomy was performed, the $4^{\text {th }}$ rib was removed, and the heart was exposed. No signs of fibrosis within pericardial sac or infection in the chest cavity were observed.

Two custom-made high-density mapping electrodes (diameter $4 \mathrm{~cm}, 247$ electrodes, interelectrode distance $2.4 \mathrm{~mm}$ ) were positioned on the free walls of the right and left atria for the recording of local unipolar atrial electrograms, while a reference electrode was placed in the chest wall. Electrograms were recorded with a custom-made 256 channel mapping amplifier (filtering bandwidth $0.1-408 \mathrm{~Hz}$, sampling rate $1 \mathrm{kHz}, \mathrm{A} / \mathrm{D}$ resolution 16 bits). The surface ECG was obtained from the standard limb leads.

As described before in detail, atrial electrograms were annotated and fibrillation waves were reconstructed with custom-made analysis software using MATLAB 8.1 (The Mathworks, Inc., Natick, Massachusetts, USA) ${ }^{24,25}$. Parameters for AF complexity included in the study were the number of waves and the number of breakthrough (BT) waves per $A F$ cycle, mean wave size, mean fractionation index and mean AF cycle length (AFCL) ${ }^{24-27}$. 


\section{Tissue harvesting}

After the mapping procedure, all recording electrodes were removed, and animals were allowed to stabilize for 30 minutes. A custom-made clamp, cooled in liquid nitrogen, was used to freeze atrial and ventricular pieces of tissue in situ. Subsequently, the heart was rapidly excised and cut into pieces that were processed for further analysis.

\section{Malondialdehyde (MDA) quantification in red blood cells}

To assess whether TMZ treatment was effective shortly after the initiation of treatment, lithium heparin blood samples were obtained in 7 goats, prior to and after 7 days of TMZ treatment to determine MDA levels in red blood cells (RBCs). The method is described elsewhere in detail ${ }^{21,28}$. In short, after four washing steps in a cold iso-osmotic $\mathrm{MgCl}_{2}$ solution, RBCs were incubated in a magnesium-sucrose buffer with or without $2 \mathrm{mM} \mathrm{PMS}$ (Phenazine methosulfate, Sigma-Aldrich No. P9625) + 1 mM DDC (diethyldithiocarbamate, Sigma-Aldrich No. 228680,) for 2 hours to stimulate ROS production. The cells were again thoroughly washed, hemolyzed and MDA was quantified in RBC membranes using absorbance at 530 $\mathrm{nm}$ in a presence of a thiobarbituric acid (TBA) assay.

\section{MDA quantification in cardiac tissue homogenates}

MDA concentrations were quantified in $100 \mu$ latrial or ventricular tissue homogenate after extraction with TBA into a fluorescent chromogen during $1 \mathrm{~h}$ boiling. The chromogen was extracted from the samples with butanol after vortexing and centrifugation at $30,000 \mathrm{~g}$ for $5 \mathrm{~min}$. The fluorescence of the butanol phase was measured by using an excitation wavelength of $530 \mathrm{~nm}$ and an emission wavelength of $560 \mathrm{~nm}$. MDA concentrations in the samples were calculated using a calibration curve ranging from 0.25-10 $\mu \mathrm{M} M \mathrm{MDA}$.

\section{Reduced (GSH) and oxidized glutathione (GSSG) quantification in cardiac tissue homogenates}

For the assessment of GSH and GSSG concentrations, $20 \mu$ ice-cold $13 \%(\mathrm{~m} / \mathrm{V})$ sulfosalicylic acid (SSA) was added to $200 \mu \mathrm{l}$ cardiac tissue homogenate. The samples were vortexed and centrifuged at $30,000 \mathrm{~g}$ and $4^{\circ} \mathrm{C}$ for $10 \mathrm{~min}$. GSH and GSSG concentrations in the supernatant were quantified as described by Rahman et al. ${ }^{29}$. GSH was spectrophotometrically measured after extraction with 0.6mM 5,5'-dithio-bis(2-nitrobenzoic acid) (DTNB) at a wavelength of $412 \mathrm{~nm}$. After removal of GSH by treating the samples with 2-vinylpyridine, GSSG concentrations were determined by an enzymatic recycling method in the presence of $1 \mathrm{U} / \mathrm{ml}$ glutathione reductase and $0.4 \mathrm{mM} \mathrm{NADPH}^{29}$.

\section{Myocardial superoxide measurements}

Myocardial $\mathrm{O}_{2}^{-}$production was measured in LA, RA, and LV samples using lucigenin (5 $\mu \mathrm{mol} / \mathrm{L}$ )-enhanced chemiluminescence as described previously ${ }^{30}$. Briefly, frozen tissue samples were homogenized in ice-cold Krebs HEPES Buffer $(\mathrm{pH}=7.35)$ supplemented with a protease inhibitor cocktail (Roche Applied Science, Indianapolis, IN) using a pre-cooled Polytron homogenizer. The contribution of NADPH-oxidases activity was estimated by addition of Vas $2870(40 \mu \mathrm{mol} / \mathrm{L})$, a pan-NADPH-oxidase inhibitor, while the coupling status of NOSs was estimated after addition of L-NAME $(1 \mathrm{mmol} / \mathrm{L})$, an irreversible inhibitor of NOS. 
Mitochondrial $\mathrm{O}_{2}^{-}$production was estimated in the presence of rotenone (100 $\left.\mu \mathrm{mol} / \mathrm{L}\right), \mathrm{a}$ respiratory chain complex 1 inhibitor.

\section{Immunoblotting}

Snap-frozen tissue samples were used for protein analysis by Western blotting upon thawing and subsequent homogenization using an Ultra-Turrax homogenizer, followed by protein determination via the Bicinchichonic acid protein assay (Pierce, Rockford, IL, USA). Per sample, $20 \mu \mathrm{g}$ of protein was used for separation by SDS-PAGE (4-12\% Bis-Tris Criterion XT precast gels; Biorad, Hercules, USA), followed by transfer to nitrocellulose membranes. Protein bands were visualized using enhanced chemiluminescence and immunoblot intensities were analyzed by using densitometry. The sources of antibodies against the following molecules were: AMPK-activated protein kinase (AMPK; phosphoThr172) and glyceraldehyde 3-phosphate dehydrogenase (GAPDH): Cell Signalling Technologies (Danvers, USA), GLUT4: Santa Cruz Biotechnology (Santa Cruz, USA), CD36 (antibody MO25): gift from Dr Tandon, Thrombosis and Vascular Biology Laboratory, Otsuka America Pharmaceutical Inc. (Rockville, MD, USA), OXPHOS complexes and Glut1: Abcam (Cambridge, UK).

\section{Glycogen content}

Snap-frozen tissue was also used for determination of glycogen upon acid hydrolysis according to Jansson ${ }^{31}$.The amount of liberated glucose moieties was determined with a glucose assay kit (GO, Sigma, Saint Louis, Missouri, USA).

\section{Histology}

LA and RA frozen tissue blocks were sectioned transmurally in $7 \mu \mathrm{m}$ thick sections and stored at $-80^{\circ} \mathrm{C}$. Wheat germ agglutinin (WGA) lectin from Triticum vulgaris conjugated to an Alexa ${ }^{\circledR} 594$ fluorophore (W11262, Thermo Fisher Scientific Inc.) was used to label the extracellular matrix (ECM) for myocyte size, inter-myocyte distance.

For staining, slides were left to dry at room temperature for one hour, fixed with fresh $-20^{\circ}$ acetone for 10 minutes and again left at room temperature until acetone completely had evaporated. After two 10min washing steps in PBS, unspecific binding was blocked with a solution of $2 \%$ bovine serum albumin (P05470, Sigma-Aldrich), and 0.3M glycine dissolved in $0.1 \mathrm{M}$ PBS for 60 minutes at room temperature. Slides were again washed 3 times for 10min with PBS and incubated with WGA (1:300) for 90 minutes. Sections were finally washed 3 more times in $0.1 \times$ PBS for 10 minutes and covered with ProLong ${ }^{\mathrm{TM}}$ Gold Antifade mounting medium (Thermo Fisher Scientrific P36930).

Photographs were taken in a blinded fashion with a Leica DM3000 fluorescence microscope at 400x magnifications using a Leica DFC300FX camera at a resolution of 1392x1040 pixels, both at epicardial and endocardial side. Cell diameter and endomysial fibrosis (determined as myocyte-to-myocyte distance) were quantified by the custommade software developed within a Fiji open-source software (https//imagej.net/Fiji) ${ }^{32}$. 


\section{Electron Microscopy}

LA tissue samples were fixated in $3 \%$ Glutaraldehyde in $0.1 \mathrm{M}$ phosphate buffer at $\mathrm{pH}$ 7.4, post-fixated in 1\% Osmium tetroxyde $+1.5 \%$ Ferrocyanide solution buffered with phosphate buffer at pH 7.4 and embedded in epoxy resin (Epon). The Epon samples were cut into $80 \mathrm{~nm}$ sections, placed on a 75-mesh copper grid and stained with Uranyl acetate and Lead citrate. Photographs were taken with an Eagle 4k camera in a Technai Biotwin iCorr $120 \mathrm{kV}$ transmission electron microscope TEM at 1900x magnification in a blinded manner. For each animal 6 to 10 transversely sectioned cardiomyocytes at the level of the nucleus were photographed. Mitochondria were manually labeled; nucleated areas were excluded, and mitochondrial number and size were calculated using 'particle analysis' function in Fiji open-source software (https//imagej.net/Fiji) ${ }^{32}$.

\section{Statistical analysis}

All data are presented as mean \pm SEM unless mentioned otherwise. Differences between the groups for normally distributed data were tested either by Student's t-test or by the One-Way ANOVA with Tukey's post-hoc correction for multiple comparisons if more than two groups were compared. Non-parametric data sets were compared with the MannWhitney $U$ test for unpaired samples and Wilcoxon test for paired samples. If more than two groups were compared the Kruskal-Wallis Test with Dunn's post-hoc correction for multiple comparisons was used. Data for structural remodeling and electron microscopy were analyzed using random intercept mixed model including goat as a random variable and group as a fixed factor. A p-value $<0.05$ was considered statistically significant.

\section{Results}

\section{Model characterization and hemodynamics}

The results of the hemodynamic measurements and animal characteristics are presented in Tables 1 and 2. There were no significant differences in age, weight, tibia length and weights of vital organs between the groups. Cardiac output did not differ significantly between the groups (Sham: $4.23 \pm 0.40, \mathrm{uAF}: 3.58 \pm 0.23, \mathrm{AF}+\mathrm{TMZ}: 3.44 \pm 0.24 \mathrm{~L} / \mathrm{min}, \mathrm{p}=0.253$. End-diastolic pressure was also comparable between the groups, but LV end-systolic pressure was lower in animals with AF compared to animals in SR (Sham: 109.0 \pm 4.8 , UAF: 93.4 $\pm 5.7, A F+T M Z 91.2 \pm 3.7 \mathrm{mmHg} ; \mathrm{p}=0.035)$. In addition, $A F$ reduced ventricular relaxation expressed as minimal dP/dt compared to Sham (Sham: $-2155 \pm 188$, UAF: $-1666 \pm 117$, AF+TMZ: $1636 \pm 69 \mathrm{mmHg} / \mathrm{sec} ; \mathrm{p}=0.025)$. Similarly, compared to Sham animals, the aortic systolic pressure was also lower in UAF and significantly lower in AF+TMZ (112.5 $\pm 4.8 \mathrm{vs.}$ $97.7 \pm 5.8$ vs. $92.3 \pm 2.2 \mathrm{mmHg}$, respectively; $\mathrm{p}=0.025$ ). However, in the $\mathrm{UAF}$ and $A F+T M Z$ groups, all hemodynamic measurements were performed during $A F$, and between these two groups, there were no differences in any of the hemodynamic parameters. 
Table 1. Model characterization

\begin{tabular}{lllll}
\hline & Sham & Control AF & $\begin{array}{l}\text { AF treated with } \\
\text { TMZ }\end{array}$ & p \\
\hline Age (months) & $36.9 \pm 5.4$ & $39.9 \pm 5.17$ & $38.1 \pm 4.0$ & 0.910 \\
Weight (kg) & $62.8 \pm 3.7$ & $66.49 \pm 3.6$ & $63.2 \pm 2.6$ & 0.700 \\
Tibia length (cm) & $25.5 \pm 0.5$ & $25.2 \pm 0.9$ & $24.1 \pm 0.6$ & 0.407 \\
Heart weight (gr) & $320.1 \pm 21.7$ & $326.9 \pm 22.8$ & $322.9 \pm 17.1$ & 0.973 \\
Lung weight (gr) & $482.9 \pm 26.9$ & $465.2 \pm 19.4$ & $523.4 \pm 38.0$ & 0.364 \\
Left kidney (gr) & $77.8 \pm 3.9$ & $83.6 \pm 5.0$ & $84.9 \pm 6.7$ & 0.581 \\
Right kidney (gr) & $79.6 \pm 4.0$ & $83.6 \pm 5.4$ & $82.3 .8 \pm 7.6$ & 0.872 \\
Liver (gr) & $903.7 \pm 60.1$ & $856.1 \pm 55.7$ & $764.7 \pm 49.0$ & 0.248
\end{tabular}

Table 2. Hemodynamic measurements

\begin{tabular}{|c|c|c|c|c|}
\hline & Sham & Control AF & $\begin{array}{l}\text { AF treated with } \\
\text { TMZ }\end{array}$ & $\mathbf{p}$ \\
\hline $\mathrm{CO}(1 / \mathrm{min})$ & $4.23 \pm 0.40$ & $3.58 \pm 0.23$ & $3.44 \pm 0.24$ & 0.171 \\
\hline $\mathrm{CO}(\mathrm{ml} / \mathrm{min} / \mathrm{kg})$ & $67.7 \pm 5.7$ & $54.5 \pm 3.3$ & $54.9 \pm 4.2$ & 0.589 \\
\hline Heart rate (bpm) & $74.3 \pm 6.7$ & $86.3 \pm 2.6$ & $99.0 \pm 12.6$ & 0.089 \\
\hline \multicolumn{5}{|l|}{ LV pressures } \\
\hline End-Diastolic $\mathrm{P}(\mathrm{mmHg})$ & $9.2 \pm 1.5$ & $9.3 \pm 1.6$ & $8.2 \pm 1.1$ & 0.881 \\
\hline End-Systolic P (mmHg) & $109.0 \pm 4.8$ & $93.4 \pm 5.7$ & $91.2 \pm 3.7$ & 0.035 \\
\hline $\mathrm{dP} / \mathrm{dT} \max (\mathrm{mmHg} / \mathrm{sec})$ & $1817 \pm 160$ & $1272 \pm 129$ & $1405 \pm 233.1$ & 0.073 \\
\hline $\mathrm{dP} / \mathrm{dT} \min (\mathrm{mmHg} / \mathrm{sec})$ & $-2155 \pm 188$ & $-1666 \pm 117 \dagger$ & $-1636 \pm 68.6 \dagger$ & 0.025 \\
\hline \multicolumn{5}{|l|}{ Aortic pressures } \\
\hline Diastolic $\mathrm{P}(\mathrm{mmHg})$ & $85.6 \pm 4.0$ & $80.2 \pm 4.7$ & $75.4 \pm 2.6$ & 0.260 \\
\hline Systolic P (mmHg) & $112.5 \pm 4.8$ & $97.7 \pm 5.8$ & $92.3 \pm 2.2 \dagger$ & 0.025 \\
\hline Mean $\mathrm{P}(\mathrm{mmHg})$ & $98.7 \pm 4.1$ & $88.4 \pm 5.2$ & $83.1 \pm 2.2$ & 0.061 \\
\hline
\end{tabular}

$+\mathrm{p}<0.05 \mathrm{vs}$. Sham, ANOVA with Tukey's post hoc correction for multiple comparisons

\section{MDA in washed red blood cells}

TMZ treatment decreased the MDA content in RBC membranes incubated in the presence of $2 \mathrm{mM}$ PMS $+1 \mathrm{mM}$ DDC from $0.66 \pm 0.14 \mu \mathrm{M} \mathrm{MDA} / 10^{9}$ cells before to $0.36 \pm 0.04 \mu \mathrm{M}$ $\mathrm{MDA} / 10^{9}$ cells after $\mathrm{TMZ}$ treatment $(\mathrm{p}=0.02)$, confirming that the treatment regimen produced a biologically significant effect early in the treatment period (Figure 2). 


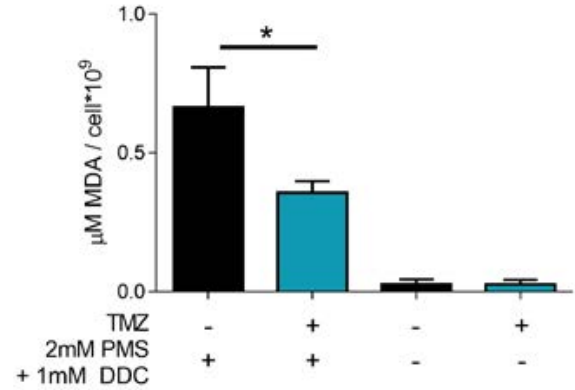

Figure 2. MDA in washed red blood cells. TMZ treatment decreased MDA content in red blood cells membranes incubated in the presence of $2 \mathrm{mM}$ PMS $+1 \mathrm{mM}$ DDC. MDA content in the red blood cells membranes that were not incubated in $2 \mathrm{mM}$ PMS +1 mM DDC were below the detection levels.

\section{Superoxide measurements}

TMZ abolished the AF-induced increase in resting $\mathrm{O}_{2}^{-}$production both in the LA and RA $\left(p<0.0001\right.$ and $p=0.0002$, respectively, Figure $3 A$ ). Rotenone stimulated $\mathrm{O}_{2}^{-}$production was increased in both atria of UAF animals and this increase was diminished in AF+TMZ animals ( $p=0.0020$ in $L A$ and $p=0.0208$ in the RA, Figure 3B). In addition, in the RA the Vas2780-inhibitable $\mathrm{O}_{2}^{-}$fraction was significantly higher in the UAF than in the AF+TMZ group ( $p=0.03$, Figure $3 C$ ). The production of ROS by uncoupled NOS was low in all chambers and similar between the groups (Figure 3D). There were no differences in $\mathrm{O}_{2}{ }_{2}$ production of the LV for any of the investigated sources of ROS (Figure 3A-D).

A

Resting $\mathrm{O}_{2} \cdot$ production

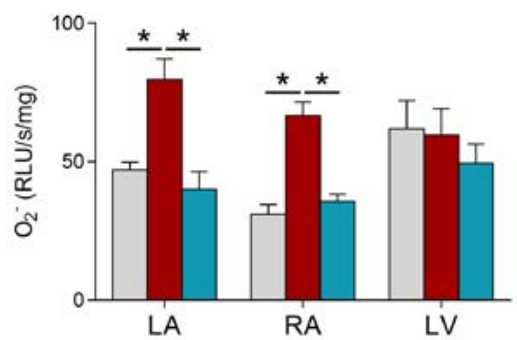

C

VAS2870 inhibitable $\mathrm{O}_{2}-$ fraction

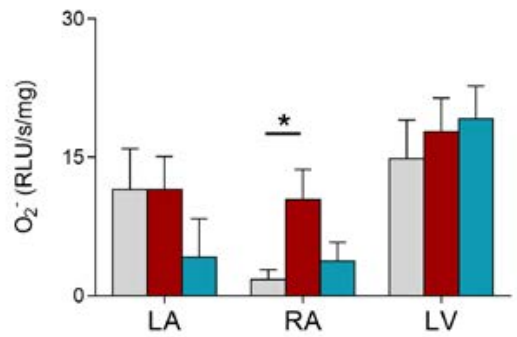

B

Rotenone stimulated $\mathrm{O}_{2}^{-}$production

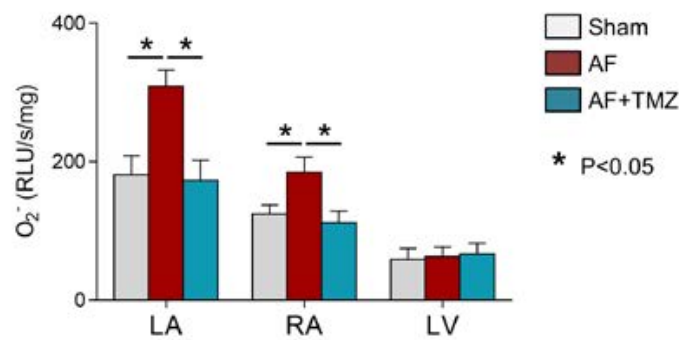

D $\mathrm{O}_{2}$ - production in a presence of L-NAME

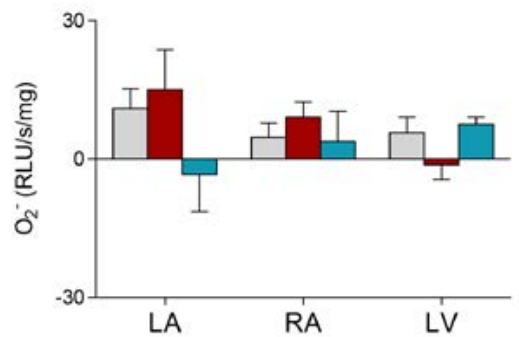

Figure 3. Measurement of O2-production using lucigenin enhanced chemiluminescence in LA, RA and LV samples from sham, control AF and TMZ treated AF animals. (A) Resting O2- production, (B) Mitochondrial O2- production in a presence of Rotenone, (C) NADPH-oxidases activity in a presence of VAS2870, a specific pan NADPH-oxidases inhibitor (D) NOSs coupling status in a presence of L-NAME. TMZ treatment abolished AF induced resting $\mathrm{O} 2$ - production that was mainly originated from the mitochondria. Data are presented as means \pm SEM. $\mathrm{n}=6-10$ independent tissue homogenates. 


\section{Changes in substrate preference and energy status}

AF had no effect on the content of the main substrate transporters and glycogen content. In the LA, TMZ treatment decreased levels of the GLUT 1 transporter and increased levels of the CD36 transporter (Figure $4 \mathrm{~A}$ and C). TMZ further increased glucose content in the RA compared to both sham animals and $U A F$ animals. A similar trend was observed in the LV compared to uAF (Figure 4, D).

P-AMPK content was not altered in the atria of any group, but it was significantly decreased in the LV of the AF+TMZ group compared to both the sham and UAF group (Figure 4. E).
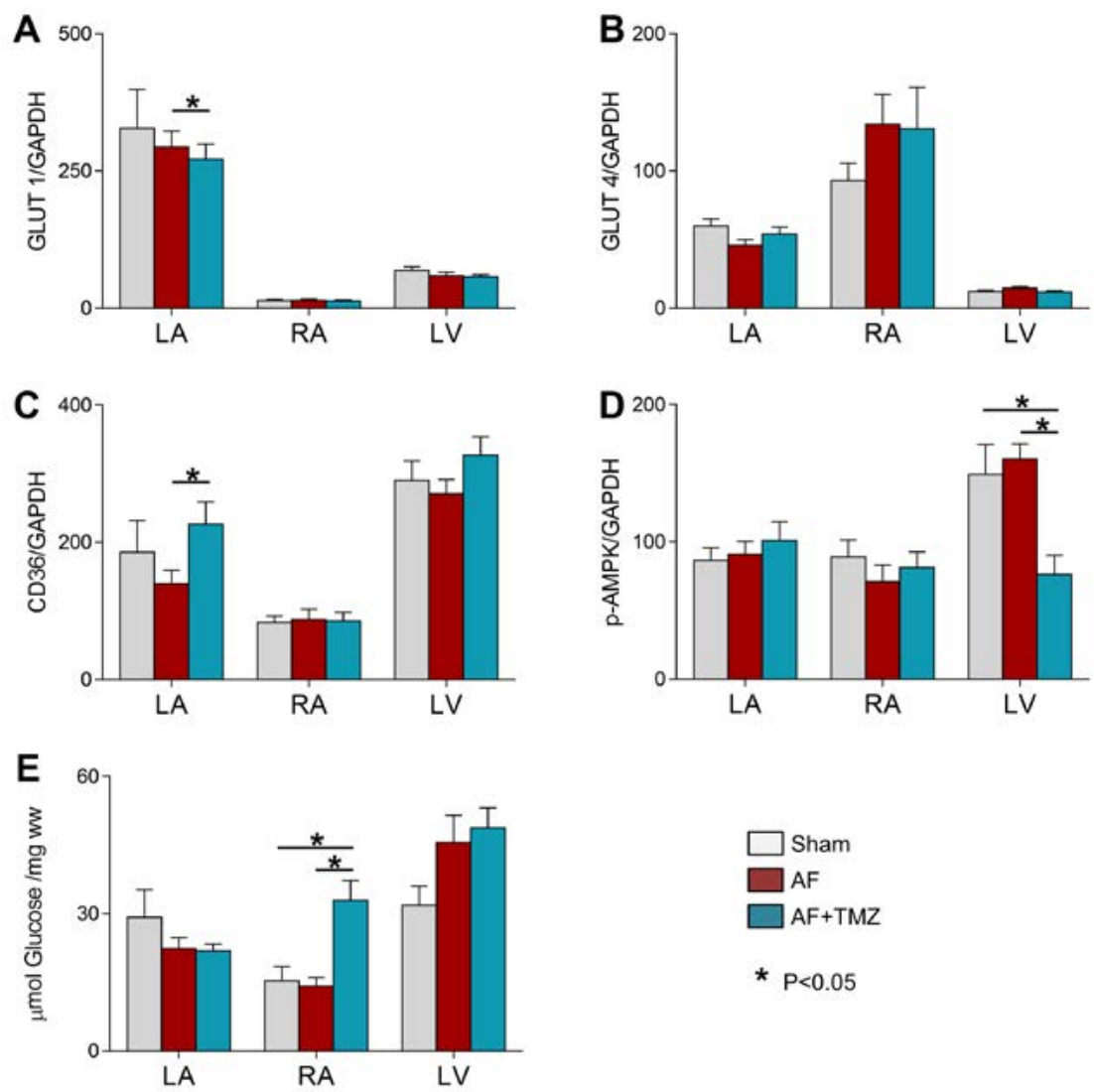

Figure 4. Shift in substrate preference and changes of energy status. (A) Glucose transporter GLUT 1, (B) Glucose transporter GLUT 2, (C) Fatty acid translocase - CD36, (D) p-AMPK content, and (E) Glucose content. The quantification of all parameters was performed in 8-10 independent LA, RA and LV tissue homogenates per group and normalized to GAPDH content. 

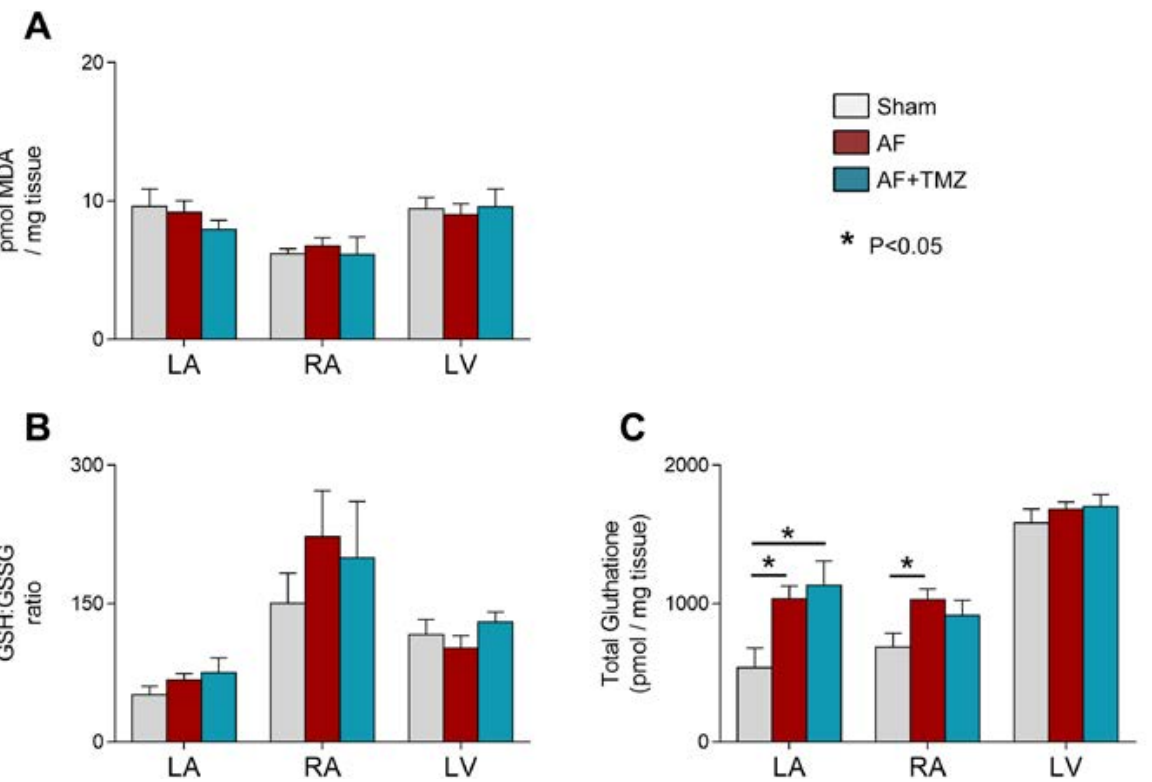

Figure 5. The effect of TMZ treatment on the markers of oxidative stress. Malondialdehyde (MDA) the marker of lipid peroxidation (A), the ratio of reduced and oxidized glutathione (GSH:GSSG) ratio (B) and the content of the total glutathione $(\mathbf{C})$.

\section{Redox potential and oxidative damage}

MDA is a sensitive marker for lipid peroxidation and increased oxidative stress. However, despite increased superoxide production, we did not observe changes in MDA content in the LV or either atrium in any of the investigated groups (Figure 6A). The ratio between reduced (GSH) and oxidized (GSSG) glutathione form, the marker of redox potential i.e. the marker of the oxidative stress burden on the cell, did not differ significantly between the groups independent of the chamber (Figure 6B). The total content of glutathione, defined as the sum of GSH and oxidized GSSG glutathione form is a marker of cell capacity to neutralize increased oxidative stress. The total content of glutathione was significantly increased in LA tissue of both $U A F$ and AF+TMZ animals. RA tissue samples of $U A F$ animals also had significantly higher values of total glutathione compared to sham. An increase in the total content of glutathione in the RA of AF+TMZ animals was also observed, but this was not statistically significant. The total glutathione levels of the LV were not different between the groups (Figure $6 \mathrm{C}$ ). These results indicate that the overall cell capability to neutralize excessive oxidative stress is upregulated. Therefore, in spite of an evident increase in superoxide production, $\mathrm{AF}$ did not cause oxidative stress specific damage such as an increase in MDA content.

\section{AF stabilization and complexity}

AF episode prolongation after the initiation of the arrhythmia was similar between the groups and time from the AF start to the episode longer than 24 hours did not differ 
between the $U A F$ and $A F+T M Z$ animals $(74.13 \pm 9.129$ vs. $79.71 \pm 28.91 h ; p=0.84)$ (Figure 5, $A$ and $B)$.

The number of waves and the number of BT waves per AFCL as well as the mean wave size was comparable between the groups for both atria. (Figure 5, C - E). In addition, there was no difference between treated and untreated animals either in the values of AFCL or mean fractionation index (Figure 6, F and G). Therefore, TMZ treatment did not affect AF complexity.

A

Maximal AF episode length during the first 5 days of AF

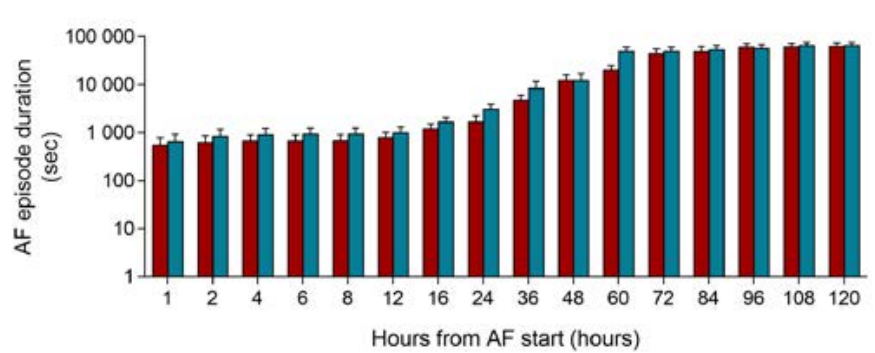

B

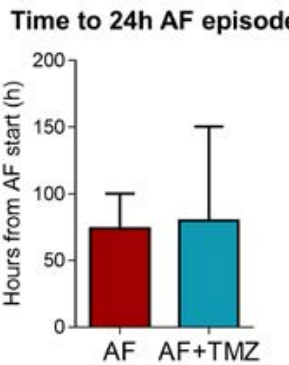

AF fibrillation complexity parameters

C

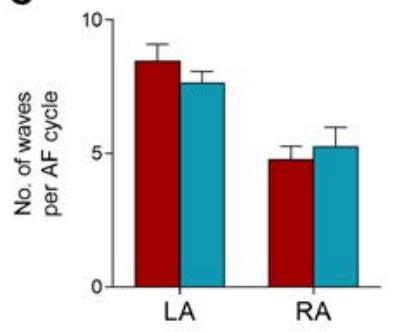

$\mathbf{F}$

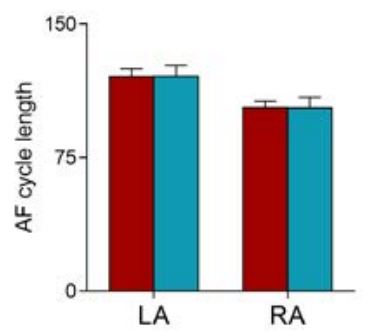

D

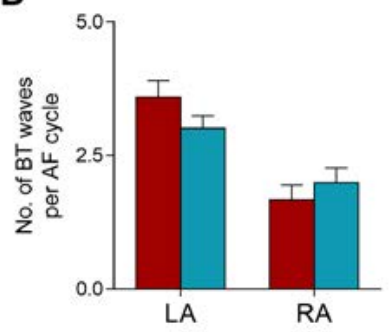

G

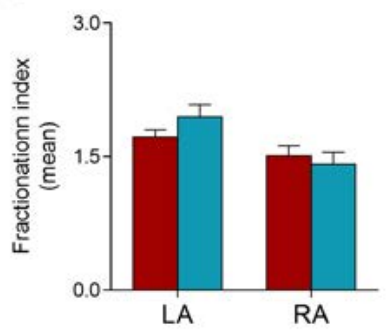

E

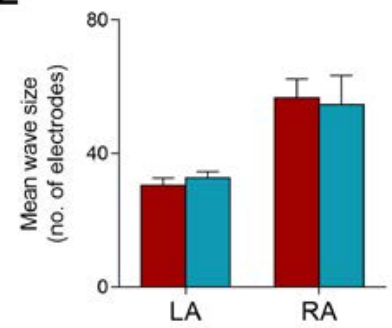

Figure 6. AF stabilization and the parameters of the AF complexity was not altered by the TMZ treatment. AF stabilization was determined by the duration of the AF episode in the first 5 days of AF induction (A) and by the time of $A F$ induction needed before the duration of the single AF episode was longer than 24 hours (B). The complexity of the AF fibrillation pattern after 16 weeks of AF was determined by the contact high density mapping at the follow up experiment. Investigated parameters of AF complexity were: No. of waves per AF cycle (C), Number of breakthrough (BT) waves per AF cycle (D), mean wave size defined as the number of electrodes per wave (E), mean AF cycle length (msec) (F), fractionation index (G). 


\section{Structural and ultrastructural remodeling}

AF caused a relatively homogeneous increase in atrial myocyte diameter of UAF animals, both in LA and RA and both in the epicardial and the endocardial layer compared to SR goats. TMZ treatment significantly inhibited AF-induced myocyte hypertrophy (Figure 7, $A$ and $B)$.

Myocyte-to-myocyte distance as an indicator for endomysial fibrosis was also increased as a result of AF, most prominently in LA epicardial layer. TMZ decreased the AF-induced increase in intermyocyte distance what was most visible in LA epicardial layer (Figure 7, ( and D).

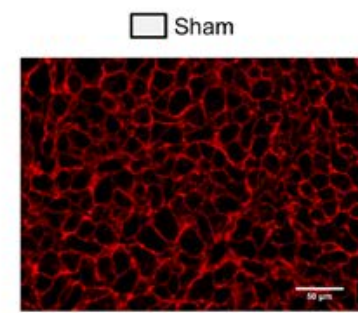

A

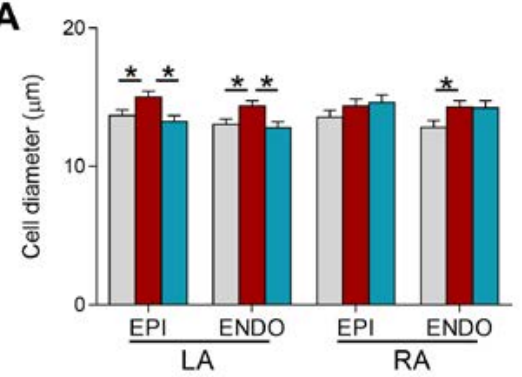

B

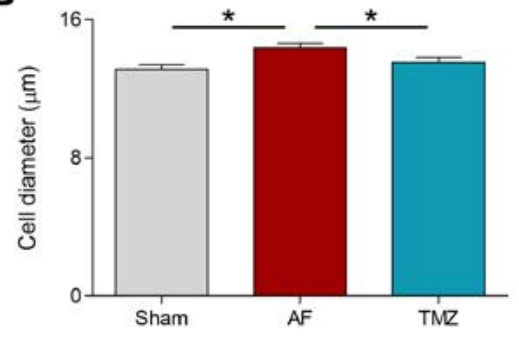

$\mathrm{AF}$

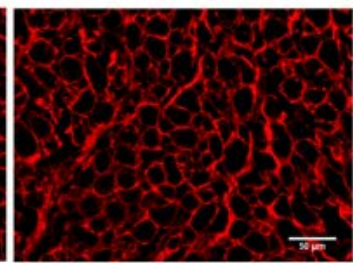

C

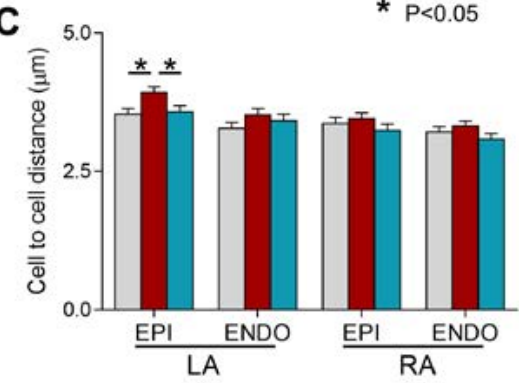

D

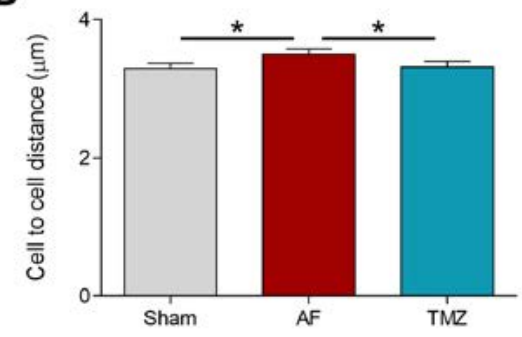

Figure 7. The effect of TMZ treatment on AF induced changes in cell diameter $(A, B)$ and cell to cell distance (C, D). WGA staining was used to label cell membrane and fibrous tissue. From the acquired slides we have quantified the cell diameter and the cell to cell distance, a determinant of endomysial fibrosis are quantified both in left (LA) and right atrium (RA) and at the epicardial (EPI) and endocardial (ENDO) side. The data are expressed as estimated mean \pm estimated standard error calculated based on the random intercept mixed model including goat as a random subject and group and location as a fixed factors. The pictures were acquired at 3-6 different locations of all investigated slide areas in 8-10 animals per group. 
At the ultrastructural level, AF decreased the fraction of the area within myocytes occupied by mitochondria. This resulted from a decrease in the mitochondrial size, while the number of mitochondria remained similar. TMZ treatment prevented the AF-induced decrease in mitochondrial size and area fraction without significant changes in the mitochondrial number. In fact, large mitochondria were observed more frequently in the TMZ treated group than in the other groups, as evidenced by the longer rightward tail in the distribution of mitochondrial size in the TMZ group (Figure 8, A-D).
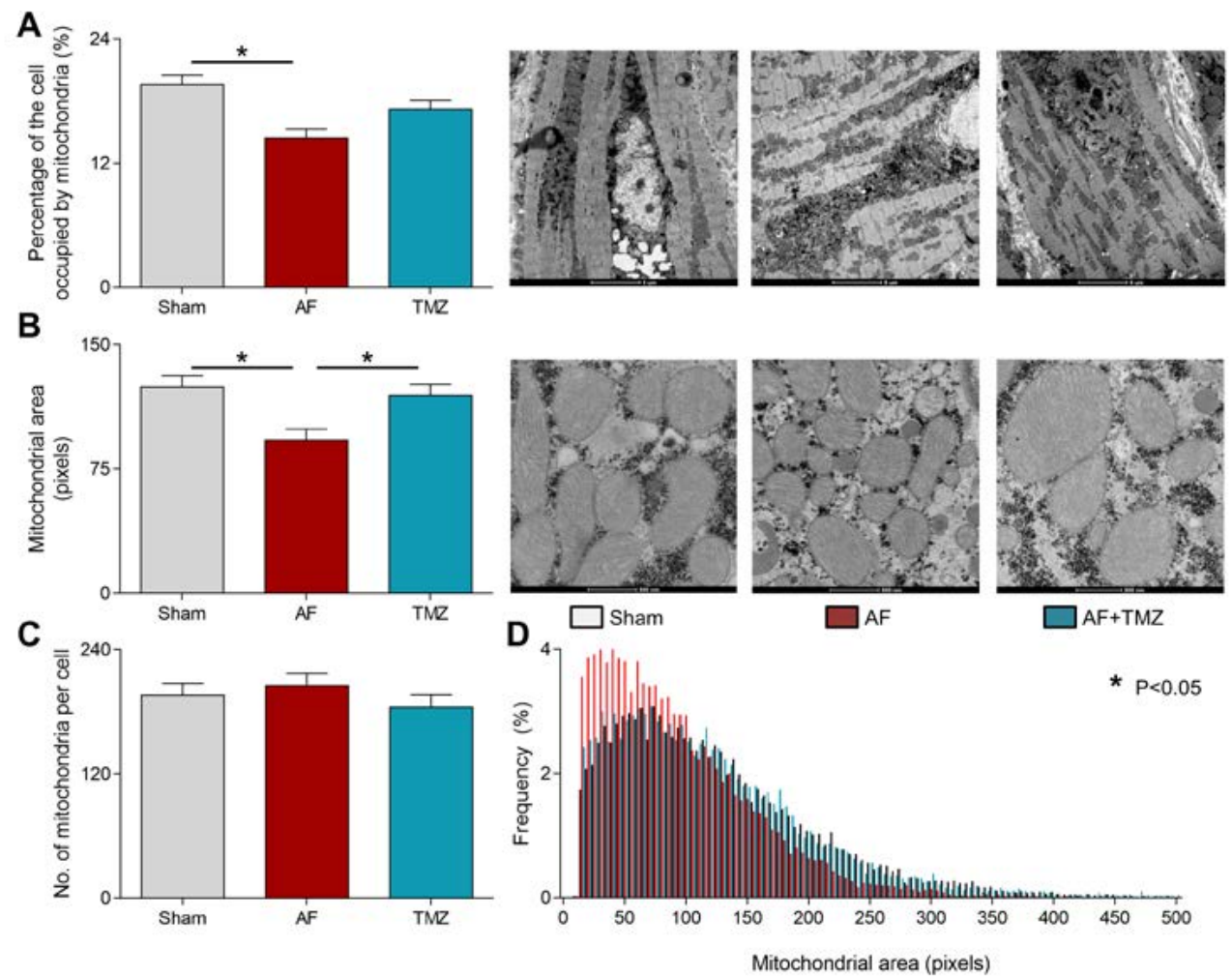

Figure 8. The effect of TMZ treatment on the number and the size of the mitochondria. The changes of the mitochondrial structure and und number are depicted with the percentage of the cell occupied by the mitochondria (A), average mitochondrial size expressed as mitochondrial area (B), the number of the mitochondria $(\mathbf{C})$ as well as the mitochondrial size distribution (D). The data are expressed as the estimated mean \pm estimated standard error calculated based on the random intercept mixed model including goat as a random subject and group as a fixed factor. The quantification of the mitochondria is performed based on 6 to 10 photographs of longitudinally sectioned cells at the level of the nucleus per animal. $n=8$ animals per group.

\section{Mitochondrial function}

To determine how AF affects mitochondrial function, and how TMZ affects AF-induced any mitochondrial remodeling, we carried out a comprehensive characterization of mitochondrial physiology in suspensions of isolated mitochondria, including mitochondrial respiration, membrane potential, ROS production, calcium uptake, as detailed in the online data supplement. Overall, we have observed that AF did not affect 
the respiration of isolated mitochondria for either glycolytic or fatty acid substrate (Figure S1), and that the levels of respiratory chain subunit were largely unaltered (Figure S2). The mitochondrial membrane potential in the LA was increased as a result of $A F$, a change that was abrogated by TMZ treatment (Figure S3). The mitochondrial calcium retention capacity was largely unaffected by AF and was slightly enhanced in the AF+TMZ group with a fatty acid substrate. Finally, ROS production (i.e. in the absence of ADP) tended to decrease as a result of $A F$, and this tendency was enhanced in the AF+TMZ group, both in the LA and LV (Figure S4).

\section{Discussion}

$\mathrm{AF}$ is a progressive disease. Both in patients ${ }^{33}$ and in animal models of $\mathrm{AF}^{3,34}$, the efficacy of antiarrhythmic drugs to restore sinus rhythm gradually decreases with increasing $A F$ duration. This gradual 'entrenchment' is thought to be dependent on a rapid process of electrical remodeling (i.e. a shortening of the atrial action potential duration (APD) and a loss of rate-dependence of the APD), which takes place within 1-2 days, and a much slower process of structural remodeling, which takes place gradually over months to years.

In the transition from sinus rhythm to acute $A F$, the atrial activation rate increases by a factor $3-6^{5}$. This increase in frequency is likely to lead to a substantial increase in atrial oxygen and energy demand. Although cardiac pump function is largely preserved during AF, atrial blood supply may fall short of the increased demand during AF. Indeed, we have previously shown that acute AF leads to a state of supply/demand ischemia, as evidenced by atrial lactate production during the first minutes of AF and a phase of reactive hyperemia after the restoration of sinus rhythm ${ }^{8}$. On the longer term, AF in a goat model leads to a transient decrease in phosphocreatine ${ }^{9}$ and an increase in the HIF1a, a marker of hypoxia ${ }^{35}$. Also, in patient biopsies, AF is associated with signs of hypoxia ${ }^{36}$. It is relevant in this context that the term 'structural remodeling' comprises a wide variety of phenomena. At the level of tissue structure, it can refer to (diverging patterns of) fibrosis, cellular hypertrophy, and adipocyte infiltration, all of which are likely to directly affect atrial propagation. At the cellular and ultrastructural level, it can refer myocyte dedifferentiation and hibernation, glycogen accumulation, loss of contractile elements, and changes in nuclear and mitochondrial structure ${ }^{6,9}, 10,37-39$. Those changes may not directly impact conduction, but may be related to (the response to) metabolic derangement and the loss of atrial contractile function. Indeed, myocyte hibernation in the fibrillating atrium is similar to that in the ventricles during low flow ischemia ${ }^{10}$ and has been described as an act of'programmed cell survival'39. However, the extent to which supply/demand ischemia and metabolic compromise contribute to electrical and structural remodeling is unclear at present ${ }^{40}$, particularly in the absence of metabolic intervention studies.

In this study, we have tested an intervention with $\mathrm{TMZ}$, a compound for which pleiotropic effects on myocardial metabolism have been reported, including a shift in substrate preference and suppression of ROS production. 


\section{Effects on substrate preference}

In the healthy ventricle, the major source of ATP production is fatty acid oxygenation (70$90 \%$ of ATP), while the glucose oxygenation contributes only $10-30 \%{ }^{41}$. In response to chronic hypoxia, ventricular substrate preference can shift from fatty acid to glucose ${ }^{41}$. This is thought to be beneficial because, although fatty acid utilization is more substrate efficient, glucose utilization is more oxygen efficient. For this reason, 'metabolic shifters', compounds that can further shift metabolism from fatty acid to glucose utilization, have been investigated as anti-anginal drugs ${ }^{42-45}$. TMZ, the compound we have investigated in the present study, can affect this shift by inhibiting 3-KAT, a key enzyme in the betaoxidation $^{15}$.

The gold standard for assessing substrate preference is a measurement of the flux of radioactive substrate labels ${ }^{46}$. Because we measured various other parameters after sacrifice experiments, this was not feasible in our study. However, under many circumstances, the levels of the main substrate transporters, Glut4 for glucose and CD36 for fatty acid parallel substrate preference ${ }^{47}$. Neither AF itself nor TMZ treatment affected these levels, and therefore our data do not support a difference in substrate preference between the groups. In addition, TMZ treatment did not introduce differences in a number of parameters for mitochondrial function when glycolytic and fatty acid substrates were compared, either for the LA or LV. Comparable observations were made by Cavar et al., who also did not observe any effect of TMZ on fatty acid and carbohydrate oxidation in permeabilized left ventricular fibers from coronary artery disease patients ${ }^{48}$. This suggests that any effects of TMZ could derive from mechanisms other than a metabolic shift.

\section{Effects on ROS production}

Interestingly, Dedkova et al. showed that the beneficial effects of TMZ in a rabbit model of heart failure were independent of the fatty acid oxidation inhibition, but actually linked to reduced mitochondrial oxidative stress and decreased the propensity for mPTP opening ${ }^{49}$.

Mice with cardiac overexpression of the NOX2 activator Rac-1 develop spontaneous $\mathrm{AF}^{50}$. Because of the damage to structural proteins, excessive ROS production has been proposed as a key mediator in structural remodeling ${ }^{12}$, and further evidence for the role of oxidative stress in AF-induced remodeling has been reviewed in reference ${ }^{13}$. In animal models of electrically induced AF, ROS production is increased ${ }^{14,51}$. We have previously shown that the sources of increased ROS production change over time. In the first weeks, NAPDH oxidase is the main source of ROS in the goat model, while mitochondrial ROS production and uncoupled NOS were the main sources after 6 months of $\mathrm{AF}^{14}$. At the 4 months time point in the present study, we found that the overall increase in ROS production was paralleled by increased mitochondrial ROS production.

Despite strong evidence that AF leads to increased ROS production, its role in AF-induced remodeling remains uncertain. In addition, statin treatment (targeting ROS production by NADPHoxidase) did not have a beneficial effect on AF occurrence in the context of post-operative $A F^{52-54}$. The fact that statins cannot reduce new onset or recurrences of $A F$ in patients without structural heart disease ${ }^{55,56}$ may be explained by our observation in 
goats that NADPHoxidase is a major source of ROS only in the early progression of $\mathrm{AF}^{14}$. However, a number of studies that aimed at treating AF by lowering ROS using general antioxidants have also yielded negative results ${ }^{57-59}$.

TMZ treatment in our study abolished the AF-induced increase of overall ROS production, which was mainly driven by mitochondrial ROS production. Antioxidant effects of TMZ have been reported previously ${ }^{19,21-23,49}$. Dedkova et al. showed that TMZ inhibited enhanced electron leak at the complex II and improved activity of the impaired complex I what restored mitochondrial membrane potential and reduced ROS production ${ }^{49}$.

Interestingly, although AF increased ROS production, the levels of MDA, a marker for lipid peroxidation were not affected by AF. Also, the ratio between reduced and oxidized glutathione, an indicator for the cellular redox potential was similarly unaffected by AF. The unaltered redox potential in the face of increased ROS production may be explained by our observation that the total level of glutathione, i.e. the ROS-neutralizing capacity of this system was increased in the AF animals. This indicates that, to a large extent, the atrial myocardium can protect itself from increased ROS production by upregulating ROS neutralizing systems, thereby limiting oxidative damage.

Previous studies in animal models have shown that chronic AF leads to alterations in mitochondrial structure ${ }^{9,10}$, but the effect of AF on mitochondrial function has not been studied extensively. We have performed a broad characterization of mitochondrial function. In our study, we did not find a strong effect of AF on isolated mitochondria from either the left atrium or the left ventricle.

In a previous study on the effect in a rabbit model of heart failure, Dedkova et al. attributed the beneficial effects of TMZ partially to a decreased the propensity for MPTP opening ${ }^{49}$. In our data either AF alone or AF with TMZ treatment increased propensity for $\mathrm{Ca}^{2+}$ induced mPTP opening in the LA oxidizing palmitoyl-carnitine-malate, although AF alone did not affect mitochondrial sensitivity towards $\mathrm{Ca}^{2+}$ overload. Increased mitochondrial $\mathrm{Ca}^{2+}$ buffering capacity could also play a role in the attenuated propagation of $\mathrm{Ca}^{2+}$ release towards the center of the cell, observed in the atrial myocytes isolated from the rabbits exposed to 5 days rapid atrial pacing ${ }^{60}$. This explanation agrees with the observation that blocking the mitochondrial calcium uniporter accelerated propagation and increased the amplitude of $\mathrm{Ca}^{2+}$ transients in atrial myocytes ${ }^{61}$. Recently, Schweitzer et al. showed that enhancing the mitochondrial $\mathrm{Ca}^{2+}$ uptake suppresses arrhythmogenic $\mathrm{Ca}^{2+}$ events $^{62}$.

\section{Effects of TMZ on AF stabilization and complexity}

In the goat model of AF, electrical remodeling is associated with an increase in AF episode duration during the first days, leading to persistent $\mathrm{AF}^{5}$, which can still be terminated pharmacologically. The slow decline in the efficacy of anti-arrhythmic drugs over the ensuing months has been attributed to structural remodeling, most notably increased endomysial fibrosis that occurs preferentially in the outer millimeter of the atrial wall and that increases the complexity of fibrillation patterns ${ }^{3,7}$. In this study, we found no effect of TMZ either on the early stabilization of AF in the first days or on the complexity 
of fibrillation patterns after 4 months. This indicates that TMZ did not prevent electrical remodeling and did not sufficiently affect the components of structural remodeling to decrease fibrillation pattern complexity.

\section{Effect of TMZ on atrial function}

As mentioned above, structural remodeling can be broadly subdivided in changes in tissue structure that can directly affect conduction (e.g. fibrosis, myocyte hypertrophy) and cellular and ultrastructural changes that a more related to myocyte metabolism (e.g. mitochondrial changes, dedifferentiation and hibernation). Although all these changes take place during $A F$, the underlying causative mechanisms for these different components of structural remodeling may vary. Therefore, an intervention may affect certain forms of AF-induced structural remodeling, while not affecting others. During open chest sacrifice experiment after cardioversion to sinus rhythm, we made two striking observations, which unfortunately were not quantified in our study protocol. Normally, after months of AF, goat atria are strongly dilated and have lost all contractility ${ }^{63}$. This was also observed in the UAF group in this study. However, in the AF+TMZ group, the atrial size was considerably smaller than in the UAF group, and the atria were still visibly contracting. These observations parallel some parameters that we did measure: AF led to myocyte hypertrophy that could be inhibited by TMZ treatment. Likewise, AF caused changes in mitochondrial structure, extensively characterized in previous studies ${ }^{10}$, that were reversed in the TMZ group.

The loss of atrial contractility is caused by down-regulation of $\mathrm{I}_{\mathrm{CaL}}{ }^{60,63}$. The concomitant APD shortening will increase atrial fibrillatory rate, thus increasing energy expenditure on ion homeostasis. However, it will reduce the energy expenditure on contraction. In addition, the slower process of myocyte hibernation ${ }^{10}$ may represent an additional adaptation to metabolic derangement caused by AF, allowing the atria to further scale back demand. Our evidence, although partially indirect and circumstantial, indicates that TMZ treatment can preserve atrial function during AF-induced remodeling. This suggests that TMZ may be of interest as an adjunctive treatment in patients in early stages of the arrhythmia.

\section{Limitations}

There is mounting evidence that AF causes metabolic derangement ${ }^{40}$. However, it is unclear to which extent this metabolic derangement causes atrial remodeling during $\mathrm{AF}$. We have investigated TMZ, a drug for which a number of mechanisms of action have been described.

To delineate mechanistic implications of the effects of $T M Z$, its pleiotropy may be considered a disadvantage, although pleiotropic drugs (e.g. statins) can be very useful clinically. Because all of TMZ's reported effects are potentially beneficial in the context of AF-induced remodeling, we still consider it an interesting first step in developing a treatment aimed at improving atrial metabolism.

We have studied mitochondrial function in suspension isolated mitochondria. This approach allowed us to study a variety of mitochondrial parameters and therefore 
perform a broad characterization of the effects of AF and TMZ on mitochondria. However, mitochondria were taken out of their cellular context, which affects their behavior. For example, we show that in tissue extracts, the capacity for mitochondrial ROS production is increased by AF. By contrast, isolated mitochondria showed a tendency towards decreased ROS production. This suggests adaptive mitochondrial changes and underscores the interaction between mitochondria and their cytoplasmic environment.

\section{Conclusion}

In summary, TMZ treatment reduced AF-induced ROS production, inhibited cardiomyocyte hypertrophy and endomysial fibrosis, and reversed alterations of the mitochondrial structure caused by chronic AF. Although TMZ did not inhibit the electrophysiological progression of $A F$, indications that it did lead to a preservation of atrial function indicate $a$ potential role as adjunctive therapy in AF patients. 


\section{References}

1. Benjamin EJ, Wolf PA, D'Agostino RB, Silbershatz H, Kannel WB and Levy D. Impact of atrial fibrillation on the risk of death: the Framingham Heart Study. Circulation. 1998;98:946-52.

2. Kopecky SL, Gersh BJ, McGoon MD, Whisnant JP, Holmes DR, Jr., Ilstrup DM and Frye RL. The natural history of lone atrial fibrillation. A population-based study over three decades. The New England journal of medicine. 1987;317:669-74.

3. Verheule S, Tuyls E, van Hunnik A, Kuiper M, Schotten U and Allessie M. Fibrillatory conduction in the atrial free walls of goats in persistent and permanent atrial fibrillation. Circ Arrhythm Electrophysiol. 2010;3:590-9.

4. Schotten U, Verheule S, Kirchhof P and Goette A. Pathophysiological mechanisms of atrial fibrillation: a translational appraisal. Physiol Rev. 2011;91:265-325.

5. Wijffels MC, Kirchhof CJ, Dorland R and Allessie MA. Atrial fibrillation begets atrial fibrillation. A study in awake chronically instrumented goats. Circulation. 1995;92:1954-68.

6. Allessie M, Ausma J and Schotten U. Electrical, contractile and structural remodeling during atrial fibrillation. Cardiovascular research. 2002;54:230-46.

7. Verheule S, Tuyls E, Gharaviri A, Hulsmans S, van Hunnik A, Kuiper M, Serroyen J, Zeemering $\mathrm{S}$, Kuijpers $\mathrm{NH}$ and Schotten U. Loss of continuity in the thin epicardial layer because of endomysial fibrosis increases the complexity of atrial fibrillatory conduction. Circ Arrhythm Electrophysiol. 2013;6:202-11.

8. van Bragt KA, Nasrallah HM, Kuiper M, Luiken JJ, Schotten U and Verheule S. Atrial supplydemand balance in healthy adult pigs: coronary blood flow, oxygen extraction, and lactate production during acute atrial fibrillation. Cardiovasc Res. 2014;101:9-19.

9. Ausma J, Coumans WA, Duimel H, Van der Vusse GJ, Allessie MA and Borgers M. Atrial high energy phosphate content and mitochondrial enzyme activity during chronic atrial fibrillation. Cardiovasc Res. 2000;47:788-96.

10. Ausma J, Wijffels M, Thone F, Wouters L, Allessie M and Borgers M. Structural changes of atrial myocardium due to sustained atrial fibrillation in the goat. Circulation. 1997;96:3157-63.

11. Liemburg-Apers DC, Willems PH, Koopman WJ and Grefte S. Interactions between mitochondrial reactive oxygen species and cellular glucose metabolism. Arch Toxicol. 2015;89:1209-26.

12. Mihm MJ, Yu F, Carnes CA, Reiser PJ, McCarthy PM, Van Wagoner DR and Bauer JA. Impaired myofibrillar energetics and oxidative injury during human atrial fibrillation. Circulation. 2001;104:174-80.

13. Simon JN, Ziberna K and Casadei B. Compromised redox homeostasis, altered nitroso-redox balance, and therapeutic possibilities in atrial fibrillation. Cardiovasc Res. 2016;109:510-8.

14. Reilly SN, Jayaram R, Nahar K, Antoniades C, Verheule S, Channon KM, Alp NJ, Schotten U and Casadei $B$. Atrial sources of reactive oxygen species vary with the duration and substrate of atrial fibrillation: implications for the antiarrhythmic effect of statins. Circulation. 2011;124:1107-17.

15. Kantor PF, Lucien A, Kozak R and Lopaschuk GD. The antianginal drug trimetazidine shifts cardiac energy metabolism from fatty acid oxidation to glucose oxidation by inhibiting mitochondrial long-chain 3-ketoacyl coenzyme A thiolase. Circ Res. 2000;86:580-588.

16. Stanley WC, Recchia FA and Lopaschuk GD. Myocardial substrate metabolism in the normal and failing heart. Physiol Rev. 2005;85:1093-129. 
17. Liedtke AJ. Alterations of carbohydrate and lipid metabolism in the acutely ischemic heart. Prog Cardiovasc Dis. 1981;23:321-36.

18. El Banani H, Bernard M, Baetz D, Cabanes E, Cozzone P, Lucien A and Feuvray D. Changes in intracellular sodium and $\mathrm{pH}$ during ischaemia-reperfusion are attenuated by trimetazidine. Comparison between low- and zero-flow ischaemia. Cardiovascular research. 2000;47:688-96.

19. Guarnieri $C$ and Muscari $C$. Effect of trimetazidine on mitochondrial function and oxidative damage during reperfusion of ischemic hypertrophied rat myocardium. Pharmacology. 1993;46:324-31.

20. Kay L, Finelli C, Aussedat J, Guarnieri C and Rossi A. Improvement of long-term preservation of the isolated arrested rat heart by trimetazidine: effects on the energy state and mitochondrial function. Am J Cardiol. 1995;76:45B-49B.

21. Maridonneau-Parini I and Harpey $C$. Effect of trimetazidine on membrane damage induced by oxygen free radicals in human red cells. Br J Clin Pharmacol. 1985;20:148-51.

22. Liu X, Gai Y, Liu F, Gao W, Zhang Y, Xu M and Li Z. Trimetazidine inhibits pressure overloadinduced cardiac fibrosis through NADPH oxidase-ROS-CTGF pathway. Cardiovasc Res. 2010;88:150-8.

23. Belardinelli $R$, Solenghi $M$, Volpe $L$ and Purcaro A. Trimetazidine improves endothelial dysfunction in chronic heart failure: an antioxidant effect. Eur Heart J. 2007;28:1102-8.

24. Zeemering S, Maesen B, Nijs J, Lau DH, Granier M, Verheule S and Schotten U. Automated quantification of atrial fibrillation complexity by probabilistic electrogram analysis and fibrillation wave reconstruction. Conf Proc IEEE Eng Med Biol Soc. 2012;2012:6357-60.

25. Lau DH, Maesen B, Zeemering S, Kuklik P, van Hunnik A, Lankveld TA, Bidar E, Verheule S, Nijs J, Maessen J, Crijns H, Sanders P and Schotten U. Indices of bipolar complex fractionated atrial electrograms correlate poorly with each other and atrial fibrillation substrate complexity. Heart Rhythm. 2015;12:1415-23.

26. Eckstein J, Maesen B, Linz D, Zeemering S, van Hunnik A, Verheule S, Allessie M and Schotten $\mathrm{U}$. Time course and mechanisms of endo-epicardial electrical dissociation during atrial fibrillation in the goat. Cardiovascular research. 2011;89:816-24.

27. Eckstein J, Zeemering S, Linz D, Maesen B, Verheule S, van Hunnik A, Crijns H, Allessie MA and Schotten $U$. Transmural conduction is the predominant mechanism of breakthrough during atrial fibrillation: evidence from simultaneous endo-epicardial high-density activation mapping. Circ Arrhythm Electrophysiol. 2013;6:334-41.

28. Maridonneau I, Braquet P and Garay RP. Na+ and K+ transport damage induced by oxygen free radicals in human red cell membranes. J Biol Chem. 1983;258:3107-13.

29. Rahman I, Kode A and Biswas SK. Assay for quantitative determination of glutathione and glutathione disulfide levels using enzymatic recycling method. Nat Protoc. 2006;1:3159-65.

30. Antonopoulos AS, Margaritis M, Verheule S, Recalde A, Sanna F, Herdman L, Psarros C, Nasrallah H, Coutinho P, Akoumianakis I, Brewer AC, Sayeed R, Krasopoulos G, Petrou M, Tarun A, Tousoulis D, Shah AM, Casadei B, Channon KM and Antoniades C. Mutual Regulation of Epicardial Adipose Tissue and Myocardial Redox State by PPAR-gamma/Adiponectin Signalling. Circulation research. 2016;118:842-55.

31. Jansson E. Acid soluble and insoluble glycogen in human skeletal muscle. Acta Physiol Scand. 1981;113:337-40. 
32. Schindelin J, Arganda-Carreras I, Frise E, Kaynig V, Longair M, Pietzsch T, Preibisch S, Rueden C, Saalfeld S, Schmid B, Tinevez JY, White DJ, Hartenstein V, Eliceiri K, Tomancak P and Cardona A. Fiji: an open-source platform for biological-image analysis. Nat Methods. 2012;9:676-82.

33. Crijns HJ, van Wijk LM, van Gilst WH, Kingma JH, van Gelder IC and Lie KI. Acute conversion of atrial fibrillation to sinus rhythm: clinical efficacy of flecainide acetate. Comparison of two regimens. Eur Heart J. 1988;9:634-8.

34. Eijsbouts S, Ausma J, Blaauw Y, Schotten U, Duytschaever M and Allessie MA. Serial cardioversion by class IC Drugs during 4 months of persistent atrial fibrillation in the goat. $J$ Cardiovasc Electrophysiol. 2006;17:648-54.

35. Thijssen VL, van der Velden HM, van Ankeren EP, Ausma J, Allessie MA, Borgers M, van Eys GJ and Jongsma HJ. Analysis of altered gene expression during sustained atrial fibrillation in the goat. Cardiovasc Res. 2002;54:427-37.

36. Gramley F, Lorenzen J, Jedamzik B, Gatter K, Koellensperger E, Munzel T and Pezzella F. Atrial fibrillation is associated with cardiac hypoxia. Cardiovasc Pathol. 2010;19:102-11.

37. Ausma J, Wijffels M, van Eys G, Koide M, Ramaekers F, Allessie Mand Borgers M. Dedifferentiation of atrial cardiomyocytes as a result of chronic atrial fibrillation. Am J Pathol. 1997;151:985-97.

38. Ausma J, van der Velden HM, Lenders MH, van Ankeren EP, Jongsma HJ, Ramaekers FC, Borgers $\mathrm{M}$ and Allessie MA. Reverse structural and gap-junctional remodeling after prolonged atrial fibrillation in the goat. Circulation. 2003;107:2051-8.

39. Thijssen VL, Ausma J and Borgers M. Structural remodelling during chronic atrial fibrillation: act of programmed cell survival. Cardiovasc Res. 2001;52:14-24.

40. Opacic D, van Bragt KA, Nasrallah HM, Schotten U and Verheule S. Atrial metabolism and tissue perfusion as determinants of electrical and structural remodeling in atrial fibrillation. Cardiovasc Res. 2016.

41. Doenst T, Nguyen TD and Abel ED. Cardiac metabolism in heart failure: implications beyond ATP production. Circ Res. 2013;113:709-24.

42. Kruszynska YT and Sherratt HS. Glucose kinetics during acute and chronic treatment of rats with 2[6(4-chloro-phenoxy)hexyl]oxirane-2-carboxylate, etomoxir. Biochem Pharmacol. 1987;36:3917-21.

43. Inglis $\mathrm{S}$ and Stewart S. Metabolic therapeutics in angina pectoris: history revisited with perhexiline. Eur J Cardiovasc Nurs. 2006;5:175-84.

44. McCarthy CP, Mullins KV and Kerins DM. The role of trimetazidine in cardiovascular disease: beyond an anti-anginal agent. Eur Heart J Cardiovasc Pharmacother. 2016;2:266-72.

45. McCormack JG, Stanley WC and Wolff AA. Ranolazine: a novel metabolic modulator for the treatment of angina. Gen Pharmacol. 1998;30:639-45.

46. Davila-Roman VG, Vedala G, Herrero P, de las Fuentes L, Rogers JG, Kelly DP and Gropler RJ. Altered myocardial fatty acid and glucose metabolism in idiopathic dilated cardiomyopathy. $J$ Am Coll Cardiol. 2002;40:271-7.

47. Glatz JF and Luiken JJ. From fat to FAT (CD36/SR-B2): Understanding the regulation of cellular fatty acid uptake. Biochimie. 2017;136:21-26.

48. Cavar M, Ljubkovic M, Bulat C, Bakovic D, Fabijanic D, Kraljevic J, Karanovic N, Dujic Z, Lavie $\mathrm{CJ}$, Wisloff $\mathrm{U}$ and Marinovic J. Trimetazidine does not alter metabolic substrate oxidation in cardiac mitochondria of target patient population. Br J Pharmacol. 2016;173:1529-40.

49. Dedkova EN, Seidlmayer LK and Blatter LA. Mitochondria-mediated cardioprotection by trimetazidine in rabbit heart failure. J Mol Cell Cardiol. 2013;59:41-54. 
50. Adam O, Frost G, Custodis F, Sussman MA, Schafers HJ, Bohm M and Laufs U. Role of Rac1 GTPase activation in atrial fibrillation. J Am Coll Cardiol. 2007;50:359-67.

51. Dudley SC, Jr., Hoch NE, McCann LA, Honeycutt C, Diamandopoulos L, Fukai T, Harrison DG, Dikalov SI and Langberg J. Atrial fibrillation increases production of superoxide by the left atrium and left atrial appendage: role of the NADPH and xanthine oxidases. Circulation. 2005;112:1266-73.

52. Almroth $\mathrm{H}$, Hoglund N, Boman $\mathrm{K}$, Englund A, Jensen S, Kjellman B, Tornvall P and Rosenqvist M. Atorvastatin and persistent atrial fibrillation following cardioversion: a randomized placebocontrolled multicentre study. Eur Heart J. 2009;30:827-33.

53. Negi S, Shukrullah I, Veledar E, Bloom HL, Jones DP and Dudley SC. Statin therapy for the prevention of atrial fibrillation trial (SToP AF trial). J Cardiovasc Electrophysiol. 2011;22:414-9.

54. Zheng Z, Jayaram R, Jiang L, Emberson J, Zhao Y, Li Q, Du J, Guarguagli S, Hill M, Chen Z, Collins R and Casadei B. Perioperative Rosuvastatin in Cardiac Surgery. N Engl J Med. 2016;374:174453.

55. Long-Term Intervention with Pravastatin in Ischaemic Disease Study G. Prevention of cardiovascular events and death with pravastatin in patients with coronary heart disease and a broad range of initial cholesterol levels. N Engl J Med. 1998;339:1349-57.

56. Rahimi K, Emberson J, McGale P, Majoni W, Merhi A, Asselbergs FW, Krane V, Macfarlane PW and Executive P. Effect of statins on atrial fibrillation: collaborative meta-analysis of published and unpublished evidence from randomised controlled trials. BMJ. 2011;342:d1250.

57. Macchia A, Grancelli H, Varini S, Nul D, Laffaye N, Mariani J, Ferrante D, Badra R, Figal J, Ramos S, Tognoni G, Doval HC and Investigators G. Omega-3 fatty acids for the prevention of recurrent symptomatic atrial fibrillation: results of the FORWARD (Randomized Trial to Assess Efficacy of PUFA for the Maintenance of Sinus Rhythm in Persistent Atrial Fibrillation) trial. J Am Coll Cardiol. 2013;61:463-8.

58. Kowey PR, Reiffel JA, Ellenbogen KA, Naccarelli GV and Pratt CM. Efficacy and safety of prescription omega-3 fatty acids for the prevention of recurrent symptomatic atrial fibrillation: a randomized controlled trial. JAMA. 2010;304:2363-72.

59. Nigam A, Talajic M, Roy D, Nattel S, Lambert J, Nozza A, Jones P, Ramprasath VR, O'Hara G, Kopecky S, Brophy JM, Tardif JC and Investigators A. Fish oil for the reduction of atrial fibrillation recurrence, inflammation, and oxidative stress. J Am Coll Cardiol. 2014;64:1441-8.

60. Greiser M, Kerfant BG, Williams GS, Voigt N, Harks E, Dibb KM, Giese A, Meszaros J, Verheule S, Ravens U, Allessie MA, Gammie JS, van der Velden J, Lederer WJ, Dobrev D and Schotten U. Tachycardia-induced silencing of subcellular Ca2+ signaling in atrial myocytes. J Clin Invest. 2014;124:4759-72.

61. Hohendanner F, Maxwell JT and Blatter LA. Cytosolic and nuclear calcium signaling in atrial myocytes: IP3-mediated calcium release and the role of mitochondria. Channels (Austin). 2015;9:129-38.

62. Schweitzer MK, Wilting F, Sedej S, Dreizehnter L, Dupper NJ, Tian Q, Moretti A, My I, Kwon O, Priori SG, Laugwitz KL, Storch U, Lipp P, Breit A, Mederos YSM, Gudermann T and Schredelseker J. Suppression of Arrhythmia by Enhancing Mitochondrial $\mathrm{Ca}(2+)$ Uptake in Catecholaminergic Ventricular Tachycardia Models. JACC Basic Trans/ Sci. 2017;2:737-747.

63. Schotten U, Duytschaever M, Ausma J, Eijsbouts S, Neuberger HR and Allessie M. Electrical and contractile remodeling during the first days of atrial fibrillation go hand in hand. Circulation. 2003;107:1433-9. 


\section{Supplement}

\section{Methods}

\section{Isolated mitochondrial function Mitochondria isolation}

After excision of the heart, small pieces of the LA and LV were immersed in an ice-cold mitochondrial isolation buffer (ISA: $300 \mathrm{mM}$ sucrose, $2 \mathrm{mM}$ EGTA, $10 \mathrm{mM}$ Tris- $\mathrm{HCl}, \mathrm{pH} 7.1$ at $4^{\circ} \mathrm{C}$ ). The tissue samples were quickly chopped with scissors and incubated in $25 \mathrm{ml}$ of ISA buffer containing $0.1 \mathrm{mg} / \mathrm{ml}$ of bacterial proteinase type XXIV (Sigma) for 7 minutes at $4^{\circ} \mathrm{C}$. The tissue suspension was then homogenized for 3 minutes in a glass Potter homogenizer with a motorized Teflon pestle and the homogenate was centrifuged at $7500 \mathrm{~g}$ for $7 \mathrm{~min}$. The obtained pellet was firstly rinsed twice with, and afterward resuspended in ISA buffer supplemented with $2 \mathrm{mg} / \mathrm{ml}$ of Fatty Acid Free Bovine Serum Albumin (ISA-BSA). The resuspended pallet was homogenized for the second time as described above. The homogenate was centrifuged at $700 \mathrm{~g}$ for 10 minutes and the supernatant was separated and centrifuged at $7000 \mathrm{~g}$ for 10 minutes. The resulting crude mitochondrial pallet was resuspended in ISA-BSA containing $25 \%(\mathrm{w} / \mathrm{v})$ Percoll $\left(\mathrm{pH} 7.1-7.2\right.$ at $\left.4^{\circ} \mathrm{C}\right)$ and centrifuged at $17,000 \mathrm{~g}$ for $10 \mathrm{~min}$ for purification. The final pure mitochondrial pallet was resuspended in ISA buffer and protein concentration was determined by a bicinchoninic acid-based assay (PierceTM BCA protein assay kit).

\section{Mitochondrial respiration}

Mitochondrial respiration was determined with Oroboros-2K high-resolution respirometry (Oroboros Instruments) at $37^{\circ} \mathrm{C}$ in a KCL-based respiration buffer (see above). Mitochondrial respiration was measured while mitochondria were oxidizing either glutamate $(5 \mathrm{mM})$ and malate $(2 \mathrm{mM})$ or Palmitoyl-Carnitine $(10 \mu \mathrm{M})$ and malate $(1 \mathrm{mM})$ in the absence or presence of $1.5 \mathrm{mM}$ ADP (state 2 and state 3 respiration, respectively). Cytochrome $C$ $(10 \mu \mathrm{M})$ was added to test the permeability of the mitochondrial outer membrane as a quality indicator of isolated mitochondria. Mitochondrial oxygen consumption rates were expressed as nmoles of oxygen used per minute per mg of proteins (nmoles $\mathrm{O}_{2} / \mathrm{min} / \mathrm{mg}$ of protein).

\section{Mitochondrial membrane potential $\left(\Delta \Psi_{m}\right)$}

The mitochondrial membrane potential was determined using 50nM of rhodamine-123 in a $\mathrm{KCl}$-based respiration buffer (see above) in the presence of either glutamate $(5 \mathrm{mM})$ and malate $(2 \mathrm{mM})$ or Palmitoyl-Carnitine $(10 \mu \mathrm{M})$ and malate $(1 \mathrm{mM}) . \Delta \Psi \mathrm{m}$ was evaluated in the presence of oxidizing substrates and after addition of 1.5mM ADP.

The recorded fluorescence was normalized to fluorescence values after addition of the

Adenine nucleotide translocator inhibitor carboxyatractyloside, CAT $(5 \mu \mathrm{M})$ to determine maximal value of $\Psi_{\mathrm{m}}$ (100\% reduced), while the mitochondrial uncoupler trifluorocarbonylcyanide phenylhydrazone (FCCP, $2 \mu \mathrm{mol} / \mathrm{L}$ ) was added to determine 
a minimal value of $\Psi_{\mathrm{m}}$ ( $100 \%$ oxidized). $\Delta \Psi_{\mathrm{m}}$ values are expressed as the percentage normalized to fluorescence values in the presence of CAT and FCCP.

\section{Mitochondrial calcium retention capacity}

Mitochondria were incubated in the buffer containing $\mathrm{KCl} 125 \mathrm{mM}, \mathrm{MOPS} 20 \mathrm{mM}$, Tris $10 \mathrm{mM}$, EGTA $10 \mu \mathrm{M}, \mathrm{KH}_{2} \mathrm{PO}_{4} 2 \mathrm{mM}$, pH 7.1 adjusted at room temperature with $\mathrm{KOH}$ together with either glutamate $(5 \mathrm{mM})$ and malate $(2 \mathrm{mM})$ or palmitoyl-carnitine $(10 \mu \mathrm{M})$ and malate $(1 \mathrm{mM})$. The concentration of free calcium in the buffer was monitored using the fluorescent dye Calcium Green $(1 \mu \mathrm{mol} / \mathrm{L})$. The maximum calcium retention capacity (CRC) was estimated as the amount of calcium added to the medium until mPTP opened. A calibration curve was recorded with known $\mathrm{Ca}^{2+}$ concentrations and $\mathrm{CRC}$, and expressed as $\mathrm{nmol}$ of free $\mathrm{Ca}^{2+}$ per $\mathrm{mg}$ of protein ( $\mathrm{nmol}$ of $\mathrm{Ca}^{2+} / \mathrm{mg}$ protein).

\section{Hydrogen peroxide emission in isolated mitochondria}

The mitochondrial $\mathrm{H}_{2} \mathrm{O}_{2}$ emission was quantified using fluorescent hydrogen peroxide indicator, Amplex Red $(10 \mu \mathrm{mol} / \mathrm{L})$ in a $\mathrm{KCl}$-based respiration buffer $(\mathrm{KCl} 125 \mathrm{mM}$, MOPS $20 \mathrm{mM}$, Tris $10 \mathrm{mM}, \mathrm{EGTA} 10 \mu \mathrm{M}, \mathrm{KH}_{2} \mathrm{PO}_{4} 2.5 \mathrm{mM}, \mathrm{MgCl}_{2} 2.5 \mathrm{mM}, 2 \mathrm{mg} / \mathrm{ml} \mathrm{BSA}, \mathrm{pH} 7.1$ at room temperature with $\mathrm{KOH})$ at $37^{\circ} \mathrm{C}$ supplemented with peroxidase $(10 \mu \mathrm{g} / \mathrm{ml})^{1,2}$. The $\mathrm{H}_{2} \mathrm{O}_{2}$ emission of the isolated mitochondria was measured before and after addition of $1.5 \mathrm{mM}$ ADP in the presence of either glutamate $(5 \mathrm{mM})$ and malate $(2 \mathrm{mM})$ or Palmitoyl-Carnitine $(10 \mu \mathrm{M})$ and malate $(1 \mathrm{mM})$. Maximal mitochondrial $\mathrm{H}_{2} \mathrm{O}_{2}$ production was determined by the addition of the complex III inhibitor Antimycin A $(5 \mu \mathrm{mol} / \mathrm{L})$. A calibration curve was recorded to quantify mitochondrial $\mathrm{H}_{2} \mathrm{O}_{2}$ emission and mitochondrial $\mathrm{H}_{2} \mathrm{O}_{2}$ emission rates were expressed as pmol of hydrogen peroxide per minute per mg of protein ( $\mathrm{pmol}_{2} \mathrm{H}_{2} \mathrm{O}_{2} /$ $\mathrm{min} / \mathrm{mg}$ of protein).

\section{Catalase activity quantification in cardiac tissue homogenates}

Catalase activity was measured in cardiac tissue homogenates by a method developed by $\mathrm{Aebi}^{3}$ with minor modifications. After 5 times dilution of the homogenates in $145 \mathrm{mM}$ sodium phosphate buffer $(\mathrm{pH}=7.4)$, the degradation of $10 \mathrm{mM}$ hydrogen peroxide $\left(\mathrm{H}_{2} \mathrm{O}_{2}\right)$ was determined spectrophotometrically at a wavelength of $240 \mathrm{~nm}$ during $30 \mathrm{sec}$. The absorbance values at $t_{1}=10 \mathrm{~s}$ and $t_{2}=30 \mathrm{~s}$ were used to calculate the $1 \mathrm{st}$-order rate constant $\mathrm{k}$ in accordance with the equation $\mathrm{k}=2.3 / \Delta \mathrm{t} * \log \left(\Delta \mathrm{A}_{1} / \Delta \mathrm{A}_{2}\right)$, where $\Delta \mathrm{t}$ is the difference in times $\mathrm{t}_{1}$ and $\mathrm{t}_{2^{\prime}} \Delta \mathrm{A}_{1}$ the difference in absorbance at $\mathrm{t}_{1}=10 \mathrm{~s}$ and absorbance before addition of $\mathrm{H}_{2} \mathrm{O}_{2}$ and $\Delta \mathrm{A}_{2}$ the difference in absorbance at $\mathrm{t}_{2}=30 \mathrm{sec}$ and absorbance before addition of $\mathrm{H}_{2} \mathrm{O}_{2}$.

\section{Superoxide dismutase 1 and 2 activity in cardiac tissue homogenates}

The activity of both superoxide dismutase (SOD) isoforms 1 (CuZnSOD) and 2 (MnSOD) was measured in a colorimetric competition assay using xanthine/xanthine oxidase to generate superoxide anion radicals $\left(\mathrm{O}_{2}^{-}\right)$and nitro blue tetrazolium chloride (NBT) to monitor $\mathrm{O}_{2}^{-*}$ generation. SOD competes with $\mathrm{NBT}$ for $\mathrm{O}_{2}^{-*}$ which leads to a decreased NBT reduction rate. The percentage inhibition of the reference NBT reduction rate (in the absence of SOD) is equivalent to the amount of SOD present in the test samples4. 
The cardiac tissue homogenates were 20 times diluted in $145 \mathrm{mM}$ sodium phosphate buffer $(\mathrm{pH}=7.4)$ before they were added to the assay. The generation of $\mathrm{O}_{2}^{-*}$ was initiated by the addition of $100 \mu \mathrm{L}$ of a $0.1 \mathrm{U} / \mathrm{ml}$ xanthine oxidase solution to $900 \mu \mathrm{L}$ of a reaction mix containing the diluted homogenate, $0.1 \mathrm{mM}$ xanthine and $0.05 \mathrm{mM}$ nitrotetrazolium blue chloride. The generation of $\mathrm{O}_{2}^{--}$was monitored at $37^{\circ} \mathrm{C}$ by an increase in absorbance at a wavelength of $\lambda=560 \mathrm{~nm}$ during $3 \mathrm{~min}$.

To determine the activity of SOD 2 only, the measurements were performed again but in the presence of $90 \mathrm{mM}$ potassium cyanide to selectively inactivate SOD1 activity. Subtraction of SOD2 activity from the total SOD activity allowed determining SOD1 activity.

\section{Results}

\section{Isolated mitochondria}

\section{Mitochondrial respiration}

Maintenance of adequate $\Delta \Psi_{\mathrm{m}}$ for an ATP synthesis is dependent on the function of oxidative phosphorylation enzymes. Mitochondrial $\mathrm{O}_{2}$ consumption of both LA and LV mitochondria was comparable between the groups independently from the oxidizing substrate used (Figure S1).
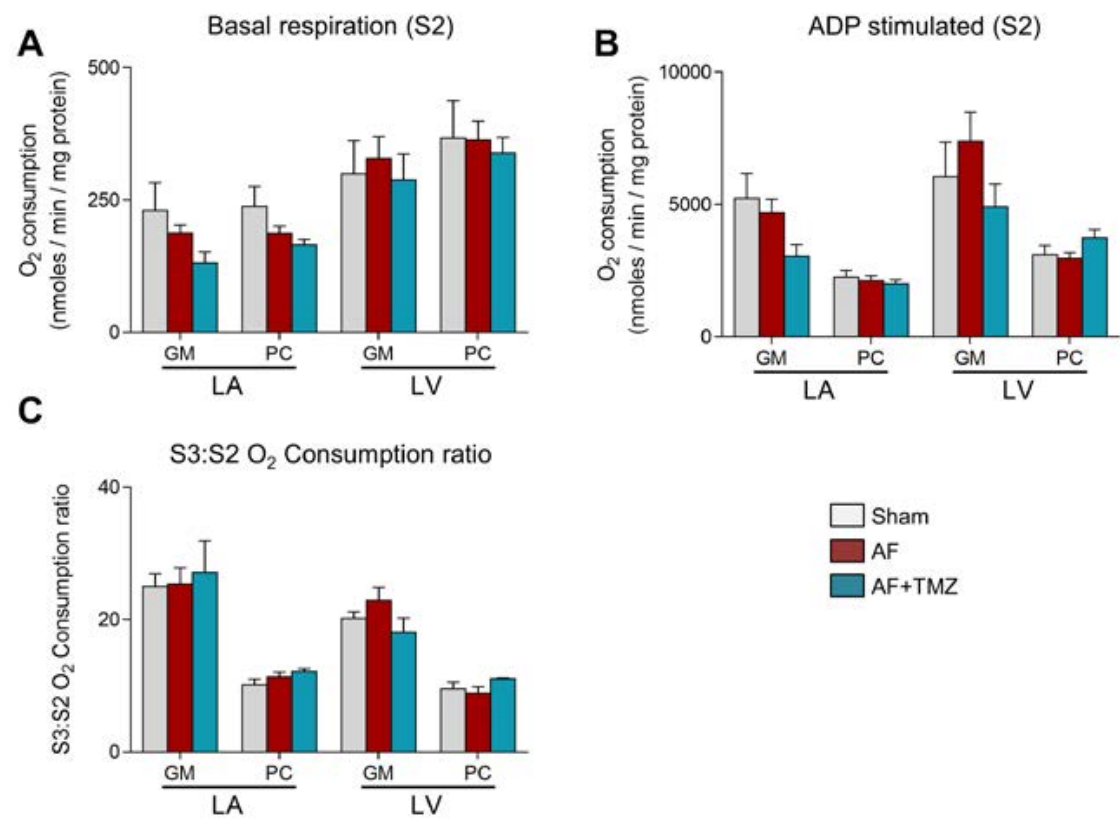

Figure S1. Mitochondrial oxygen consumption. Oxygen consumption of the isolate LA and LV mitochondria was measured at baseline only in the presence of substrates as a baseline (A) and after the addition of the ADP (B). Mitochondrial respiratory control was determined as the ratio between the $\mathrm{O}_{2}$ consumption at baseline and in the presence of the saturating ADP concentration (C). 


\section{Expression of the mitochondrial respiration complexes}

Atrial fibrillation did not dramatically alter the expression of the mitochondrial respiratory chain complexes. The only significant difference was observed in the expression of the Complex $\mathrm{V}$ of the mitochondrial respiratory chain in the LA, which was lower in the UAF group. TMZ treatment on the other hand significantly increased expression of the Complex I in the LA, compared to UAF and almost statistically significant compared to AF control group $(p=0.06)$ (Figure S2).

A

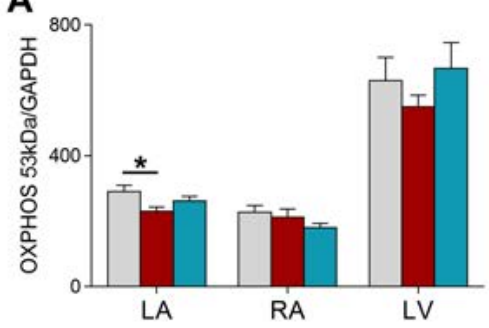

D

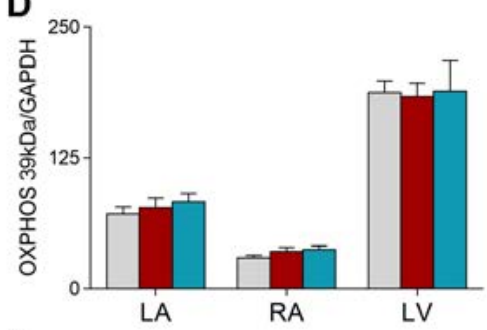

E

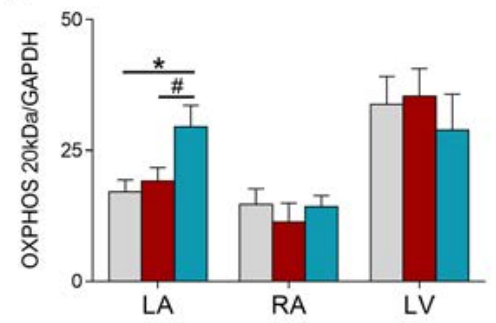

B

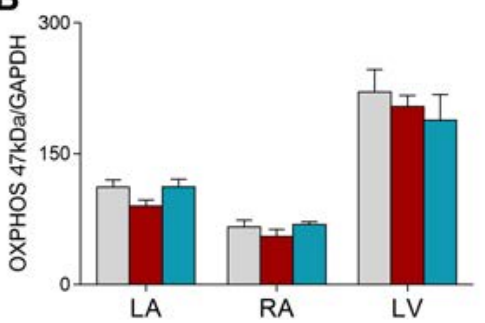

C

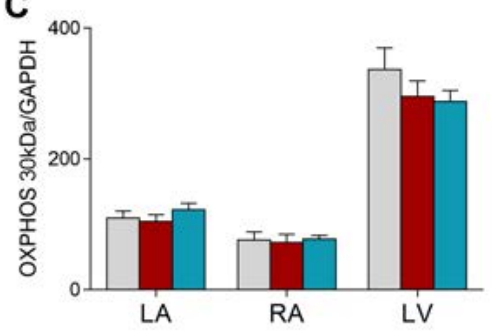

Figure S2. Mitochondrial oxidative phosphorylation complexes protein content. (A) OXPHOS $53 \mathrm{kDa}-$ Complex V, (B) OXPHOS 47kDa - Complex III, (C) OXPHOS 39 kDa - Complex IV, (D) OXPHOS 30 kDa - Complex II, (E) OXPHOS $20 \mathrm{kDA}$ - Complex I. All measurements are performed in 8 to 10 animals and normalized to GAPDH content. 


\section{Mitochondrial membrane potential $(\Delta \Psi \mathrm{m})$}

High values of $\Delta \Psi_{\mathrm{m}}$ are strongly associated with the increased ROS production ${ }^{4}$, and therefore we quantified the relative value $\Delta \Psi_{\mathrm{m}}$ of LA and LV mitochondria oxidizing either GM or PCM in the presence or absence of ADP. This method allows quantification of relative changes in $\Delta \Psi_{\mathrm{m}}$.

$\Delta \Psi_{\mathrm{m}}$ was higher in the LA mitochondria isolated from uAF compared to shams. This increase in $\Delta \Psi_{\mathrm{m}}$ was abolished by the TMZ treatment (Figure S3 A). The difference in $\Delta \Psi_{\mathrm{m}}$ between LA mitochondria of sham and UAF animals disappeared after the addition of the saturating concentration of ADP, but $\Delta \Psi_{\mathrm{m}}$ of LA mitochondria from the TMZ treated animals was still significantly lower (Figure S3 B). At baseline, $\Delta \Psi_{\mathrm{m}}$ of the mitochondria isolated from the LV was comparable between the groups independently of the oxidizing substrate. However, after the ADP addition, the LV mitochondria of the TMZ animals were more depolarized compared both to sham and to control AF animals in a presence of GM (Figure S3, A and B).

A

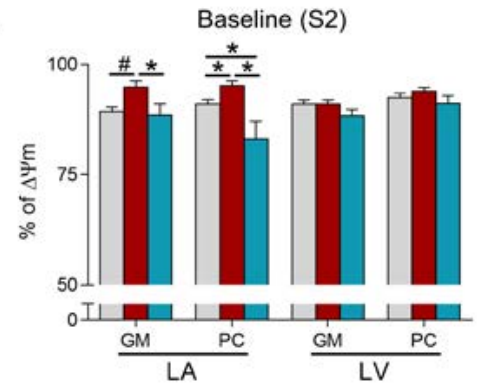

C

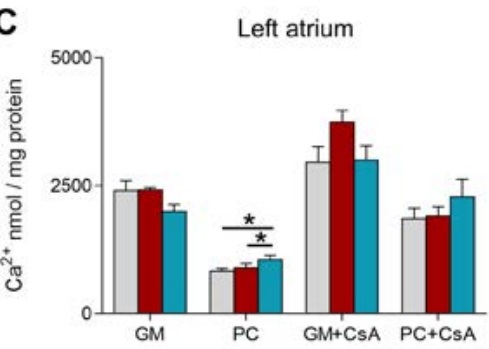

B

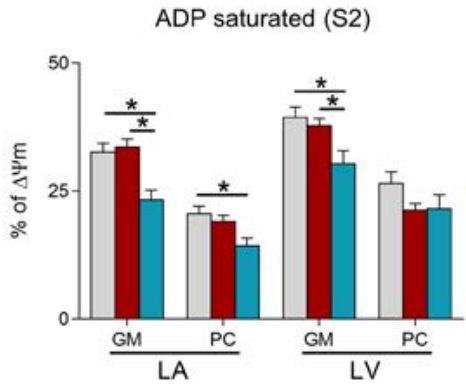

D

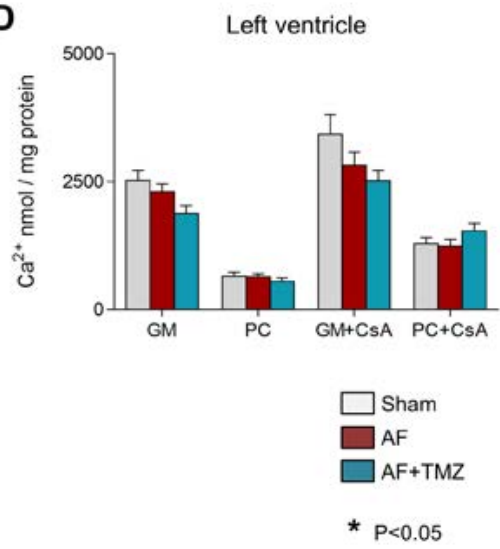

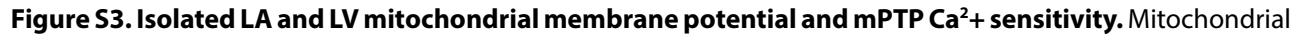
membrane potential was measured using the rhodamine 123 dye both at baseline $(\mathbf{A})$ and in the presence of the saturating concentrations of ADP (B). Mitochondrial $\mathrm{Ca}^{2}+$ retention capacity with and without cyclosporine $\mathrm{A}$ (CsA) of the left atrium (C) and left ventricle (D). All measurements were performed in the presence of glutamatemalate $(\mathrm{GM})$ and palmitoyl-carnitine-malate $(\mathrm{PC})$ as the substrates of the oxidation. $\mathrm{n}=6$ to10 independent mitochondrial isolations. 


\section{Mitochondrial $\mathrm{Ca}^{2+}$ retention capacity}

Mitochondria isolated from the UAF animals had similar mitochondrial sensitivity to $\mathrm{Ca}^{2+}$ induced MPTP opening compared to sham animals. However, TMZ treatment inhibited $\mathrm{Ca}^{2+}$-induced mPTP opening of LA mitochondria oxidizing PCM as a substrate. This trend was preserved after the addition of cyclosporine $A$, an inhibitor of mPTP opening (Figure S3, C and D).

\section{$\mathrm{H}_{2} \mathrm{O}_{2}$ emission in isolated mitochondria}

$\mathrm{H}_{2} \mathrm{O}_{2}$ emission of LA mitochondria oxidizing $\mathrm{GM}$ did not differ significantly between the groups at baseline and in the presence of ADP, while basal $\mathrm{H}_{2} \mathrm{O}_{2}$ emission of the LA mitochondria isolated from TMZ treated animals was significantly lower compared to sham (Figure $\mathrm{S} 4, \mathrm{~A}$ and $\mathrm{B}$ ). After maximally stimulating mitochondrial $\mathrm{H}_{2} \mathrm{O}_{2}$ emission by the addition of Antimycin $\mathrm{A}, \mathrm{H}_{2} \mathrm{O}_{2}$ emission was significantly lower in AF animals treated with TMZ compared to sham (Figure S4 C). A similar trend was also observed in uAF animals, but this difference was not statistically significant. LV mitochondria isolated from AF animals treated with TMZ had a lower $\mathrm{H}_{2} \mathrm{O}_{2}$ emission in all conditions investigated irrespective from the substrate metabolized. LV mitochondria isolated from the UAF animals also had significantly lower $\mathrm{H}_{2} \mathrm{O}_{2}$ emission at baseline oxidizing PCM, and after treatment with Antimycin A independent of the substrate (Figure S4, A-C).

A

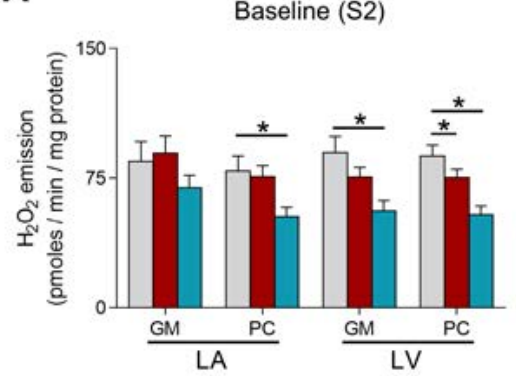

C

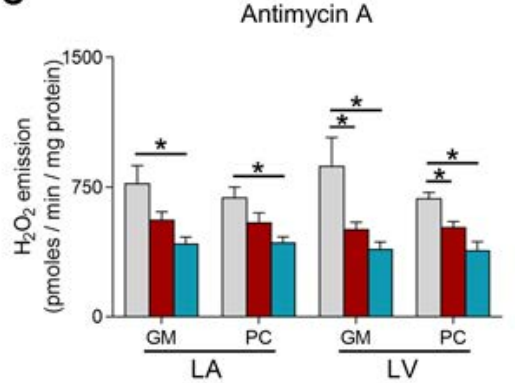

B

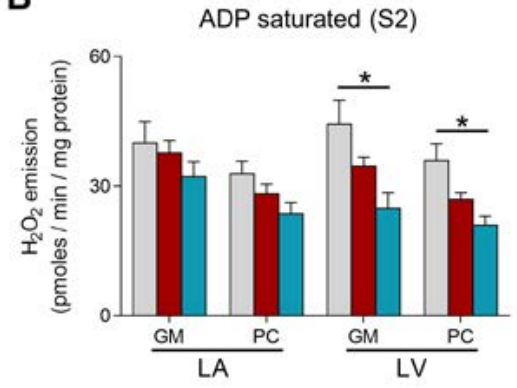

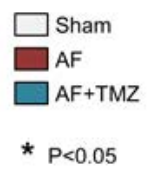

Figure S4. Isolated LA and LV mitochondrial $\mathbf{H}_{2} \mathbf{O}_{2}$ production. The mitochondrial $\mathrm{H}_{2} \mathrm{O}_{2}$ production was measured from LA and LV isolated mitochondria both in the presence of glutamate-malate (GM) or in the presence of palmitoyl-carnitine-malate (PC). (A) Mean $\mathrm{H}_{2} \mathrm{O}_{2}$ emission at baseline and after addition of the saturating concentrations of ADP (B). (C) Mean maximal $\mathrm{H}_{2} \mathrm{O}_{2}$ emission after the addition of the complex III inhibitor Antimycin A. Data are presented as means \pm SEM. $n=6$ to 10 independent mitochondrial isolations. 


\section{Catalase and SOD activity}

Catalase and superoxide dismutase (SOD) are enzymes that neutralize $\mathrm{O}_{2}^{-}$. After $\mathrm{O}_{2}^{-}$is generated, SOD dismutates superoxide anion generating hydrogen peroxide which is later neutralized to $\mathrm{H}_{2} \mathrm{O}$ either by catalase or by glutathione peroxidase/glutathione reductase cycle ${ }^{5}$. Therefore, since the $\mathrm{AF}$ increased $\mathrm{O}_{2}^{-}$production in tissue homogenates and decreased $\mathrm{H}_{2} \mathrm{O}_{2}$ emission in isolated mitochondria we investigated whether the main mitochondrial superoxide neutralization mechanism next to glutathione were upregulated. However, neither, catalase nor SOD 1 or 2 activity were altered in all three chambers (Figure S5).

A
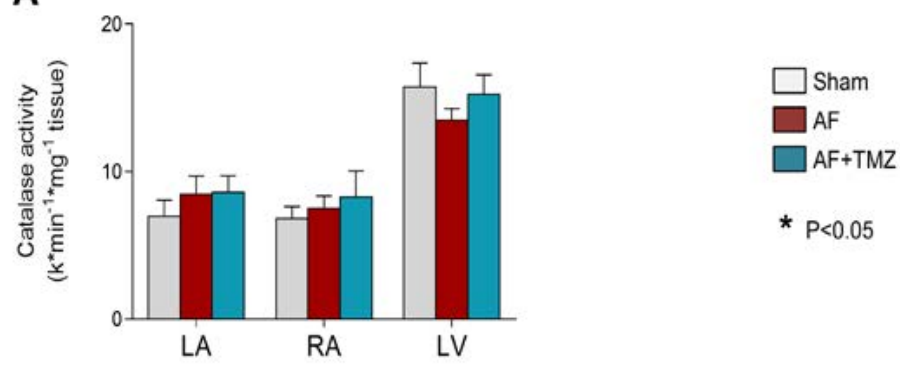

* $P<0.05$

B

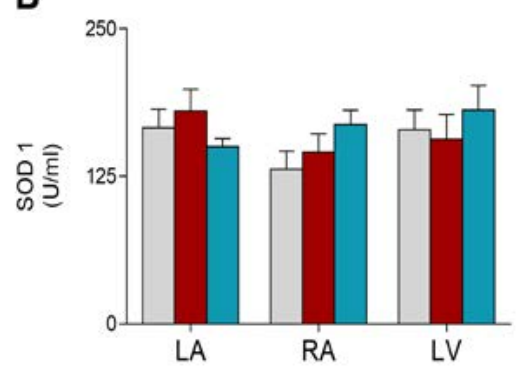

C

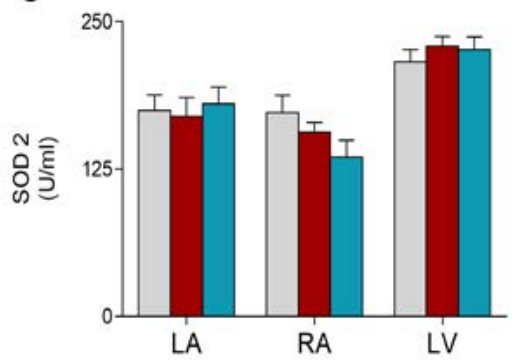

Figure S5. The effect of TMZ treatment on the activity of main ROS neutralizing enzymes in tissue homogenates. (A) Catalase; (B) SOD 1 - Superoxide dismutase 1; (C) SOD 2 - Superoxide dismutase 2. Data are presented as means \pm SEM. The quantification of all parameters was performed in 8-10 independent LA, RA and LV tissue homogenates per group. 


\section{References}

1. Pasdois P, Parker JE, Griffiths EJ and Halestrap AP. The role of oxidized cytochrome c in regulating mitochondrial reactive oxygen species production and its perturbation in ischaemia. The Biochemical journal. 2011;436:493-505.

2. Pasdois P, Parker JE and Halestrap AP. Extent of mitochondrial hexokinase II dissociation during ischemia correlates with mitochondrial cytochrome $c$ release, reactive oxygen species production, and infarct size on reperfusion. J Am Heart Assoc. 2012;2:e005645.

3. Aebi H. Catalase in vitro. Methods Enzymol. 1984;105:121-6.

4. Suski JM, Lebiedzinska M, Bonora M, Pinton P, Duszynski J and Wieckowski MR. Relation between mitochondrial membrane potential and ROS formation. Methods Mol Biol. 2012;810:183-205.

5. Zorov DB, Juhaszova M and Sollott SJ. Mitochondrial reactive oxygen species (ROS) and ROSinduced ROS release. Physiol Rev. 2014;94:909-50. 



\section{Chapter VII}

General discussion 



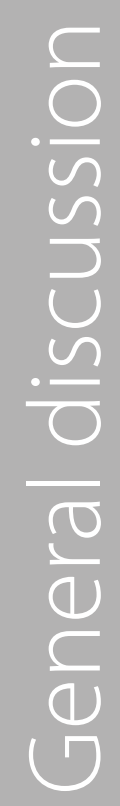




\section{General discussion}

The main focus of this thesis is to investigate the effect of metabolic modulators on various aspects of pathophysiological mechanisms operative at different stages of atrial fibrillation (AF) associated atrial remodeling. As mentioned in the general introduction, $\mathrm{AF}$ has a significant and growing impact on healthcare due to the aging population and the lack of effective treatment options to prevent progression of AF. In addition, we outlined different remodeling processes taking place during AF progression, emphasizing the potential role of metabolic compromise and metabolic remodeling. In the second chapter, we reviewed the currently available knowledge regarding changes in myocardial metabolism and tissue perfusion during different stages of $\mathrm{AF}^{1}$. Furthermore, we suggested metabolic interventions such as ranolazine and trimetazidine that may assuage metabolic compromise during $\mathrm{AF}$, thereby inhibit remodeling processes, and hinder AF progression.

In chapter $\mathbf{3}$ we have investigated the electrophysiological effects of the metabolic modulator ranolazine in an awake goat model of lone atrial fibrillation at different stages of AF-induced atrial remodelling. In chapter 4 we have shown that the inhibition of the inward rectifier $\mathrm{K}^{+}$current $\left(\mathrm{I}_{\mathrm{K} 1}\right)$ with pentamidine analogue 6 (PA-6) can effectively cardiovert stable AF in goats to sinus rhythm without proarrhythmic effects on the ventricles in either goats or dogs.

In chapter 5 we have characterized the functionality of the atrial and ventricular resistance sized arteries in healthy animals and in animals with long-term atrial fibrillation.

Finally, in the last experimental chapter (chapter 6) we have investigated whether a metabolic intervention with trimetazidine can affect some of the hallmarks of AF induced atrial remodeling and therefore preserve atrial structure and function in the goat model of long-term atrial fibrillation.

\section{Metabolic alterations and ion channels}

Both metabolic alterations and remodelling of the ion channels in the atria during AF are most prominent during the first days of AF. In the second chapter of this thesis, we presented a schematic representation of the numerous relations between energy production, mitochondrial function, ROS, and ion channel function in atrial myocytes. Although this schematic presentation is simplified, it delineates the complex interconnection between cellular electrophysiology and different steps of energy production and utilization in the cell.

The rapid rates during $A F$, on the one hand, lead to 'electrical remodelling' i.e. shortening of the atrial action potential duration (APD) and atrial effective refractory period (AERP), while on the other hand, they increase energy demand and cause supply/demand mismatch ${ }^{1,2}$. Both processes are closely linked and can influence and regulate each other. However, the extent to which this interaction can contribute to the progression of AF is unclear at present. 
lon currents that are known to be relevant for AF development are depolarizing long-lasting $\mathrm{Ca}^{2+}$ current $\left(\mathrm{I}_{\mathrm{CaL}}\right)$ and several repolarizing potassium currents including transient outward $\mathrm{K}^{+}$current $\left(\mathrm{I}_{\text {to }}\right)$, inward rectifier $\mathrm{K}^{+}$current $\left(\mathrm{I}_{\mathrm{K} 1}\right)$, acetylcholine-activated inward rectifier $\mathrm{K}^{+}$ current $\left(I_{\mathrm{KACh}}\right)$ and ultra-rapid delayed rectified potassium current $\left(\mathrm{I}_{\mathrm{Kur}}\right)^{2,3}$. Downregulation of $\mathrm{I}_{\mathrm{CaL}}$ shortens the APD by reducing depolarizing current during the plateau phase and also attenuates the contractility of atrial cardiomyocytes ${ }^{4}$. These changes are thought to be adaptations to $\mathrm{Ca}^{2+}$ overload occurring in $\mathrm{AF}^{5}$. On the other hand, the resulting decrease in atrial external work also scales down the energy consumption needed for the activation of the contractile apparatus. The simultaneous increase in repolarizing potassium currents, mainly $I_{\mathrm{K} 1^{\prime}}$ strongly abbreviates APD, but also stabilizes the arrhythmia ${ }^{6}$.

From another perspective, metabolic stress and increase in ROS production can affect several ion currents including $\mathrm{I}_{\mathrm{Na}^{\prime}} \mathrm{I}_{\mathrm{to}}, \mathrm{I}_{\mathrm{K} 1^{\prime}} \mathrm{I}_{\mathrm{KATP}} \mathrm{NCX}, \mathrm{RyR}$, and SERCA ${ }^{7,8}$. In the ventricles, ischemia alone upregulates several currents such as $I_{\text {KATP }}$ the $\mathrm{Na}^{+} \mathrm{H}^{+}$exchanger (NHX) and the persistent sodium current $\left(\mathrm{I}_{\mathrm{Na}, \text { late }}\right.$ ). A role for both $\mathrm{I}_{\mathrm{Na} \text {, late }}$ and $\mathrm{NHX}$ has been proposed in

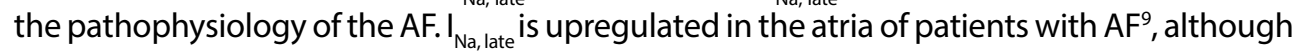
the functional relevance of this observation has been challenged ${ }^{10}$. The inhibition of $\mathrm{NHX}$ prevents APD shortening ${ }^{11}$ and attenuates loss of the contractility ${ }^{12}$ in a model of acute AF in dogs.

Therefore, some aspects of both 'electrical remodelling' and early metabolic alterations during first days of AF may represent adaptive changes in enabling atrial cardiomyocytes to withstand rapid rates during $A F$, but at the same time promote early stabilization of $A F$. This is in line with the notion that $A F$ is a paradigm of a vicious cycle leading to disease progression ${ }^{13}$.

This complex constellation of ion channel and metabolic remodelling that sustain the progression of AF provide an opportunity to interfere with the vicious cycle at many different sites, in order to ultimately inhibit remodelling and restore sinus rhythm.

Ranolazine is a metabolic modulator that inhibits fatty acid oxidation and thus favours glucose utilization, which is more energy efficient in the setting of limited oxygen supply. For this reason, ranolazine has first been used as an anti-anginal drug in the setting of ischemic heart disease $\mathrm{e}^{14}$. In addition, ranolazine blocks peak sodium current at clinically used doses $(2-6 \mu \mathrm{mol} / \mathrm{l})$ with remarkable atrial selectivity ${ }^{15}$. Ranolazine also blocks $\mathrm{I}_{\mathrm{Na}}$, late ${ }^{\prime}$ while at higher doses it also blocks the rapid delayed rectifier $\mathrm{K}^{+}$current $\left(\mathrm{I}_{\mathrm{Kr}}\right)$, slow delayed rectifier $\mathrm{K}^{+}$current $\left(\mathrm{I}_{\mathrm{Ks}}\right)$ and $\mathrm{I}_{\mathrm{CaL}}{ }^{16}$. Therefore, ranolazine has an ability to interfere with $\mathrm{AF}$ at several different sites of action. In this thesis, we have investigated the electrophysiological effects of ranolazine in different stages of AF-induced electrical remodelling. We show that ranolazine has similar electrophysiological effects both in normal and 'electrically remodelled' atria. The main effects of ranolazine without and with 'electrical remodelling' were a decrease in conduction velocity and a prolongation of the AERP. In persistent AF (14 days), ranolazine prolonged the atrial fibrillation cycle length (AFCL), but was ineffective in cardioverting AF to SR. Since most of the effects we observed on atrial electrophysiology and AFCL prolongation are similar to class I antiarrhythmic drugs, we propose that these effects result mainly from I ${ }_{\mathrm{Na}}$ blockade $^{17}$, 
${ }^{18}$. Due to technical difficulties in isolating goat atrial cardiomyocytes we were not able to directly confirm this hypothesis. However, we do conclude that despite low efficacy in SR restoration, ranolazine does not cause ventricular proarrhythmia in our animal model, and that its electrophysiological effects are preserved in 'electrically remodelled' atria. Therefore, it may be of interest both in short-term administration for pharmacological cardioversion in combination with other anti-arrhythmic drugs, or in longer-term administration to prevent the metabolic consequences of AF.

The second ion channel blocker that we have investigated, in the chapter 4 of this thesis, is the pentamidine analogue 6 (PA-6), a highly specific $\mathrm{I}_{\mathrm{K} 1}$ channel blocker ${ }^{19,20}$. Upregulation of the atrial $I_{k 1}$ during $A F$ is a well described phenomenon ${ }^{6,21}$. However, $I_{k 1}$ can be found in almost all excitable tissues, complicating the development of an $\mathrm{I}_{\mathrm{k} 1}$-specific blocker as an antiarrhythmic drug for AF. Concerns in this respect are not only potential ventricular proarrhythmia, but also side-effects related to changes in neurons, smooth muscle and skeletal muscle. Therefore, in order to assess both the antiarrhythmic effect on AF, but also ventricular proarrhythmic effects, we have used two dedicated animal models. To test the antiarrhythmic properties of PA- 6 we have used the goat model of electrically induced AF while the chronic atrioventricular (AV) block in dogs was used to evaluate drug safety. The latter model has a well-documented increased propensity for ventricular Torsade de Pointes (TdP) arrhythmias ${ }^{22,23}$. PA-6 proved to be a potent antiarrhythmic drug since it restored sinus rhythm in 5 of 6 goats shortly after the bolus infusion. The PA- 6 infusion reduced AF complexity, as evidenced by a decreased number of waves, number of breakthroughs and fractionation index, accompanied by an increase in AFCL. No ventricular proarrhythmic effects were observed in goats. In the dog model of chronic AV block, PA- 6 showed a safety profile superior to dofetilide, because it did not induce any TdP arrhythmias. Because of the technical difficulties in isolating atrial cardiomyocytes from goats we were not able to directly confirm the specificity of PA- 6 in $\mathrm{I}_{\mathrm{K} 1}$ blockade, but this specificity has been reported to be high in dogs and humans ${ }^{19,20}$.

\section{Tissue perfusion as determinant of energy production in AF}

A prerequisite for adequate cellular metabolism and energy production is adequate supply of the oxygen and nutrients. A major determinant of this availability is tissue perfusion, which is in turn determined by the capillary blood pressure and the integrity and functionality of the capillary endothelium. The former is in turn determined by the mean arterial blood pressure and the vascular tone of resistance arterioles in the tissue. Because AF does not have dramatic effects on cardiac output and mean arterial blood pressure, atrial tissue perfusion is determined by the functionality of the atrial vasculature, both resistance arterioles and capillaries.

Both acute and long-term AF are associated with atrial tissue ischemia ${ }^{24-26}$. The upregulation of the hypoxic signalling pathway would be expected to stimulate the development of new capillaries $^{27}$. However, several studies reported a reduction in the capillary density of the atria from the AF patients ${ }^{28-30}$. Alterations in atrial tissue perfusion associated with AF were also observed as a reduction in coronary flow reserve of LA coronary branches in patients 
with lone recurrent $\mathrm{AF}^{31}$. However, it is not clear whether the changes in the atrial vasculature are a cause or a consequence of AF. In chapter 5, our experiments investigate how AF itself affects the functionality of atrial resistance arteries in healthy animals.

We had previously shown that 1 week of AF in pigs causes an increased sensitivity of such arteries to bradykinin ${ }^{32}$. Because a similar phenomenon has been observed in coronary arteries as a result of exercise training ${ }^{33}$, we interpreted this change as an adaptation of the atrial vasculature to the increased demand imposed by AF. However, we have also previously shown that long lasting AF in goats is associated with uncoupling of endothelial nitric oxide synthase $(\mathrm{eNOS})^{34}$, which has been linked to a decreased sensitivity to vasodilators (a hallmark of 'endothelial dysfunction' $)^{35}$. Therefore, we originally hypothesized that, on the longer term, AF would also cause endothelial dysfunction. Contrary to our expectations, AF improved the vasodilatory response of atrial resistance arteries to endothelium-dependent vasodilatation by bradykinin. Thus, the state of increased sensitivity to vasodilators, which could be called 'endothelial hyperfunction', is still present after 4 months of AF in goats. This mechanism may contribute to maintain adequate tissue perfusion and $\mathrm{O}_{2}$ supply.

Interestingly, coronary artery disease often coexists with $\mathrm{AF}^{36,37}$, and manifestations of coronary artery disease, even subtle or subclinical, are recognized as independent risk factor for $\mathrm{AF}^{38}$. In the patients with coronary artery disease, where endothelial dysfunction is already present ${ }^{39}$ this adaptive vasodilatory response may be compromised, which could exacerbate atrial supply/demand mismatch when AF occurs.

\section{Metabolic alterations as a contributor to AF-induced atrial remodelling}

In comparison to electrical remodelling, structural remodelling is much slower, but a to a large extent irreversible process ${ }^{2},{ }^{13}$. AF-induced structural changes of the atria include atrial dilatation ${ }^{40}$, increased endomysial fibrosis ${ }^{41}$, myocyte hypertrophy, loss of sarcomeres, accumulation of glycogen, and mitochondrial abnormalities ${ }^{42,43}$. Some of the hallmarks of structural remodelling such as accumulation of glycogen, mitochondrial abnormalities, but also myocyte hypertrophy, are closely related to metabolic processes in cardiomyocytes. Therefore, it is conceivable that the rapid atrial activation rates during AF and accompanying increased energy demand could play a causative role in the development of those features of AF-induced structural remodelling.

In previous work, we have shown that much of the metabolic derangements already occurs early in the pathogenesis of AF. Within minutes, acute AF causes supply demand ischemia and a shift from aerobic to anaerobic metabolism, evidenced by an increase in lactate production ${ }^{24}$. One week of AF induced pronounced changes in mitochondrial structure and function ${ }^{32}$. In these experiments we have observed that AF caused changes in mitochondrial structure and function that had both adaptive and maladaptive aspects ${ }^{32}$. From this, it is not possible to ascertain that mitochondrial and other metabolic changes play a causative role in AF-induced remodelling. Our interventional study with trimetazidine was designed to provide evidence whether intervening in metabolic processes during AF has beneficial effects on AF-associated structural remodelling, AF progression, and atrial function. TMZ 
has pleiotropic effects. However, its effect on diminishing $\mathrm{O}_{2}^{-}$production originating from mitochondria and reversing the mitochondrial structural changes indicates that trimetazidine has a modulating effect on mitochondria. In order to better define the effect of AF itself and trimetazidine treatment on mitochondria, we have performed thorough characterization of mitochondrial function in isolated mitochondria both from left the atrium and left ventricle, but did not observe dramatic changes. In addition, although trimetazidine was initially described as a metabolic shifter that favours glucose oxidation over beta fatty acid oxidation by blocking long-chain 3-ketoacyl-CoA thiolase, recent studies imply that this effect was not the dominant one ${ }^{44,45}$. It is actually suggested that trimetazidine's beneficial effects is mediated by the improvement of mitochondrial function by attenuating mitochondrial ROS production $^{45}$.

TMZ did not affect endomysial fibrosis, early AF stabilization and the complexity of fibrillation patterns. However, TMZ did alleviate some aspects of AF-induced structural remodelling such as myocyte hypertrophy and the decrease in mitochondrial size. Normally, after months of $A F$, the atria show a pronounced enlargement and are completely non-contractile. This was also the case in the goats with 4 months of AF in chapter 6. Strikingly, in the TMZ-treated AF group, atrial size was smaller, and atria were still visibly contracting. Although we did not record these parameters quantitatively, we did observe that microscopic correlates of atrial size (myocyte diameter) and metabolic function (mitochondrial structure) were normalized by TMZ.

Our findings confirm that the metabolic changes observed in the atria during AF play an important role in the development of some aspects of structural remodelling while not affecting others. Modulation of the metabolic pathways could preserve some of the functional properties of the atria and be advantageous for patients with AF. In particular, a metabolic modulator could be used in patients with recent-onset AF to prevent early remodelling, bridging the time period to an (ablation) procedure aimed at restoring sinus rhythm.

Both ranolazine and trimetazidine are drugs that are currently prescribed to the patients with angina pectoris ${ }^{46,47}$. Coronary artery disease in itself is a risk factor for $\mathrm{AF}^{36,48}$. Metabolic modulation therapy has already been recognized as beneficial for heart failure patients. Trimetazidine improves ejection fraction in heart failure patients and reduces both cardiovascular and overall mortality in this group of patients ${ }^{49}, 50$. Therefore, implementing currently available metabolic modulators as an adjuvant therapy to prevent new onset and the progression of AF should be considered. Neither trimetazidine nor ranolazine have relevant proarrhythmic or hemodynamic side-effects ${ }^{51,52}$. Although trimetazidine is well tolerated by most patients, it was associated with a parkinsonism and exacerbation of movement disorders ${ }^{53}$. The actual incidence of the movement disorders observed in the post-marketing analysis was low $(0.36 / 100,000$ person-years), and the majority of the symptoms was resolved within months after discontinuation of treatment ${ }^{51}$. We believe that our work provides evidence that trimetazidine and metabolic modulation can affect several hallmarks of AF-induced atrial remodeling and may preserve atrial function during AF. However, further studies are necessary to further clarify exact mechanism of action and to investigate the efficacy of this approach in preventing AF onset and progression. 


\section{Further implications for AF treatment}

As already mentioned in the chapter 1 of this thesis, AF remains to be one of the major health care burdens of the modern society with the increasing prevalence ${ }^{54}$. However, the treatment options for $A F$ are still very often based on tertiary prevention, i.e. prevention of the complications associated with AF such as stroke or tachycardia-induced cardiomyopathy ${ }^{55}$.

Current treatment recommendation for the patients with AF together with the order of introduction and desired outcome on cardiac function and patient benefit are presented in Figure $1^{55}$.

Overall, long term rhythm control with antiarrhythmic drugs has been shown to be nonsuperior to the rate control mainly due to low efficacy of the antiarrhythmic drugs to restore and maintain SR, and high incidence of numerous side effects ${ }^{55}, 56$. For example, flecainide and propafenone, although effective in SR restoration, should be avoided in patients with structural heart disease since these drugs increase the likelihood of lifethreatening ventricular arrhythmias ${ }^{57}$. In patients with heart failure and other forms of structural heart disease, the drug of choice would be amiodarone, but due to numerous cardiac and extracardiac side-effects, the use of amiodarone is limited only to selected cases $^{55}$. Additionally, most of antiarrhythmic drugs that have effect on phase 3 of the action potential that are used to treat AF are not sufficiently atrial selective and therefore also prolong QT interval, and are therefore associated with life-threatening ventricular Torsades de Pointes arrhythmias ${ }^{58-60}$. Therefore, there is still an unmet need for safer, more atrial-selective antiarrhythmic drugs.

Ranolazine has already been successfully used as alone and as additional therapy for AF cardioversion to SR or for the prevention of new-onset $A F^{61,62}$. In principle, this old antianginal drug might represent a 'magic bullet' for AF treatment: its metabolic action may confer protective effects similar to those of TMZ described above, but in addition, its direct effects on ion channels may help terminate AF. In fact, some animal models have shown an atrial-selective anti-arrhythmic effect of ranolazine, e.g. intact porcine hearts ${ }^{63,64}$, rabbits ${ }^{65}$ and dogs ${ }^{66}$. In our goat model, ranolazine did prolong the AFCL, but was not effective in restoring sinus rhythm at concentrations that are expected to selectively affect atrial late and peak $\mathrm{I}_{\mathrm{Na}}{ }^{15,16}$.

Inward rectifier currents, which are responsible for stabilizing the resting membrane potential and the terminal repolarization of the action potential, form an alternative target for anti-arrhythmic drugs. The main inward rectifier, $\mathrm{I}_{\mathrm{k} 1}$, is expressed in the heart, but also in skeletal muscle and other tissue. Within the heart, expression is much lower in atrial than in ventricular myocytes ${ }^{67}$. Therefore, blocking of $I_{k 1}$ may have some degree of atrial-selectivity, in the sense that the atrial myocytes are more sensitive to $\mathrm{I}_{\mathrm{K} 1}$ block. 
A

Treatment

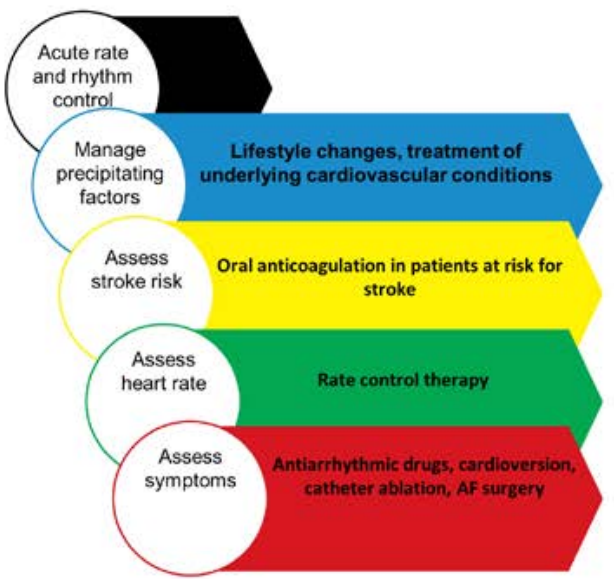

Desired outcome

Hemodynamic stability

Cardiovascular risk reduction

Stroke prevention

Symptom improvement preservation of LV function

Symptom improvement
Patient benefit

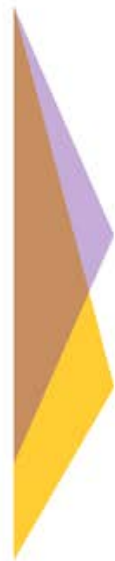

Improved life expectancy
B

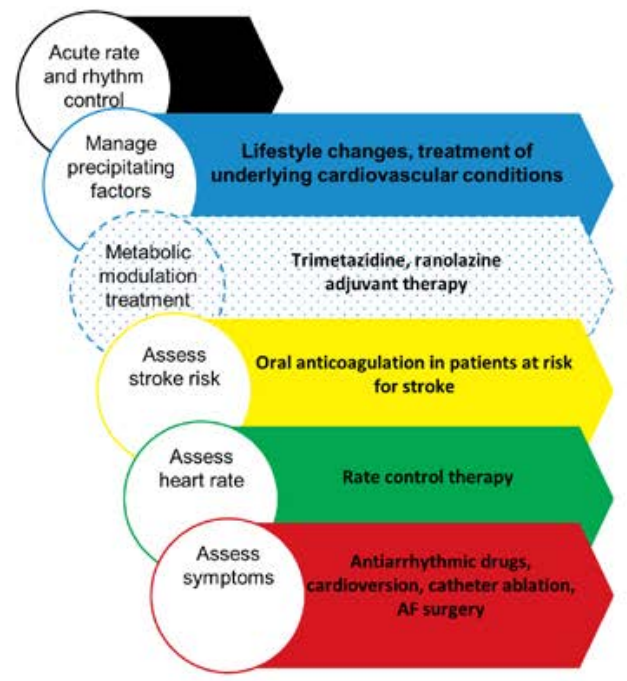

\section{Desired outcome}

Patient benefit
Hemodynamic stability

\section{Cardiovascular risk} reduction

\section{Attenuate atrial remodeling} and preserve atrial function

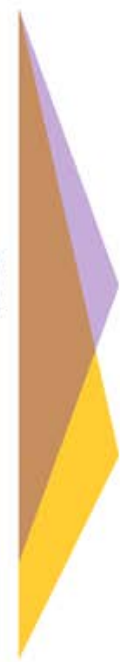
preservation of LV function

Symptom improvement
Improved life expectancy

mproysd quality of life. autonamy, social functionint

Figure 1. Acute and chronic management of atrial fibrillation patients, desired cardiovascular outcomes, and patient benefits. Adapted from the report on the 4th AFNET/EHRA consensus conference ${ }^{72}$ (A). Possible place for adjuvant therapy with metabolic modulators with expected cardiovascular outcomes and patients benefits (B). 
To investigate this, we have used the novel inward rectifier current inhibitor PA- 6 to terminate AF in goat model and to show its safety in a chronic AV block dog model (chapter 4) ${ }^{20}$. Although very efficient in our experimental setting, the PA-6 was not effective in treating dogs with spontaneous AF in veterinary practice ${ }^{68}$. In addition, PA-6 administration in conscious goats was also associated with muscular dysfunction, which may have been caused by the ubiquitous presence of $\mathrm{I}_{\mathrm{K} 1}$ channels in skeletal muscle ${ }^{68}$.

Nevertheless, we show that as an anti-arrhythmic strategy, inward rectifier blockade can be very effective in terminating AF. A larger degree of atrial-selectivity for this strategy could potentially be attained by targeting the acetylcholine-regulated $\mathrm{K}^{+}$-current $\left(\mathrm{I}_{\mathrm{KACh}}\right)$, which is an inward rectifier that is selectively expressed in the atria, and which becomes more prominent in atrial myocytes during AF-induced electrical remodeling ${ }^{69-71}$.

Trimetazidine is scarcely studied in a context of AF. To our knowledge, there are no studies investigating the incidence of AF or supraventricular arrhythmias in the patients treated with trimetazidine. We believe that our work has provided a sound proof that trimetazidine and metabolic modulation can affect several hallmarks of AF induced atrial remodeling and may preserve atrial function during AF. Possible place to incorporate metabolic modulation therapy within a current treatment options for AF is presented in the Figure 1. 


\section{References}

1. Opacic D, van Bragt KA, Nasrallah HM, Schotten $U$ and Verheule S. Atrial metabolism and tissue perfusion as determinants of electrical and structural remodeling in atrial fibrillation. Cardiovasc Res. 2016.

2. Schotten U, Verheule S, Kirchhof P and Goette A. Pathophysiological mechanisms of atrial fibrillation: a translational appraisal. Physiol Rev. 2011;91:265-325.

3. Heijman J, Voigt N, Nattel S and Dobrev D. Cellular and molecular electrophysiology of atrial fibrillation initiation, maintenance, and progression. Circ Res. 2014;114:1483-99.

4. Schotten U, Duytschaever M, Ausma J, Eijsbouts S, Neuberger HR and Allessie M. Electrical and contractile remodeling during the first days of atrial fibrillation go hand in hand. Circulation. 2003;107:1433-9.

5. Ausma J, Dispersyn GD, Duimel H, Thone F, Ver Donck L, Allessie MA and Borgers M. Changes in ultrastructural calcium distribution in goat atria during atrial fibrillation. J Mol Cell Cardiol. 2000;32:355-64.

6. Dobrev D, Wettwer E, Kortner A, Knaut M, Schuler S and Ravens U. Human inward rectifier potassium channels in chronic and postoperative atrial fibrillation. Cardiovasc Res. 2002;54:397404.

7. Wolke C, Bukowska A, Goette A and Lendeckel U. Redox control of cardiac remodeling in atrial fibrillation. Biochim Biophys Acta. 2015;1850:1555-65.

8. Yang KC, Bonini MG and Dudley SC, Jr. Mitochondria and arrhythmias. Free Radic Biol Med. 2014;71:351-61.

9. Sossalla S, Kallmeyer B, Wagner S, Mazur M, Maurer U, Toischer K, Schmitto JD, Seipelt $\mathrm{R}$, Schondube FA, Hasenfuss G, Belardinelli L and Maier LS. Altered $\mathrm{Na}(+)$ currents in atrial fibrillation effects of ranolazine on arrhythmias and contractility in human atrial myocardium. J Am Coll Cardiol. 2010;55:2330-42.

10. Poulet C, Wettwer E, Grunnet M, Jespersen T, Fabritz L, Matschke K, Knaut M and Ravens U. Late Sodium Current in Human Atrial Cardiomyocytes from Patients in Sinus Rhythm and Atrial Fibrillation. PLoS One. 2015;10:e0131432.

11. Jayachandran JV, Zipes DP, Weksler J and Olgin JE. Role of the $\mathrm{Na}(+) / \mathrm{H}(+)$ exchanger in shortterm atrial electrophysiological remodeling. Circulation. 2000;101:1861-6.

12. Altemose GT, Zipes DP, Weksler J, Miller JM and Olgin JE. Inhibition of the $\mathrm{Na}(+) / \mathrm{H}(+)$ exchanger delays the development of rapid pacing-induced atrial contractile dysfunction. Circulation. 2001;103:762-8.

13. Allessie M, Ausma J and Schotten U. Electrical, contractile and structural remodeling during atrial fibrillation. Cardiovasc Res. 2002;54:230-46.

14. Pepine CJ and Wolff AA. A controlled trial with a novel anti-ischemic agent, ranolazine, in chronic stable angina pectoris that is responsive to conventional antianginal agents. Ranolazine Study Group. Am J Cardiol. 1999;84:46-50.

15. Burashnikov A, Di Diego JM, Zygmunt AC, Belardinelli L and Antzelevitch C. Atrium-selective sodium channel block as a strategy for suppression of atrial fibrillation: differences in sodium channel inactivation between atria and ventricles and the role of ranolazine. Circulation. 2007;116:1449-1457.

16. Antzelevitch C, Belardinelli L, Wu L, Fraser H, Zygmunt AC, Burashnikov A, Di Diego JM, Fish JM, Cordeiro JM, Goodrow RJ, Scornik F and Perez G. Electrophysiologic properties and 
antiarrhythmic actions of a novel antianginal agent. J Cardiovasc Pharmacol Ther. 2004;9 Suppl 1:S65-83.

17. Eijsbouts S, Ausma J, Blaauw $Y$, Schotten $U$, Duytschaever $M$ and Allessie MA. Serial cardioversion by class IC Drugs during 4 months of persistent atrial fibrillation in the goat. $J$ Cardiovasc Electrophysiol. 2006;17:648-54.

18. Wijffels MC, Dorland R and Allessie MA. Pharmacologic cardioversion of chronic atrial fibrillation in the goat by class IA, IC, and III drugs: a comparison between hydroquinidine, cibenzoline, flecainide, and d-sotalol. J Cardiovasc Electrophysiol. 1999;10:178-93.

19. Ji Y, Varkevisser R, Opacic D, Bossu A, Kuiper M, Beekman JDM, Yang S, Khan AP, Dobrev D, Voigt N, Wang MZ, Verheule S, Vos MA and van der Heyden MAG. The inward rectifier current inhibitor PA-6 terminates atrial fibrillation and does not cause ventricular arrhythmias in goat and dog models. Br J Pharmacol. 2017.

20. Takanari H, Nalos L, Stary-Weinzinger A, de Git KC, Varkevisser R, Linder T, Houtman MJ, Peschar M, de Boer TP, Tidwell RR, Rook MB, Vos MA and van der Heyden MA. Efficient and specific cardiac IK(1) inhibition by a new pentamidine analogue. Cardiovasc Res. 2013;99:203-14.

21. Veldhuis MG, Y. J and van der Heyden MA. A little too much: cardiac electrophysiological effects of elevated inward rectifying current carried by the KIR2.1 ion channel protein. Adaptive Medicine. 2015;7:1-8.

22. Oros A, Beekman JD and Vos MA. The canine model with chronic, complete atrio-ventricular block. Pharmacol Ther. 2008;119:168-78.

23. Antoons G, Oros A, Beekman JD, Engelen MA, Houtman MJ, Belardinelli L, Stengl M and Vos MA. Late na(+) current inhibition by ranolazine reduces torsades de pointes in the chronic atrioventricular block dog model. J Am Coll Cardiol. 2010;55:801-9.

24. van Bragt KA, Nasrallah HM, Kuiper M, Luiken JJ, Schotten $U$ and Verheule S. Atrial supplydemand balance in healthy adult pigs: coronary blood flow, oxygen extraction, and lactate production during acute atrial fibrillation. Cardiovasc Res. 2014;101:9-19.

25. XuY, Sharma D, Du F and Liu Y.The role of Toll-like receptor 2 and hypoxia-induced transcription factor-1alpha in the atrial structural remodeling of non-valvular atrial fibrillation. Int $J$ Cardiol. 2013;168:2940-1.

26. Scridon A, Morel E, Nonin-Babary E, Girerd N, Fernandez C and Chevalier P. Increased intracardiac vascular endothelial growth factor levels in patients with paroxysmal, but not persistent atrial fibrillation. Europace. 2012;14:948-53.

27. Lee SH, Wolf PL, Escudero R, Deutsch R, Jamieson SW and Thistlethwaite PA. Early expression of angiogenesis factors in acute myocardial ischemia and infarction. NEng/ J Med. 2000;342:626-33.

28. Corradi D, Callegari S, Maestri R, Ferrara D, Mangieri D, Alinovi R, Mozzoni P, Pinelli S, Goldoni M, Privitera YA, Bartoli V, Astorri E, Macchi E, Vaglio A, Benussi S and Alfieri O. Differential structural remodeling of the left-atrial posterior wall in patients affected by mitral regurgitation with or without persistent atrial fibrillation: a morphological and molecular study. J Cardiovasc Electrophysiol. 2012;23:271-9.

29. Corradi D, Callegari S, Maestri R, Benussi S, Bosio S, De Palma G, Alinovi R, Caglieri A, Goldoni M, Mozzoni P, Pastori P, Manotti L, Nascimbene S, Dorigo E, Rusconi R, Astorri E and Alfieri O. Heme oxygenase- 1 expression in the left atrial myocardium of patients with chronic atrial fibrillation related to mitral valve disease: its regional relationship with structural remodeling. Hum Pathol. 2008;39:1162-71. 
30. Boldt A, Scholl A, Garbade J, Resetar ME, Mohr FW, Gummert JF and Dhein S. ACE-inhibitor treatment attenuates atrial structural remodeling in patients with lone chronic atrial fibrillation. Basic Res Cardiol. 2006;101:261-7.

31. Skalidis El, Hamilos MI, Karalis IK, Chlouverakis G, Kochiadakis GE and Vardas PE. Isolated atrial microvascular dysfunction in patients with lone recurrent atrial fibrillation. J Am Coll Cardiol. 2008;51:2053-7.

32. Nasrallah H. Left atrial vascular and metabolic remodeling in pig models of atrial fibrillation; 2015.

33. Muller JM, Myers PR and Laughlin MH. Vasodilator responses of coronary resistance arteries of exercise-trained pigs. Circulation. 1994;89:2308-14.

34. Reilly SN, Jayaram R, Nahar K, Antoniades C, Verheule S, Channon KM, Alp NJ, Schotten U and Casadei $B$. Atrial sources of reactive oxygen species vary with the duration and substrate of atrial fibrillation: implications for the antiarrhythmic effect of statins. Circulation. 2011;124:1107-17.

35. Vallet B. Endothelial cell dysfunction and abnormal tissue perfusion. Crit Care Med. 2002;30:S229-34.

36. Weijs B, Pisters R, Haest RJ, Kragten JA, Joosen IA, Versteylen M, Timmermans CC, Pison L, Blaauw $Y$, Hofstra L, Nieuwlaat R, Wildberger J and Crijns HJ. Patients originally diagnosed with idiopathic atrial fibrillation more often suffer from insidious coronary artery disease compared to healthy sinus rhythm controls. Heart Rhythm. 2012;9:1923-9.

37. Kannel WB and Benjamin EJ. Status of the epidemiology of atrial fibrillation. Med Clin North Am. 2008;92:17-40, ix.

38. Krahn AD, Manfreda J, Tate RB, Mathewson FA and Cuddy TE. The natural history of atrial fibrillation: incidence, risk factors, and prognosis in the Manitoba Follow-Up Study. Am J Med. 1995;98:476-84.

39. Veerasamy M, Bagnall A, Neely D, Allen J, Sinclair $\mathrm{H}$ and Kunadian V. Endothelial dysfunction and coronary artery disease: a state of the art review. Cardiol Rev. 2015;23:119-29.

40. Shi Y, Ducharme A, Li D, Gaspo R, Nattel S and Tardif JC. Remodeling of atrial dimensions and emptying function in canine models of atrial fibrillation. Cardiovasc Res. 2001;52:217-25.

41. Verheule S, Tuyls E, Gharaviri A, Hulsmans S, van Hunnik A, Kuiper M, Serroyen J, Zeemering $S$, Kuijpers NH and Schotten U. Loss of continuity in the thin epicardial layer because of endomysial fibrosis increases the complexity of atrial fibrillatory conduction. Circulation Arrhythmia and electrophysiology. 2013;6:202-11.

42. Ausma J, Wijffels $M$, Thone F, Wouters $L$, Allessie $M$ and Borgers M. Structural changes of atrial myocardium due to sustained atrial fibrillation in the goat. Circulation. 1997;96:3157-63.

43. Morillo CA, Klein GJ, Jones DL and Guiraudon CM. Chronic rapid atrial pacing. Structural, functional, and electrophysiological characteristics of a new model of sustained atrial fibrillation. Circulation. 1995;91:1588-95.

44. Cavar M, Ljubkovic M, Bulat C, Bakovic D, Fabijanic D, Kraljevic J, Karanovic N, Dujic Z, Lavie $\mathrm{CJ}$, Wisloff $U$ and Marinovic J. Trimetazidine does not alter metabolic substrate oxidation in cardiac mitochondria of target patient population. Br J Pharmacol. 2016;173:1529-40.

45. Dedkova EN, Seidlmayer LK and Blatter LA. Mitochondria-mediated cardioprotection by trimetazidine in rabbit heart failure. J Mol Cell Cardiol. 2013;59:41-54.

46. Ferrari R, Pavasini R, Camici PG, Crea F, Danchin N, Pinto F, Manolis A, Marzilli M, Rosano GMC, Lopez-Sendon J and Fox K. Anti-anginal drugs-beliefs and evidence: systematic review covering 50 years of medical treatment. Eur Heart J. 2018. 
47. Ferrari R, Camici PG, Crea F, Danchin N, Fox K, Maggioni AP, Manolis AJ, Marzilli M, Rosano GMC and Lopez-Sendon JL. Expert consensus document: A 'diamond' approach to personalized treatment of angina. Nat Rev Cardiol. 2018;15:120-132.

48. Weijs B, de Vos CB, Tieleman RG, Peeters FECM, Limantoro I, Kroon AA, Cheriex EC, Pisters R and Crijns HJGM. The occurrence of cardiovascular disease during 5-year follow-up in patients with idiopathic atrial fibrillation. Europace. 2013;15:18-23.

49. Gao D, Ning N, Niu X, Hao G and Meng Z. Trimetazidine: a meta-analysis of randomised controlled trials in heart failure. Heart. 2011;97:278-86.

50. Fragasso G, Rosano G, Baek SH, Sisakian H, Di Napoli P, Alberti L, Calori G, Kang SM, Sahakyan L, Sanosyan A, Vitale C, Marazzi G, Margonato A and Belardinelli R. Effect of partial fatty acid oxidation inhibition with trimetazidine on mortality and morbidity in heart failure: results from an international multicentre retrospective cohort study. Int J Cardiol. 2013;163:320-325.

51. McCarthy CP, Mullins KV and Kerins DM. The role of trimetazidine in cardiovascular disease: beyond an anti-anginal agent. Eur Heart J Cardiovasc Pharmacother. 2016;2:266-72.

52. Shenasa M, Assadi H, Heidary S and Shenasa H. Ranolazine: Electrophysiologic Effect, Efficacy, and Safety in Patients with Cardiac Arrhythmias. Card Electrophysiol Clin. 2016;8:467-79.

53. Marti Masso JF, Marti I, Carrera N, Poza JJ and Lopez de Munain A. Trimetazidine induces parkinsonism, gait disorders and tremor. Therapie. 2005;60:419-22.

54. Krijthe BP, Kunst A, Benjamin EJ, Lip GY, Franco OH, Hofman A, Witteman JC, Stricker BH and Heeringa J. Projections on the number of individuals with atrial fibrillation in the European Union, from 2000 to 2060. Eur Heart J. 2013;34:2746-51.

55. Kirchhof P, Benussi S, Kotecha D, Ahlsson A, Atar D, Casadei B, Castella M, Diener HC, Heidbuchel $H$, Hendriks J, Hindricks G, Manolis AS, Oldgren J, Popescu BA, Schotten U, Van Putte B, Vardas P, Agewall S, Camm J, Baron Esquivias G, Budts W, Carerj S, Casselman F, Coca A, De Caterina R, Deftereos S, Dobrev D, Ferro JM, Filippatos G, Fitzsimons D, Gorenek B, Guenoun M, Hohnloser SH, Kolh P, Lip GY, Manolis A, McMurray J, Ponikowski P, Rosenhek R, Ruschitzka F, Savelieva I, Sharma S, Suwalski P, Tamargo JL, Taylor CJ, Van Gelder IC, Voors AA, Windecker S, Zamorano $J L$ and Zeppenfeld K. 2016 ESC Guidelines for the management of atrial fibrillation developed in collaboration with EACTS. Eur Heart J. 2016;37:2893-2962.

56. Roy D, Talajic M, Nattel S, Wyse DG, Dorian P, Lee KL, Bourassa MG, Arnold JM, Buxton AE, Camm AJ, Connolly SJ, Dubuc M, Ducharme A, Guerra PG, Hohnloser SH, Lambert J, Le Heuzey JY, O'Hara G, Pedersen OD, Rouleau JL, Singh BN, Stevenson LW, Stevenson WG, Thibault B, Waldo AL, Atrial F and Congestive Heart Failure I. Rhythm control versus rate control for atrial fibrillation and heart failure. N Engl J Med. 2008;358:2667-77.

57. Cardiac Arrhythmia Suppression Trial I. Preliminary report: effect of encainide and flecainide on mortality in a randomized trial of arrhythmia suppression after myocardial infarction. $N$ Engl J Med. 1989;321:406-12.

58. Kirchhof P, Franz MR, Bardai A and Wilde AM. Giant T-U waves precede torsades de pointes in long QT syndrome: a systematic electrocardiographic analysis in patients with acquired and congenital QT prolongation. J Am Coll Cardiol. 2009;54:143-9.

59. Fetsch T, Bauer P, Engberding R, Koch HP, Lukl J, Meinertz T, Oeff M, Seipel L, Trappe HJ, Treese $\mathrm{N}$, Breithardt $\mathrm{G}$ and Prevention of Atrial Fibrillation after Cardioversion I. Prevention of atrial fibrillation after cardioversion: results of the PAFAC trial. Eur Heart J. 2004;25:1385-94. 
60. Freemantle N, Lafuente-Lafuente $C$, Mitchell S, Eckert $L$ and Reynolds M. Mixed treatment comparison of dronedarone, amiodarone, sotalol, flecainide, and propafenone, for the management of atrial fibrillation. Europace. 2011;13:329-45.

61. De Vecchis R, Ariano C, Giasi A and Cioppa C. Antiarrhythmic effects of ranolazine used both alone for prevention of atrial fibrillation and as an add-on to intravenous amiodarone for its pharmacological cardioversion: a meta-analysis. Minerva Cardioangiol. 2018;66:349-359.

62. Guerra F, Romandini A, Barbarossa A, Belardinelli $L$ and Capucci A. Ranolazine for rhythm control in atrial fibrillation: A systematic review and meta-analysis. Int J Cardiol. 2017;227:284291.

63. Kumar K, Nearing BD, Carvas M, Nascimento BCG, Acar M, Belardinelli L and Verrier RL. Ranolazine exerts potent effects on atrial electrical properties and abbreviates atrial fibrillation duration in the intact porcine heart. J Cardiovasc Electrophysiol. 2009;20:796-802.

64. Carvas M, Nascimento BC, Acar M, Nearing BD, Belardinelli L and Verrier RL. Intrapericardial ranolazine prolongs atrial refractory period and markedly reduces atrial fibrillation inducibility in the intact porcine heart. J Cardiovasc Pharmacol. 2010;55:286-91.

65. Aidonidis I, Doulas K, Hatziefthimiou A, Tagarakis G, Simopoulos V, Rizos I, Tsilimingas N and Molyvdas PA. Ranolazine-induced postrepolarization refractoriness suppresses induction of atrial flutter and fibrillation in anesthetized rabbits. J Cardiovasc Pharmacol Ther. 2013;18:94-101.

66. Bhimani AA, Yasuda T, Sadrpour SA, Khrestian CM, Lee S, Zeng D, Belardinelli L and Waldo AL. Ranolazine terminates atrial flutter and fibrillation in a canine model. Heart Rhythm. 2014;11:1592-9.

67. Wang Z, Yue L, White M, Pelletier G and Nattel S. Differential distribution of inward rectifier potassium channel transcripts in human atrium versus ventricle. Circulation. 1998;98:2422-8.

68. Szatmari V, Ji Y, Herwijnen BV, Feng M, Wang MZ, Bossu A and van der Heyden MAG. Efficacy of pentamidine analogue 6 in dogs with chronic atrial fibrillation. J Vet Intern Med. 2018;32:15491554.

69. Dan GA and Dobrev D. Antiarrhythmic drugs for atrial fibrillation: Imminent impulses are emerging. Int J Cardiol Heart Vasc. 2018;21:11-15.

70. Ehrlich JR and Nattel S. Atrial-selective pharmacological therapy for atrial fibrillation: hype or hope? Curr Opin Cardiol. 2009;24:50-55.

71. Ehrlich JR and Nattel S. Novel approaches for pharmacological management of atrial fibrillation. Drugs. 2009;69:757-74.

72. Kirchhof P, Breithardt G, Aliot E, Al Khatib S, Apostolakis S, Auricchio A, Bailleul C, Bax J, Benninger G, Blomstrom-Lundqvist C, Boersma L, Boriani G, Brandes A, Brown H, Brueckmann M, Calkins $H$, Casadei B, Clemens A, Crijns H, Derwand R, Dobrev D, Ezekowitz M, Fetsch T, Gerth A, Gillis A, Gulizia M, Hack G, Haegeli L, Hatem S, Hausler KG, Heidbuchel H, Hernandez-Brichis J, Jais $P$, Kappenberger L, Kautzner J, Kim S, Kuck KH, Lane D, Leute A, Lewalter T, Meyer R, Mont L, Moses G, Mueller M, Munzel F, Nabauer M, Nielsen JC, Oeff M, Oto A, Pieske B, Pisters R, Potpara T, Rasmussen L, Ravens U, Reiffel J, Richard-Lordereau I, Schafer H, Schotten U, Stegink W, Stein K, Steinbeck G, Szumowski L, Tavazzi L, Themistoclakis S, Thomitzek K, Van Gelder IC, von Stritzky $B$, Vincent A, Werring D, Willems S, Lip GY and Camm AJ. Personalized management of atrial fibrillation: Proceedings from the fourth Atrial Fibrillation competence NETwork/European Heart Rhythm Association consensus conference. Europace. 2013;15:1540-56. 
Appendix 




\section{Summary}

Atrial fibrillation, one of the most common arrhythmias in clinical practice, is characterized by the fast and irregular atrial activation and irregular ventricular rate. This chaotic atrial activation is associated with disturbed blood flow in the atria and consequent cloth formation. In many patients AF is asymptomatic, but if not treated properly, it can cause devastating thromboembolic complications, including stroke. Therefore, due to its high prevalence and high complication rates, AF represent one of the major health problems that requires timely diagnosis and adequate treatment.

Present treatment strategies for AF could be roughly divided in three groups. The first, 'rhythm control', is aiming to restore and preserve sinus rhythm (SR) while the second one, 'rate control' is aiming to prevent cardiac and extracardiac complications by maintaining a normal heart rate while the atria remain in AF. The third one is focused on preventing the formation of the blood cloths in the atria and consequent thromboembolic complications, by inhibiting different coagulation pathways. Although this strategy is satisfactory for some patients, in others, especially patients who experience direct symptoms, restoration and maintenance of sinus rhythm is desirable. For rhythm control, it is important to understand the natural course of the AF and the processes responsible for perpetuation of the arrhythmia.

AF often begins with short episodes (paroxysms) of the arrhythmia that become longer over time, until arrhythmia becomes persistent. This progressive course of AF is maintained through a number of remodeling processes that include changes in electrophysiological properties ('electrical remodeling'), metabolic alterations ('metabolic remodeling') and finally changes of the atrial tissue structure ('structural remodeling').

The treatment strategies that are used to restore SR are counteracting these remodeling process, and include antiarrhythmic drugs and several ablation procedures. Antiarrhythmic drugs affect the function of ion channels, while ablation procedures impact atrial structure and conduction. However, currently there are no treatment strategies that are used to interfere with the metabolic alterations during AF and from that perspective contribute to the preservation of atrial structure and function.

Therefore, the main focus of this thesis was to investigate effect of metabolic modulators on different stages and different aspects of AF-induced atrial remodeling. The second chapter of this thesis gives an overview of the current knowledge about changes in myocardial metabolism and tissue perfusion during different stages of AF. In this chapter, we also propose ranolazine and trimetazidine as drugs that can affect metabolic processes of myocardial cells that may assuage metabolic compromise during AF and thereby inhibit remodeling processes and inhibit AF progression. 
In addition to the effect of ranolazine on the metabolic shift towards glucose utilization, ranolazine is also a multi-ion channel blocker with reported high atrial selectivity in the blockade of the peak $\mathrm{Na}^{+}$current $\left(\mathrm{I}_{\mathrm{Na}}\right)$. To start investigating the potential use of ranolazine as a metabolic modulator for long-term treatment of AF, we have first assessed the direct effects of ranolazine in an awake goat model of lone atrial fibrillation at different stages of AF-induced atrial remodelling (chapter 3). Ranolazine decreased conduction velocity and prolonged atrial effective refractory period, irrespective of the stage of electrical remodelling, without apparent proarrhythmic effects on ventricles. Based on this evidence, ranolazine can be considered as a safe antiarrhythmic drug for AF treatment, allowing further study of its possible long term (metabolic) effects. However, short-term ranolazine administration was ineffective in cardioverting AF. Because there is still an unmet need for safe (i.e. atrial-selective), effective anti-arrhythmic drugs for pharmacological cardioversion of $A F$, we proposed inward-rectifier currents as an appropriate target. In chapter 4 we have shown that the inhibition of the inward rectifier $\mathrm{K}^{+}$current $\left(\mathrm{I}_{\mathrm{K} 1}\right)$ with pentamidine analogue 6 (PA-6) can effectively cardiovert persistent AF in goats to sinus rhythm without proarrhythmic effects on the ventricles in either goats or dogs. We further propose that the acetylcholine-activated inward rectifier potassium current $\left(I_{\mathrm{KACh}}\right)$ may form a target with similar effects, but an even higher degree of atrial selectivity.

Adequate tissue perfusion is a prerequisite for sufficient $\mathrm{O}_{2}$ supply and therefore for adequate energy production. In the chapter $\mathbf{5}$ we have shown that chronic AF in goats increases the sensitivity of atrial resistance arteries to endothelium-dependent vasodilatation. The factor that was responsible for this shift is most likely endotheliumderived hyperpolarizing factor (EDHF). EDHF actually represents several different substances secreted by the endothelial cells. Unfortunately, in our experiments we were not able to identify exact pathway, but it was clear that chronic atrial fibrillation leads to notable changes in the regulation of the atrial vessels, which may represent an adaptive change to the higher energy demand of the fibrillating atrial myocardium.

We have previously shown that AF causes a state of supply/demand ischemia that can persist for weeks. To investigate whether these and other AF-induced changes in atrial metabolism can contribute to atrial remodeling, we have studied the long-term effects of a metabolic intervention during AF. In chapter 6 we have performed an extensive characterization of the several metabolic parameters including production of, damage by and neutralization capacity for reactive oxygen species (ROS), mitochondrial function and structure during chronic AF in goats. We show that trimetazidine, a metabolic modulator, can attenuate several hallmarks of the AF-induced remodelling processes mainly by inhibiting excessive ROS production originating from mitochondria. 


\section{Сажетак}

Атријална фибрилација (АФ - преткоморско треперење), једна од најчешћих срчаних аритмија, је карактерисана брзом и нерегуларном активацијом преткомора и неправилним коморним ритмом. Хаотична активација преткомора је удружена са поремећеним током крви у преткоморама и последичним формирањем тромба. Код многих пацијената АФ не проузрокује симптоме, али уколико се не третира правилно, може изазвати тешке тромбоемболијске компликације, укључујући и шлог. 3бог велике учесталости и бројних компликација, АФ представља један од главних здравствених проблема данашњице који захтева правовремену дијагнозу и адекватно лечење.

Актуелне стратегије за лечење АФ могу се грубо поделити у три групе. Прва је "контрола ритма" чији је циљ поновно успостављање синусног ритма (СР), док код друге, "контрола срчане фреквенције" циљ је превенција настанка срчаних и осталих компликација одржавањем срчане фреквенце у нормалним границама док су преткоморе у АФ. Трећа стратегија у лечењу АФ се фокусира на спречавање настанка тромба у преткоморама и последичних тромбоемболијских компликација. Иако ова стратегија даје задовољавајуће резултате, код пацијената који осећају симптоме поремећаја ритма, поновно успостављање и одржавање СР је неопходно. У циљу успостављања и одржавања СР неопходно је разумети природан ток АФ и процесе који су одговорни за одржавање ове аритмије.

АФ често почиње као кратка епизода (пароксизам) које временом постају све дужедок аритмија не постане перзистентна. Овакав прогресиван природан ток АФ омогућују различити процеси ремоделовања ткива преткомора. Процеси ремоделовања су промене у електрофизиолошким карактеристикама ("електрично ремоделовање"), промене у метаболизму ("метаболичко ремоделовање") и промене у структури преткомора ("структурно ремоделовање").

Терапијске стратегије које се користе за поново успостављање СР делују на поменуте процесе ремоделовања и односе се на употребуантиаритмијскихлекова и различитих процедура за аблацију срца. Антиаритмијски лекови делују на јонске канале, док се различите врсте аблација срца користе у циљу промене структуре преткомора. Тренутно не постоје терапијске опције које делују на метаболичке промене током АФ и на тај начин утичу на очување структуре и функције преткомора.

С тим у вези, главни фокус ове тезе је да испита ефекат метаболичких модулатора на различите стадијуме и различите аспекте атријалног ремоделовања током АФ. У другом поглављу ове тезе дат је опширан преглед тренутно доступних информација о променама у метаболизму и перфузији срца током различитих стадијума АФ. У овом поглављу се скреће пажња на ранолазин и триметазидин, као лекове који могу да утичу на метаболичке процесе у ћелијама и побољшају метаболички дисбаланс током АФ, те успоре процесе ремоделовања одговорне за прогресију АФ. 
Поред ефекта на метаболизам, ранолазин је такође и блокатор неколико јонских канала са високом селективношћу према преткоморској $\mathrm{Na}^{+}$струји $\left(\mathrm{I}_{\mathrm{Na}}\right)$. Како би испитивали евентуалну употребу ранолазина као метаболичког модулатора у дугорочној терапији АФ прво смо испитали директне електрофизиолошке ефекте ранолазина на различите стадијуме АФ-условљеног ремоделовања у моделу АФ код коза (3. поглавље). Ранолазин је смањио брзину провођења и продужио ефективни рефракторни период независно од стадијума ремоделовања и то без значајних аритмогених ефеката на коморе. Према нашим резултатима, ранолазин се може користити као сигуран антиаритмијски лек за АФ код ког је могуће испитивати и дугорочне (метаболичке) ефекте. Ипак, краткорочна примена ранолазина није била ефикасна у кардиоверзији АФ у СР. Како је још увек незадовољена потреба за сигурним (атријално специфичним) антиаритмијским лековима за фармаколошку кардиоверзију АФ у СР, предложили смо улазно ректификујућу струје као могућу мету. У четвртом поглављу смо показали да се инхибицијом улазно ректификујуће $\mathrm{K}^{+}$струје $\left(I_{\kappa l}\right)$ са пентамидиновим аналогом 6 (ПА-6) може ефикасно кардиовертирати перзистентна АФ код коза у СР без значајних аритмогених ефеката на коморе како ни код коза, тако ни код паса. Такође, сматрамо да ацетилхолином-активирана улазна ректификујућа струја $\left(I_{\text {KАСn }}\right)$ може бити мета са сличном ефикасношћу, али са још већим нивоом селективности према преткоморама.

Адекватна прокрвљеност тиква је предуслов за задовољавајуће снабдевање $\mathrm{O}_{2}$ и одговарајућу производњу енергије. У петом поглављу смо показали да хронична АФ код коза доводи до побољшања сензитивитета атријалних артериола на ендотелзависну вазодилатацију. Фактор одговоран за ову промену је највероватније изендотела-ослобођени хиперполаришући фактор (ЕОХФ). ЕОХФ заправо представља скупину неколико различитих супстанци ослобођених из ендотелних ћелија. Нажалост у нашим експериментима нисмо могли да утврдимо тачан механизам који је довео до ове промене. Ипак, евидентно је да хронична АФ доводи до значајних поремећаја у регулацији преткоморских крвних судова које могу представљати адаптивне промене у складу са повећаном енергетском потребом треперећег преткоморског миокарда.

Претходно смо показали да АФ доводи до дисбаланса у снабдевању и потрошњи енергије, тј. исхемије, која може трајати недељама. Како би испитали да ли исхемија и остале промене у атријалном метаболизму током АФ могу допринети атријалном ремоделовању тестирали смо дугорочан третман АФ метаболичким модулаторима. У шестом поглављу смо урадили екстензивну карактеризацију неколико различитих метаболичких параметара укључујући продукцију, оштећење узрокована и неутралишући капацитет слободних радикала кисеоника (POC) као и функцију и структуру митохондрија током хроничне АФ код коза. Показали смо да триметазидин, метаболички модулатор, може да ублажи неколико кључних одлика ремоделовања током $А Ф$, и то највећим делом инхибицијом прекомерне продукције РОС из митохондрија. 


\section{Valorization}

\section{Social relevance}

In 2010, approximately 33.5 million people were suffering from atrial fibrillation (AF), defining this arrhythmia as the most common rhythm disturbance in clinical practice'. The burden of AF in Dutch general population amounts to $1.6 \%$ and up to $1.8 \%$ in the European Union overall ${ }^{2}$. The major risk factors for AF are age, hypertension, heart failure, coronary artery disease, valvular heart disease, obesity, diabetes mellitus, and chronic kidney disease. Taking into account that actual demographic trends suggest a significant increase in the average age of the European Union population it is estimated that the burden of AF is going to be doubled by the year of $2060^{2}$.

Atrial fibrillation is recognized as an independent predictor of mortality and is associated with many disabling diseases including stroke and heart failure ${ }^{3}$. It is estimated that one in five strokes is a direct consequence of AF. In addition, patients with AF are more often hospitalized and have a significantly lower quality of life ${ }^{4,5}$. It is important to note that AF is a chronic disease that needs permanent surveillance and very often constant treatment. Considering the above, it is clear that $A F$ is a disease that causes a significant burden for our health care system, which is going to rise over time.

\section{Current treatment options}

Current evidence-based treatment strategies include interventions that aim to restore and maintain sinus rhythm, also named 'rhythm control', or interventions whose main goal is to prevent the development of AF-related complications such as heart failure ('rate control') or the prevention thromboembolic events ${ }^{6}$.

Rhythm control includes drug treatments administered either acutely for pharmacological cardioversion (restoration of sinus rhythm) or chronically for sinus rhythm maintenance. Electrical cardioversion is also used for acute sinus rhythm restoration. Various interventional and surgical ablation procedures that produce scar tissue in the atria and therefore prevent the propagation of fibrillation waves are also recognized as rhythm control treatment strategies ${ }^{6}$.

The development or exacerbation of heart failure as a consequence of AF is mainly related to the high and irregular ventricular activation rates ${ }^{7}$. Therefore, ventricular protection in AF patients requires the maintenance of ventricular rate within a more normal range. This treatment strategy is also known as 'rate control' and includes mainly chronic drug administration to inhibit $\mathrm{AV}$ node conduction and in some cases combinations of ablation procedures and pacemaker implantation ${ }^{6}$

The prevention of the thromboembolic events includes the use of various anticoagulation medication $^{8}$. In some cases, different interventional or surgical techniques can be also used to close or to remove the left atrial appendage which is the most frequent location of emboli ${ }^{9}, 10$. 
Although at the first glance the possibilities to treat AF are plentiful, their success rate and especially long-term results are still unsatisfactory. In addition, many of the mentioned treatments are often associated with numerous serious complications and a further reduction in the quality of life of patients with AF.

Cardioversions i.e. restoration of sinus rhythm either by means of pharmacological or electrical cardioversions are highly successful in directly restoring sinus rhythm, but AF recurrence is very frequent ${ }^{11}$. For sinus rhythm maintenance different antiarrhythmic drugs are used, but prolonged treatment with available antiarrhythmic drugs are often associated with various cardiac and extracardiac side effects ${ }^{12}$. This underscored the need for more specific antiarrhythmic drugs that are more atrial-selective and therefore produce fewer side-effects.

Ablation strategies are recommended as the second line of treatment for symptomatic paroxysmal, persistent, and probably long-standing persistent AF patients in which pharmacological SR maintenance was not achievable ${ }^{6}$. Ablation strategies have a better success rate in maintaining SR, but there is no proof that successful ablation would reduce hospitalization or enable discontinuation of anticoagulation therapy. Importantly, the ablation strategies are associated sometimes with life-threatening complications such as death in $<0.2 \%$ or periprocedural stroke in $<1 \%$, while clinically undetectable strokes can be demonstrated in up to $20 \%$ of cases $^{6,13}$. Together with other less severe complications different ablations strategies should be employed with caution and used only in selected patients.

Prevention of thromboembolic complications such as stroke is mainly achieved with the chronic use of anticoagulation drugs ${ }^{14}$. The most common side-effect of long-term anticoagulation is an increase in the incidence of bleeding complications, which in exceptional cases could lead to severe disability or even death ${ }^{15}$. It is also important to mention that anticoagulation therapy is also associated with the reduction in quality of life and increased medical costs ${ }^{16,17}$.

\section{The novelty of our research}

In the first two experimental chapters of this thesis (Chapter 3 and 4) we have investigated two compounds that can be potentially used for the restoration and eventually maintenance of the SR in patients with AF. The advantage of both compounds i.e. ranolazine and pentamidine analog ${ }^{6}$ (PA-6), in a first place is the selectivity of the compounds for atrial tissue and therefore high safety.

The PA- 6 is a newly synthesized compound that inhibits $I_{k 1}$. A next step in the development of this compound would be the confirmation of its safety and efficacy in humans.

On the other hand, ranolazine is already a registered drug to treat chronic angina pectoris. 
We have provided the proof that ranolazine retains its effectiveness and specificity for atrial tissue at different stages of AF mediated 'electrically remodeled' atria. However, in our study, ranolazine was unsuccessful in restoring SR, but clinical data suggest that it is effective in a group of patients with a recent onset of AF or postoperative $\mathrm{AF}^{18}$. In addition, ranolazine is safe in patients with the structurally altered hearts and therefore can be considered as an additional therapy for SR maintenance in patients with reduced left ventricular function. Further, because of ranolazine's good safety properties and present approval for long term use, further studies investigating its long term (metabolic) effects in AF are warranted.

Trimetazidine (Chapter 6) is also a drug with metabolism-modulating properties that we have investigated. To the best of our knowledge, metabolic modulation as a longterm treatment option for AF has never been investigated before. We have shown that trimetazidine abolished increased production of reactive oxygen species, and attenuated the hallmarks of structural remodeling observed during AF including cell hypertrophy, interstitial fibrosis, and it preserved mitochondrial shape. Achieving this, trimetazidine could be used as an adjuvant drug, not only in AF patients, but also in the patients at risk for AF.

We believe that patients with new-onset or paroxysmal AF would benefit most from treatment with trimetazidine because it could prevent accumulation of atrial structural alterations leading to arrhythmia stabilization. Preservation of atrial function and structure as a bridge to permanent rhythm control strategies could increase ablation success rate by reducing the complexity of the fibrillation substrate. 


\section{References}

1. Benjamin EJ, Wolf PA, D'Agostino RB, Silbershatz H, Kannel WB and Levy D. Impact of atrial fibrillation on the risk of death: the Framingham Heart Study. Circulation. 1998;98:946-52.

2. Krijthe BP, Kunst A, Benjamin EJ, Lip GY, Franco OH, Hofman A, Witteman JC, Stricker BH and Heeringa J. Projections on the number of individuals with atrial fibrillation in the European Union, from 2000 to 2060. Eur Heart J. 2013;34:2746-51.

3. Stewart S, Hart CL, Hole DJ and McMurray JJ. A population-based study of the long-term risks associated with atrial fibrillation: 20-year follow-up of the Renfrew/Paisley study. Am J Med. 2002;113:359-64.

4. Thrall G, Lane D, Carroll D and Lip GY. Quality of life in patients with atrial fibrillation: a systematic review. Am J Med. 2006;119:448 e1-19.

5. Steinberg BA, Kim S, Fonarow GC, Thomas L, Ansell J, Kowey PR, Mahaffey KW, Gersh BJ, Hylek E, Naccarelli G, Go AS, Reiffel J, Chang P, Peterson ED and Piccini JP. Drivers of hospitalization for patients with atrial fibrillation: Results from the Outcomes Registry for Better Informed Treatment of Atrial Fibrillation (ORBIT-AF). Am Heart J. 2014;167:735-42 e2.

6. Kirchhof P, Benussi S, Kotecha D, Ahlsson A, Atar D, Casadei B, Castella M, Diener HC, Heidbuchel $H$, Hendriks J, Hindricks G, Manolis AS, Oldgren J, Popescu BA, Schotten U, Van Putte B, Vardas P, Agewall S, Camm J, Baron Esquivias G, Budts W, Carerj S, Casselman F, Coca A, De Caterina R, Deftereos S, Dobrev D, Ferro JM, Filippatos G, Fitzsimons D, Gorenek B, Guenoun M, Hohnloser SH, Kolh P, Lip GY, Manolis A, McMurray J, Ponikowski P, Rosenhek R, Ruschitzka F, Savelieva I, Sharma S, Suwalski P, Tamargo JL, Taylor CJ, Van Gelder IC, Voors AA, Windecker S, Zamorano $J L$ and Zeppenfeld K. 2016 ESC Guidelines for the management of atrial fibrillation developed in collaboration with EACTS. Eur Heart J. 2016;37:2893-2962.

7. Gopinathannair R, Etheridge SP, Marchlinski FE, Spinale FG, Lakkireddy D and Olshansky B. Arrhythmia-Induced Cardiomyopathies: Mechanisms, Recognition, and Management. J Am Coll Cardiol. 2015;66:1714-28.

8. January CT, Wann LS, Calkins H, Chen LY, Cigarroa JE, Cleveland JC, Jr., Ellinor PT, Ezekowitz MD, Field ME, Furie KL, Heidenreich PA, Murray KT, Shea JB, Tracy CM and Yancy CW. 2019 AHA/ACC/HRS Focused Update of the 2014 AHA/ACC/HRS Guideline for the Management of Patients With Atrial Fibrillation. Circulation. 2019:CIR0000000000000665.

9. Holmes DR, Jr., Doshi SK, Kar S, Price MJ, Sanchez JM, Sievert H, Valderrabano M and Reddy VY. Left Atrial Appendage Closure as an Alternative to Warfarin for Stroke Prevention in Atrial Fibrillation: A Patient-Level Meta-Analysis. J Am Coll Cardiol. 2015;65:2614-2623.

10. Healey JS, Crystal E, Lamy A, Teoh K, Semelhago L, Hohnloser SH, Cybulsky I, Abouzahr L, Sawchuck C, Carroll S, Morillo C, Kleine P, Chu V, Lonn E and Connolly SJ. Left Atrial Appendage Occlusion Study (LAAOS): results of a randomized controlled pilot study of left atrial appendage occlusion during coronary bypass surgery in patients at risk for stroke. Am Heart J. 2005;150:288-93.

11. Frick M, Frykman V, Jensen-Urstad M, Ostergren J and Rosenqvist M. Factors predicting success rate and recurrence of atrial fibrillation after first electrical cardioversion in patients with persistent atrial fibrillation. Clin Cardiol. 2001;24:238-44. 
12. Al-Khatib SM, Allen LaPointe NM, Chatterjee R, Crowley MJ, Dupre ME, Kong DF, Lopes RD, Povsic TJ, Raju SS, Shah B, Kosinski AS, McBroom AJ and Sanders GD. Rate- and rhythm-control therapies in patients with atrial fibrillation: a systematic review. Ann Intern Med. 2014;160:760-73.

13. Haeusler KG, Kirchhof $P$ and Endres M. Left atrial catheter ablation and ischemic stroke. Stroke. 2012;43:265-70.

14. Le Heuzey JY, Ammentorp B, Darius H, De Caterina R, Schilling RJ, Schmitt J, Zamorano JL and Kirchhof P. Differences among western European countries in anticoagulation management of atrial fibrillation. Data from the PREFER IN AF registry. Thromb Haemost. 2014;111:833-41.

15. Frankel DS, Parker SE, Rosenfeld LE and Gorelick PB. HRS/NSA 2014 survey of atrial fibrillation and stroke: Gaps in knowledge and perspective, opportunities for improvement. Heart Rhythm. 2015;12:e105-13.

16. Biskupiak J, Ghate SR, Jiao T and Brixner D. Cost implications of formulary decisions on oral anticoagulants in nonvalvular atrial fibrillation. J Manag Care Pharm. 2013;19:789-98.

17. Coban E, Atakli D, Soysal A and Kirbas D. Quality of Life of Patients Under Anticoagulant Therapy Compared to Patients Treated with Antiplatelet Therapy. Noro Psikiyatr Ars. 2018;55:157-160.

18. Guerra F, Romandini A, Barbarossa A, Belardinelli L and Capucci A. Ranolazine for rhythm control in atrial fibrillation: A systematic review and meta-analysis. Int J Cardiol. 2017;227:284291. 



\section{Acknowledgements}

When I recall my PhD trajectory, I realize that the path I took could be best compared to climbing a very high mountain. Being at the beginning of my career as a medical doctor I realized that 'climbing the research mountain' will provide me a higher standpoint with a much broader view and better perspective to understand the physiology of the human body and the mechanisms of diseases I wanted to treat. Therefore, in accordance with my character, I completely devoted myself to climb that mountain as quickly as I could, or at least as quickly as I believed it was possible. I believed that higher I climb the better the view is going to be, and my understanding of medicine is going to thrive. And it is true! But needless to say, I underestimated 'the mountain'. I forgot how difficult it is to climb it, I forgot how unpredictable the weather conditions can be, how strong winds can blow. I forgot, or it is better to say, I was not aware, that the higher you climb you enter the clouds so thick that make you wander aimlessly not being aware if you are climbing or descending. I realized that it is difficult, that it is painful and often I had a feeling that it is impossible.

However, I was lucky! I was very lucky! I had a group of people by my side who showed me the way, who gave me support and who led me to the top. They taught me not to fight the winds and clouds but to tame them and accept them as they are all the part of 'the mountain', the same as a stone I wanted to stand on to widen my horizons. They taught me how to climb. And thanks to their guidance I succeed, the thesis has been written, and before me lays the best view I could have ever hoped for. A result that surpasses what I was hoping for: an uncountable number of mountains to climb and me with the skills and tools to climb them.

The person who gave me the chance to learn all that and the person I am the most grateful to is my promotor Prof. Ulrich Schotten. Dear Uli, first of all, thank you for giving me the chance to be a PhD candidate in your group. I enjoyed working with you and learning from you so much. You taught me how to ask a proper scientific question and not to look for the answer in a most doable way but to search for the approach that will give me the best and the most accurate answer on that question. It was a pleasure hearing your explanations and comments on our work. I often had a feeling that your explanations could be directly written down and used in textbooks. It was such a joy and honor to be your PhD student.

Dear Dr. Verheule, beste Sander, it was my pleasure and luck to be supervised by you. In Germany, the term Doctorvater is often used for a $\mathrm{PhD}$ supervisor. This term truly describes the role you played in my PhD. The importance of your guidance and care for the whole project are immeasurable. Your capability to get me out of a dead-end only by glancing at the data and giving me a couple of tips that would make me see and understand the data in a completely different way was just unbelievable. You had this strange ability to organize my thoughts and then explained them to me. I still remember the interview when you defined my relation to clinics and science - 'I can imagine sciences without clinics, but not the clinics without science'. Your wide interests and knowledge in so many 
different fields make you a really remarkable person. Thank you for being there for me and for guiding me to the end of my PhD.

Dear Dr. Zeemering, beste Stef. Thank you for being a part of my promotion team. Your calmness, steadiness and precision are directly reflected in your work and the tools you have developed. Your programs were impeccable (despite that they made my laptop CPU sound like an airplane) and without them, the realization of my thesis would not be possible. Although your work requires silence and deep concentration you were always available for my interrupting questions giving me the answer I needed. You did this always instantaneously and in a most pleasant way possible. One can only wish a supervisor and a colleague like you.

Sincere thanks to my thesis committee members: Prof. Frits Prinzen, Prof. Harry Crijns, Prof. Bianca Brundel, and Prof. Anton Jan van Zonneveld. Thank you for reviewing my thesis and giving it such nice comments.

Dear Dr. van der Heyden, beste Marcel, thank you for giving me an opportunity to investigate pentamidine analogue in a goat model of AF and to use the data we acquired as one of the major chapters in my thesis. Dear Prof. Antoniades, dear Charis, thank you for having me for two secondments in Oxford and providing me the possibility to learn and use many of the prestigious techniques in your laboratory. Dear Dr. Pasdois, dear Philippe, thank you for introducing me to the exciting world of mitochondria and for selflessly teaching me and setting up all the precious measurements in our lab. Dear Dr. Weseler, beste Antje, thanks a lot for providing us your expertise and the expertise of your lab that yielded some of the crucial data in our study. Special thanks for Marie-José and her efforts. Dear Dr. Schiffers, beste Paul thank you for guiding and supporting me in the field of vascular pharmacology. Our work resulted in a very nice chapter of my thesis. Special thanks to Ger and his assistance in all vascular measurements. Many thanks to Dr. Joost Luiken and Will Coumans for the assistance they provided. Dear Dr. Antoons, beste Gudrun, thanks for being a valuable member of our group. Dear Dr. Belardinelli thank you for reviewing our manuscript and giving us useful input.

Dear Dr. van Hunnik, beste Arne. I can tell you: Yes! Yes, you were hard on me, but I appreciated that and listened to your every advice. You taught me how to use the lab and how to perform experiments. You showed me how accurate planning and precise experimental execution will not only yield good data but will save you a tremendous amount of time once you start analyzing it. Your nature to question everything is the nature of a true scientist. You taught me how to think scientifically and shaped me not only in a scientific way but in a way that made me a much better person. You did it completely selflessly not expecting anything in return. In that way, you showed how good a person you are. It is a pleasure to have you as a friend and colleague. And of course, I am looking forward to cycle together with you!

Dear Patrick, my companion, my paranymph. Thank you for being there for me and helping me with my experiments, data analysis, kitchen and being my hard-listening companion. 
Even sometimes when you were not in a mood to listen to my long monologues, you took care to provide an equally good replacement. My thanks to Mr. Glove. It was nothing but joy working with you and sharing an office with you. Yes, we fought a couple of wars over pipets, stealing them from each other, but it was never a hassle it was actually fun (at least for me). Somehow, we never needed them exactly at the same time although we often stayed long hours at the lab, our work was always complementary (from my point of view). You are one of the most gifted persons I met. I hope that one day we will have a chance to work together again (I will do my best!).

Dear Stephanie, my friend, my companion. It was such a joy working with you. In the beginning, we had our problems, but you became the person I cared about the most. Your cheerfulness, friendliness and good heart grew on me and now I am proud to have you by my side. We spent a lot of time together planning experiments, building setups, traveling and attending different workshops all over Europe within RADOX ITN. I have to admit that I felt always a bit safer having you around. However, you decided to pursue a different career path, a career path you are passionate about, a career in sports. I can tell you; you are amazing at sports. You did something I did not believe it was possible. You made a person (Patrick) who was shorter than me, a couple of centimeters taller than me. You showed me that as long as you are passionate about something unbelievable goals can be achieved.

Dearest Marion, thank you for all the work, ideas, sweat and sometimes blood that you gave to help me perform all complicated and long protocols that we planned together. You were always friendly, nice and available. We had to make so many plans for our projects that would require long hours and experiments on weekends, but you were always eager to sacrifice your private time to make projects run smoothly. Your experience, expertise, knowledge and kindness make you a unique person. I was happy to have you as a colleague during my PhD and now as a friend.

Dear Jorik, one of the key players in our team. Although just a student in the first years of medical studies the role you fulfilled and the way you did it surpasses capabilities of the many graduate students. Your work ethics and questions you were asking indicated to me that you are going to make a great medical doctor. I wish you to successfully finish your studies (in what I have no doubt) and I am sure that any specialty you chose you are going to excel in it.

Dear Hussein, thank you for paving the path of metabolic remodeling in atrial fibrillation for me. Your thesis often was used by me as a guideline on how to conduct experiments and perform analysis. It was a pleasure working with you. I enjoyed our small smoking breaks together with Ali when we discussed so many different topics. Dear Ali, thank you for giving me some of the most useful tips during my settlement in the Netherlands. You were the most knowledgeable person in Dutch immigration law and the Maastricht area social life that I have met. Thank you for being my tennis partner. I hope that you, unlike me, have continued to play tennis. 
Dear Pawel and dear Piotr, my Slavic-Polish brothers. It is no surprise that Pan-Slavism used to be so popular. Spending time with you really made me feel at home. Knowing you two guys, as long as someone asks me, Polish people are the most gifted people. I am sure that you are going to achieve great things with your companies.

Dear Matthias, thank you for teaching me German and for inviting me to play football after years of physical inactivity. Thank you for giving me tips on how to prepare myself for the interviews in Aachen and in Bad Oeynhausen. I am sad, and I know you as well, that the things in Aachen did not work out as expected, and that we will not have a chance to regularly play football. However, here in Bad Oeynhausen, I have a very good team with whom I am going to practice and develop my skills. Who knows, maybe we will play sometime for the same team.

Dear Joris, Giulia, Billy, Elisa, Vladimir, and Martijn it was a pure pleasure working with you guys. I am proud that such talented men and women are going to continue the research I was a part of. It is definitive that every new generation is better, and I am sure that all of you are going to finish your thesis in the best possible way. Looking forward to reading your books.

Dear members of the animal facility, beste Huub, Petra, Sanne, and Joyce. Working with large animals is extremely interesting and challenging. The way you took care of them, the amount of effort you invest made our work much easier. You were always available and ready to help us to find a way to perform our experiments in the best possible way to preserve animal welfare. Special thanks to Huub who in addition to helping me with the experiments also on weekends also helped me to learn German.

Dear Bianca and Vivian thank you for being always there for me. Asking you for help was never a problem, you were always available and friendly. I was honored to have you as my colleagues.

Dear Oxford crew, dear loannis, Akansha and Fabio thank taking care of me and tutoring me during my secondments in your lab. Your patience and willingness to help make my stay in Oxford one of the best time of my PhD.

Dear Radox ITN member, the time we spent together was fun an exciting. We have traveled so much and learned so many interesting things. I am proud that I had the possibility to meet all those excellent people from all over Europe. I am sure that all of you will make great careers.

My special thanks go to my family members who supported me no matter what. They were this invisible hand that pulled me up or gave me a foundation to stand on and never let me go a step-down. 
Dear Jovan, my dear father, my dear friend, your positivity, energy and determination to reject any possibility of failure are just unbelievable for me. You are that kind of person who sees an opportunity in every problem and has an understanding of everything and everyone. Over the years I learned so much from you, but still, I have a feeling that I did not even scratch a surface. I hope that I will be able to provide such support for my family as you did for us.

Dear mother, dear Zoki, thanks for being there for me every single step of my path. The amount of love, tenderness, and care you gave to me and my family is just inconceivable. You taught me how to be sympathetic and to care for the others.

My dearest aunts Dada and late Ljilja, thank you for developing my scientific-medical brain. I believe that you two are the most responsible for the fact that I decided to pursue a career in medicine and science. I am sure that you are proud of me as well as I am honored to have you by my side.

Dear Dragana, my little older sister, one can only dream of having you for a sibling. We used to live together for years either together with or without parents and we have never entered a real fight. I am sure that you were the only reason that never happened. If I am to be asked, you are the most normal person I have ever met. I wish you all the luck of this world and all the best to your husband Goran and your cute daughter Nadja.

Dear family Lukić, first of all, thank you for raising such a beautiful flower, my wife Tatjana. Without her, this whole story would not be only impossible, but it would be pointless. Therefore, you are directly responsible for giving me the cause to fight and to develop myself. Dear Tanja, thank you for being my muse, my partner and my ally in all the adventures we have been through. Thank you for giving me the greatest gift, our two sons: Milan and Jovan.

I would also like to thank our parents for sacrificing their holidays to look after Milan and Jovan. We are blessed and grateful to have such devoted parents, whose sacrifice has made it possible both for me and for my wife to pursue careers and to have a family. 



\section{Curriculum vitae}

Dragan Opačić was born on $25^{\text {th }}$ of October 1987 in Šabac, Serbia. He graduated in 2006 from Šabac Gymnasium with the profile Science and Mathematics. In the same year he started his Medicine studies at the Medical Faculty University of Belgrade, Serbia, graduating in 2012 with the thesis: "The rupture of the abdominal aortic aneurysm in octogenarians" under supervision of Prof. Dušan Kostić. During his studies, he was a student research assistant in the laboratory for Cardiovascular Pharmacology at the Department of Pharmacology, Clinical Pharmacology and Toxicology under supervision of Prof. Ljiljana Gojkovic-Bukarica.

Following his graduation, in parallel to his clinical work at the Clinic for Vascular and Endovascular Surgery Clinical Center of Serbia, in September 2012 he enrolled in Specialist academic studies in Vascular surgery with Angiology under the supervision of Prof. Dušan Kostic graduating with the thesis "Effect of atmospheric pressure and biometeorological phases on abdominal aortic aneurysm rupture". From the June till December 2013, he worked at the University Children's Hospital in Belgrade Serbia.

In January 2014 he moved to Maastricht, the Netherlands as a Marie Skłodowska Curie Fellow within RADOX ITN (RADical reduction of OXidative stress in cardiovascular diseases - International Training Network) to pursue a PhD degree at the Department of Physiology under the supervision of Prof. Ulrich Schotten and Dr. Sander Verheule. Being a Marie Skłodowska Curie Fellow, his PhD training included next to scientific work an opportunity to visit several leading European Universities and attend a number of scientific and translational workshops organized at different partner sites. Part of his PhD work was performed at the Division of Cardiovascular Medicine, Radcliffe Department of Medicine, Oxford University under supervision of Prof. Charalambos Antoniades. The data collected during his $\mathrm{PhD}$ was published in several peer-reviewed journals and presented on different national and international congresses.

From the August 2017, he started his residency in cardiac surgery at the Heart and Diabetes Center North Rhine-Westphalia (Herz- und Diabeteszentrum Nordrhein-Westphalen) in Bad Oeynhausen, Germany under supervision of Prof. Jan Gummert.

Dragan is married to his wife Tatjana with whom he has two sons, Milan and Jovan. 



\section{List of publications}

1. Opačić D, van Bragt KA, Nasrallah HM, Schotten U, Verheule S.. Atrial metabolism and tissue perfusion as determinants of electrical and structural remodelling in atrial fibrillation. Cardiovasc Res. 2016 Apr 1;109(4):527-41.

2. Ji $Y^{*}$, Varkevisser R*, Opačić D*, Bossu A, Kuiper M, Beekman H, Yang S, Khan P, Dobrev D, Voigt $N$, Zhuo Wang M, Verheule $S$, Vos M, Van der Heyden $M$. The inward rectifier current inhibitor PA-6 terminates atrial fibrillation and does not cause ventricular arrhythmias in dedicated goat and dog models. Accepted in British Journal of Pharmacology, *authors contributed equally*

3. Radakovic D, Opačić D, Börgermann J, Hsieh WC, Krutzinna M, Gummert J, Aboud A. Model for end-stage liver disease predicts mortality after pericardiectomy for constrictive pericarditis. Interact Cardiovasc Thorac Surg. 2018 Dec 1;27(6):813-818.

4. Opačić D, Ilic N, Sladojevic M, Schönleitner P, Markovic D, Kostic D, Davidovic L. Effects of atmospheric pressure dynamics on abdominal aortic aneurysm rupture onset. Vasa. 2018 Feb;47(2):137-142. doi: 10.1024/0301-1526/a000681. Epub 2018 Jan 4.

5. Ilic NS, Opačić D, Mutavdzic P, Koncar I, Dragas M, Jovicic S, Markovic M, Davidovic L. Evaluation of the renal function using serum Cystatin $C$ following open and endovascular aortic aneurysm repair. Vascular. 2018 Apr;26(2):132-141. doi: 10.1177/1708538117717348.

6. Pejkic S, Tomic I, Opačić D, L Pejinović, N Grubor, I Činara, L Davidović. Splenic artery aneurysms: Two cases of varied etiology, clinical presentation and treatment outcome. Srpski arhiv za celokupno lekarstvo 143 (5-6), 326-331

7. Dragas M, Koncar I, Opačić D, Ilic N, Maksimovic Z, Markovic M, Ercegovac M, Simic T, PljesaErcegovac M, Davidovic L. Fluctuations of serum neuron specific enolase and protein S-100B concentrations in relation to the use of shunt during carotid endarterectomy. PLoS One. 2015 Apr 10;10(4):e0124067. doi: 10.1371/journal.pone.0124067. eCollection 2015.

8. Pejkić S, Dragaš M, llić N, Končar I, Opačić D, Maksimović Z, Davidović L. Incidence and relevance of groin incisional complications following aortobifemoral bypass grafting. Ann Vasc Surg. 2014 Nov;28(8):1832-9. doi: 10.1016/j.avsg.2014.06.064. Epub 2014 Jul 7.

9. Sretenović $A$, Perisić V, Vujović D, Opačić D, Vukadinović V, Pavićević P, Radević B. Vorenov šant s parcijalnom splenektomijom kod dece s ekstrahepatičnom portnom hipertenzijom, masivnom splenomegalijom i značajnim hipersplenizmom. Srpski arhiv za celokupno lekarstvo $142(7-8), 419-423$

10. Pejkić S, Opačić D, Mutavdžić $\mathrm{P}$, Radmili O, Krstić N, Davidović L. Chronic complete thrombosis of abdominal aortic aneurysm: an unusual presentation of an unusual complication. Ann Vasc Surg. 2014 Nov;28(8):1832-9. doi: 10.1016/j.avsg.2014.06.064. 
11. Milica M Labudović Borović, Milan M Obradović, Jelena T Kostić, Ivan V Zaletel, Dejan G Milašinović, Marija T Stojanović, Slavica S Mutavdžin, Milena N Vesković, Dragan J Opačić, Dejan D Radaković, Nela S Puškaš, Tatjana S Radosavljević, Saša D Borović, Zvezdana Z Kojić, Božidarka L Zarić, Ljiljana G Šćepanović, Esma R Isenović. Myocardial Na+ K+-ATPase and SERCA: Clinical and Pathological Significance From a Cytological Perspective In Regulation of Membrane Na+-K+ ATPase. Springer 2016, pp 113-144. 

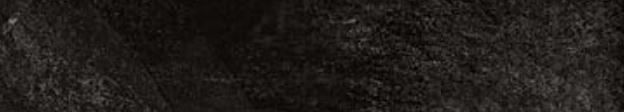

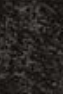
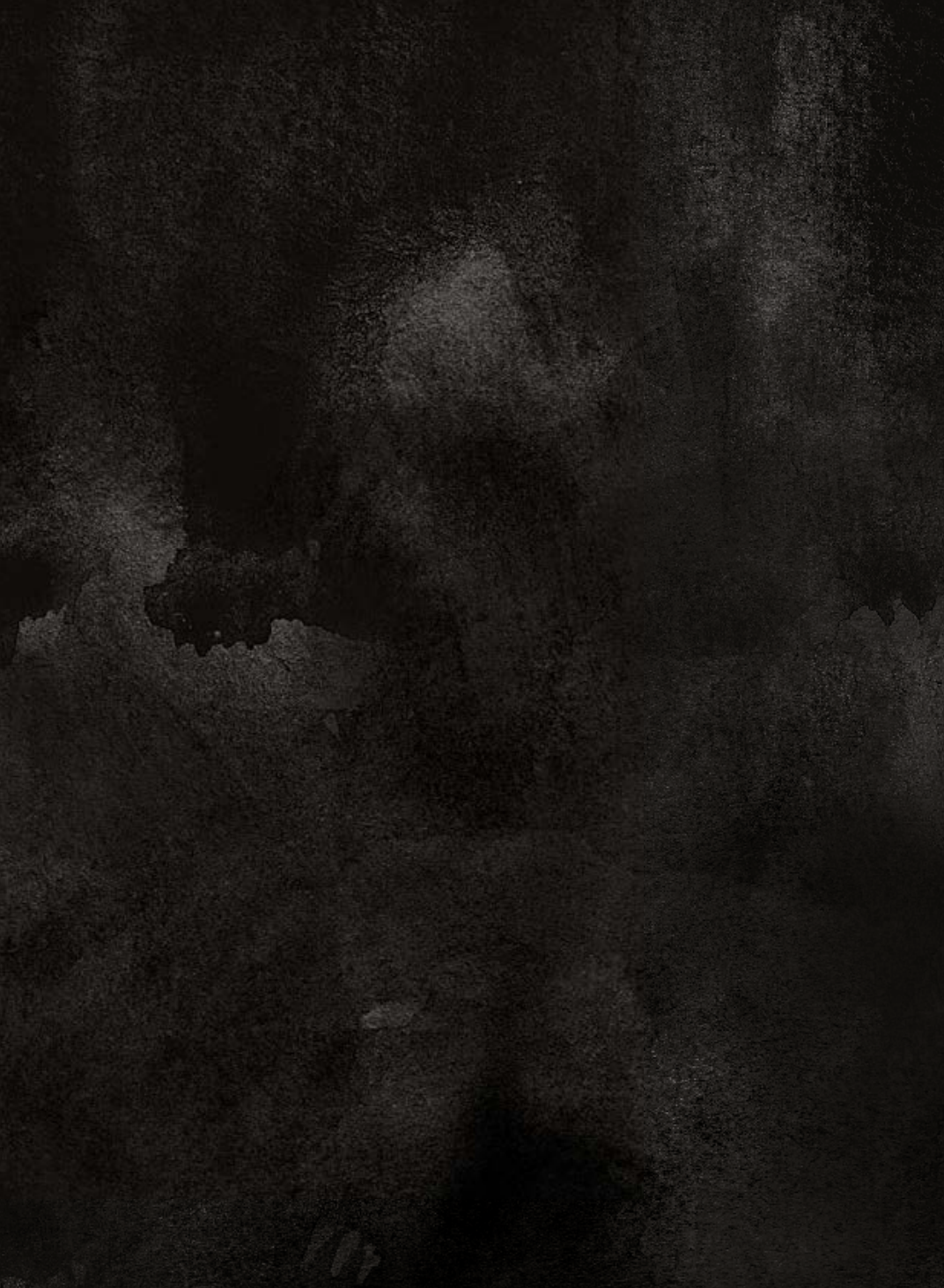